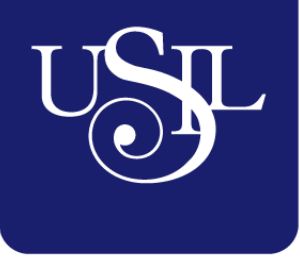

UNIVERSIDAD

SAN IGNACIO

DE LOYOLA

ESCUELA DE POSTGRADO

Maestría en Ciencias Empresariales

\title{
PLAN DE NEGOCIO: CREACIÓN DE UNA EMPRESA FABRICADORA Y COMERCIALIZADORA DE BLOQUETAS DE PLÁSTICO EN LA CIUDAD DE AREQUIPA
}

Tesis para optar el grado de Maestro en Ciencias Empresariales

\author{
EDUARDO JAVIER CHUNGA PURISACA \\ STEFHANIE MARIA EUGENIA MORALES TEJADA \\ VICTOR MANFREDO VALDIVIA PALACIOS
}

Asesor:

Edmundo Rafael Casavilca Maldonado

Lima-Perú

2018 


\section{Tabla de Contenido}

Introducción 1

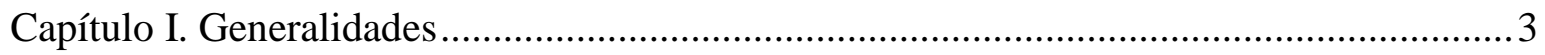

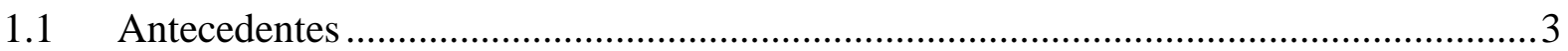

1.2 Determinación del problema u oportunidad .........................................................

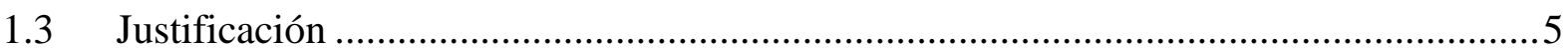

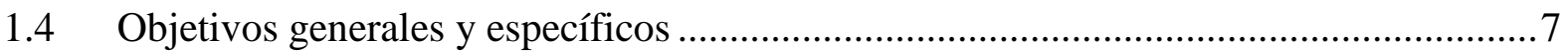

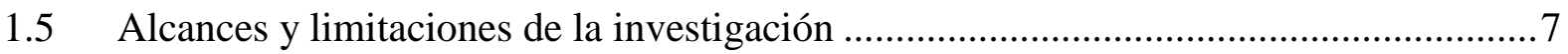

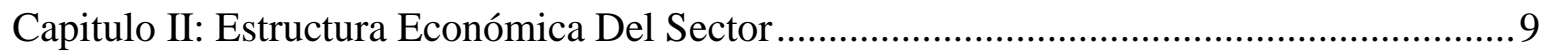

2.1. Descripción del estado actual de la industria ................................................................

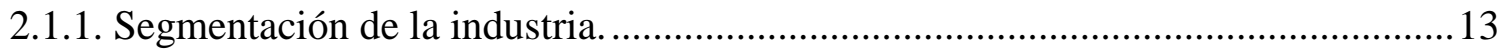

2.1.2. Empresas que la conforman (ubicación, volumen de ventas, empleados, etc).......15

2.2. Tendencias de la Industria (crecimiento e inversiones) ............................................... 17

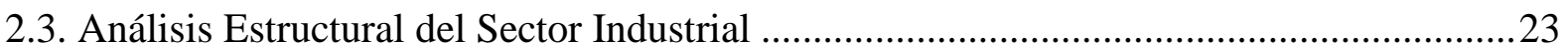

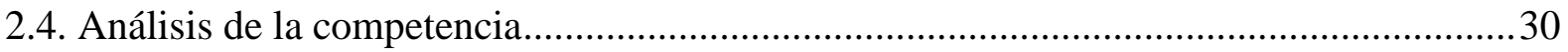

2.4.1. Empresas que ofrecen el mismo producto o servicio, indicando las semejanzas y

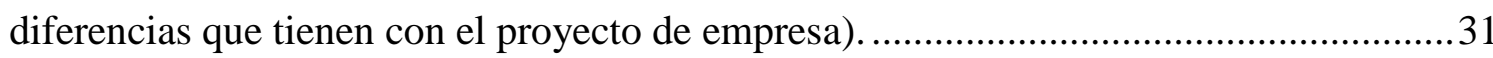

2.4.2. Participación de mercado de cada uno de ellos. .........................................................33

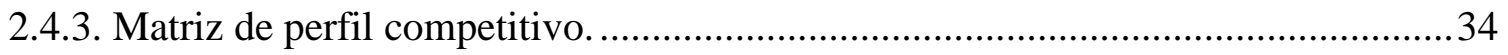

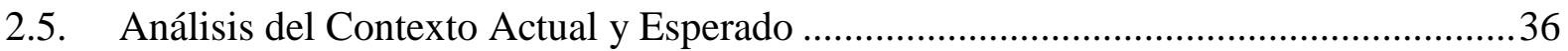

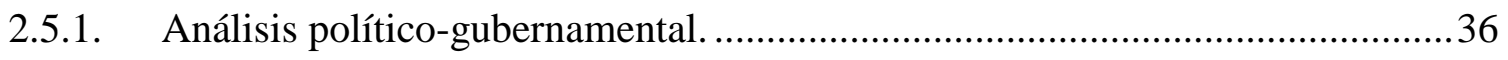

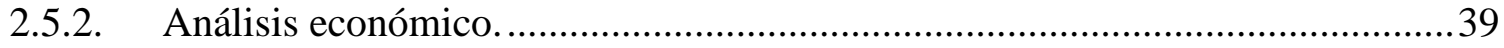

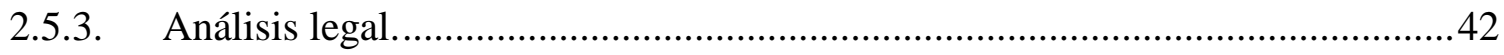


2.5.4. Análisis cultural. .43

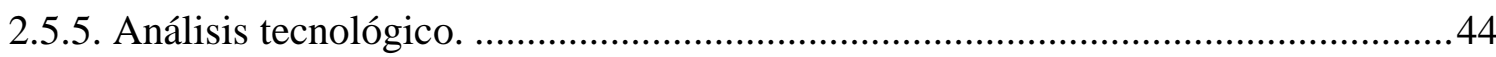

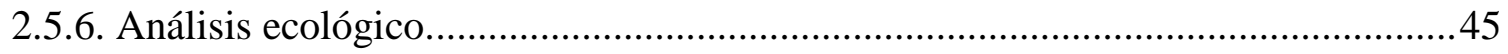

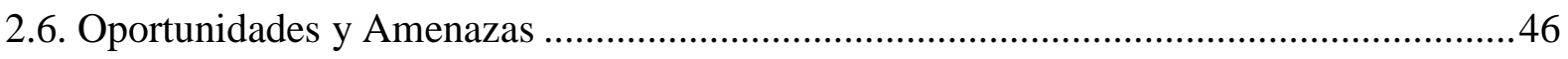

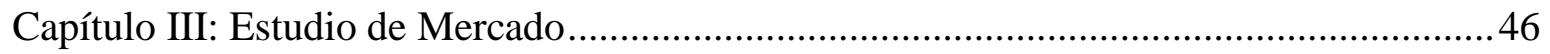

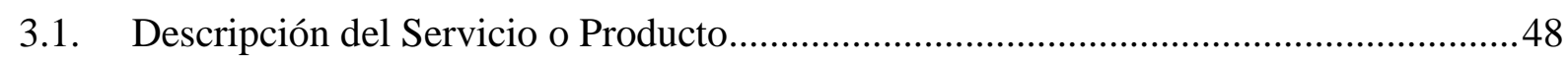

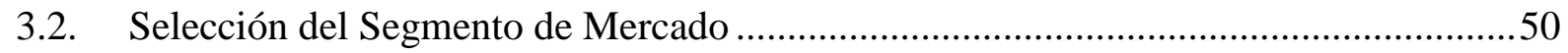

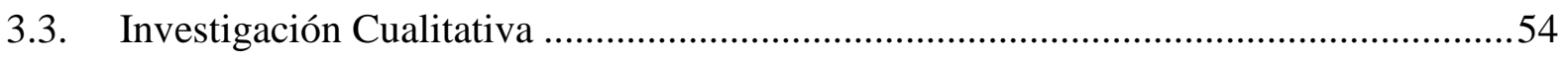

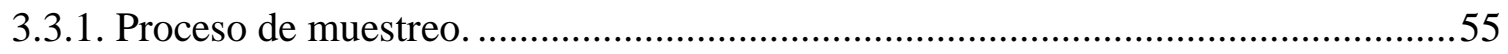

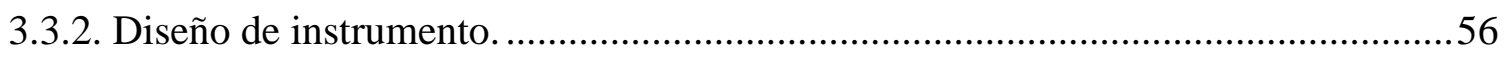

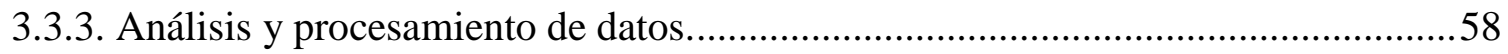

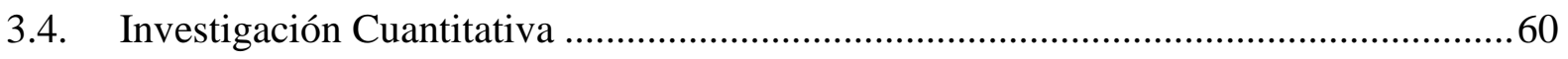

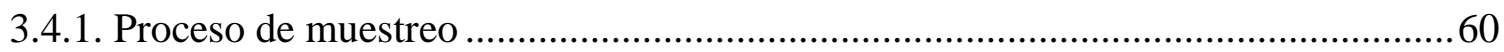

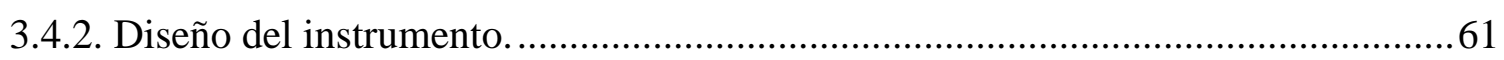

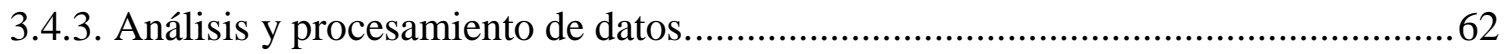

3.5. Conclusiones y recomendaciones del Estudio Cualitativo y cuantitativo ........................6 68

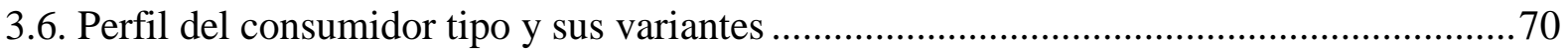

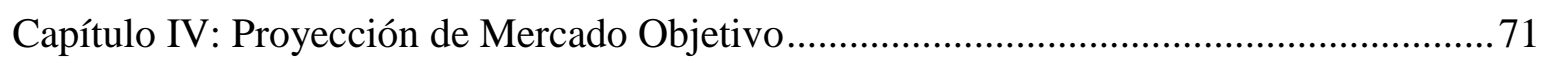

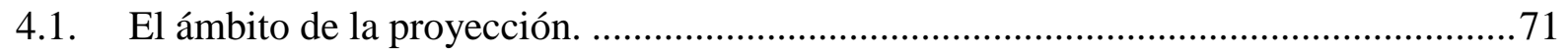

4.2. Selección del método de proyección........................................................................ 72

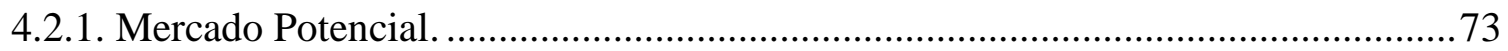

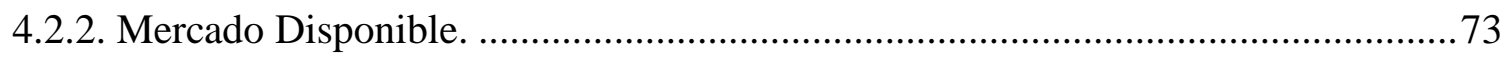

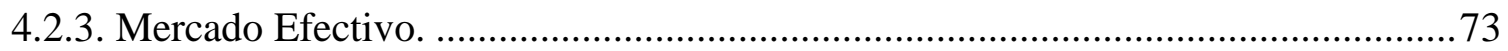

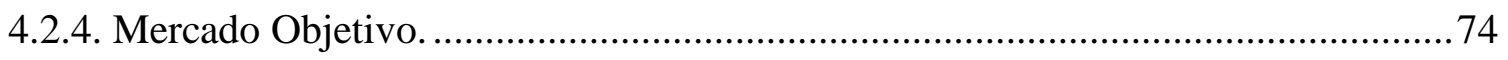




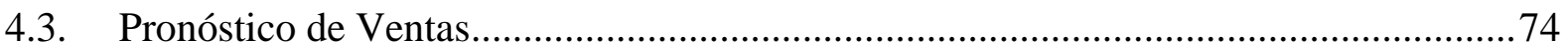

4.4. Aspectos críticos que impactan el pronóstico de ventas ............................................. 77

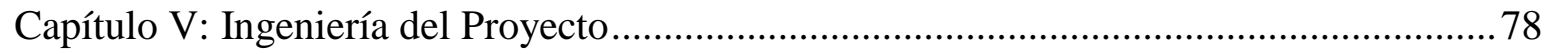

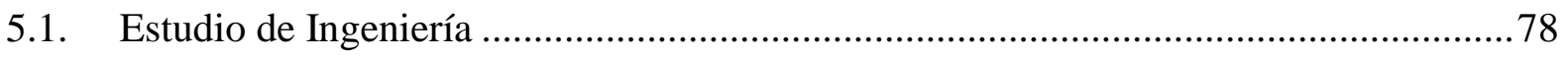

5.1.1. Modelamiento y selección de procesos productivos...........................................79

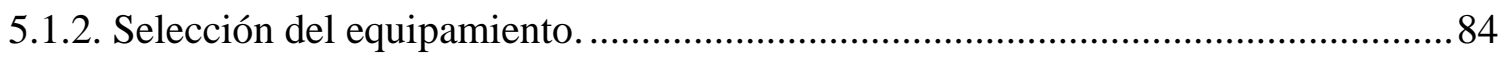

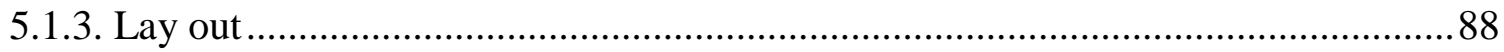

5.1.4. Distribución de equipos y maquinarias ............................................................ 91

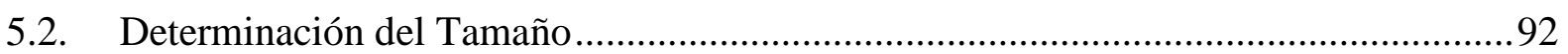

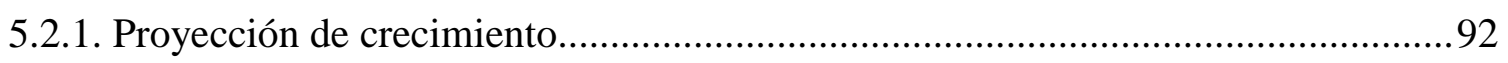

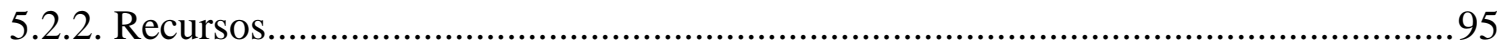

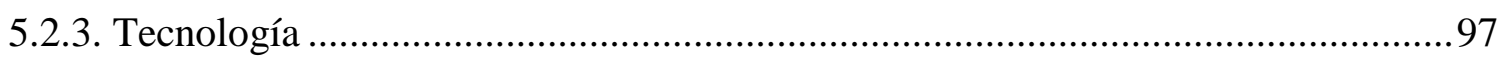

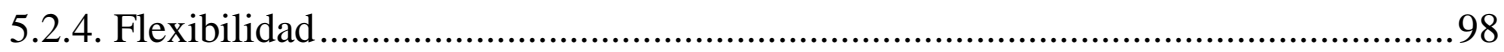

5.2.5. Selección del tamaño ideal ........................................................................ 98

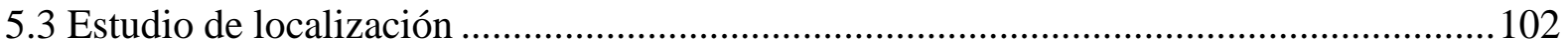

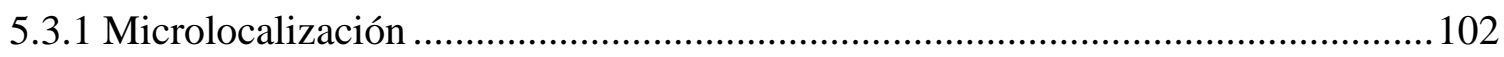

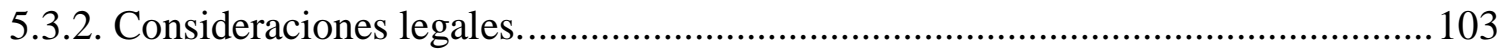

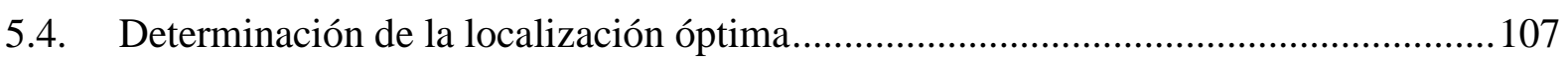

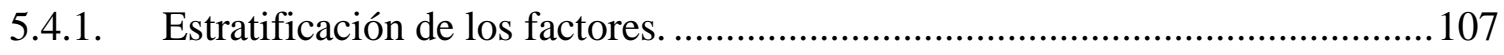

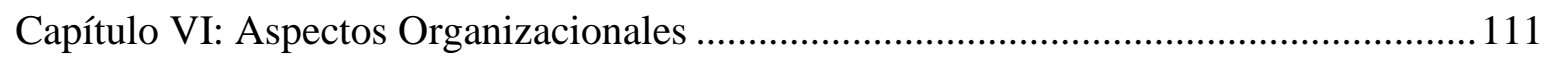

6.1. Caracterización de la cultura organizacional deseada ..............................................111

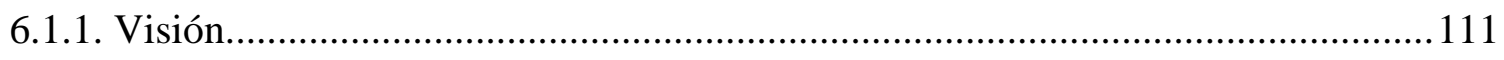

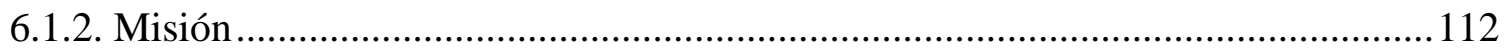

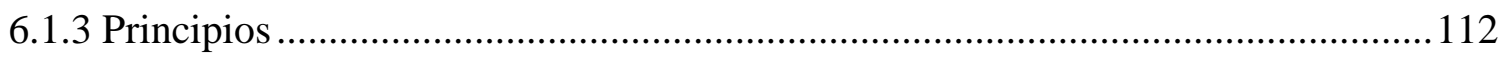


6.2. Formulación de Estrategias del Negocio

6.3. Determinación de las ventajas competitivas críticas

6.4. Diseño de la estructura organizacional deseada.

6.5. Diseño de los perfiles de puestos clave

6.6. Remuneraciones, compensaciones e incentivos

6.7. Política de recursos humanos

Capítulo VII: Plan De Marketing

7.1. Estrategias de marketing.

7.1.1. Estrategia de Producto

7.1.2. Estrategia de Precio

7.1.3. Estrategia de distribución

7.1.4. Estrategia de promoción y publicidad

7.2. Estrategia de ventas

7.2.1. Plan de ventas

7.2.2. Políticas de servicios y garantías.

Capítulo VIII: Planificación Financiera.

8.1. La Inversión.

8.1.1. Inversión Preoperativa.....

8.1.2. Inversión en capital de trabajo 146

8.1.3. Costo del proyecto. 148

8.1.4. Inversiones futuras

8.2. Financiamiento.

8.2.1. Endeudamiento y condiciones. 
8.2.3. Costo de capital promedio ponderado

8.3. Presupuestos Base

8.3.1. Presupuesto de ventas

8.3.2. Presupuesto de costo de producción 154

8.3.3. Presupuesto de compras.

8.3.4. Presupuesto de costo de ventas......... 160

8.3.5. Presupuesto de gastos administrativos 161

8.3.6. Presupuesto de marketing y ventas...... 161

8.3.7. Presupuesto de gastos financieros 162

8.4. Presupuestos de Resultados 166

8.4.1. Estado de ganancias y pérdidas proyectado 166

8.4.2. Balance proyectado. 168

8.4.3. Flujo de caja proyectado 169

Capítulo IX: Evaluación Económica Financiera. 171

9.1. Evaluación Financiera. 171

9.1.1. Tasa Interna de Retorno (TIR). 171

9.1.2. Valor Actual Neto (VAN) 172

9.1.3. Rentabilidad Financiera (ROE) 172

9.1.4. Ratios 173

9.2. Análisis de riesgo. 174

9.2.1. Análisis de punto de equilibrio 174

9.2.2. Análisis de sensibilidad 174

9.2.3. Análisis de escenarios 178

Conclusiones y Recomendaciones 182 


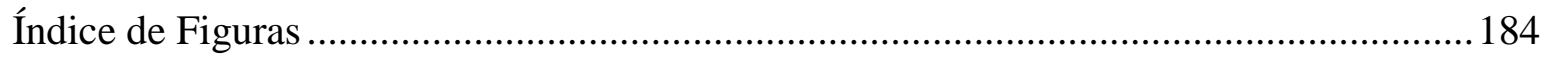

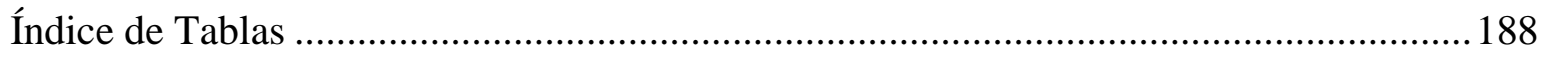

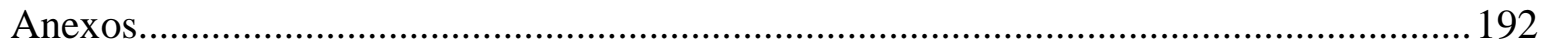

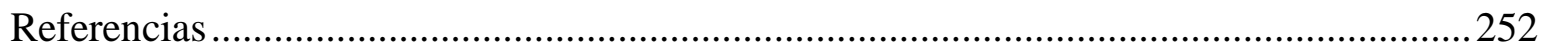




\section{Introducción}

El presente proyecto evalúa la viabilidad técnica, económica y financiera de un Plan de Negocios para fundar una fábrica productora de Bloquetas de Plástico con la característica diferencial de añadir en el proceso de producción la utilización de deshechos plásticos, en la ciudad de Arequipa.

El plan de negocios contiene detalladamente la siguiente información: Estructura Económica del Sector, Estudio de Mercado, Proyección del mercado Objetivo, Ingeniería del Proyecto, Aspectos Organizacionales, Plan de Marketing, Planificación financiera y Evaluación económica financiera.

En la Estructura Económica del Sector se muestra la evolución del sector construcción desde el año 2,000 y su influencia de crecimiento tanto a nivel nacional como en el Departamento de Arequipa; se muestran las principales variables de segmentación de mercado y las tendencias de crecimiento e inversiones. Se realiza un análisis de la competencia bajo el esquema de las cinco fuerzas de Porter.

En el Estudio del Mercado se hace una descripción del producto y la determinación del mercado donde se pretende ofertar el producto y el perfil del consumidor, mediante una investigación cualitativa para entender las motivaciones de compra a través de Focus Group y una investigación cuantitativa a través de encuestas.

En el capítulo de la Proyección de Mercado Objetivo, se determina la metodología para definir el ámbito de la proyección y estimar el comportamiento futuro de las variables. La técnica de los pronósticos (método de juicios) nos permitirá obtener proyecciones de ventas y los aspectos críticos que impactan en ella.

En el capítulo de Ingeniería del Proyecto se explica el proceso productivo seleccionado, la tecnología a emplear. Se detallan las obras físicas a implementar, utilizando métodos de determinación de tamaño y localización óptimos. Otros aspectos que abarca el 
estudio son los recursos necesarios (recursos humanos, maquinarias y equipos, insumos) que requiere el proyecto, además de sus consideraciones legales.

En los Aspectos Organizacionales del proyecto de negocios, se utilizó la teoría de los autores Thompson, Petergraf, Gamble \& Strickland (2012), para definir la visión, la misión y principios. Este capítulo desarrolla las estrategias del negocio, determina las ventajas competitivas, establecemos una estructura organizacional de acuerdo a las necesidades del proyecto. Se diseña perfiles determinados para los puestos de la organización, se explica la política remunerativa y la política de recursos humanos.

El Plan de Marketing del proyecto, desarrolla las estrategias a aplicar en base a las características de: producto, precio, distribución y publicidad, y que se enfoca en un posicionamiento de diferenciación del producto. Este capítulo desarrolla el plan de ventas, la estrategia de precios y promociones, los canales de distribución y de publicidad, de acuerdo a la proyección de ventas establecida en el estudio de ingeniería, además explica las políticas del servicio de post-venta.

La Planificación financiera del proyecto valora los recursos reales y financieros que necesita el proyecto. Este análisis abarca la inversión preoperativa, el capital de trabajo y el costo del proyecto. Se identifica el financiamiento, los presupuestos base y los presupuestos de resultados; para finalmente obtener los resultados del estado de ganancias y pérdidas, el balance y flujo de caja proyectado.

El capítulo de Evaluación económica financiera analiza los indicadores de tasa interna de Retorno (TIR), valor actual neto (VAN), rentabilidad financiera (ROE), ratios financieros y análisis de riesgo, para que a través de ellos objetivamente obtener las conclusiones y recomendaciones del proyecto. 


\section{Capítulo I. Generalidades}

\subsection{Antecedentes}

El ladrillo o bloqueta es una pieza fundamental en la construcción de edificaciones, desde tiempos remotos (1500 a.c.), siendo a la fecha aún muy importantes para la construcción de casas, edificios, etc.

A nivel mundial, se viene presentando un problema de contaminación de desechos de residuos plásticos como lo mencionan Noguera, Torres \& Zúñiga (2015). Es a partir de estas premisas que buscamos aprovechar este tipo de residuos para ofrecer un producto alternativo al sector construcción como la "bloqueta de plástico".

Esta idea nace a partir de la experiencia aplicada en el país vecino de Argentina, en su Centro Experimental de la Vivienda Económica (CEVE), donde se desarrollan una serie de proyectos, relacionados a tecnologías de la construcción para personas de bajos recursos, es aquí donde se viene desarrollando la idea de la bloqueta o ladrillo plástico.

En el Perú, se tiene de referencia que, en el año 2010, por intermedio del programa Construyendo Perú desarrollado por el Ministerio de Trabajo y Promoción del Empleo (MTPE), en el distrito de los Olivos, de la ciudad de Lima se presentó ante el Ministro de dicha cartera la idea de un prototipo de ladrillo plástico. (sagiromeo romeo, YouTube, 2016)

De acuerdo al Marco Macroeconómico Multianual 2017 -2019 ([MMN], 2016), presentado por el Ministerio de Economía y Finanzas ([MEF], 2016) el sector construcción tendrá una reactivación en sus perspectivas de crecimiento para los próximos años, esto debido a mayor inversión privada, propiciada por el destrabe de proyectos de infraestructura. La estimación de crecimiento al cierre del 2016 es de $0.7 \%$, y para los años 2017 - 2019 será de $5.1 \%$.

El Banco Central de Reserva del Perú ([BCRP], 2016), señala que en la Provincia de Arequipa no se dispone de información detallada del sector construcción, sin embargo, 
mantiene perspectivas positivas de crecimiento en el sector inmobiliario, ya que se vienen desarrollando varios proyectos de vivienda. Menciona en su informe que el crecimiento del sector entre el 2007 y el 2014 fue de $16 \%$ anual.

Para el desarrollo del proyecto, se consideró la Norma E.0.70, de Albañilería contenida en el Reglamento Nacional de Edificaciones (RNE), publicada en la Normas Legales del diario Peruano (2006).

\subsection{Determinación del problema u oportunidad}

En la actualidad, la provincia de Arequipa y la mayoría de sus distritos están enfrentando problemas de sobrepoblación debido a su rápido crecimiento demográfico.

De acuerdo al informe económico y social de la Región Arequipa presentado por el BCR el 2016, se menciona que la expansión urbana, se ha dado por un intenso proceso migratorio de la población alto andino a las zonas urbanas de la ciudad. Según cifras del INEI (2015), la población se estimaba en 869,4 mil habitantes, lo que convierte la ciudad y capital provincial de Arequipa, en la segunda ciudad más poblada.

Desde el año 2002 la Municipalidad Provincial de Arequipa viene trabajando planes y programas sobre el Área Metropolitana de Arequipa, que tiene como finalidad la implementación del Plan de Acondicionamiento Territorial (PAT) y el Plan de Desarrollo Metropolitano (PDM) de la Provincia de Arequipa. Estas iniciativas no han prosperado por temas coyunturales, gestiones de diferentes alcaldes.

El 26 de junio del 2014, por medio de la Ordenanza Municipal № 875, se decide la creación del Instituto Municipal de Planeamiento (IMPLA), cuya función primordial es organizar y dirigir el proceso de planificación del desarrollo a corto, mediano y largo plazo de la provincia de Arequipa. Este organismo hasta el momento no ha llegado a desplegar los planes antes mencionados. La falta de implementación del PAT y del PDM, está conllevando 
a un crecimiento urbano desordenado, permitiendo que las familias de más bajos recursos económicos viven de manera precaria, acondicionados en ambientes que no cumplen con estándares mínimos de salubridad.

Las actividades del sector construcción son una de las causantes del deterioro medio ambiental, debido al alto consumo de materias primas, ya que no existe reposición de las mismas.

Por lo aspectos antes mencionados se identifican las siguientes oportunidades para el desarrollo del proyecto:

1. Incremento en la demanda de viviendas.

2. Desarrollo de varios proyectos inmobiliarios por el Fondo MiVivienda y privados.

3. Impulso de la Banca para brindar mayor acceso a créditos hipotecarios.

Los riesgos identificados son:

a) La alta informalidad en el sector, agrupados en gremios.

b) Los conflictos sociales que se generan con las empresas industriales y mineras, al momento que adquieren hectáreas de materias primas, lo que conlleva a la demora el desarrollo de las obras civiles en ejecución.

c) La desaceleración de la actividad constructora, debido a la falta de terrenos.

\subsection{Justificación}

En el Perú, durante los años 2005 al 2014, se ha tenido un notorio incremento en la formalización de lotes en asentamientos humanos. Este incremento de asentamientos humanos ha generado el crecimiento desordenado y descontrolado de las principales ciudades. De acuerdo a datos obtenidos del Instituto Nacional de Estadística (INEI), del Ministerio de Vivienda, Construcción y Saneamiento (MVCS) y Comisión de Formalización de la Propiedad Informal (COFOPRI), se tiene que en estos últimos 10 años se han 
formalizado 1'105,421 lotes a nivel nacional, principalmente en las siguientes ciudades: Lima 11\%, Puno 9\%, Piura 7\%, San Martín e Ica con el 6\%, Arequipa 5\%. Este crecimiento, no planificado en su mayoría de casos, ha sido a consecuencia de la migración de pobladores a las principales ciudades en búsqueda de mejores posibilidades de desarrollo y calidad de vida. La inserción de los inmigrantes en las ciudades en general y edificación de sus viviendas con materiales de todo tipo y de calidad sub estándar es precaria y desordenada, la barriada resulta siendo el inevitable lugar de asentamiento poblacional.

El plan de negocio radica en la creación de una empresa fabricadora y comercializadora de bloquetas plásticas en la ciudad de Arequipa. Dentro del proceso de producción se está incorporando como material predominante el plástico reciclado, de esta manera se logrará una reducción significativa en los costos de construcción de las viviendas. Este tipo de bloqueta plástica brinda suficiente protección y seguridad. Su proceso productico está diseñado para que no dañen el medio ambiente, además que contempla un servicio postventa que no posee la oferta actual.

La producción de las bloquetas plásticas no conlleva a un proceso dificultoso ya que consiste en las siguientes fases: Reciclaje de plástico, triturado, mezclado (cemento y agua), moldeado, curado, secado y almacenaje, teniendo un bajo impacto en la contaminación del medio ambiente. Los diseños de las bloquetas están alineados a las características técnicas indicadas en la norma peruana de construcción, por lo que su uso se adecua en la construcción de paredes, ventanas, puertas, edificación de columnas y pisos frontales.

El Plan de Negocio se aplicará en la Provincia de Arequipa, ya que, de acuerdo a nuestro análisis de mercado, existe un público con una demanda no cubierta por la oferta tradicional. 


\subsection{Objetivos generales y específicos}

Objetivo General:

1. Determinar la viabilidad de implementar una empresa fabricadora y comercializadora de bloquetas de plástico en la ciudad de Arequipa.

Objetivos Específicos:

1. Investigar la industria donde se desenvolverá la empresa.

2. Realizar la investigación de mercados para determinar la aceptación del producto, preferencias del consumidor y establecer la competencia del producto.

3. Diseñar un plan de operaciones, donde se establezcan los aspectos técnicos, de producción y sus planes de contingencia.

4. Definir los aspectos organizacionales de la empresa.

5. Elaborar un plan de marketing, donde se consignen las estrategias que aplicará la empresa.

6. Determinar la viabilidad financiera del proyecto mediante índices y los posibles escenarios que pudieran suceder.

\subsection{Alcances y limitaciones de la investigación}

a) Alcances de la investigación:

La investigación que se realizó para el proyecto fue de tipo exploratoria. Se desarrolló la investigación cualitativa y cuantitativa, de acuerdo a Hair, Bush, y Ortinau (2010).

Para realizar la investigación se recurrió al estudio de varias técnicas de construcción realizadas en diversas partes de América del Sur como es el caso de Colombia, donde se ha desarrollado de manera innovadora la construcción de vivienda a partir del aprovechamiento de los residuos plásticos, bajo el formato de ladrillos ensamblables, proyecto desarrollado en 
el departamento de Cauca, donde interviene población vulnerada, recicladores de plástico y los municipios locales.

Se aprovechó la información y experiencia Argentina, del Centro Experimental de Vivienda Económica (CEVE), entidad encargada de desarrollar proyectos de vivienda para personas de escasos recursos, en la provincia de Córdova, donde los mismos pobladores, en especial mujeres son las encargadas del reciclaje de plástico, transformación del mismo y posteriormente de la propia construcción de viviendas.

El presente proyecto busca demostrar la viabilidad de establecer una empresa fabricadora y comercializadora de bloquetas plásticas en la ciudad de Arequipa, habiendo determinado un mercado objetivo.

b) Limitaciones del proyecto:

1. Bancos de datos del sector con poca data y desactualizada.

2. Informalidad del mercado, con respecto a las empresas que lo componen.

3. La investigación se limita a 20 distrito de la provincia de Arequipa: Arequipa, Alto Selva Alegre, Cayma, Cerro Colorado, Characato, Jacobo Hunter, José Luis Bustamente y Rivero, Mariano Melgar, Miraflores, Mollebaya, Paucarpata, Polobaya, Quequeña, Sabandía, Sachaca, Socabaya, Tiabaya, Uchumayo, Yanahuara e Yarabamba.

4. El límite de edad de la población comprendida en la investigación es entre 30 y 50 años de edad, hombres y mujeres. 


\section{Capitulo II: Estructura Económica Del Sector}

\subsection{Descripción del estado actual de la industria}

De acuerdo al Ministerio de Vivienda, Construcción y Saneamiento ([MCVS], 2016) el sector construcción participa en un 5.6\% de la producción nacional.

El Instituto Nacional de Estadística e Informática ([INEI], 2010) en su informe sobre la clasificación industrial internacional uniforme (CIIU), ubica el sector ladrillero dentro del segmento de industrias manufactureras, de la siguiente manera: Ver tabla uno.

Tabla 1

Clasificación Industrial Internacional Uniforme

\begin{tabular}{|c|c|c|c|}
\hline Sección & División & Grupo & Clase \\
\hline$\overline{\mathrm{C}}$ & 23 & 239 & 2392 \\
\hline $\begin{array}{l}\text { Industrias } \\
\text { Manufactureras }\end{array}$ & $\begin{array}{l}\text { Fabricación de } \\
\text { otros productos } \\
\text { minerales no } \\
\text { metálico }\end{array}$ & $\begin{array}{l}\text { Fabricación de } \\
\text { otros } \\
\text { productos } \\
\text { minerales no } \\
\text { metálico n.c.p }\end{array}$ & $\begin{array}{l}\text { Fabricación de } \\
\text { materiales de } \\
\text { construcción de } \\
\text { arcilla }\end{array}$ \\
\hline
\end{tabular}

Nota. Adaptado de "Clasificación Industrial Internacional Uniforme, de todas las actividades económicas, Revisión 4”, por INEI-Dirección de Cuentas Nacionales 2010.

Según cifras del MVCS (2016): la evolución del sector construcción desde el año 2000 al 2014 tuvo un crecimiento constante impulsado por el boom inmobiliario y la ejecución de varios proyectos de infraestructura, es a partir del 2015 que se produce una desaceleración, debido a crisis externas y a la desaceleración de la economía. En lo que va del primer semestre del 2016, el sector ha registrado una leve recuperación, con perspectivas a seguir mejorando. Ver figura 1. 


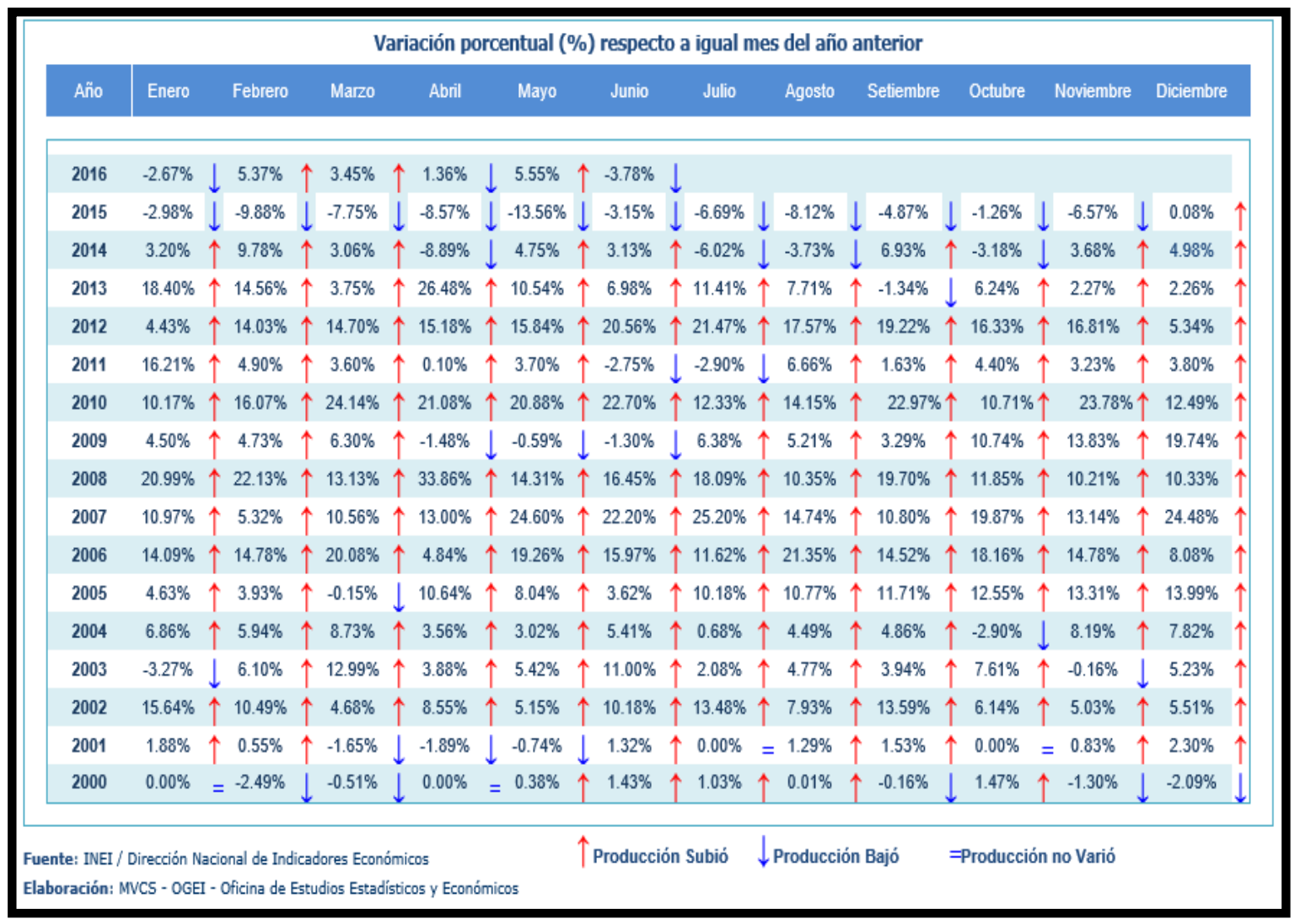

Figura 1. Evolución mensual de la actividad del sector construcción (Pbi Construcción): 2011-2016, variación porcentual mensual. Tomado de estadísticas del Ministerio de Vivienda Construcción y Saneamiento.

Los cambios en el sector construcción estuvieron influenciados por el comportamiento creciente que tuvo la economía peruana en los últimos 10 años, específicamente porque la variable de oferta y demanda global creció de manera constante en los últimos cinco años, debido al buen desempeño del consumo privado, el consumo público y la inversión. Ver Tabla 2 y Figura 2. 
Tabla 2.

Perú: Oferta y demanda Global 2000-2015

(Variación porcentual del índice de volumen físico)

\begin{tabular}{|c|c|c|c|c|c|c|c|c|}
\hline Año & $\begin{array}{r}\text { Producto } \\
\text { Bruto } \\
\text { Interno }\end{array}$ & $\begin{array}{r}\text { Importa- } \\
\text { ciones }\end{array}$ & $\begin{array}{r}\text { Ofertay } \\
\text { Demanda } \\
\text { Global }\end{array}$ & $\begin{array}{r}\text { Demanda } \\
\text { Interna }\end{array}$ & $\begin{array}{r}\text { Consumo } \\
\text { Final }\end{array}$ & $\begin{array}{r}\text { Consumo } \\
\text { Final } \\
\text { Privado }\end{array}$ & $\begin{array}{c}\text { Consumo } \\
\text { Final del } \\
\text { Gobierno }\end{array}$ & $\begin{array}{l}\text { Esporta- } \\
\text { ciones }\end{array}$ \\
\hline 2000 & 2.7 & 3.8 & 2.9 & 1.6 & 2.6 & 2.5 & 3.1 & 7.8 \\
\hline 2001 & 0.6 & 2.9 & 1.0 & -0.7 & 0.7 & 1.0 & -0.8 & 6.8 \\
\hline 2002 & 5.5 & 2.5 & 5.0 & 4.1 & 4.1 & 4.9 & 0.0 & 7.8 \\
\hline 2003 & 4.2 & 2.4 & 3.9 & 3.1 & 2.7 & 2.5 & 3.9 & 6.3 \\
\hline 2004 & 5.0 & 10.4 & 5.8 & 2.9 & 3.5 & 3.4 & 4.1 & 14.7 \\
\hline 2005 & 6.3 & 12.2 & 7.2 & 4.8 & 4.4 & 3.7 & 9.1 & 14.2 \\
\hline 2006 & 7.5 & 12.7 & 8.4 & 11.3 & 6.4 & 6.2 & 7.6 & 1.2 \\
\hline 2007 & 8.5 & 21.3 & 10.8 & 12.3 & 8.0 & 8.6 & 4.3 & 6.7 \\
\hline 2008 & 9.1 & 25.0 & 12.2 & 13.7 & 8.3 & 8.9 & 4.8 & 7.8 \\
\hline 2009 & 1.1 & -15.9 & -2.6 & -2.4 & 4.4 & 3.1 & 12.1 & -3.3 \\
\hline 2010 & 8.3 & 26.6 & 11.7 & 14.5 & 8.3 & 9.1 & 3.9 & 3.2 \\
\hline 2011 & 6.3 & 13.6 & 7.9 & 8.6 & 7.2 & 7.2 & 7.4 & 5.5 \\
\hline 2012 & 6.1 & 10.0 & 7.0 & 8.1 & 7.6 & 7.4 & 8.3 & 3.1 \\
\hline 2013P/ & 5.9 & 2.9 & 5.2 & 6.7 & 6.0 & 5.7 & 7.5 & -0.6 \\
\hline 2014P/ & 2.4 & -1.0 & 1.6 & 2.9 & 4.6 & 3.9 & 8.3 & -3.8 \\
\hline 2015E/ & 3.3 & -0.8 & 2.4 & 2.5 & 3.8 & 3.4 & 5.8 & 1.6 \\
\hline
\end{tabular}

Nota.Oferta y demanda global 2000 -2015, Tomado de Instituto Nacional de Estadística e Informática (INEI).

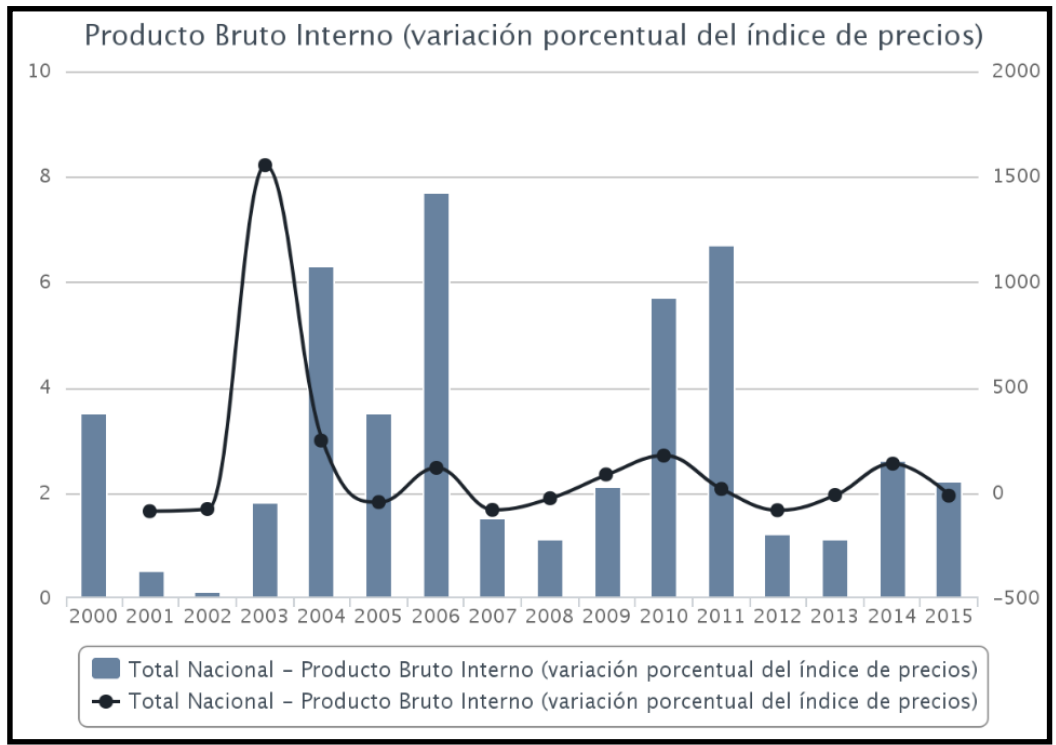

Figura 2. Evolución del PBI año 2000 al 2015, Tomado de Instituto Nacional de Estadística e Informática - Dirección Nacional de Cuentas Nacionales.

De acuerdo a la Cámara Peruana de Construcción ([CAPECO], 2016) menciona que el desempeño del sector construcción tuvo una mejora en el segundo bimestre del 2016.

Dicho informe se basa en el análisis de las expectativas de tres grupos de interés: (a) los promotores inmobiliarios, (b) constructores de infraestructura y (c) proveedores. Sólo los dos 
primeros mantienen expectativas de crecimiento en $6.8 \%$ y $0.15 \%$ respectivamente, quienes no son muy optimistas con dicho pronóstico son los proveedores quienes estiman que sus operaciones se reducirán en $1.51 \%$. El dinamismo del sector se recuperará conforme la inversión privada se vaya reenganchando. Ver Figura 3 .

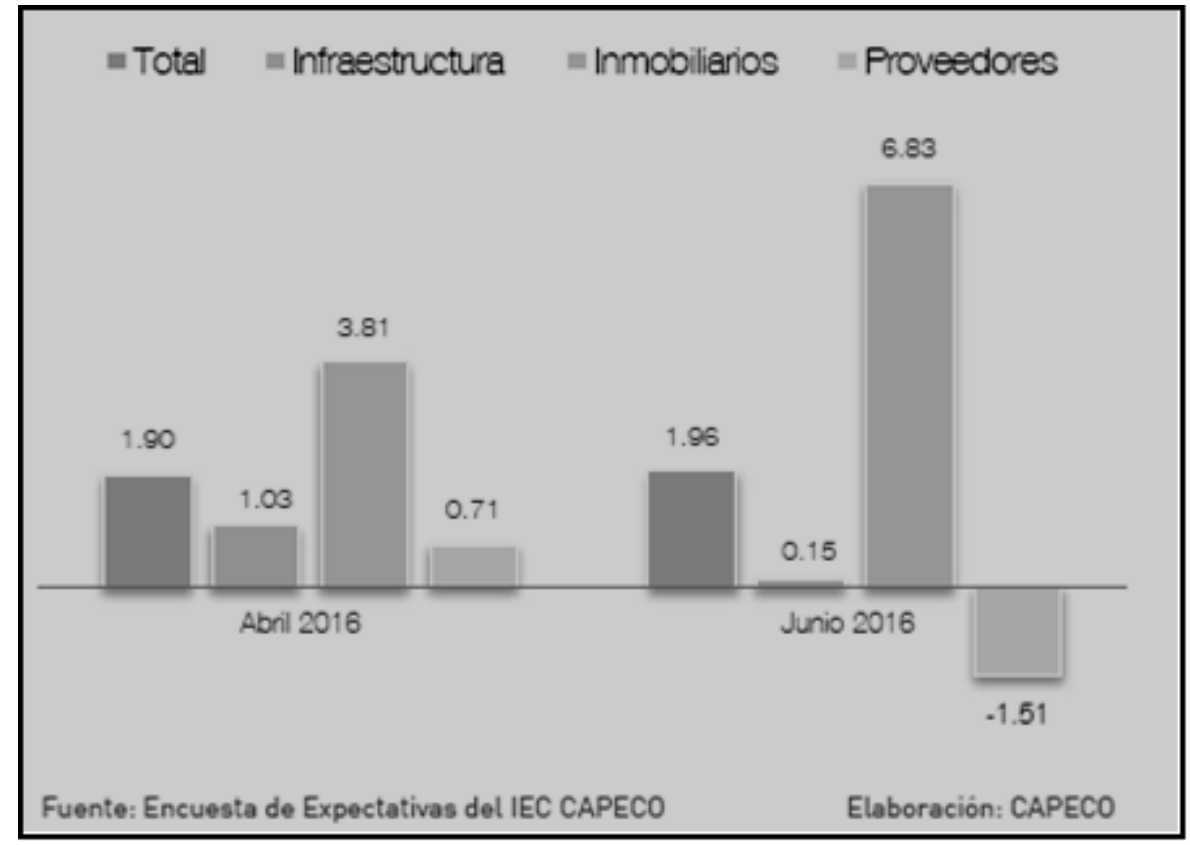

Figura 3. Comparativo entre situación esperada y real del nivel de las operaciones en las empresas constructoras (segundo bimestre 2016 vs segundo bimestre 2015), tomado de informe económico de la construcción (IEC) $\mathrm{N}^{\circ}$ 9, por la Cámara Peruana de Construcción (CAPECO), Julio 2016.

El Banco Central de Reserva del Perú ([BCRP], 2016) señala que el sector construcción en la ciudad de Arequipa, entre los años 2007-2014, tuvo un crecimiento de producción alrededor del 10\%, basado en la coexistencia de la auto-construcción y microempresas, unas altamente informales y otro grupo formal relacionados a proyectos de inversión pública, proyectos inmobiliarios y de infraestructura. El BCRP, reconoce el mayor crecimiento regional anualmente en un 16\%, en el periodo indicado del 2007-2014. Ver Tabla 3. 
Tabla 3.

Indicadores de Construcción Arequipa

\begin{tabular}{|c|c|c|c|c|c|c|c|c|c|c|}
\hline \multicolumn{11}{|c|}{$\begin{array}{c}\text { Cuadro } 49 \\
\text { INDICADORES DE CONSTRUCCIÓN } \\
\text { (Miles de T.M y millones de Soles) }\end{array}$} \\
\hline & \multicolumn{2}{|c|}{ Venta de cemento } & \multicolumn{4}{|c|}{ Crédito del Fondo MiVivienda " } & \multicolumn{2}{|c|}{ Bonos Techo Propio } & \multicolumn{2}{|c|}{ Crédito hipotecario $^{2}$} \\
\hline & \multirow[t]{2}{*}{ Nacional } & \multirow{2}{*}{ Arequipa } & \multicolumn{2}{|c|}{ Nacional } & \multicolumn{2}{|c|}{ Arequipa } & \multirow{2}{*}{$\begin{array}{c}\text { Nacional } \\
\text { (S) }\end{array}$} & \multirow{2}{*}{$\begin{array}{c}\text { Arequipa } \\
\text { (S) }\end{array}$} & \multirow{2}{*}{$\begin{array}{c}\text { Nacional } \\
\text { (S) }\end{array}$} & \multirow{2}{*}{$\begin{array}{c}\text { Arequipa } \\
\text { (S) }\end{array}$} \\
\hline & & & $\begin{array}{l}\text { Número } \\
\text { de créditos }\end{array}$ & $\begin{array}{c}\text { Crédito } \\
(\mathbf{S})\end{array}$ & $\begin{array}{l}\text { Número } \\
\text { de créditos }\end{array}$ & $\begin{array}{l}\text { Crédito } \\
\text { (S) }\end{array}$ & & & & \\
\hline 2006 & 5040 & 297 & $\because$ & $\because$ & $\because$ & $\because$ & $\because$ & $\because$ & $\because$ & $\because$ \\
\hline 2007 & 5878 & 332 & $\because$ & $\because$ & $\because$ & $\because$ & $\because$ & $\because$ & $\because$ & $\because$ \\
\hline 2008 & 6741 & 362 & 2996 & 189 & 183 & 9,0 & 135 & 1,5 & 11717 & $\because$ \\
\hline 2009 & 7094 & 452 & 3527 & 251 & 110 & 8,4 & 460 & 17,2 & 13514 & $\because$ \\
\hline 2010 & 8218 & 508 & 6438 & 589 & 271 & 26,4 & 314 & 6,8 & 16688 & 616 \\
\hline 2011 & 8570 & 526 & 8893 & 905 & 494 & 44,4 & 212 & 1,6 & 20217 & 795 \\
\hline 2012 & 9516 & 682 & 10138 & 1090 & 636 & 45,9 & 299 & 7,0 & 26616 & 1020 \\
\hline 2013 & 10961 & 747 & 12096 & 1386 & 723 & 59,3 & 418 & 3,3 & 30785 & 1221 \\
\hline 2014 & 11032 & 788 & 10226 & 1172 & 523 & 49,1 & 802 & 8,3 & 34602 & 1398 \\
\hline 2015 & $\because$ & $\because$ & 4785 & 554 & 241 & 26,0 & 458 & 6,4 & 37550 & 1579 \\
\hline
\end{tabular}

Nota. Tomado de i informe económico y social de Arequipa, por el Banco Central de Reserva del Perú (BCRP), Julio 2016

Las perspectivas de desarrollo del sector aún son favorables, pese al momento económico que se vive, esto debido a que hay en cartera proyectos de inversión mineros y de infraestructura además de las empresas industriales y de servicios.

\subsubsection{Segmentación de la industria.}

En lo correspondiente a la definición de segmentación de mercados industriales (Kotler \& Armstrong, 2012), mencionan que los especialistas usan variables análogas, para la segmentación de mercados de consumidores e industriales. Las principales variables que consideran son: (a) geográfica, (b) demográfica, (c) psicográficas, y (d) conductuales. Sin embargo, los especialistas en segmentación de industrias adicionan las siguientes variables a 
su análisis: (a) Características de operación del cliente, (b) métodos de compra, (c) factores situacionales, y (d) características personales.

Para el desarrollo de la segmentación industrial correspondiente al presente proyecto se debe identificar claramente el mercado al que se pretende llegar y definir las características del consumidor final. Para ello se definen las siguientes variables:

\section{a) Variable geográfica}

El departamento de Arequipa está conformado por ocho provincias: Arequipa, Camaná, Caravelí, Caylloma, Condesuyos, Islay, Castilla y La Unión.

Arequipa cuenta con 29 distritos: Alto Selva Alegre, Arequipa, Cayma, Cerro Colorado, Characato, Chiguata, Jacobo Hunter, José Luis Bustamante y Rivero, La Joya, Mariano Melgar, Miraflores, Mollebaya, Paucarpata, Pocsi, Polobaya, Quequeña, Sabandía, Sachaca, San Juan de Siguas, San Juan de Tarucani, Santa Isabel de Siguas, Santa Rita de Siguas, Socabaya, Tiabaya, Uchumayo, Vítor, Yanahura, Yarabamba, Yura.

En la ciudad de Arequipa predomina el sistema de autoconstrucción, está estimado que el $80 \%$ de las viviendas han sido edificadas de manera informal, de acuerdo al estudio realizado por la Escuela Profesional de Ingeniería Civil de la Universidad San Martin de Porres (USMP), filial Arequipa. (Diario el Pueblo, 18 de Julio de 2016)

Bajo este criterio se selecciona la Ciudad de Arequipa, es decir Arequipa Metropolitana, para el desarrollo del proyecto.

\section{b) Variable demográfica}

Para el proyecto de implementación de la empresa fabricadora y comercializadora de bloquetas plásticas, se da preponderancia a las variables de edad, género y segmento socioeconómico. Se segmenta a hombres y mujeres de 30 a 50 años, ya que tienen necesidades de vivienda y dentro de este rango de edades seleccionado pueden acceder a 
financiamientos para vivienda. De la muestra elegida, solo se evaluará a los que se encuentren dentro de la población económicamente activa.

\subsubsection{Empresas que la conforman (ubicación, volumen de ventas, empleados, etc).}

CAPECO (2016) señala que a nivel nacional no existen bases informativas, una data detallada de cuantas empresas conforman el sector, sin embargo, refiere que existen alrededor de 65 ladrilleras formales en el Perú y que estas alcanzaron una facturación de 104 millones de dólares en el año 2014. Las empresas que representan el mayor porcentaje de facturación está concentrado en seis empresas y representan el 92\% del mercado son: Pirámide, Lark, Rex, Diamante, Fortes y Sagitario.

Todas las empresas mencionadas tienen su sede principal en la ciudad de Lima, excepto Ladrillera Diamante originaria de Arequipa. Ver Figura 4.

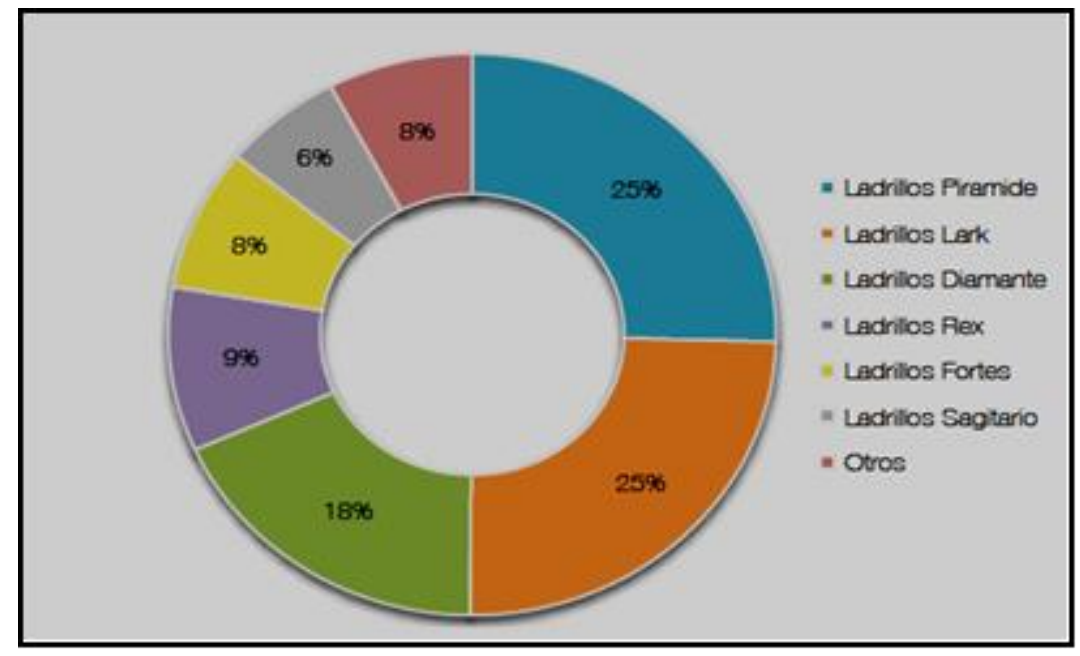

Figura 4. Participación de mercado de empresas nacionales, productores formales de Ladrillos de Arcilla - 2014 (En Facturación), tomado de informe económico de la construcción (IEC) № 9, por la Cámara Peruana de Construcción (CAPECO), Julio 2016.

A nivel región Arequipa, las entidades municipales y la Cámara de Comercio, carecen de información, con respecto a los fabricantes de ladrillo, ya que es un sector altamente 
informal. Se pudo revisar que la información disponible sobre la producción de ladrillo es del Programa Regional Aire Limpio (PRAL) y el ministerio del medio ambiente de los años 2005 - 2008 y un estudio de la empresa Mercadeando S.A del 2012, donde se realiza un diagnóstico nacional del sector ladrillero.

Mercadeando S.A. (2012) señala que en Arequipa hay 216 ladrilleras y que el 76.39\%, se encuentran en el distrito de Mollebaya. ver Tabla 4 y 5.

Tabla 4.

Descripción de las zonas de producción y número de ladrilleras en Arequipa.

\begin{tabular}{|l|l|c|r|}
\hline Provincia & Zonas & Empresas & Porcentaje \\
\hline AREQUIPA & Mollebaya & 165 & 76.39 \\
\hline & Socabaya & 10 & 4.63 \\
\hline & Mariano Melgar & 5 & 2.31 \\
\hline & Quequeña & 4 & 1.85 \\
\hline & Characato & 4 & 1.85 \\
\hline & Hunter & 3 & 1.39 \\
\hline & Paucarpata & 2 & 0.93 \\
\hline & Chiguata & 20 & 9.26 \\
\hline & Cerro Colorado & 1 & 0.46 \\
\hline & Cayma & 1 & 0.46 \\
\hline & Yura & 1 & 0.46 \\
\hline TOTAL & & $\mathbf{2 1 6}$ & 100.00 \\
\hline
\end{tabular}

Nota. Tomado de "Diagnostico Nacional del Sector Ladrillero Artesanal”, por Mercadeando S.A 2012

Tabla 5.

Zonas de mayor producción de ladrillo artesanal

\begin{tabular}{|l|l|c|}
\hline Provincia & Zonas & Empresas \\
& & \\
\hline Mollebaya & Alcosa & 70 \\
\hline & Virgen de Chapi & 60 \\
\hline & Machahuaya & 20 \\
\hline & Señor de los Milagros & 10 \\
\hline \multicolumn{2}{|l}{} & $\mathbf{1 6 0}$ \\
\hline
\end{tabular}

Nota. Tomado de "Diagnostico Nacional del Sector Ladrillero Artesanal”, por Mercadeando S.A 2012 


\subsection{Tendencias de la Industria (crecimiento e inversiones)}

De acuerdo a las proyecciones del Marco Macroeconómico Multianual 2016-2018, presentadas por el Ministerio de Economía y finanzas ([MEF“], 2016) se estima que con la adjudicación de proyectos de infraestructura se reactive el sector construcción y se consolide como uno de los ejes del crecimiento económico. Cabe mencionar que las alianzas público privadas (APP), tendrán un alto impacto en el desarrollo de los proyectos que el estado prevé ejecutar.

Se tiene en cartera los siguientes proyectos:

- La Línea 2 del Metro de Lima

- El Aeropuerto Internacional de Chinchero

- Los proyectos de irrigación: Chavimochic III y Majes Siguas II

- La Red Dorsal Nacional de Fibra Óptica

- La carretera Longitudinal de la Sierra (Tramo 2)

- La Modernización de la Refinería de Talara (obra pública)

- Gasoducto Sur Peruano

- El Nodo Energético del Sur (Centrales Termoeléctricas de Ilo y Puerto Bravo)

- $\quad$ La línea de transmisión Mantaro-Montalvo, entre otros. Ver Tabla 6. 
Tabla 6.

Proyección de gastos por app del sector no financiero del 2014 al 2018

\begin{tabular}{|c|c|c|c|c|c|}
\hline \multicolumn{6}{|c|}{ (Millones de Nuevos Soles) } \\
\hline $\begin{array}{l}\text { POR COMPONENTES DEL SPNF } \\
\text { (En millones de Nuevos Soles) }\end{array}$ & 2014 & 2015 & 2016 & 2017 & 2018 \\
\hline I. GOBIERNO GENERAL $(a+b)$ & 3854 & 6586 & 9957 & 8976 & 6469 \\
\hline a. Obligaciones de Pago . Etapa de Construcción & 2295 & 4524 & 7455 & 6142 & 3317 \\
\hline Gobiemo Nacional & 2256 & 4465 & 7383 & 5947 & 3214 \\
\hline Gobiemos Regionales & 38 & 59 & 72 & 194 & 103 \\
\hline b. Compromisos Firmes - Etapa de Operación & 1559 & 2062 & 2502 & 2834 & 3152 \\
\hline Gobiemo Nacional & 1454 & 1947 & 2380 & 2705 & 3020 \\
\hline Gobiemos Regionales & 105 & 115 & 122 & 128 & 132 \\
\hline II. EMPRESAS PÚBLICAS & 163 & 174 & 209 & 268 & 268 \\
\hline Contraprestación por serucios - Etapa de Operación & 163 & 174 & 209 & 268 & 268 \\
\hline TOTAL $(1+11)$ & 4016 & 6760 & 10165 & 9243 & 6737 \\
\hline \multicolumn{6}{|l|}{ Del cual: } \\
\hline Gasto Cornente & 797 & 1269 & 1636 & 1752 & 1960 \\
\hline Gasto de Capital & 3219 & 5491 & 8529 & 7491 & 4777 \\
\hline
\end{tabular}

Nota.. Tomado de "Marco Macroeconómico Multianual (MMM) 2016-2018”, por el Ministerio de Economía y Finanzas (MEF) 2016

CAPECO (2016), en su Informe Económico de la Construcción sustenta las expectativas del sector construcción de la siguiente manera:

a) Respecto al desempeño de las diversas formas de construcción para el 2016, la mayoría de empresarios consideraron que crecerán las construcciones de vivienda formal e informal, sobre todo las del último tipo. Ver Figura 5 y 6. 


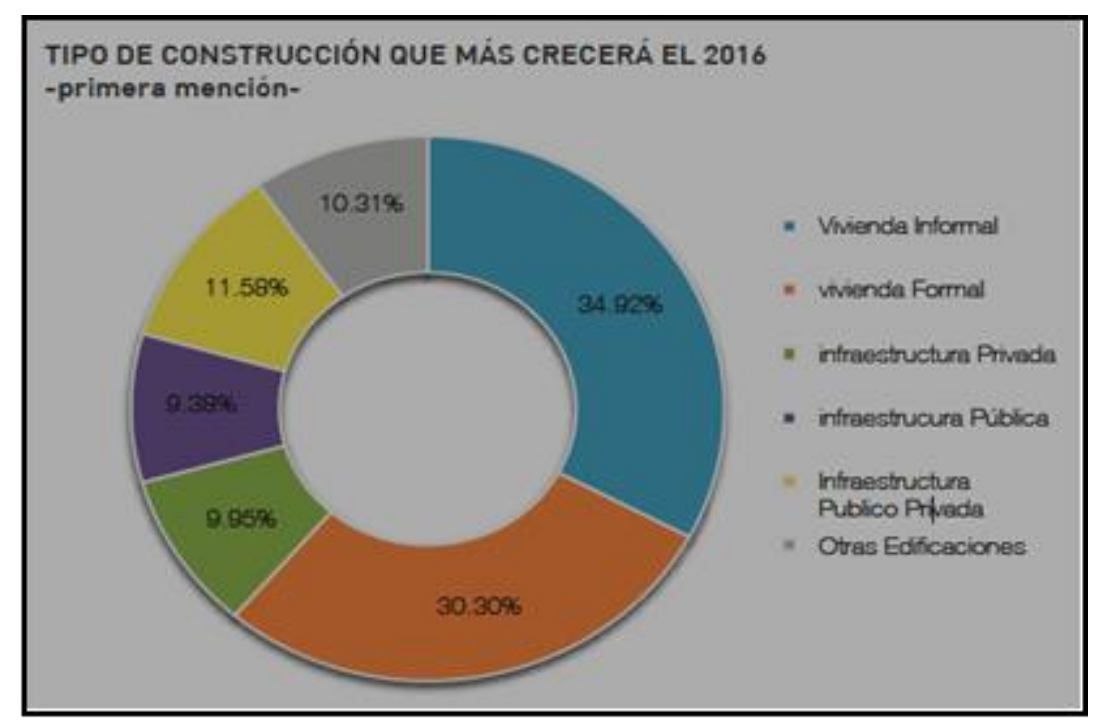

Figura 5. Tipo de Construcción que más crecerá el 2016.Perspectivas sobre el desempeño de los diferentes tipos de construcción en el 2016. Tomado del "Informe Económico de la Construcción” (IEC) Julio 2016, por Cámara Peruana de la Construcción (CAPECO)

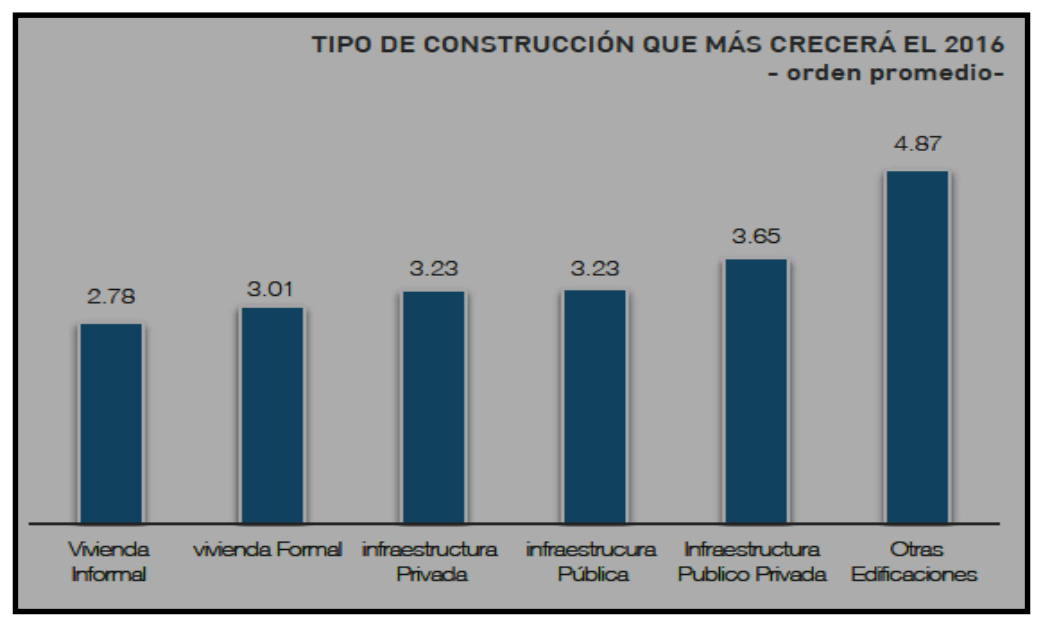

Figura 6. Perspectivas sobre el desempeño de los diferentes tipos de construcción en el 2016. Tomado del "Informe Económico de la Construcción" (IEC) Julio 2016, por Cámara Peruana de la Construcción (CAPECO)

b) Con respecto a las obras de infraestructura, consideran que sus principales ingresos son generados de obras localizadas en el interior del país. De las obras desarrolladas por iniciativas privadas, la mayoría de empresarios muestra mayor preferencia por desarrollar proyectos en el siguiente orden:

1. De infraestructura eléctrica.

2. Servicios de agua y desagüe 
3. Establecimientos de salud

4. Carreteras, establecimientos penitenciarios e inmuebles del Estado.

El último grupo presenta similar preferencia por su desarrollo sin anteponerse uno a otro. Ver Figura 7.

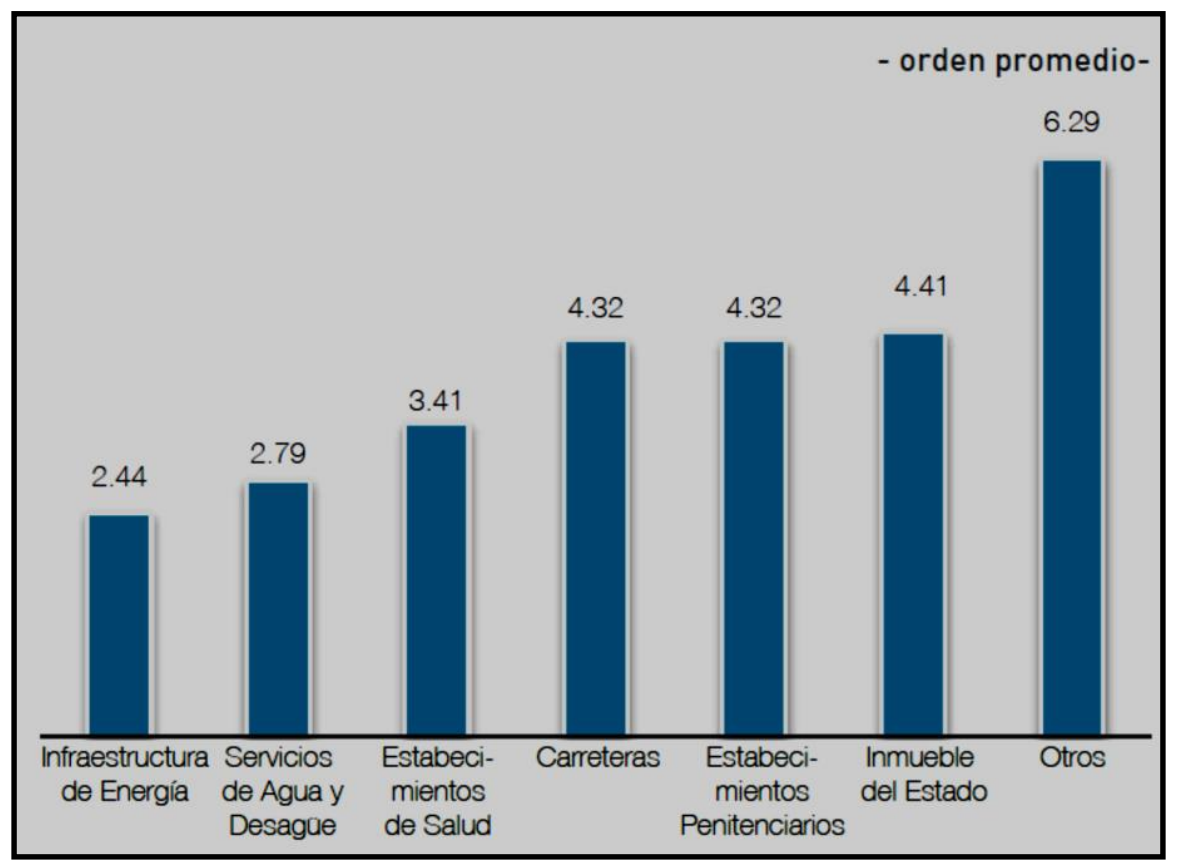

Figura 7. Tipos de proyectos susceptibles a ser desarrollados por iniciativas privadas. Tomado del "Informe Económico de la Construcción" (IEC) Julio 2016, por Cámara Peruana de la Construcción (CAPECO)

c) Los empresarios del sector inmobiliario; de acuerdo a las encuestas de expectativas, prevén un incremento de nuevos proyectos inmobiliarios hasta en $8 \%$, esto respaldado por las medidas tomadas por el gobierno con la finalidad de dinamizar el sector, con la liberación del 25\% de los fondos de AFP. (CAPECO, 2016). Ver Figura 8. 


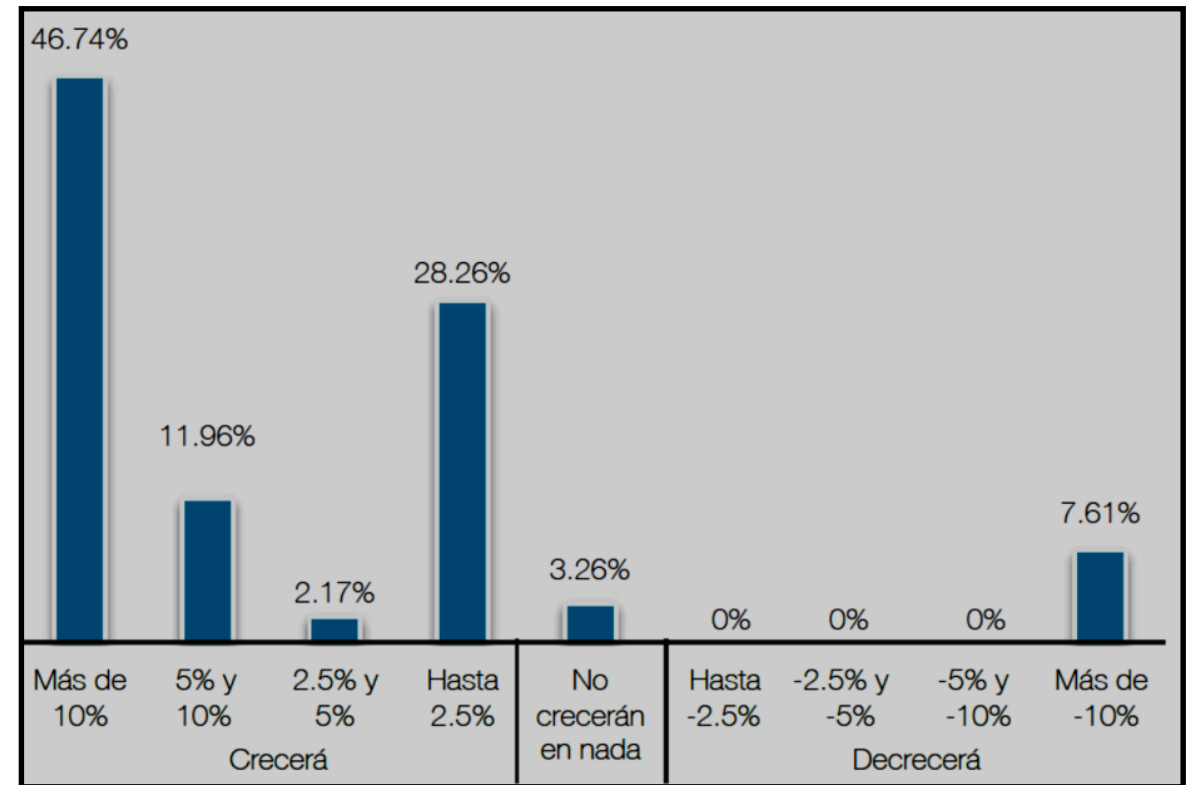

Figura 8. Expectativas sobre la variación del nivel de inversión en nuevos proyectos. Tomado del "Informe Económico de la Construcción (IEC)" Julio 2016, por Cámara Peruana de la Construcción (CAPECO)

d) Para el segmento de empresarios que se dedica a la venta de materiales y servicios para la construcción, las expectativas de crecimiento no son tan favorables, de acuerdo a CAPECO (2016): el 66\% indica, no variarán los precios, el 32\% creen que aumentarán y el 3\% cree que se reducirán. Ver Figura 9 y 10.

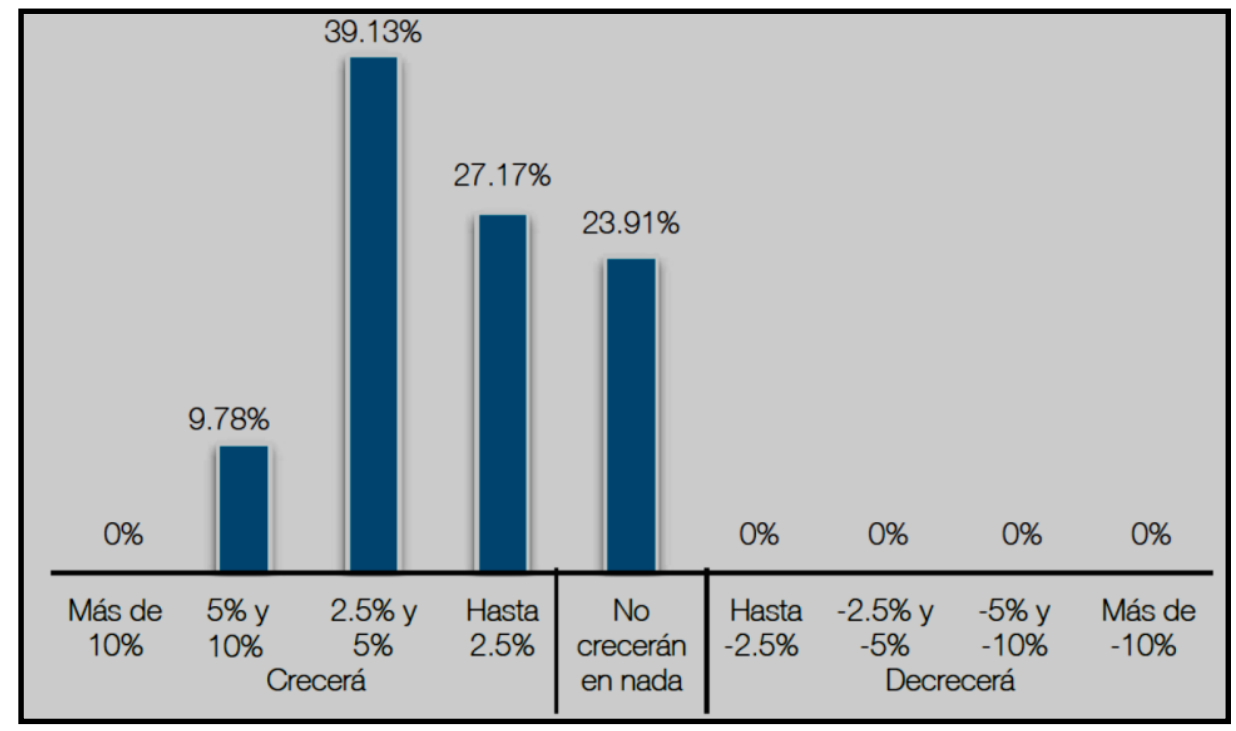

Figura 9. Expectativas sobre la variación de precios de materiales de construcción. Tomado del "Informe Económico de la Construcción (IEC)" Julio 2016, por Cámara Peruana de la Construcción (CAPECO) 


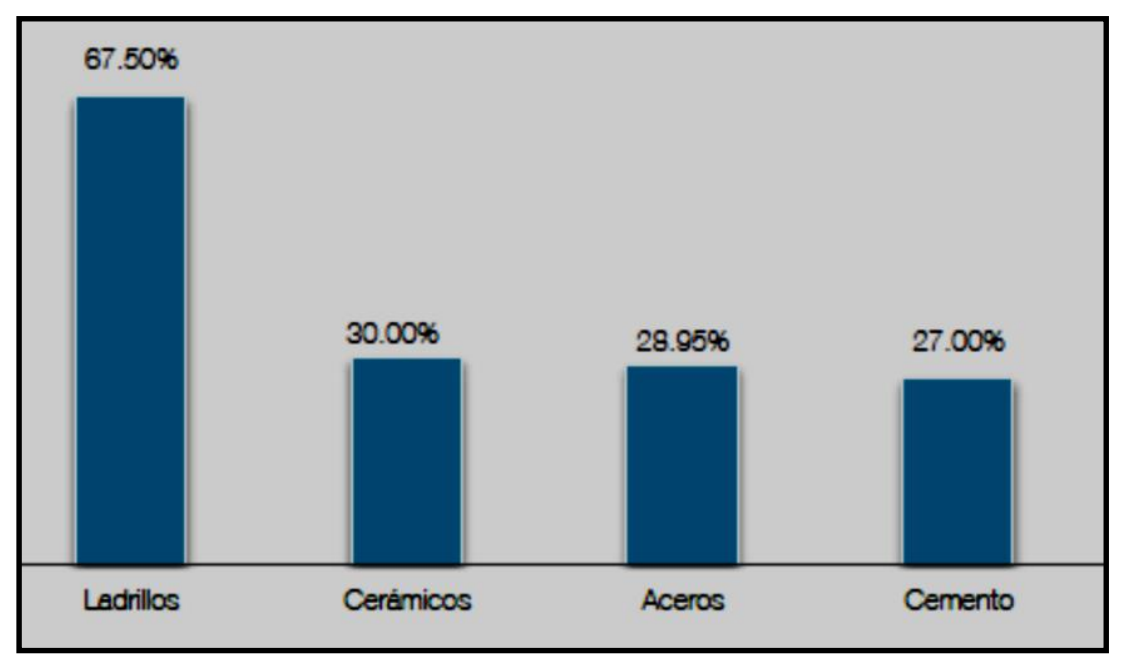

Figura 10. Nivel de oferta informal de materiales de construcción por industria. Tomado del "Informe Económico de la Construcción (IEC)" Julio 2016, por Cámara Peruana de la Construcción (CAPECO)

e) En un porcentaje del $80.7 \%$ de empresarios, no tienen previsto elevar su capacidad instalada al próximamente (alrededor de dos años). La mayoría de sus ingresos provienen del mercado autoconstrucción. Se tiene previsto un incremento de la oferta informal.

BCRP (2016) hace mención que, en Arequipa, se tiene previsto una demanda potencial de viviendas en al menos 208,000.00 unidades y que la demanda efectiva sea de 21,000.00 viviendas, centradas en el segmento C. Se recalca que las entidades regionales no se cuentan con información detallada, pero la información proporcionada por el Fondo MiVivienda y empresarios privados señalan el desarrollo de varios proyectos inmobiliarios:

f) Torres del Mirador Condominio Club

g) Mirador La Alameda

h) Valle Blanco II

i) Villa Verde

j) Quinta Privada El Solar y Alegría 
La información señalada anteriormente acerca de la región Arequipa tendría un alto impacto en el proyecto, ya que menciona la existencia de diferentes proyectos inmobiliarios, lo que podría ser aprovechado para ganar segmentos de mercado, de acuerdo a las especificaciones técnicas de nuestro producto.

\subsection{Análisis Estructural del Sector Industrial}

Thompson, Peteraf, Gamble y Strickland (2012) mencionan que, para entender el entorno industrial y competitivo de una organización, los gerentes deben centrarse en definiciones exactas y herramientas analíticas para responderse 7 cuestiones:

1. ¿Qué oportunidades atractivas ofrece la industria para el desarrollo?

2. ¿A qué fuerzas competitivas se enfrentan los miembros de una industria y cual la es la intensidad de cada una de ellas?

3. ¿En la industria qué fuerzas impulsan el cambio y qué efectos tienen sobre la competitividad y rentabilidad?

4. ¿Qué posición ocupan los rivales en el mercado y que tan sólida es?

5. ¿Cuál será la probable respuesta estratégica de los rivales?

6. ¿Qué factores son claves en el futuro éxito competitivo?

7. ¿Qué tan atractivas son las proyecciones de ganancia de la industria?

Para Thompson et al. (2012) el desarrollo del análisis de la competencia de la industria se realiza bajo el esquema de las 5 Fuerzas de Porter:

1. Rivalidad entre empresas competidoras

2. Entrada de potenciales competidores

3. Desarrollo de productos sustitutos

4. Poder de negociación de proveedores

5. Poder de negociación de los clientes 


\section{Rivalidad entre competidores}

David (2013), la rivalidad entre competidores es la más poderosa de las cinco fuerzas. El éxito de una estrategia organizacional es medible cuando obtiene una ventaja competitiva sobre sus rivales. Al ser detectadas las falencias de la competencia, se despliegan nuevas estrategias de marketing y de producción para capitalizar la oportunidad de mercado.

El autor señala las siguientes condiciones, por los que se produce una alta rivalidad: (a) ingreso de varios competidores, (b) disminución en la demanda de un producto, (c) reducción continua de precios, (d) facilidad para marca, (e) barreras de salida de mercado altas, (f) costos fijos altos, etc.

Cuando se intensifica la condición de alta competencia, el mercado de determinada industria pierde rentabilidad y se vuelve poco atractivo.

La Norma Técnica Peruana E.0.70, en su artículo 5, unidades de albañilería define que ladrillos y bloques, a aquellas unidades que pueden ser manipuladas con una sola mano por su dimensión y peso. Estas unidades tienen como características siendo sólidas, ser huecas, ser alveolares o tubulares y su composición de materia prima es en base de arcilla, sílice-cal o concreto. El proceso de fabricación que señala la norma es de manera artesanal o industrial.

En la ciudad de Arequipa, se dan estos dos tipos de fabricación de ladrillos: la artesanal y la mecanizada, por lo que establecemos como competencia directa del proyecto los ladrillos de arcilla (Ladrillo King Kong, ladrillo pandereta y ladrillo hueco) fabricado bajo estas modalidades.

Esta industria es bastante fragmentada, ya que existen varios productores artesanales y mecanizados en la ciudad de Arequipa, y su participación en el mercado no está bien definida.

Al tener varios competidores en la industria local, se puede comprobar las condiciones de alta rivalidad, mencionadas por David (2012), en los siguientes casos: 
a) Arequipa cuenta con 216 empresas ladrilleras. De las cuales 165 se concentran en el distrito de Mollebaya, lo que revela un gran número de competidores.

b) La capacidad de producción promedio de las ladrilleras artesanales en promedio es de 30 millares por quema.

c) Los consumidores finales no están identificados con una marca específica, por lo que recurren a diversos proveedores, centrándose en el precio del producto.

d) Las ladrilleras artesanales, no pueden hacerle frente a la producción de dos de las empresas más representativas del segmento en la ciudad de Arequipa, que son Ladrillera Choque y Ladrillera Diamante.

e) Debido a la desaceleración que se presenta en el sector construcción, las ladrilleras informales se han visto afectadas, con la disminución en los precios de venta de sus productos. Los costos fijos de producción han incrementado ya que el precio de los combustibles incrementa año tras año y este representa el $30 \%$ del costo de producción del ladrillero artesanal.

f) El hecho de que el proyecto de fabricación y comercialización de bloquetas plásticas sea un producto sustito al tradicional, es un factor importante, debido a que cumple con las mismas condiciones técnicas y ofrece ventajas tecnológicas, ecológicas, económicas y sociales. Esto encaja dentro de las condiciones de barreras de entrada de mercado bajas.

\section{Entrada de potenciales competidores}

David (2013) establece que el ingreso de nuevos competidores, siempre es una posibilidad latente, ya que incrementa la competitividad; este puede estar restringido por barreras de entrada, tales como: tecnologías, economías de escala, aranceles, regulaciones, etc. Incluso teniendo diversas barreras de entrada, se da que el ingreso de algunas empresas 
en la industria este determinado por productos de alta calidad, precios más bajos y recursos de marketing.

La estrategia de las empresas de la industria hacia los nuevos competidores es de vigilancia constante, ya que, ante signos de amenaza, las empresas de la industria ya establecida, tienden a fortalecer sus posiciones y despliegan acciones comerciales como reducción de precios, garantías, facilidades de financiamiento para mantener su público consumidor.

Como nuevos competidores dentro de la industria ladrillera de la ciudad de Arequipa, se evalúan las siguientes barreras de entrada:

a) Tecnología: Las empresas contras las que se pretende competir son ladrilleras artesanales, las cuales hacen uso de hornos de barro. Estas industrias usan en su proceso de producción combustibles, llantas usadas, aceite usado, plásticos, residuos orgánicos, etc.

El proyecto de bloquetas plásticas, plantea establecer una fábrica con un proceso industrializado que cumple las siguientes etapas: Reciclaje de plástico, trituración, mezclado, secado, almacenaje y comercialización.

b) Economías de escala: Las ladrilleras tradicionales establecidas primordialmente en el distrito de Mollebaya son altamente informales por lo que cuentan con ventajas de costos, tales como pago de personal por debajo del mínimo, no pagan impuestos.

El proyecto al ingresar con una persona jurídica formal y un proceso de producción sofisticado, ha diseñado planes de producción, distribución, marketing y finanzas, ya que son las áreas donde se tiene mayor impacto con referencia a la competencia. Al ser un nuevo competidor se contempla dentro de los planes entrar 
en desventaja de costos, lo que como consecuencia otorga menores ganancias, en los primeros años de operación.

c) El proyecto de fabricación y comercialización de bloquetas hace frente a las preferencias de los consumidores por marcas establecidas. Se tiene diseñado un plan de marketing donde establece las actividades a realizar para promocionar el producto, el cual cuenta con un presupuesto establecido por el plan de inversión.

d) Los requerimientos de capital son altos para los nuevos competidores ya que obviamente deben invertir en recursos financieros para competir. El plan de inversión del proyecto contempla los montos de inversión fija, inversión intangible, capital de trabajo.

e) Las ladrilleras informales cuentan con redes de distribuidores ya establecidas, en algunos casos son propias y otras tercerizadas. El proyecto ha desarrollado dentro del plan de marketing, la estrategia de distribución de canal directo e indirecto. Para lo que se hará uso de promociones, publicidad compartida.

\section{Desarrollo de productos sustitutos}

David (2013) explica, que la mayoría de industrias conviven de manera cercana con fabricantes de productos sustitos. Esto significa que existe una alta competencia entre ellos, a nivel de precios, lo que determina sus ganancias máximas.

La presión de la competencia se denota a medida que se incrementa la producción de productos sustitos y estos realizan cambios para aumentar su capacidad de producción también manejan proyecciones de crecimiento de ventas y utilidades.

Señala el autor que para medir la competitividad de los productos sustitutos, debemos fijarnos en su participación de mercado y en los planes que hacen las empresas para incrementar su capacidad y penetración de mercado. 
Tradicionalmente lo sustitutos de los ladrillos son los bloques de concretos pre armados o concreto pre mezclado. Estos productos cuentan con la certificación de la norma ISO 9001, ya que, a diferencia de los ladrillos de arcilla y los bloques de cemento, dan resistencia ante cualquier fenómeno sísmico. Su costo elevado lo pone en desventaja para el mercado tanto en autoconstrucción y construcción de viviendas, debido a que son sometidos a diferentes pruebas de laboratorio para verificar su calidad. De acuerdo a CAPECO (2016), los materiales más demandados para construcción de viviendas son el ladrillo de arcilla y el concreto armado.

El proyecto de fabricación y comercialización de bloquetas plásticas, al ser un nuevo producto sustituto, se ha propuesto como meta obtener un $4.5 \%$ del mercado de la industria ladrillera Arequipeña, esto se desarrolla en el Capítulo IV del plan de negocios, en el punto mercado objetivo.

Los usos de la bloqueta plástica son para construcción de vivienda, edificios, muros, vías, recubrimientos o cercos perimétricos, etc. Los atributos del producto están enfocados en la tecnología del producto (livianos, resistentes, etc.), el enfoque ecológico, su costo y el enfoque social.

El desarrollo de este producto está contemplado dentro de la Norma Técnica Peruana (NTP) 3331.017:2003, calificación Tipo 21 (Utilizado cuando se necesite alta resistencia a la compresión y resistencia a la penetración de humedad y a la acción severa del frío)

\section{Poder de negociación de los proveedores o vendedores}

Como David (2013) indica sobre la teoría de Porter, el poder de negociación de los proveedores interfiere con la competitividad de la industria, cuando estos son varios y la materia prima es escasa y de alto valor. Las asociaciones entre proveedores y productores pueden resultar beneficiosas en el largo plazo, si ambos trabajan sobre la base de precios razonables, productos de calidad, implementando nuevos servicios, reduciendo costos, etc. 
Las empresas buscan controlar a los proveedores, a través de la estrategia de integración hacia atrás, cuando estos no cumplen con los requerimientos de ellas. Para otras resulta más ventajoso trabajar con proveedores externos para comprarles componentes en vez de fabricarlos, estas alianzas estratégicas buscan beneficios como: (a) disminuir costos en inventarios y logística, (b) incrementar la disponibilidad de recursos de última generación, (c) mejorar la calidad de productos que proveen, reduciendo su índice de defectos, y (d) minimizar costos para ambos.

El poder de negociación de los proveedores es bajo debido ya que existe un incremento notorio en la obtención de materia prima y son varias las empresas que participan en este mercado, tanto a nivel formal e informal. Se analizan los siguientes factores:

a) En la ciudad Arequipa la concentración de proveedores de residuos plásticos es aún bastante baja, debido a que es un producto abundante ya que los problemas de contaminación, en la ciudad no han sido abordados correctamente.

b) En la ciudad de Arequipa, existen varios acopiadores de residuos plásticos, tanto formales como informales, por lo que el proceso de negociación está sujeto al poder adquisitivo del comprador y se utiliza los descuentos de acuerdo a la cantidad del residuo.

c) La diferenciación en el producto que ofrecen los recicladores de residuos plásticos es bastante baja, ya que se está desarrollando un producto nuevo como las bloquetas plásticas.

d) La relación entre proveedores y la empresa a crear es importante, ya que se basa en los volúmenes de compra. La oferta depende de la cantidad y se mide en metros cúbicos, toneladas, etc. 
e) Los proveedores de residuos plásticos realizan sus ventas al contado ya que requieren de liquidez.

\section{Poder de negociación de los clientes}

El poder de negociación que tienen los clientes es alto debido a los bajos costos para cambiar de ladrilleras, los productos están estandarizados, pero tienen una alta competencia en sus precios y calidad. En conjunto los consumidores limitan el potencial de utilidades de esta industria por las mismas razones que otro grupo de compradores ejercen presiones competitivas. Se detallan estas razones:

a) Cambiar de proveedor de bloquetas tiene un bajo impacto en costos y tiempo, porque muchos sustitutos están disponibles en un mismo distrito en la ciudad de Arequipa.

b) Dependiendo del tipo proyecto y construcción a ejecutar, es que toma importancia el volumen de transacción con el cliente. La oferta que se maneja en el mercado es por millar.

c) Las ladrilleras tradicionales no guardan estrecha relación con los clientes, es por ello que el presente proyecto sobre bloquetas plásticas, en el capítulo correspondiente a Plan de Marketing se desarrollan estrategias relacionadas a la venta del producto y el servicio postventa.

d) Los compradores exigen descuentos por volúmenes de compra.

\subsection{Análisis de la competencia}

CAPECO (2016), en su informe económico de la construcción menciona que la participación de mercado a nivel nacional, está cubierta en 50\%, sólo por 2 ladrilleras. Ladrillos LARK y Ladrillos Pirámide cuentan cada una con la participación del 25\% y a nivel provincia destaca Ladrillos Diamante con una participación del 18\%. Ver Figura 11. 


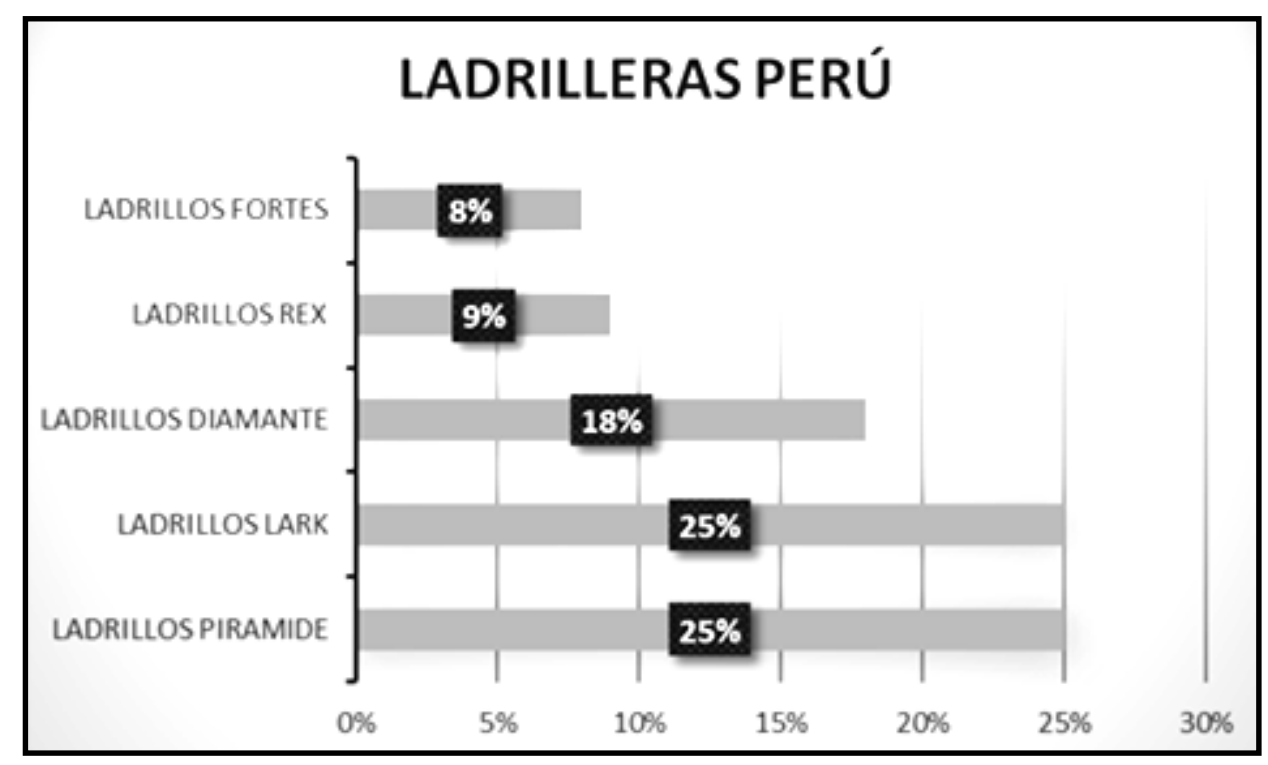

Figura 11.Participación de mercado de empresas nacionales, productores formales de Ladrillos de Arcilla - 2014 (En Facturación), de informe económico de la construcción (IEC) N 9, por la Cámara Peruana de Construcción (CAPECO), Julio 2016.

En la provincia de Arequipa, el líder en producción de ladrillos es Ladrillera Diamante, en el 2015 creció 5\% y opera con tres turnos. No obstante que se enfrenta una alta informalidad. Cabe indicar que la empresa ha desarrollado una estrategia innovadora de posicionamiento de sus productos en el mercado, que a la vez redunda en acciones de responsabilidad social y seguridad en las obras de construcción, a través de la capacitación y certificación de los maestros de obra para una adecuada construcción.

Como productos de competencia directa se tienen solo ladrillos fabricados a base de arcilla cocida, los ladrillos tradicionales, los bloques y los adoquines de concreto.

\subsubsection{Empresas que ofrecen el mismo producto o servicio, indicando las semejanzas y} diferencias que tienen con el proyecto de empresa).

En la ciudad de Arequipa, no hay un registro de empresas que trabajen con ladrillo plástico. La industria ladrillera es bastante informal. 
La única empresa formal dedicada a la elaboración de ladrillos en Arequipa es Ladrillera Diamante.

La industria ladrillera artesanal en Arequipa, se concentra en el distrito de Mollebaya, lo que representa un $76.3 \%$ de la producción local y teniendo la siguiente cantidad de empresas en las siguientes zonas: Alcosa con 70 empresas y Virgen de Chapi con 60. A pesar de ser la zona de mayor producción, en la actualidad se encuentra sin canteras de arcillas para ser extraídas, es decir los ladrilleros artesanales ya han consumido toda la previsión posible de arcilla que poseían, lo que les obliga a comprar arcilla de alguna comunidades campesinas, que se encuentran en la zonas más altas de la región. Ver figura 12 y 13.

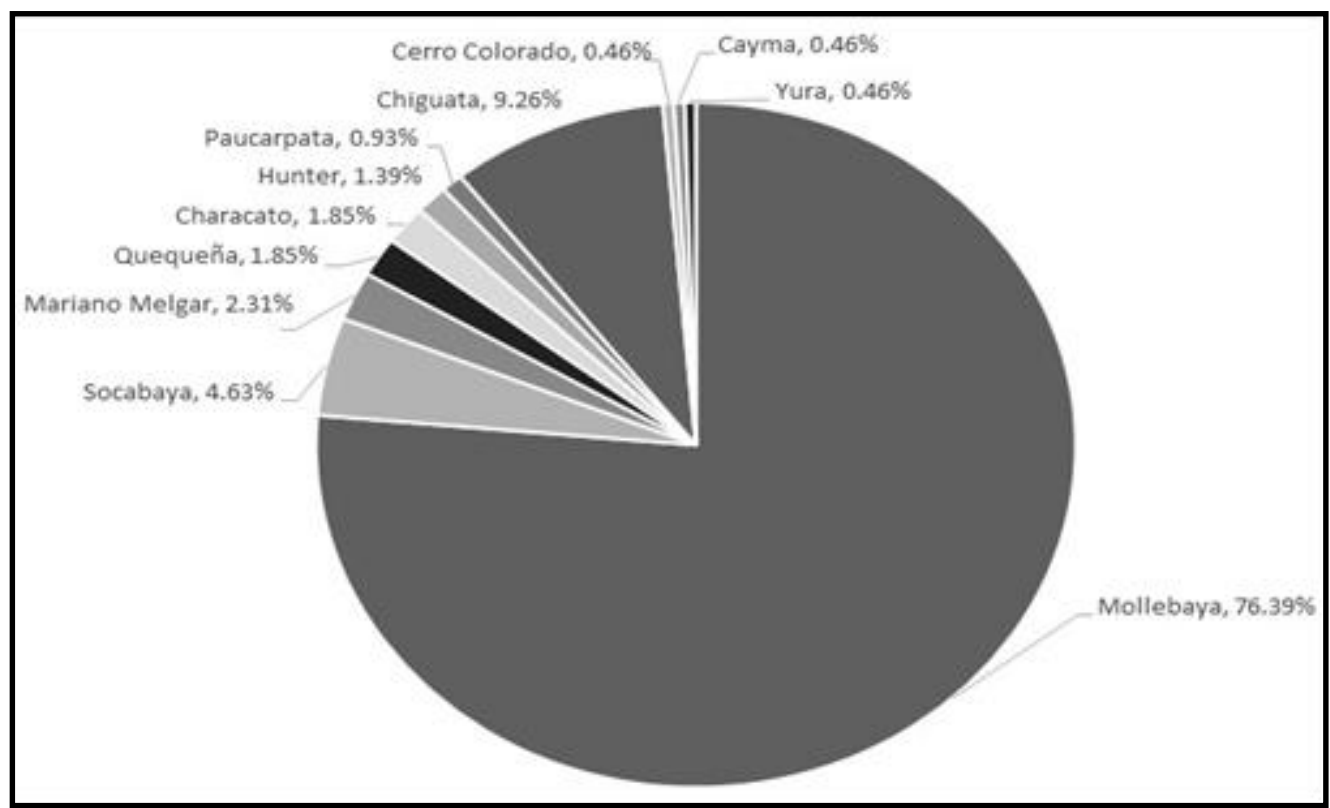

Figura 12. Zonas de producción de ladrillo artesanal en Arequipa. Adaptado de "Diagnóstico Nacional del Sector Ladrillero Artesanal" por Mercadeando S.A 2012 


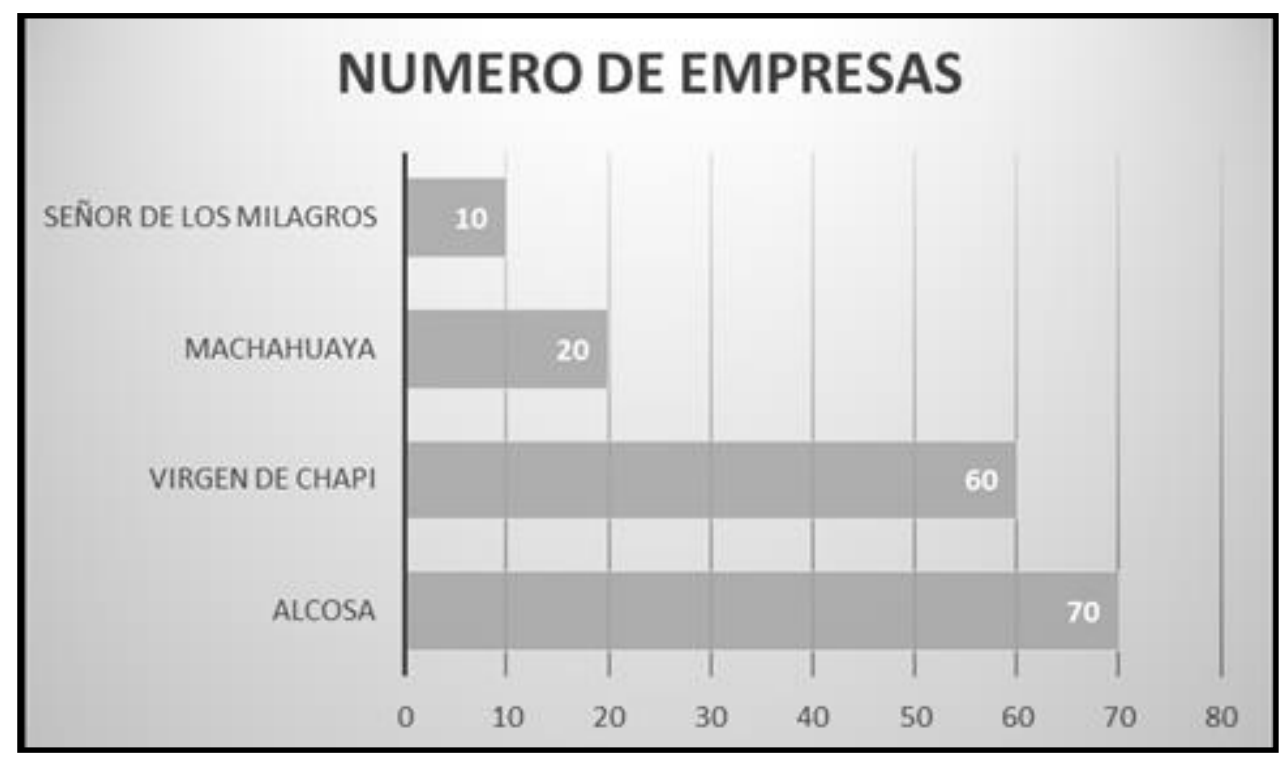

Figura 13. Número de empresas que fabrican ladrillo en Mollebaya. Adaptado de "Diagnóstico Nacional del Sector Ladrillero Artesanal” por Mercadeando S.A 2012

Con respecto a la industria ladrillera artesanal; la principal semejanza con el proyecto es el uso de la materia prima de la tierra, por lo demás ninguna ladrillera ha incluido dentro de su proceso la mezcla de materiales plásticos para la elaboración de los ladrillos.

\subsubsection{Participación de mercado de cada uno de ellos.}

Según CAPECO (2016), de las 65 empresas formales que se estiman en el mercado, las empresas que representan el mayor porcentaje de facturación está concentrado en seis empresas y representan el 92\% del mercado son: Pirámide, Lark, Rex, Diamante, Fortes y Sagitario.

Todas las empresas mencionadas tienen su sede principal en la ciudad de Lima, excepto Ladrillera Diamante originaria de Arequipa. Ver Tabla 7. 
Tabla 7

Participación de mercado de las principales empresas productoras de ladrillo de arcilla

\begin{tabular}{ll}
\hline $\begin{array}{c}\text { Empresas } \\
\text { Productoras }\end{array}$ & $\begin{array}{c}\text { Participación } \\
\text { de mercado }\end{array}$ \\
\hline Ladrillos Piramide & $25 \%$ \\
Ladrillos Lark & $25 \%$ \\
Ladrillos Diamante & $18 \%$ \\
Ladrillos Rex & $9 \%$ \\
Ladrillos Fortes & $8 \%$ \\
Ladrillos Sagitario & $6 \%$ \\
Otros & $8 \%$ \\
\hline
\end{tabular}

Nota. Adaptado de participación de mercado de empresas nacionales, productores formales de Ladrillos de Arcilla - 2014 (En Facturación), tomado de informe económico de la construcción (IEC) № 9, por la Cámara Peruana de Construcción (CAPECO), Julio 2016.

La producción formal de ladrillos de arcilla es llevada a cabo por empresas que cumplen con obligaciones legales, tributarias y laborales y además cuentan con certificaciones a la calidad de sus productos. De acuerdo a CAPECO (2016) estas ladrilleras solamente captan el $41 \%$ de la producción, la producción semi-formal cubre el 59\% restante, esto involucra a empresas que adoptan ciertos atributos de la formalidad (tienen RUC, declaran utilidades, pagan impuestos y/o brindan información sobre su producción al Ministerio de Producción) y a su vez desarrollan prácticas informales como vender parte su producción sin facturas, condiciones laborales precarias. La principal característica de los semi-formales es ofrecer productos de baja calidad que pone en peligro el patrimonio y hasta la vida de las personas.

\subsubsection{Matriz de perfil competitivo.}

Según David (2013) la matriz del perfil competitivo (MPC) desarrollada por Charles H. Kepner y Benjamin B. Tregoe, en los años 60, sirve para identificar las fortalezas y debilidades de los competidores de la compañía con relación a otra empresa. Sus 
calificaciones se denotan de la siguiente manera: (4) fortaleza principal, (3) fortaleza menor, (2) debilidad menor, (1) debilidad principal.

Para la evaluación de la matriz de perfil competitivo, se realizó entrevistas a expertos, Ver Anexo XI; a través de la cual se obtuvo los factores críticos y la calificación como se muestra en la Tabla 8, de una de las empresas ladrilleras más formales del distrito de Mollebaya en Arequipa, Ladrillera Choque y la del presente proyecto de fabricación y comercialización de bloquetas plásticas.

Tabla 8

Matriz de perfil competitivo, de empresa ladrillera y proyecto.

\begin{tabular}{lccccc}
\hline & \multicolumn{2}{c}{ LADRILERA CHOQUE } & \multicolumn{2}{c}{ PROYEC TO } \\
\hline Factores criticos para el éxito & Ponderación & Calificación & Puntuación & Calificación & Puntuación \\
\hline Calidad de producto & 0,20 & 4 & 0,80 & 4 & 0,80 \\
Distribución de ventas & 0,20 & 4 & 0,80 & 2 & 0,40 \\
Servicio al cliente & 0,10 & 2 & 0,20 & 3 & 0,30 \\
Competitividad de Precios & 0,25 & 2 & 0,50 & 4 & 1,00 \\
Capacidad de producción & 0,15 & 4 & 0,60 & 1 & 0,15 \\
Publicidad & $\underline{0.1}$ & 3 & $\underline{0.30}$ & 4 & $\underline{0.40}$ \\
Total & 1,00 & & 3,20 & & 3,05 \\
\hline
\end{tabular}

Nota. Adaptado del Anexo XI del presente estudio.

Tomando en cuenta las preguntas realizadas se obtuvo los siguientes factores Críticos: Participación de mercado, calidad de producto, lealtad del cliente, distribución de ventas, servicio al cliente, competitividad de precios. Dentro de la misma tabla se evaluó la estructura organizacional, para poder compararnos con respecto a nuestros aspectos organizacionales planteados en el proyecto. Por último, se menciona la capacidad de producción y publicidad de Ladrillera Choque, para evaluar nuestro proyecto de ingeniería y el plan de marketing.

Se concluye que las principales fortalezas de Ladrillera Choque son: (a) La calidad de sus productos, es una empresa local con más de 15 años en el rubro ya que predomina a diferencia de sus pares establecido en el sector de Mollebaya, su producción es más industrializada, y es aquí donde nuestro proyecto ofrece una gran fortaleza ya que desarrollaremos un producto alternativo que brinda las mismas características técnicas que el 
ladrillo tradicional. (b) La distribución de ventas de Ladrillera Choque, ya cuenta con una red de distribuidores autorizados y puntos de ventas propio, por lo que nuestro proyecto ha desarrollado dentro de su plan de marketing estrategias de distribución que nos permitan competir con esta empresa. (c) La capacidad de producción de Ladrillera choque, ya se encuentra en funcionamiento y va más allá de los 30 millares tradicionales, siendo esto una de nuestras principales debilidades, ya que recién se establecerá la planta de producción.

\subsection{Análisis del Contexto Actual y Esperado}

\subsubsection{Análisis político-gubernamental.}

De acuerdo a la revista América Económica (2015), en un artículo publicado por Alfredo Ferrero, quien fue ministro de Comercio Exterior y Turismo durante el gobierno de Alejandro Toledo, explica en su artículo que el Perú durante las dos últimas décadas se disfruta de una relativa estabilidad política. Se han sucedido de manera ininterrumpida varios gobiernos democráticamente elegidos por la población.

El Banco Mundial (2017) por intermedio de diferentes representantes, en entrevistas a diferentes medios escritos, electrónicos, señalan que el entorno legal del Perú es bastante saludable y reconocen el innegable progreso en cuanto a la continuidad de políticas públicas consideradas como primordiales en los asuntos del Estado como son la apertura de la economía al mercado globalizado y los programas de apoyo e inclusión social a los sectores más pobres del país. No dejan de reconocer que existen diversos factores políticos, tales como el escándalo de corrupción asociado a la empresa constructora Odebrecht, que ha debilitado la imagen del gobierno en tema de lucha contra la corrupción.

A nivel internacional, el Perú es visto como una país demócrata, pero en la práctica se reconoce como una democracia imperfecta, tal y como lo señala el Índice de Democracia del 
2016, publicado por la revista “The Economist”, en ella el Perú ocupa el lugar 59 en

Latinoamérica. (Diario Gestión, 2017). Ver tabla 9.

Tabla 9

Índice de la Democracia 2016 para América Latina y el Caribe.

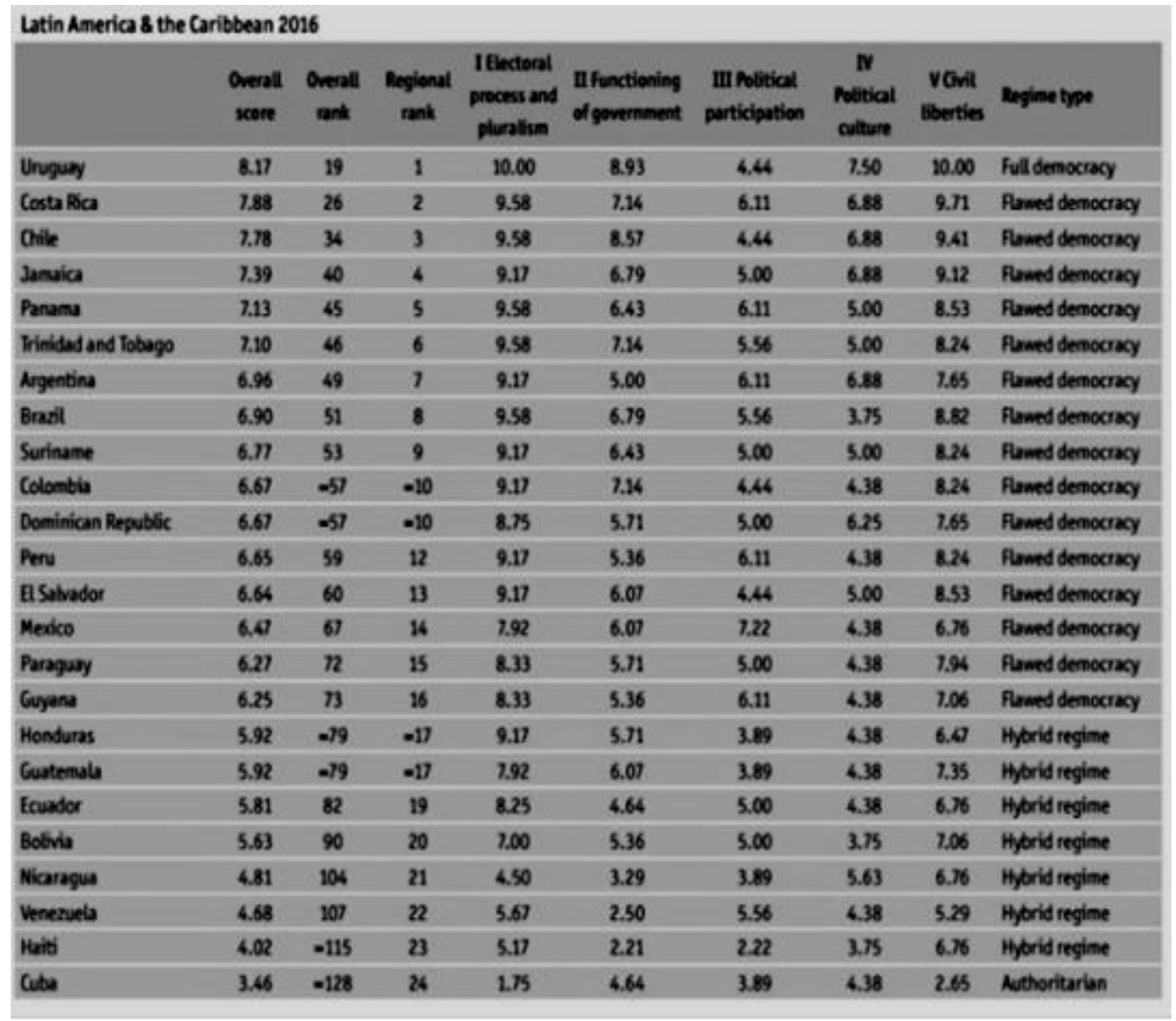

Nota. ¿Qué país latinoamericano tiene la democracia que mejor funciona? Recuperado de https://gestion.pe/politica/que-pais-latinoamericano-tiene-democracia-que-mejor-funciona2180909/4, por "The Economist", 2017.

La situación política y social del país aún es inestable y podría condicionar en lo sucesivo la continuidad de sus políticas en el futuro, en lo que va del presente gobierno correspondiente a Pedro Pablo Kuczynski, ha tenido que hacer frente a una mayoría parlamentaria adversa, escándalos de corrupción al interior de su propio círculo de asesores, huelgas civiles de los diferentes gremios, el fenómeno del niño, crisis ministeriales. A todo ello el gobierno ha tenido respuestas que están dentro del marco jurídico democrático. La 
guía de este gobierno está enfocada en conseguir el consenso con todas las fuerzas políticas de esta manera se le permita seguir avanzando de acuerdo a sus objetivos y planes como gobierno, siendo los principales: a) Seguridad ciudadana, b) Recuperar el dinamismo de la economía, c) Lucha contra la corrupción, d) Inversión social (Memoria del gobierno 20162017)

Desde fines del gobierno del Presidente Ollanta Humala, se está mostrando, un gran interés por el desarrollo de programas e incentivos medioambientales a través del Ministerio de la Producción y el Ministerio del Ambiente, en busca del equilibrio ecológico, para direccionar esfuerzos conjuntos con la industria nacional para lograr una empresa amigable con el medio ambiente. El Organismo de Evaluación y Fiscalización Ambiental (OEFA), será el encargado de ofrecer incentivos económicos a las empresas que prevengan y reduzcan impactos negativos en el medio ambiente. (Diario Gestión, 2014). Es en este sentido que ha desarrollado el concepto de calidad ambiental y su relación con la disponibilidad y facilidad de acceso a los recursos naturales y a la ausencia o presencia de agentes nocivos. Todo esto necesario para el mantenimiento y crecimiento de la calidad de vida de los seres humanos.

Paralelo a este esfuerzo de control medioambiental y buscando convencer a la industria, el Gobierno está incentivando la ley Investigación Tecnológica en las empresas. Se trata de un incentivo tributario a la innovación empresarial que otorga un porcentaje de deducción adicional al 100\% a los gastos que realicen las empresas en investigación científica, desarrollo tecnológico e innovación tecnológica (actividad conocida como I+D+i). Esta deducción adicional, que puede llegar al 75\% del gasto, reduce la renta neta a partir de la cual se calcula el impuesto a la renta. En buena medida, reduce el impuesto a pagar, de manera proporcional al gasto en $\mathrm{I}+\mathrm{D}+\mathrm{i}$. (Ministerio de la Producción, 2015) 
Se puede evidenciar entonces cierta coherencia en el control medioambiental y el incentivo tecnológico por parte del Gobierno para lograr una industria con desarrollo ecológico.

Concluimos que el Perú está pasando por una etapa de inestabilidad política, que puede ser tanto una oportunidad como una amenaza para la industria ladrillera. Amenaza ya que la constante fricción entre poderes tanto ejecutivo y legislativo, genera incertidumbre entre los inversores y la población en general y a su vez es una oportunidad debido a que el país se encuentra en un proceso de reconstrucción debido al fenómeno del niño y esto es atractivo para la entrada de nuevos competidores con productos alternativos.

\subsubsection{Análisis económico.}

El MEF (2017) menciona que la economía peruana se encuentra en proceso de recuperación. De acuerdo a las proyecciones del Marco Macroeconómico Multianual 2018 al 2021, la tasa de crecimiento promedio del Producto Bruto Interno (PBI) al cierre del 2017 estimada es del $2.8 \%$, con proyecciones de crecimiento hasta de $5 \%$ hasta el 2020 , en un entorno de baja inflación al cierre del año en promedio de $2 \%$ el cual es su rango meta. Ver Figura 14 y 15.

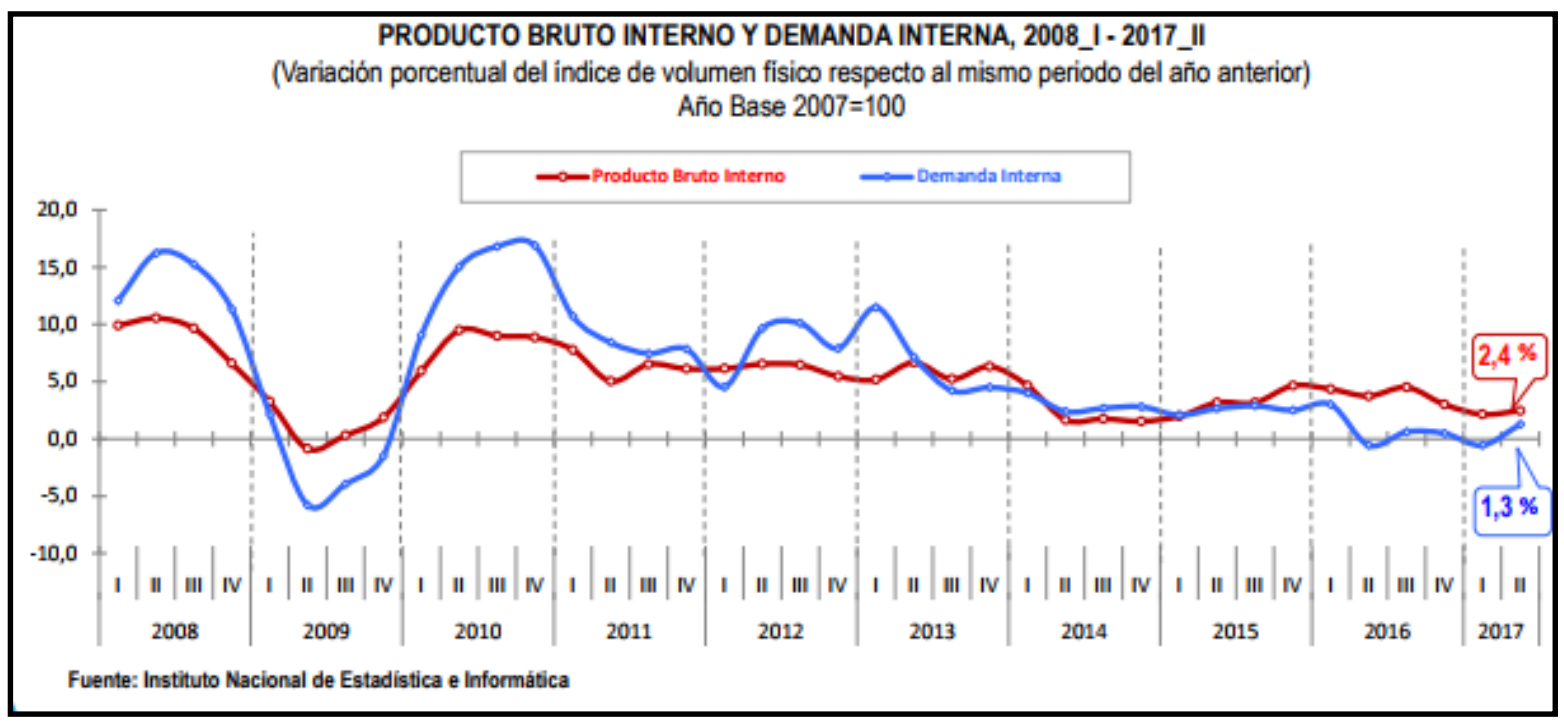

Figura 14.Evolución del Producto Bruto Interno y Demanda Interna 2008 al 2017, por el Instituto Nacional de Estadística (INEI), 2017. 


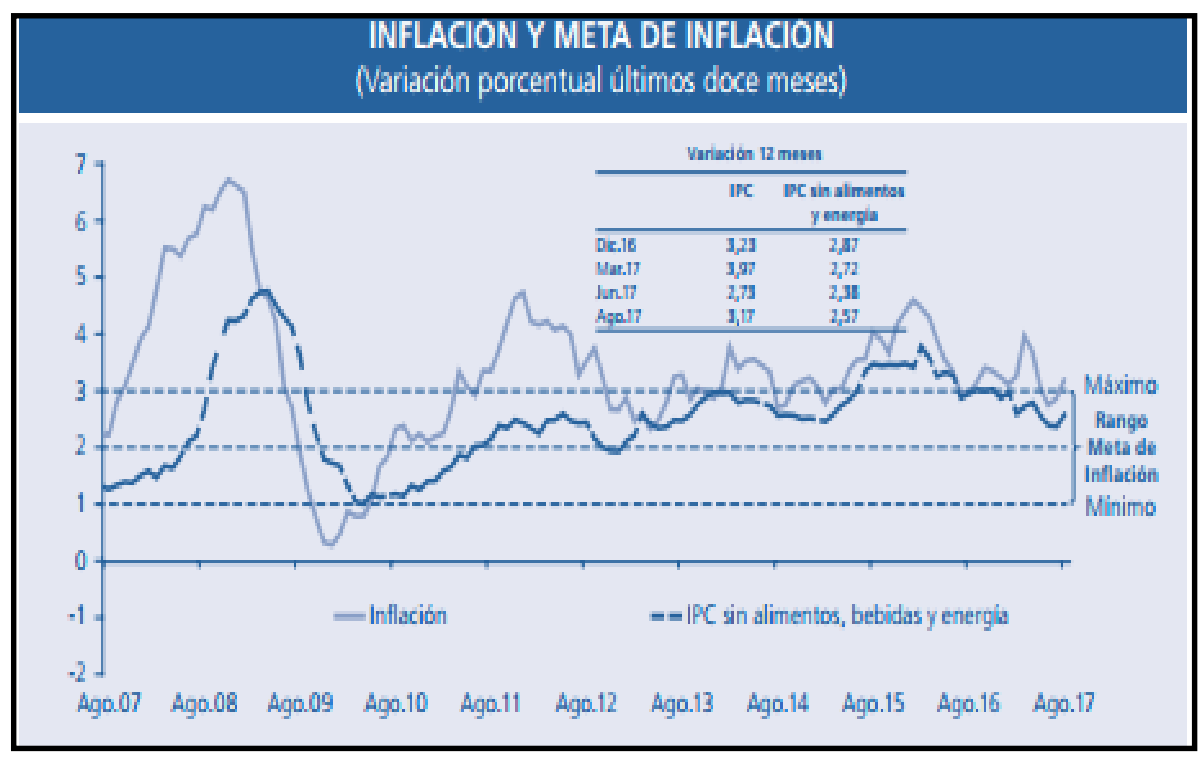

Figura 15. Inflación y meta de Inflación 2007 al 2017, por el Banco Central de Reserva del Perú (BCRP), setiembre 2017.

La actividad económica se desaceleró durante el último trimestre del 2016 y primer trimestre del 2017, por el impacto de las medidas fiscales, el caso de corrupción de las empresas brasileñas, el Fenómeno del Niño. La recuperación se viene dando desde el segundo trimestre del 2017, con el crecimiento del sector comercio y servicio, la mayor inversión público y privada.

De acuerdo al BCR (2017), se prevé que para el año 2018, el impulso del sector construcción, generado a partir de la reconstrucción de la zona norte del Perú, y el destrabe de proyectos de infraestructura tales como la línea 2 del metro de lima, incrementen el empleo y los ingresos de la ciudadanía. Las proyecciones apuntan a un incremento de la inversión privada, en el sector minero, energía e hidrocarburos. Ver Tabla 10. 
Tabla 10.

Principales proyectos de inversión al 2019.

\begin{tabular}{|c|c|c|}
\hline SECTOR & INVERSIONISTAS & PROYECTO \\
\hline \multirow{5}{*}{ MINERIA } & Southern Perù Cocper Corp. & Amplación de Mina Joquepala \\
\hline & Aluminium Corp. Of China Ltd.(Chinako) & Mejoras y amplisción en el sistema productivo de Joromocho \\
\hline & Shougang Corporation & Aurplasción de Mina Marcona \\
\hline & Angloamerican & Quelaveco \\
\hline & Grupo Breca & Mina Justa \\
\hline \multirow{3}{*}{ HIDROCARBUROS } & Repsd YFF SA. & Lote $57 \cdot$ Kinteroni \\
\hline & China National Petroleum Corporation & Exploración Lote 58 \\
\hline & Calidda Gas Natural del Perú & Masificación de Gers \\
\hline \multirow{3}{*}{ ENERGIA } & Lue del Sư & Central Termoeitectrica Pacifico Sur \\
\hline & Tetmochica & Central Térmica Dorningo Olleros-Ciclo Combinado \\
\hline & Interconevión Electrics & Linea de Transmisión $500 \mathrm{kV}$ \\
\hline \multirow{3}{*}{ INDUSTRLA } & Corporación Lindky & Almacenes, centros de distribución y mejoras en infraestructura \\
\hline & Repsd YFF & Amplación de Refineria La Pampills \\
\hline & Grupo Celepsa & Amplación de planta en fisco \\
\hline \multirow{5}{*}{ INFRAESTRUCTURA } & Grupo Vokan & Terrinal Portuario de Chancay \\
\hline & $A D P$ & Mejoras y nuevas pistas de aterrizaje \\
\hline & Lims Airport Partners & Amplación Terminal Aeropueto Jorge Chavez \\
\hline & APM Terminats & Modernizadón Muele Norte \\
\hline & Consorcio Nuevo Metro de Lima & Linea 2 Metro de Lima \\
\hline \multirow{8}{*}{ OTROS SECTORES } & Grupo Teleforrica & Infraestructura e implementadón del senvicio 4G \\
\hline & Entel & Desarolo de servidios y redes $4 G$ \\
\hline & America Móvd & Implementación y expansion de redes $4 G$ \\
\hline & Grupo falabels & Expansión y nuevos centros comerciales \\
\hline & Inverviones Centenario & Inversiones Inmobilarias y amplacón de centros comercistes \\
\hline & Grupo hterbank & Expansión y nuevos centros comercisles \\
\hline & Grupo Brecs & Expansion y nuevos hoteles, dhicas y centros comerciaks \\
\hline & Cencosud & Centro Comercis \\
\hline
\end{tabular}

Nota. Tomado del Banco Central de Reserva del Perú (BCRP), setiembre 2017.

Las menores tasas de crecimiento del PBI desde el 2014, se deben a un ciclo de desaceleración de la economía, por ende a un menor crecimiento del PBI potencial. Se tienen perspectivas positivas con respecto a la recuperación del PBI potencial a partir del impacto que generará el plan de reconstrucción sobre la inversión y una mejora gradual de la productividad total de factores.

De acuerdo a cifras del Ministerio de Construcción Vivienda y Saneamiento (2017), el sector construcción ha frenado su caída, teniendo un crecimiento en el mes de junio de 
$3.49 \%$, ante el aumento del consumo interno de cemento y el avance en obras físicas. Siendo esta información de vital importancia para el impacto en el proyecto, ya que se ha descentralizado la inversión de proyectos inmobiliarios a provincias, generando oportunidades de negocios para los proveedores de materiales y servicios.

La Cámara Peruana de la Construcción (2017) en su boletín del mes de setiembre, señala que los ingresos por ventas de proveedores el 36\% está destinado al mercado de autoconstrucción, segmento en el cual también se enfoca el proyecto.

\subsubsection{Análisis legal.}

El Ministerio de Vivienda Construcción y Saneamiento (MVCS) cuenta con una entidad de Tratamiento Especial, Servicio Nacional de Capacitación para la Industria de la Construcción (SENCICO), el objetivo de esta entidad es la formación de los trabajadores del sector construcción. A su vez se encarga de supervisar y hacer cumplir la Norma técnica E.070 de Albañilería.

La Norma E.070, establece en su capítulo uno, aspectos generales, siendo en el artículo uno donde se brindan los siguientes alcances: requisitos mínimos para el diseño, materiales, construcción, control de calidad y la inspección de edificaciones de albañilería. La aplicación de la norma se da en la medida de lo posible, en estructuras especiales tales como muros de contención, arcos, chimeneas y reservorios. Los sistemas de albañilería ajenos a la norma, deberán ser aprobados por el MVCS para poder ser evaluados por SENCICO.

Al cumplir con la Norma E.070 y la supervisión de SENCICO, la Bloqueta Plástica frente a productos similares, es un producto de calidad que cumple con los estándares de resistencia, fortaleza y durabilidad. Las características antes mencionadas le permiten resistir a los desastres naturales, como los sismo a diferentes niveles, lo cuales suelen presentarse en nuestro país, lo cual es una ventaja competitiva 
El Ministerio del Ambiente (MINAM) es la entidad encargada a través de su normatividad de establecer los límites máximos permisibles a las emisiones atmosféricas. Al contar con leyes y entes de control de apoyo del Ministerio del Ambiente se incentiva la reducción de contaminación por parte de las empresas productoras y se busca la formalización de las mismas.

\subsubsection{Análisis cultural.}

De acuerdo al portal de la Municipalidad de Arequipa (2016), con respecto al análisis cultural se consideró la inclinación que tienen los pobladores de la provincia de Arequipa al optar por una vivienda, las cuales son predominantemente de material noble en zonas residenciales y de mayor poder económico, también hay viviendas bien construidas y algunas zonas donde las condiciones son más precarias y los sistemas constructivos poco seguros.

Según el diagnóstico realizado al sector ladrillero artesanal en la ciudad de Arequipa (Mercadeando S.A., 2012), los fabricantes de ladrillos en la provincia de Arequipa son núcleos familiares, compuestos por padre, madre y los hijos que trabajan de manera informal. La participación de estos últimos varía ya que asisten a las escuelas y deben cumplir tareas. No existe una gestión empresarial y su acceso a servicios ni prestaciones de salud es limitado; sin embargo, al ser empresas familiares, tienen gran importancia en la economía de las comunidades y localidades donde se constituyen, ya que por lo general es la única o la principal actividad productiva.

Es usual que los ladrilleros artesanales construyan sus viviendas en zonas cercanas a los hornos donde fabrican los ladrillos, y estas zonas tienen como característica común que carecen de servicios básicos como agua, desagüe o luz, con vías de acceso en mal estado. Las municipalidades no los tienen incluidos en sus planos catastrales ya que son terrenos no saneados. 


\subsubsection{Análisis tecnológico.}

La incorporación de la tecnología en el sector construcción en el país está un poco rezagada respecto a otros países de la región.

De acuerdo al diagnóstico nacional del sector ladrillero artesanal (Mercadeando S.A., 2012) el proceso productivo de ladrillo en el Perú se lleva a cabo en hornos tradicionales.

Los hornos tradicionales cuentan con las siguientes características: Tienen una base rectangular, sin columnas. Están divididos en dos cuerpos, teniendo el inferior paredes de mayor grosor en comparación con el cuerpo superior, siendo en general paredes delgadas y sin aislamiento, con una amplia área horizontal de cocción restando eficiencia y velocidad de cocción y calidad de producto, deficiencia que los productores compensan usando combustibles de alto poder calorífico y altamente contaminantes. Por lo general son construidos en ladrillos o adobe. Su capacidad de producción, es en promedio de 30 millares por quema, habiendo hornos desde 20 hasta 70 millares. Para el encendido del horno, tienen malecones de grandes dimensiones donde se alimenta el combustible. (Programa Aire Limpio, 2009)

El Ministerio de Ambiente (2009) en coordinación con varias entidades, desarrolló un programa piloto de implementación del horno vertical, la cual es de tecnología desarrollada en China e implementada con éxito en Nepal. Sin embargo, en el Perú se requirió adaptar dicha tecnología.

Tecnológicamente es un horno ecoeficiente, cuya generación de contaminantes es inferior a los hornos tradicionales. Este tipo de hornos reduce progresivamente la cantidad necesaria de carbón y los días necesarios para la quema de los ladrillos. La operación de este tipo de hornos implica un cambio en los hábitos de trabajo a producción continua, no estacional, como se hace con los hornos tradicionales. 
Lamentablemente por el poco apoyo brindado por instituciones públicas de la Ciudad de Arequipa (Municipalidad Provincial, Municipalidad de Socabaya, Dirección Regional de la Producción), la tecnología de hornos verticales, no tuvo el impacto deseado y solo se desplegó como un piloto. (Programa Aire Limpio, 2009)

La tecnología aplicada por las empresas más importantes del sector ha logrado reducir la emisión de gases contaminantes en un 90\%, instalando sistemas de gas natural a sus máquinas de cocción, reduciendo sus cotos en el proceso productivo.

\subsubsection{Análisis ecológico.}

Pese a la desaceleración del sector inmobiliario, en el Perú existen 31 edificios verdes, que son la más viva muestra de las nuevas tendencias en el país con respecto a la construcción de edificios ecológicos. (Edificios Verdes en el Perú, La República, 2016)

En nuestro país la entidad encargada de fomentar los proyectos de edificios verdes es el Consejo Peruano de Construcción Sostenible en el Perú, Perú Green Building Council (PGB), son ellos los que se encargan de la preparación y evaluación para la Certificación LEED y el Sello Verde.

Las nuevas tendencias en el sector construcción son los edificios ecológicos cuya tecnología es acompañada por de sistemas de reutilización y ahorro de recursos. Esto es bastante beneficioso para la población y al medio ambiente.

La implementación de nuevos sistemas productivos que están bajo el control y las regulaciones en las emisiones atmosféricas con respecto a la producción del ladrillo, permitirá disminuir el impacto en la emisión de gases, un mejor aprovechamiento de los recursos hídricos y una mejor preservación del ecosistema. 


\subsection{Oportunidades y Amenazas}

De acuerdo a la presente investigación se pudieron determinar las siguientes oportunidades y amenazas:

Oportunidades:

a) El gobierno ha implementado medidas para reactivar el sector construcción, lo que impulsará el sector, por ende se espera que la demanda de nuestro producto, sea positiva.

b) Al contar con políticas de desarrollo medio ambientales, nuestro producto encaja perfectamente en sus lineamientos, ya que es el aprovechamiento del residuo plástico, considerado altamente contaminante, el cual tendrá un nuevo uso con características ecológicas.

c) El incentivo que reciben las empresas por innovación empresarial, sería aprovechado por nuestro proyecto, ya que es un aporte a la industria, este tipo de producto aún no es aplicado en construcciones, las ventajas que ofrece son a nivel económico y ambiental.

d) Las bloquetas plásticas cumplen con las normas técnicas peruanas exigidas por SENCICO y la E0.70., sino también presentan mejores estándares de resistencia y durabilidad a los ladrillos de arcilla, acercándose a los bloques de cemento, lo cual será una ventaja competitiva

e) Las expectativas se mantienen positivas tanto a nivel del sector construcción como autoconstrucción, por lo que el precio de la bloqueta plástica se adecua a las necesidades de los consumidores y esto mejora mejorara las perspectivas de adquisición del producto. 
f) La demanda futura tiene proyecciones positivas, ya que el gobierno regional de Arequipa y la Municipalidad distrital de Arequipa, se han visto obligados a realizar actividades de saneamiento para nuevas zonas urbanas.

g) Debido a que Arequipa es una ciudad con actividad sísmica, se tiene la necesidad de vivir en edificaciones seguras, esto es una oportunidad para demostrar que la Bloqueta plástica es adecuada para edificaciones sismo resistente.

h) La reutilización de plástico en el proceso productivo fomenta el cuidado del medio ambiente y favorece a la reducción de costos, teniendo como resultado un producto a precio accesible.

Amenazas:

a) Desconocimiento y escasa preocupación por alinearse a las políticas medioambientes.

b) Los ladrillos convencionales ya cuentan con un posicionamiento, lo que sería una traba para nuestros potenciales están familiarizados con los ladrillos convencionales.

c) Poca fiscalización del Ministerio de vivienda y sus órganos anexos, para velar por el cumplimiento de los estándares de producción y requisitos técnicos de ladrillo.

d) Incremento de empresas informales, productoras de ladrillo.

e) Incremento de los precios de productos complementarios para la construcción, debilitaría la demanda de la bloqueta plástica.

f) Incremento en gastos de transporte, ya que se desarrollan proyectos inmobiliarios en las zonas periféricas de la ciudad.

g) Implementar tecnología de producción que cumpla con los estándares técnicos y condiciones ecológicas requeridas por el mercado resultan bastante costosas.

h) Poca aceptación a las nuevas construcciones de edificios ecológicos, ya que conlleva a adaptarse a nuevos sistemas de vivienda. 


\section{Capítulo III: Estudio de Mercado}

\subsection{Descripción del Servicio o Producto}

El producto que se desea ofrecer (Bloqueta de plástico) presenta las siguientes características:

\begin{tabular}{|c|c|}
\hline Nombre del Producto & LadriplastAQP \\
\hline $\begin{array}{l}\text { Descripción del } \\
\text { Producto }\end{array}$ & $\begin{array}{l}\text { Las bloquetas de plástico son ladrillos ecológicos en forma de } \\
\text { paralelepípedo que cuentan con } 10 \text { cavidades ovaladas en las caras } \\
\text { superior e inferior para permitir el mayor agarre al momento de su } \\
\text { utilización. Utiliza el plástico reciclado como principal } \\
\text { componente, lo cual hace de este producto un bien ecológico y } \\
\text { amigable con el medio ambiente. }\end{array}$ \\
\hline Usos del Producto & $\begin{array}{l}\text { Son utilizados en la construcción de viviendas, edificios, muros, } \\
\text { vías, recubrimientos o cercos perimétricos, etc }\end{array}$ \\
\hline Lugar de Elaboración & Provincia de Arequipa - \\
\hline $\begin{array}{l}\text { Composición del } \\
\text { Producto }\end{array}$ & $\begin{array}{l}\text { - Plástico Reciclado } \\
\text { - Cemento } \\
\text { - Agua }\end{array}$ \\
\hline $\begin{array}{l}\text { Presentación } \\
\text { Comercial }\end{array}$ & \\
\hline
\end{tabular}




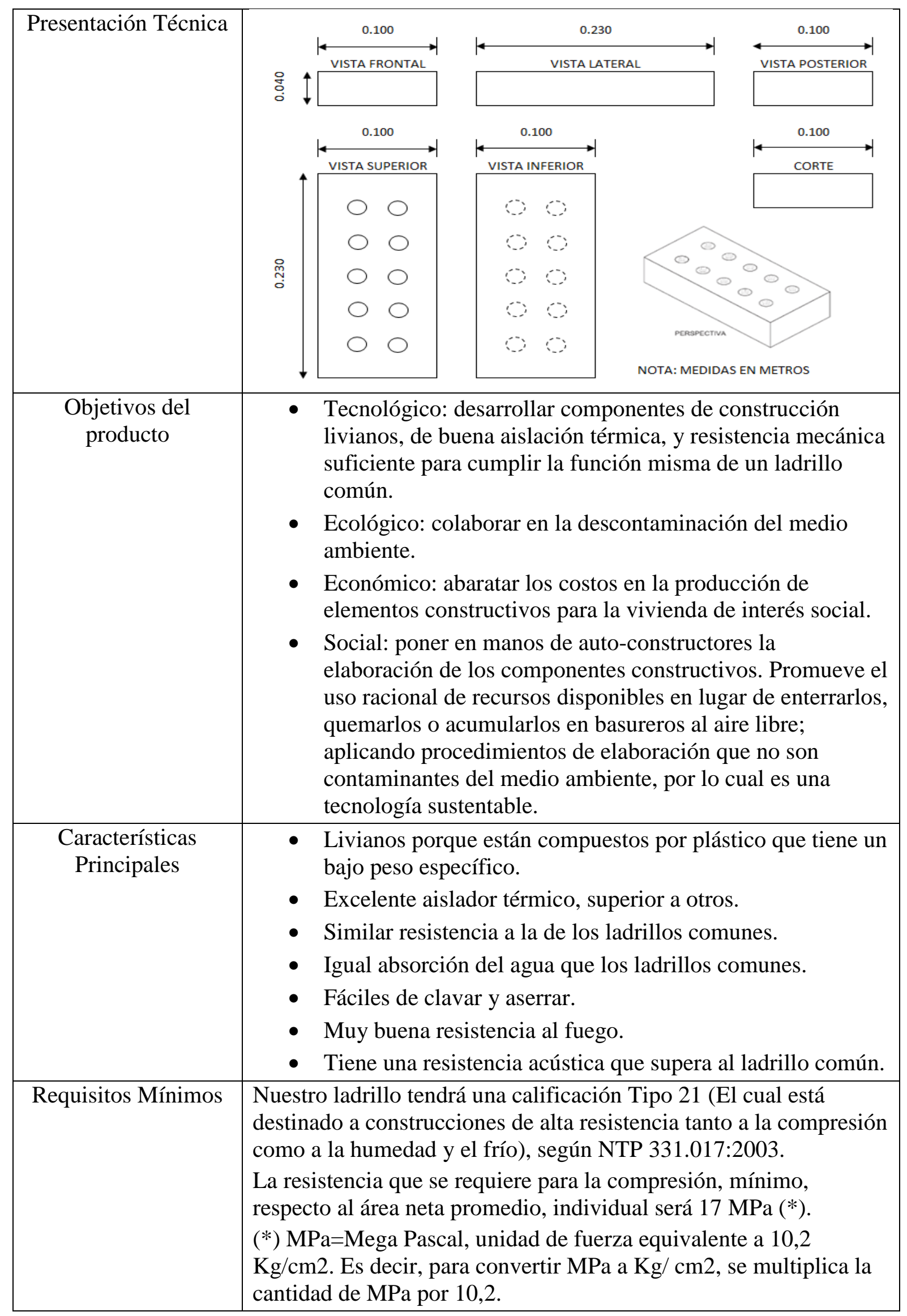




\subsection{Selección del Segmento de Mercado}

Para el estudio fue necesario identificar de manera clara las características que debe tener el mercado donde se pretende ofertar el producto. Es por ello que se procedió a detallar cada una de las variables que se utilizaron para determinar el perfil del mercado y por ende el perfil de los consumidores potenciales.

a. Geográfica: Comprende el área donde se ubicará el producto. Se analizó la ubicación de los consumidores potenciales y es así que se seleccionó la provincia de Arequipa ya que es ahí donde se ubicará la fábrica de bloquetas de cemento.

La provincia de Arequipa posee 29 distritos, por lo cual, para determinar exactamente la intervención del producto, se consideraron 20 distritos (ver Figura 16) entre los cuales se tiene: Arequipa, Alto selva Alegre, Cayma, Cerro Colorado, Characato, Jacobo Hunter, José Luis Bustamante y Rivero, Mariano Melgar, Miraflores, Mollebaya, Paucarpata, Polobaya, Quequeña, Sabandía, Sachaca, Socabaya, Tiabaya, Uchumayo, Yanahuara y Yarabamba (ver Tabla 11).

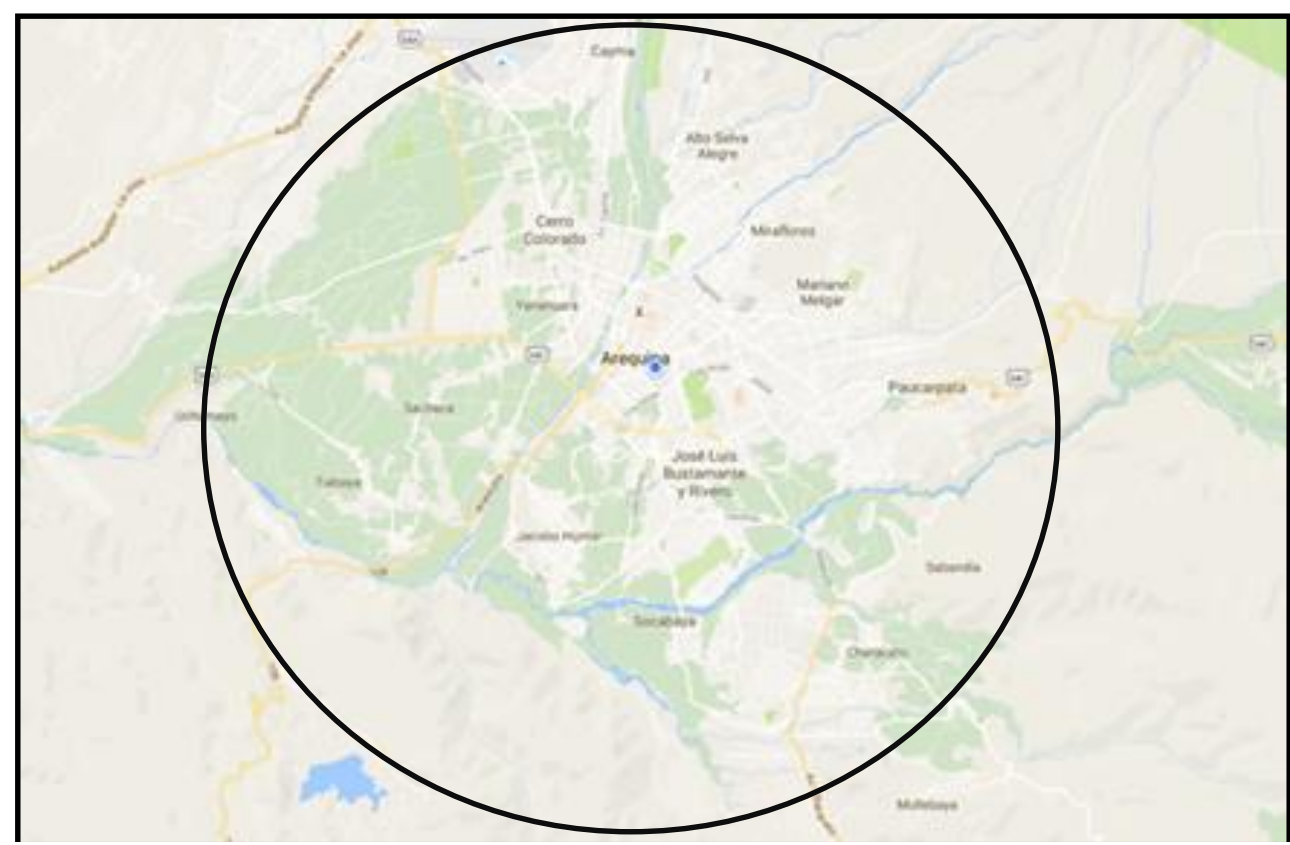

Figura 16. Distritos incluidos en la segmentación. Tomado de https://www.google.com.pe/maps 
Tabla 11

Población seleccionada de los Distritos de Arequipa

\begin{tabular}{lr}
\hline Distritos & Población \\
\hline Arequipa & 61,519 \\
Alto Selva Alegre & 72,696 \\
Cayma & 74,776 \\
Cerro Colorado & 113,171 \\
Characato & 6,726 \\
Jacobo Hunter & 46,092 \\
Jose L.B. y Rivero & 76,410 \\
Mariano Melgar & 52,144 \\
Miraflores & 50,704 \\
Mollebaya & 1,410 \\
Paucarpata & 120,446 \\
Polobaya & 1,445 \\
Quequeña & 1,219 \\
Sabandia & 3,699 \\
Sachaca & 17,537 \\
Socabaya & 59,671 \\
Tiabaya & 14,677 \\
Uchumayo & 10,672 \\
Yanahuara & 22,890 \\
Yarabamba & 1027 \\
\hline Total & 808,931 \\
\hline Na: Adaptado
\end{tabular}

Nota: Adaptado de INEI - Censos Nacionales 2007: XI de Población y VI de Vivienda

De acuerdo al INEI (2007), la población total de los distritos seleccionados es 808,931 personas y en base a esa población se desarrolló la segmentación.

b. Demográfica: Esta variable comprende los indicadores como edad y género, por lo tanto, se determinó para el segmento que los consumidores serán hombres y mujeres que poseen entre 30 y 50 años de edad (ver Tabla 12), pues este rango de edad se encuentra habilitado para poder obtener un crédito de vivienda. 
Tabla 12

Población de Distritos de Arequipa por edades

\begin{tabular}{lrrrrr}
\hline & \multicolumn{5}{c}{ Grupos de Edades } \\
\cline { 2 - 6 } \multicolumn{1}{c}{ DISTRITOS } & $30-34$ & $35-39$ & $40-44$ & $45-50$ & Total \\
\hline Arequipa & 4,509 & 4,098 & 3,992 & 4,693 & 17,292 \\
Alto Selva Alegre & 5,567 & 5,261 & 4,921 & 5,065 & 20,814 \\
Cayma & 5,705 & 5,135 & 4,651 & 4,738 & 20,229 \\
Cerro Colorado & 9,714 & 8,253 & 7,080 & 6,483 & 31,530 \\
Characato & 612 & 486 & 410 & 399 & 1,906 \\
Jacobo Hunter & 3,971 & 3,417 & 2,826 & 2,987 & 13,201 \\
Jose L.B. y Rivero & 6,328 & 5,570 & 4,971 & 5,313 & 22,182 \\
Mariano Melgar & 4,301 & 3,748 & 3,303 & 3,415 & 14,767 \\
Miraflores & 4,100 & 3,669 & 3,416 & 3,327 & 14,512 \\
Mollebaya & 126 & 73 & 70 & 82 & 352 \\
Paucarpata & 10,559 & 9,019 & 7,467 & 7,051 & 34,096 \\
Polobaya & 129 & 111 & 101 & 124 & 466 \\
Quequeña & 91 & 119 & 65 & 76 & 352 \\
Sabandia & 293 & 283 & 222 & 197 & 996 \\
Sachaca & 1,385 & 1,258 & 1,120 & 1,155 & 4,917 \\
Socabaya & 5,103 & 4,599 & 3,909 & 3,974 & 17,584 \\
Tiabaya & 1,070 & 987 & 878 & 944 & 3,880 \\
Uchumayo & 841 & 761 & 698 & 723 & 3,023 \\
Yanahuara & 1,671 & 1,608 & 1,586 & 1,718 & 6,584 \\
Yarabamba & 74 & 57 & 70 & 65 & 266 \\
\hline Total & 66,151 & 58,513 & 51,755 & 52,530 & 228,949 \\
\hline Nota: Adaptado
\end{tabular}

Nota: Adaptado de INEI - Censos Nacionales 2007: XI de Población y VI de Vivienda

Se obtuvo un segmento de 228,949 personas .Después se consideró que los pobladores deben pertenecer a la población económicamente activa, que está representada por el 95.2\% de la población Arequipeña, según el informe emitido por INEI (2012) como se muestra en la Tabla 13. 
Tabla 13

Perú: Población Económicamente Activa, Según Departamento.

\begin{tabular}{|c|c|c|c|c|c|c|c|c|c|c|}
\hline & & & & & rentaja) & & & & & \\
\hline & & & 2004 & & & & & 2012 & & \\
\hline & & Poblacion & ocupada & & & & Población & ocupada & & \\
\hline Departamento & $\begin{array}{r}\text { Total } \\
\text { Poblacion } \\
\text { ocupada }\end{array}$ & $\begin{array}{l}\text { Adecuar } \\
\text { damente } \\
\text { empleada }\end{array}$ & $\begin{array}{l}\text { Sub- } \\
\text { empleada } \\
\text { por horas } \\
\text { (visible) }\end{array}$ & $\begin{array}{r}\text { Sub. } \\
\text { empleada } \\
\text { por } \\
\text { ingresos } \\
\text { (invisible) }\end{array}$ & $\begin{array}{r}\text { Población } \\
\text { desocupada }\end{array}$ & $\begin{array}{r}\text { Total } \\
\text { Población } \\
\text { ocupada }\end{array}$ & $\begin{array}{l}\text { Adecua- } \\
\text { damente } \\
\text { empleada }\end{array}$ & $\begin{array}{r}\text { Sub- } \\
\text { empleada } \\
\text { por horas } \\
\text { (visible) }\end{array}$ & $\begin{array}{r}\text { Sub- } \\
\text { empleada } \\
\text { por } \\
\text { ingresos } \\
\text { (invisible) }\end{array}$ & $\begin{array}{r}\text { Poblacion } \\
\text { desocupada }\end{array}$ \\
\hline Total & 94,7 & 22,2 & 6,9 & 65,6 & 5,3 & 96,3 & 48,1 & 4,3 & 43,8 & 3,7 \\
\hline Amazonas & 98,8 & 14,4 & 4,9 & 79.5 & 1,2 & 98,3 & 32,2 & 2,9 & 63,2 & 17 \\
\hline Ancash & 95,6 & 16,6 & 8.0 & 71,1 & 4,4 & 95,2 & 40,6 & 8,4 & 47.2 & 3,8 \\
\hline Apurimac & 979 & 13,5 & 3.2 & 81,2 & 2,1 & 97,7 & 26,2 & 4.5 & 67,0 & 2,3 \\
\hline Arequipa & 91,3 & 25.5 & 12,6 & 53,2 & 8,7 & 95,2 & 60,6 & 6,7 & 27.9 & 4 \\
\hline Ayaaucho & $\overline{97}, \overline{7}$ & 11,4 & 4,3 & $\overline{82,0}$ & 2,3 & $\overline{\$ 5}, \overline{2}$ & $\overline{29,2}$ & $\overline{2} \overline{7}$ & $-\overline{64,3}$ & 38 \\
\hline Cajamerca & 98,5 & 10.8 & 3,4 & 84,3 & 1,5 & 98,7 & 30,9 & 4,3 & 63,5 & 1,3 \\
\hline Cusco & 96,0 & 11,0 & 4,1 & 81,0 & 4,0 & 98,1 & 45,2 & 5,7 & 47,2 & 1,9 \\
\hline Huancavelica & 98,1 & 7,4 & 4,2 & 86,6 & 1,9 & 98,1 & 21,9 & 1,9 & 74,3 & 1,9 \\
\hline Huanuco & 96,4 & 7,4 & 10,1 & 78,9 & 3,6 & 96,9 & 29,0 & 7,4 & 60,5 & 3,1 \\
\hline lea & 93,5 & 27,6 & 7,8 & 58,1 & 6,5 & 94,9 & 58,0 & 5,6 & 31,2 & 5,1 \\
\hline Junin & 96,6 & 17,9 & 3,7 & 75,0 & 3,4 & 97,6 & 43,1 & 3,0 & 51,4 & 2,4 \\
\hline La Lbertad & 95,4 & 22,7 & 8,7 & 64,0 & 4,6 & 96,1 & 44,4 & 5,1 & 46,6 & 3,9 \\
\hline Lambayeque & 95,0 & 20,0 & 18,1 & 56,9 & 5,0 & 95,9 & 41,3 & 6.4 & 49,3 & 3,1 \\
\hline Lima y Callao & 91,8 & 34,0 & 5,5 & 52,2 & 8,2 & 95,1 & 61,1 & 3,0 & 31,0 & 49 \\
\hline Loreto & 98,0 & 14,3 & 5,5 & 78,2 & 2,0 & 97,0 & 37,6 & 3,4 & 55,9 & 3,0 \\
\hline Madre de Dios & 96,6 & 36.2 & 4,2 & 56,1 & 3,4 & 97,4 & 68,4 & 3,7 & 25,3 & 2,6 \\
\hline Moquegua & 94,9 & 27,7 & 8.6 & 58,6 & 5,1 & 94,6 & 55,2 & 77 & 31,7 & $\$, 4$ \\
\hline Pasco & 93.0 & 18.2 & 9,9 & 64,9 & 7,0 & 95,8 & 35,9 & 4,1 & 55,7 & 4.2 \\
\hline Piura & 94,8 & 16.5 & 7,5 & 70,9 & 5,2 & 96,6 & 42,5 & 5,8 & 48,3 & 3,4 \\
\hline Puno & 98,3 & 10.5 & 9,8 & 78,0 & 1,7 & 97,7 & 30,2 & 4,5 & 63,0 & 2,3 \\
\hline San Martin & 97,6 & 12,7 & 5,5 & 79,4 & 2,4 & 97,8 & 40,9 & 4.3 & 52.6 & 22 \\
\hline Tacna & 95,6 & 29,2 & 7,5 & 58,9 & 4,4 & 94,6 & 57,8 & 5,7 & 31,1 & 5,4 \\
\hline Tumbes & 94,0 & 27,9 & 13,6 & 52,6 & 6,0 & 95,3 & 54,6 & 6.5 & 34,2 & 4,7 \\
\hline Ucayali & 96.8 & 20,9 & 1,9 & 74,0 & 3,2 & 97,4 & 53,1 & 1,3 & 43,0 & 2.6 \\
\hline
\end{tabular}

Nota.. Tomado de

https://www.inei.gob.pe/media/MenuRecursivo/publicaciones_digitales/Est/Lib1105/cap03.p 
Tabla 14

Población Económicamente Activa de los Distritos de Arequipa

\begin{tabular}{lrrrrr}
\hline & \multicolumn{5}{c}{ Grupos de Edades } \\
\cline { 2 - 6 } \multicolumn{1}{c}{ DISTRITOS } & $30-34$ & $35-39$ & $40-44$ & $45-50$ & Total \\
\hline Arequipa & 4,293 & 3,901 & 3,800 & 4,468 & 16,462 \\
Alto Selva Alegre & 5,300 & 5,008 & 4,685 & 4,822 & 19,815 \\
Cayma & 5,431 & 4,889 & 4,427 & 4,510 & 19,258 \\
Cerro Colorado & 9,248 & 7,857 & 6,740 & 6,172 & 30,017 \\
Characato & 583 & 462 & 390 & 379 & 1,814 \\
Jacobo Hunter & 3,780 & 3,253 & 2,690 & 2,844 & 12,567 \\
Jose L.B. y Rivero & 6,024 & 5,303 & 4,733 & 5,058 & 21,117 \\
Mariano Melgar & 4,095 & 3,568 & 3,144 & 3,251 & 14,058 \\
Miraflores & 3,903 & 3,493 & 3,252 & 3,167 & 13,815 \\
Mollebaya & 120 & 70 & 67 & 78 & 335 \\
Paucarpata & 10,052 & 8,586 & 7,108 & 6,713 & 32,459 \\
Polobaya & 123 & 106 & 96 & 118 & 443 \\
Quequeña & 87 & 113 & 62 & 72 & 335 \\
Sabandia & 279 & 270 & 212 & 188 & 949 \\
Sachaca & 1,319 & 1,197 & 1,066 & 1,099 & 4,681 \\
Socabaya & 4,858 & 4,378 & 3,721 & 3,783 & 16,740 \\
Tiabaya & 1,018 & 940 & 836 & 899 & 3,693 \\
Uchumayo & 801 & 725 & 665 & 688 & 2,878 \\
Yanahuara & 1,591 & 1,531 & 1,510 & 1,636 & 6,268 \\
Yarabamba & 71 & 54 & 67 & 62 & 254 \\
\hline Total & 62,976 & 55,705 & 49271 & 50,008 & 217,960 \\
\hline Nota. Segme & &
\end{tabular}

Nota. Segmentación final para el proyecto.

Por lo tanto, la población total del segmento es de 217,960 personas.

\subsection{Investigación Cualitativa}

En el estudio se aplicó la Investigación cualitativa, ya que surge la necesidad de entender a la población, para conocer aspectos relacionados a sus motivaciones al momento de realizar la compra, como lo menciona Hair, Bush y Ortinau (2010).

En el presente estudio se detectó las necesidades de conocer más respecto a cómo percibirá el cliente el nuevo producto y la opinión de personas que tienen experiencia en el sector al cual se pretende ingresar.

Es por ello que se utilizó la técnica del Focus Group, que consiste en la reunión de un pequeño grupo de personas para recolectar datos sobre un tema; y las entrevistas a expertos, 
que como lo define de Hair et al. (2010), es una técnica utilizada para indagar un tema específico a través personas conocedoras de dicho tema.

\subsubsection{Proceso de muestreo.}

Para la técnica del Focus Group se determinaron los objetivos de la investigación:

Objetivo General:

Conocer el grado de aceptación o rechazo por parte de los posibles consumidores frente a las bloquetas de plástico.

Objetivos Específicos:

1. Identificar las características que los consumidores consideran más relevantes al momento de elegir el material de construcción.

2. Determinar las promociones a ofrecer y sus respectivos puntos de ventas

3. Establecer los factores importantes para la decisión de compra del consumidor.

4. Conocer las expectativas del consumidor respecto al nuevo producto.

Para elegir a los participantes se agrupo por porcentajes según el indicador demográfico de edad y sexo, que pertenecen al segmento de mercado detallado en el punto 3.2 (217,960 pobladores).

Como menciona Hair et al. (2010), el focus group debe estar compuesto entre 812 personas, por lo cual se consideró para determinar la muestra un grupo de 12 personas para cada sesión, las cuales fueron seleccionas en base a las variables consideradas en la segmentación.

Para la entrevista a expertos se utilizó para reunir opiniones de especialistas en cada uno de los temas que se requiere información, como lo señala Hair et al. (2010). 
En el presente estudio se vio la necesidad de conocer información actual del sector ladrillero en relación a temas de marketing, construcción y producción, por ello se consideró realizar tres entrevistas, cada una con su respectivo especialista.

Para seleccionar a cada experto se determinó las características necesarias que deben cumplir para poder ser participantes de la entrevista (ver Tabla 15) para esta investigación.

Tabla 15

Perfil de participante de las entrevistas a expertos

\begin{tabular}{lll}
\hline \multicolumn{3}{c}{ Perfil de Participantes (Entrevista a Expertos) } \\
\hline \multicolumn{1}{c}{ Experto de Marketing } & \multicolumn{1}{c}{ Experto de Construcción } & Experto de la Industria \\
\hline 1. Profesional y /o técnico de & 1. Profesional de la Carrera & 1. Representante de \\
la Carrera de Administración & de, Ing. Civil o & alguna empresa del \\
de empresas, Ing. Industrial & Arquitectura. & sector construcción. \\
entre otras. & 2. Con Experiencia en el & 2. Estar laborado \\
2. Con Experiencia en el & rubro de la construcción & durante la industria \\
rubro del sector construcción & mayor a 4 años. & más de 4 años. \\
mayor a 3 años en el área de & 3. Edad entre 35 a 45 años. & 3. Edad entre 35 a 50 \\
ventas o marketing. & 4. Con conocimiento en: & años. \\
3. Edad entre 30 años a más. & - Normas Técnicas de & 4. Con conocimiento \\
4. Conocimiento de & Construcción vigentes & del movimiento del \\
estrategias de marketing de & -Supervisión de la calidad & sector ladrillero, en los \\
empresa. & de los materiales y equipos. últimos años. & \\
& -Sistemas constructivos & \\
& más adecuados para el tipo & \\
& de tareas a ejecutar en las & \\
& obras.
\end{tabular}

Nota: Adaptado de la guía de entrevista a expertos (anexos II, III y IV)

Detallados los criterios de selección y con los objetivos determinados para cada entrevista se procederá a describir los instrumentos a utilizar.

\subsubsection{Diseño de instrumento.}

Para el Focus Group se utilizó el instrumento de medición Guía de Pautas para las dos sesiones realizadas. La Guía de Pautas (ver Anexo I) que se elaboró contiene siete pasos, el primer paso es brindar la bienvenida a los participantes, dicha 
bienvenida es dada por el moderador del grupo quien tiene a su cargo la dirección de Focus Group y a su vez dar a conocer las reglas para el desarrollo de la sesión.

Luego se desarrolló el segundo paso que consiste en realizar una dinámica que permite la integración de los participantes del focus group, terminada la dinámica, el moderador procederá a continuar con el desarrollo de la guía de pautas.

El tercer, cuarto y quinto paso detallan los temas establecidos con sus respectivas preguntas (estructuradas), permitiendo, que los participantes brinden toda la información posible.

El sexto paso desarrolla el cierre de la sesión pidiendo así los últimos comentarios o recomendaciones de los participantes. Por último, en el séptimo paso se brinda el agradecimiento por el tiempo e información otorgada y se hace entrega de los obsequios por la asistencia.

La entrevista a expertos fue realizada a cada uno de los especialistas de cada uno de los temas de investigación, para ello se elaboró las guías de entrevista (Ver Anexo II, Anexo III y Anexo IV) que son los instrumentos de medición.

Cada guía de entrevista, incluye datos como, nombre del participante, día, lugar y hora de la entrevista, se indica el tema al cual se pretende abordar. Además, cada una de ellas posee tres partes, en la primera parte desarrolló la presentación y saludo al entrevistado dando una explicación breve de la forma como se desarrollará la entrevista.

La segunda parte, consta de seis a siete preguntas estructuradas (dependiendo del experto). La tercera parte consiste en solicitar las recomendaciones respectivas de su área conocimiento y se realiza el cierre de la entrevista, agradeciendo por el tiempo e información brindada. 


\subsubsection{Análisis y procesamiento de datos.}

Después de realizada las dos sesiones de Focus Group, se procedió a realizar el análisis de las respuestas de los participantes, de lo cual se pudo observar que:

1. Se determinó que las características físicas externas como (tamaño, color, textura, etc.) no muestran una influencia para determinar la compra de los consumidores. Las características de importancia son las propiedades de durabilidad y seguridad de las viviendas. La bloqueta de plástico es del agrado de los posibles consumidores, y se muestra la intención de comprarla siempre y cuando esté garantizada su seguridad.

2. De los servicios adicionales se identificó que es necesario el transporte del producto al lugar donde se ejecuta la construcción, a su vez sugieren que el precio incluya este envió. Para los participantes ir a una tienda física es de mayor agrado porque pueden constatar la calidad del producto y analizar el precio al que pueden adquirir el producto. Comprar vía internet, no cuenta con mucha aceptación por lo antes mencionado.

3. Se determinó que a la hora de realizar la compra el consumidor potencial toma en cuenta el precio, la resistencia, el peso y también factor ambiental. Además, se observó que los consumidores potenciales se muestran interesados por el producto, por ser ecológico, aunque no poseen información concreta del tema, se arriesgarían a realizar la compra para probar sus características.

4. Se determinó las expectativas del consumidor, se muestran muy interesados en el producto y solicitan información sobre el lugar de comercialización, este interés demuestra que habrá una demanda por satisfacer. Es de interés conocer las certificaciones o respaldos del producto, para así poderlo comprar con mayor seguridad, ya que se preocupan por la resistencia ante los sismos. 
De las entrevistas realizadas a los expertos se obtuvo lo siguiente:

1. El experto en Marketing sugiere realizar un plan de introducción, en el cual se debe resaltar la importancia ambiental que representa el producto.

Considera que para la promoción del producto se debe contar con vendedores que realicen visitas a los sectores en crecimiento y así poder obtener información de los requerimientos del consumidor. Cabe resaltar que el experto se muestra muy interesado en el producto por su elaboración en base a desechos plásticos y lo resalta como una gran oportunidad en el mercado.

2. Respecto al sector construcción, el experto resalta la importancia de estar respaldados por alguna institución, esto se debe dar en base a reglamentos establecidos. Con respecto al producto considera que podría recomendarse para las construcciones de viviendas, si cumple con el Reglamento Nacional de Edificaciones, y sugiere que se haga promoción del producto en conferencias de construcción a los arquitectos, ingenieros civiles, etc. y así ser difundido entre las personas encargadas de la construcción.

3. El experto que se encuentra en el sector ladrillero, comenta respecto a la rentabilidad que se tiene, indicando que es buena, indica a su vez la variedad de productos que se encuentran y que poseen funciones diferentes. Indica que la inversión para tener una planta artesanal no es tan alta, sin embargo, una planta para ladrillos mecanizados es alta debido a algunas maquinarias que son costosas. A su vez comento sobre la compra de ladrillos para viviendas indicando que oscila entre 300 a 5000 ladrillos por compra. 


\subsection{Investigación Cuantitativa}

Según Hair et al (2010), la investigación cuantitativa permite conseguir datos reales con la finalidad de obtener información que permita establecer relaciones o identificar las cusas de un fenómeno dado, es por ello que para poder realizar la investigación cuantitativa se utilizó la encuesta como técnica de investigación.

\subsubsection{Proceso de muestreo}

Para realizar la encuesta se determinó los siguientes objetivos.

Objetivo General:

Descubrir el mercado de los consumidores de bloquetas de plástico en la ciudad de Arequipa.

Objetivos Específicos:

a) Identificar los posibles consumidores de bloquetas de plástico.

b) Determinar las zonas dentro de la provincia de Arequipa que tienen mayor consumo de producto sustituto.

c) Determinar los competidores del mercado objetivo.

d) Determinar los canales de comercialización que se requieren para las empresas de fabricación y comercialización.

e) Determinar el precio de las bloquetas de plástico en el mercado que se pretende ingresar.

La población del segmento objetivo es de 217,960 pobladores por lo tanto para el cálculo de la muestra se utilizó la fórmula de población Finita ya que se conoce la población, con un nivel de confianza del 95\% y un margen de error de 5\%. Se utilizó un margen de seguridad del 50\%. 
En donde,

$\mathrm{N}=$ población

$$
n=\frac{Z^{2} * p * q * N}{e^{2} *(N-1)+Z^{2} * p * q}
$$

$\mathrm{Z}=$ nivel de confianza:

e $=$ precisión (Error máximo admisible en términos de proporción)

$\mathrm{n}=$ Tamaño de la muestra

$\mathrm{p}=$ Probabilidad a favor

$\mathrm{q}=$ Probabilidad en contra

Del cálculo realizado se obtuvo que el cuestionario debe ser aplicado a una muestra de 384 personas, luego se determinó que el muestreo es de tipo no probabilístico, y se aplicó el método de muestreo por cuotas teniendo participantes según los indicadores de edad y sexo (ver Tabla 16).

Tabla 16 Muestra perteneciente al Segmento del Mercado para el Cuestionario

\begin{tabular}{lrrrrr}
\hline \multirow{2}{*}{ Sexo } & \multicolumn{5}{c}{ Grupos de Edades(años) } \\
\cline { 2 - 6 } & $30-34$ & $35-39$ & $40-44$ & $45-50$ & Total \\
\hline Hombres & 52 & 46 & 41 & 41 & 179 \\
Mujeres & 59 & 52 & 46 & 47 & 204 \\
\hline Total & 111 & 98 & 87 & 88 & 384 \\
\hline
\end{tabular}

\subsubsection{Diseño del instrumento.}

Para desarrollar la encuesta se utilizó el instrumento del cuestionario el cual contiene un grupo de preguntas que permitirán obtener la información deseada. Existen diversos tipos de preguntas como lo menciona, Hair et al. (2010), de las 
cuales se utilizó las preguntas estructuradas, son aquellas que limitan las respuestas a opciones ya establecidas, para el cuestionario (Ver Anexo V).

Por lo mencionado, el cuestionario que se elaboró inicia con un breve saludo y la respectiva presentación del tema a abordar además se pide la cooperación de los entrevistados. Luego se procedió a realizar las preguntas, las cuales incluyen las preguntas de control, que tomando en cuenta el objetivo se decidió incluir:

4 Preguntas dicotómicas.

7 Preguntas de opción múltiple.

1 Pregunta no estructurada.

Finalizando el cuestionario se agradeció al encuestado.

\subsubsection{Análisis y procesamiento de datos.}

Para el analisis de datos se utilizó el softwar microsoft excel 2013, a través del cual se pudo plasmar los datos en gráficas para su respectiva interpretacion.

Se obtuvo lo siguiente:

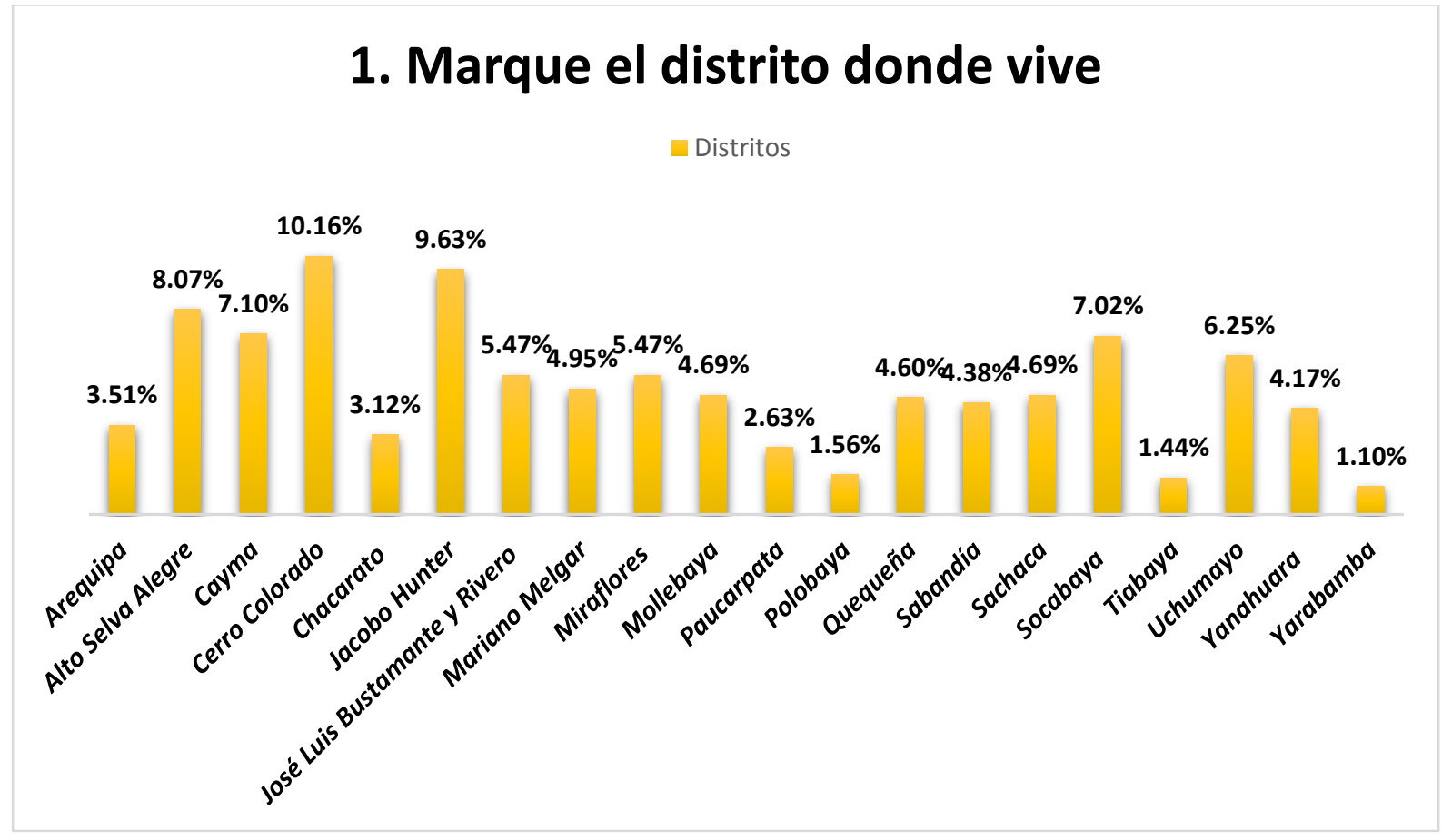

Figura 17. Pregunta 1. Adaptado de la Recolección de datos del Cuestionario 
De las 384 personas entrevistadas, se obtuvo los distritos en los cuales se realizan la mayoria de construcciones. Entre los que lideran se tiene Cerro Colorado, Alto Selva Alegre, Jacobo Hunter, en los cuales se tendra que poner mayor atencion al momento de realizar estrategias de marketing.

\section{2. ¿Ud. tiene planificado la construcción y/o ampliación de vivienda?}

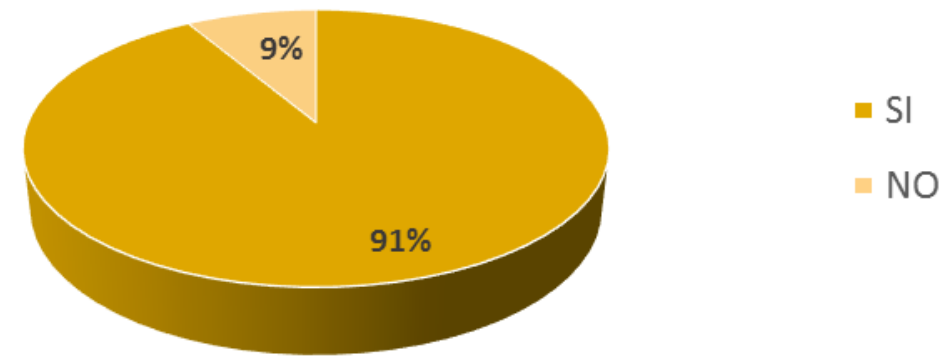

Figura 18. Pregunta 2. Adaptado de la Recolección de datos del Cuestionario

Se puede inferir que la mayoría de personas ha planificado la construcción y/o ampliación de su vivienda, es decir que existe un mercado considerable para poder ofertar productos para la construcción. Se visualiza que la población si desea realizar este tipo de actividades, lo que generará un mercado al cual se desee ingresar.

\section{3.¿Qué estrategia utilizará Ud. para la construcción y/o ampliación de su vivienda?}

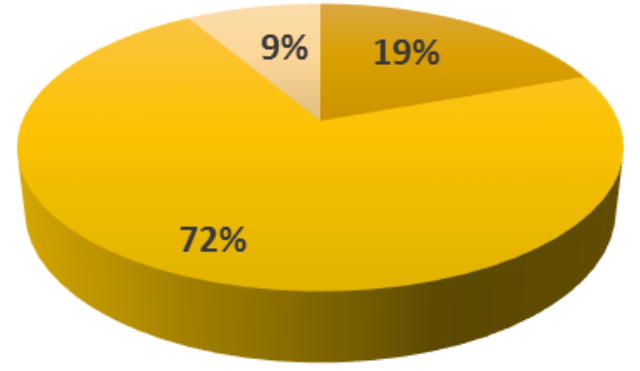

- Lo construye Ud mismo

Mano de Obra contratada

- (Pasaron a 4ta pregunta)

Figura 19. Pregunta 3. Adaptado de la Recolección de datos del Cuestionario 
La mayoría de la población contrata personal para poder realizar las construcciones, eso conlleva a ver una gran oportunidad de crear alianzas con maestros constructores, arquitectos, ingenieros entre otros, para que puedan sugerir el producto que se desea ofertar para la construcción de sus viviendas.

\section{En su distrito ¿Qué materiales predominan para la construcción?}

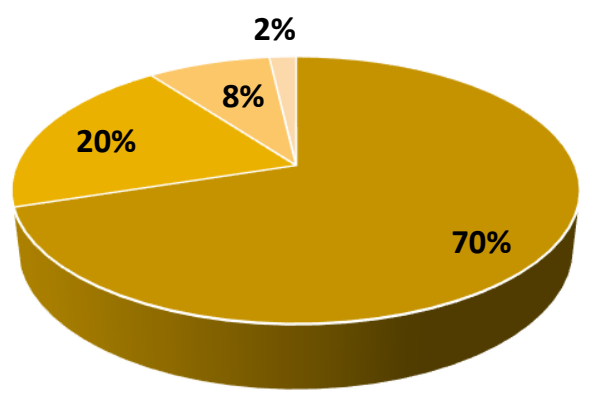

- Ladrillo

- Bloquetas de cemento

- Madera

Otro

Figura 20. Pregunta 4. Adaptado de la Recolección de datos del Cuestionario

De la Figura 20, se puede deducir que un fuerte competidor es el ladrillo convencional, debido a que en la mayoría de distritos las construcciones que existen son de este material, es decir que se tendrá que romper el paradigma del uso del ladrillo para la construcción de viviendas. Se debe rescatar la importancia que tiene la población que seleccionó la bloqueta de cemento ya que el producto que se pretende ofertar posee mejores características. 


\section{5.¿Cuál es el material de su preferencia para la construcción?}

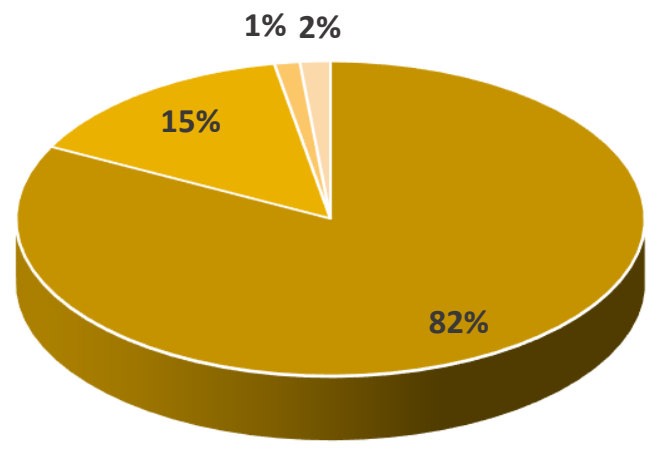

- Ladrillo

- Bloquetas de cemento

- Madera

Otro

Figura 21. Pregunta 5. Adaptado de la Recolección de datos del Cuestionario

En la Figura 21, se puede visualizar que la poblacion tiene la intención de compra orientada al "ladrillo " lo que permite ver una oportunidad para crear estrategias de marketing para informar a la poblacion sobre las caracteristicas similares al ladrillo que poseen las bloquetas de plástico .

\section{6. ¿A cuál de las característica de ladrillo, bloquetas de cemento u otros, le da más importancia a la hora de Comprarlo?}

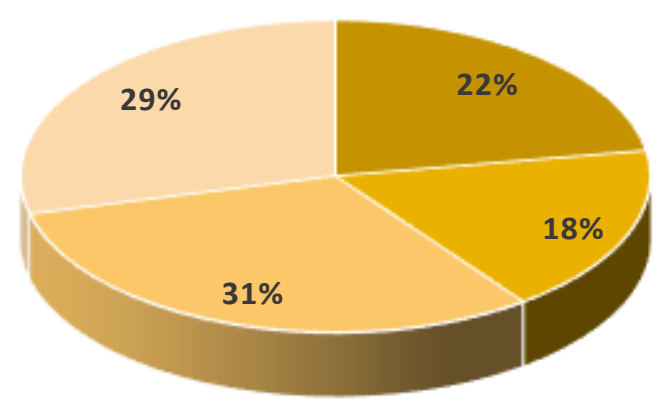

- Resistencia

- Peso

Precio

Amigable con el Medio Ambiente

Figura 22. Pregunta 6. Adaptado de la Recolección de datos del Cuestionario

De la pregunta seis se puede deducir que los factores más importantes son el precio y "amigable con el medio ambiente", esto permite analizar su comportamiento 
y poder utilizar la información a la hora de elaborar el plan de introducción del producto.

\section{7.¿En qué lugar compra los ladrillos, bloquetas de cemento u otros?}

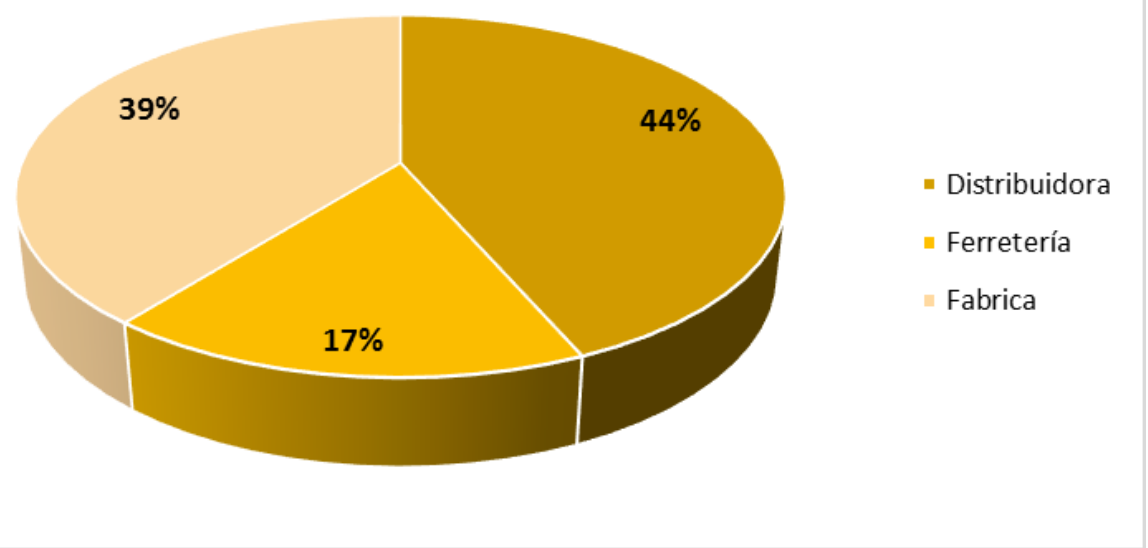

Figura 23. Pregunta 7. Adaptado de la Recolección de datos del Cuestionario

De la figura 23, se puede inferir que la población compra en distribuidoras y en segundo lugar en fabricas, lo cual permite considerar colocar distribuidoras de manera estratégica para vender el producto y buscar alianzas con otras distribuidoras.

\section{8.¿De qué empresa de ladrillos u otro material solicita, cuando va a adquirirlos?}

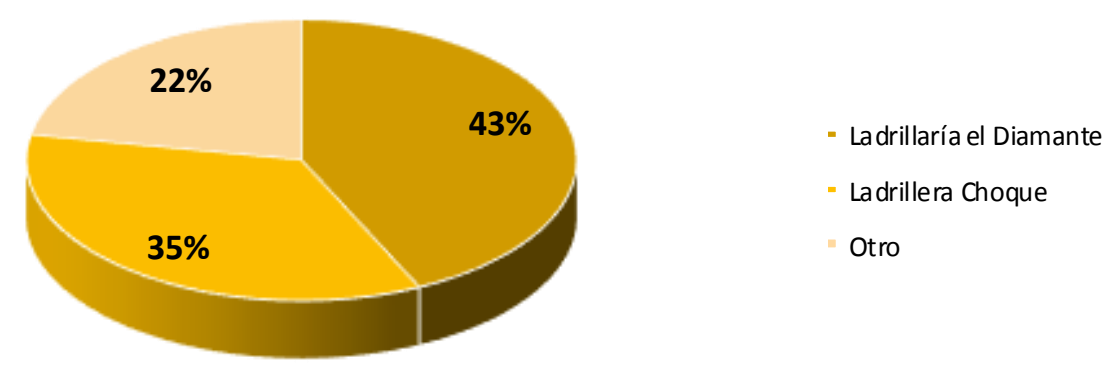

Figura 24. Pregunta 8. Adaptado de la Recolección de datos del Cuestionario

Se puede deducir que la empresa reconocida para la población arequipeña es la “Ladrillera el diamante”, siendo esta una de los principales competidores será 
necesario crear una estrategia de venta para posicionar la marca, buscando igualarla y en un futuro superarla.

\section{Compraría un material de construcción ("bloqueta de plástico" o "ladrillo de plástico" que contiene cemento) que tenga características similares a un ladrillo convencional?}

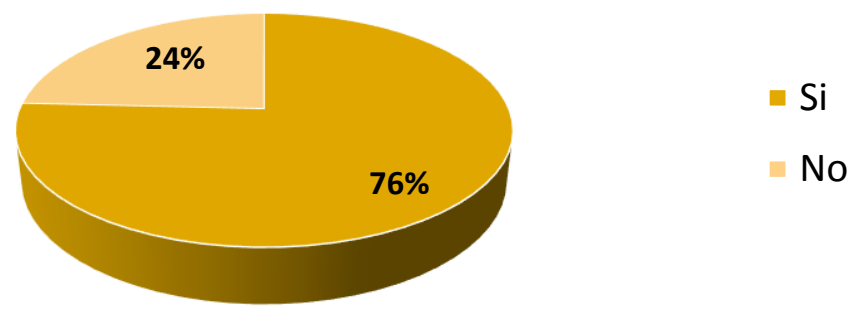

Figura 25. Pregunta 9. Adaptado de la Recolección de datos del Cuestionario

Se puede observar que la mayoría tiene la intención de comprar el producto, es decir que existe una población que si utilizaría bloquetas de plástico para construir su vivienda. Considerando los factores que deciden la compra podremos llegar abarcar una buena parte del mercado. 


\section{0.¿Cuánto estaría dispuesto a pagar si existirá una bloqueta de plástico con las características similares a un ladrillo convencional?(Precio por unidad)}

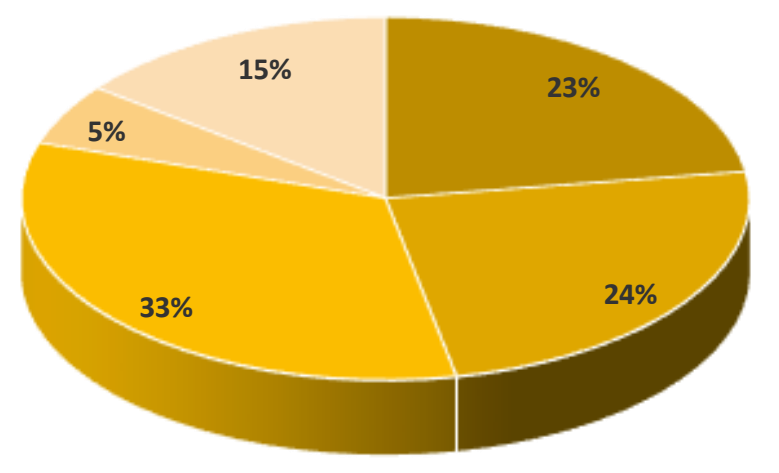

- de S/. 0.40 a S/.0.49

- de $S / .0 .50$ a S/.0.59

$=$ de $S / .0 .60$ a $S / .0 .79$

de $S / .0 .80$ a $S / .0 .89$

de $S / .0 .90$ a $S /, 1.10$

Figura 26. Pregunta 10. Adaptado de la Recolección de datos del Cuestionario

La población no decide por un precio bajo es decir que se deciden por un precio menor al que poseen los ladrillos actuales. El precio que se podría vender las bloquetas de plástico oscila entre S/ 600.00 y S/ 790.00 el millar.

\subsection{Conclusiones y recomendaciones del Estudio Cualitativo y cuantitativo}

Del Estudio Cualitativo:

1. Los posibles consumidores se ven atraídos al producto por sus características de precio, resistencia, etc. Consideran que el producto puede ser utilizado para sus arreglos de viviendas y sus futuras viviendas. A su vez los consumidores creen necesario el asesoramiento en la construcción por la compra de este nuevo producto.

2. Las personas conocedoras del producto piensan que sería acertado introducirlo al mercado. A su vez señalan que producto es accesible al mercado debido a que cumple los estándares permitidos y se han observado casos similares.

3. A través del estudio realizado se pudo determinar que existe un potencial de consumidores de bloquetas de plástico y que actualmente la mayoría cuenta con una 
vivienda o terreno en el cual pretenden realizar construcciones, para ello buscan la opinión de arquitectos, obreros, para seleccionar el material.

4. Se logró determinar con el estudio que los 20 distritos encuestados, se encuentran en crecimiento, y de los cuales Cerro Colorado, Alto Selva Alegre, Jacobo Hunter demandaran las bloquetas de plástico en mayor cantidad.

5. Se logró identificar que la población posee poca información de bloquetas o ladrillos de plástico en el Perú y es necesario brindar charlas para dar a conocer las características, funcionalidades, el cumplimiento de reglamentos, además de pruebas técnicas que respalden las características del producto, para que pueda ser recomendado por las personas que trabaja en el sector construcción.

A su vez se determinó que los competidores de manera indirecta es la empresa Ladrillera el diamante seguida por la ladrillaría Choque que tienen ya una participación en el mercado y que son reconocidas por el consumidor.

6. Se logró determinar la necesidad de contar con otros puntos de venta de la empresa, para que sea más accesible a los consumidores, y a la vez crear alianzas estratégicas con distribuidores para la expansión del producto y creación de estrategias para brindar la accesibilidad a la compra y venta del bien.

7. Del estudio se determinó que las bloquetas de plástico poseen una gran diferencia ante los competidores, por dos factores; el precio y el tema ambiental.

Del Estudio Cuantitativo:

1. Se identificó a los posibles consumidores que encuentran interesadas por el producto, por sus características de precio, resistencia. A su vez el 91\% de la población pretende realizar construcciones lo que genera un mercado al cual satisfacer dicha necesidad. 
2. De la investigación se determinó que de los 20 distritos seleccionados para el segmento, tres poseen mayor consumo y son Cerro Colorado, Jacobo Hunter y Alto Selva Alegre, en dichos distritos la población tiene planificado la construcción y/o ampliación de la vivienda.

3. Se determinó que los competidores de las bloquetas de plástico es en primer lugar Ladrillera el Diamante y la Ladrillera Choque.

4. Se determinó que los consumidores compran los producto de manera directa, en la fábrica o en las tiendas de distribución.

5. Se determinó que el precio para las bloquetas plásticas debe ser menor a S/ 600.00 por millar.

\subsection{Perfil del consumidor tipo y sus variantes}

De la investigación cualitativa y cuantitativa, se pudo identificar que el perfil del consumidor de bloquetas de plástico son los hombres y mujeres en el rango de edad entre los 30 a 50 años que se encuentran dentro de la población económicamente activa ,pertenecientes a los distritos de: Arequipa, Cayma, Characato, José Luis Bustamante y Rivero, Mariano Melgar, Miraflores, Mollebaya, Paucarpata, Polobaya, Quequeña, Sabandía, Sachaca, Socabaya, Tiabaya, Uchumayo, Yanahuara e Yarabamba y con mayor atención a los distritos de Cerro Colorado, Alto Selva Alegre y Jacobo Hunter ,estos últimos demandaran las bloquetas de plástico en mayor cantidad., que tienen la meta de tener una vivienda propia y si en caso la posee, desea buscar su crecimiento. Se siente motivado por un buen precio y un producto que contribuya con el ambiente. 


\section{Capítulo IV: Proyección de Mercado Objetivo}

\subsection{El ámbito de la proyección.}

Considerando que existen una serie de metodologías para definir el ámbito de proyección y poder estimar el comportamiento futuro de las variables, en el presente trabajo de investigación, se analiza la importancia de las variables como la cantidad de ladrillos o bloquetas (material para la construcción de viviendas) mensual y anual, para saber cómo se va a atender al mercado encontrado.

Según el Programa regional de Aire Limpio (2008), la producción de ladrillos de la ciudad de Arequipa fue de 11,733 millares mensuales, ver Tabla 17. Desde esa fecha no se realizaron estudios similares de la producción de ladrillos en la zona donde se desarrolla el proyecto.

Tabla 17

Producción Mensual del ladrillo en Arequipa.

\begin{tabular}{|c|c|c|}
\hline $\begin{array}{l}\text { Tipo de } \\
\text { Producción }\end{array}$ & Productos & $\begin{array}{l}\text { Producción Mensual en Arequipa } \\
\text { (millares) }\end{array}$ \\
\hline \multirow{3}{*}{ Artesanal } & Ladrillo King kong & 6,595 \\
\hline & Ladrillo pandereta & 2,029 \\
\hline & Ladrillo con huecos & 1,522 \\
\hline \multirow{7}{*}{ Mecanizada } & Ladrillo King kong & 984 \\
\hline & Pandereta & 322 \\
\hline & Ladrillo 18 huecos & 213 \\
\hline & Teja & 213 \\
\hline & Blocker & 15 \\
\hline & Pastelero artesanal & 52 \\
\hline & $1 / 2$ piso & 1 \\
\hline
\end{tabular}

Nota. Tomado de "Experiencias en el Sector Ladrillero artesanal en las ciudades de Arequipa y Cusco" Programa regional de Aire Limpio, febrero del 2008, p.7.

Por lo expuesto anteriormente es importante determinar la elección del método de proyección correcto y esto dependerá de la cantidad y calidad de los antecedentes disponibles, así como de los resultados esperados. 


\subsection{Selección del método de proyección.}

Para determinar el método de proyección se debe conocer el comportamiento del sector en el que se encuentra el proyecto, a través del cual determinaremos el tiempo de proyección donde se realizará el análisis. Para calcular la demanda se tomará de referencia la investigación realizada.

Para pronosticar la demanda, se deberá seleccionar una técnica de pronóstico de acuerdo a los patrones básicos de la demanda como lo propone Krajewski,,Ritzman,, Malhotra (2013), para ello se determinará la secuencia con la que se presentan a la demanda , para dicho producto se utilizará una proyección de "tendencia" ya que los datos del sector al que pertenece el producto aumentan o disminuyen en forma constante, Ver Figura 27.

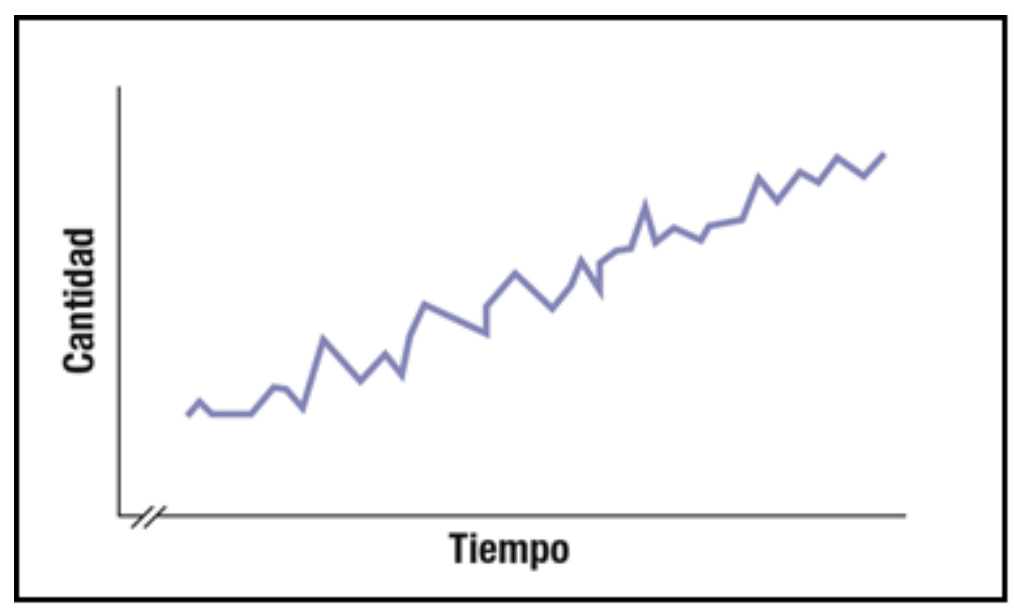

Figura 27. Tendencia: datos que aumentan o disminuyen en forma constante. Tomado de Administración de Operaciones Procesos y Cadena de Suministro (p.466), Krajewski, et al., 2013, Décima Edición, Pearson Educación.

La técnica de los pronósticos a utilizar será el método de juicio que según Krajewski et al. (2013), a través de las opiniones de los expertos y de la investigación de mercado se podrá obtener la demanda esperada de ventas. 


\subsubsection{Mercado Potencial.}

Como lo menciona Kinner y Keller (2012), el mercado potencial incluye a todos los consumidores que podrían requerir el producto que se pretende ofertar.

De acuerdo a lo mencionado, al inicio del capítulo tres se calculó el segmento de consumidores que podrían requerir las bloquetas de plástico siendo este de 217,960 consumidores.

Es así que esta cantidad será el mercado potencial del proyecto en estudio y sobre el cual se calculó el mercado disponible, efectivo y objetivo.

\subsubsection{Mercado Disponible.}

El mercado disponible está compuesto por todos los consumidores que tienen la necesidad de comprar el producto, como lo define Kinner y Keller (2012).

Anteriormente se obtuvo el mercado potencial y a través del cuestionario (pregunta 2) se tuvo el porcentaje de la población que necesita el producto siendo este de $91 \%$.

Se realizó el cálculo de Mercado Disponible:

$$
\text { Mercado Disponible }=M P *(\% \text { pregunta } 2)
$$

(\% preguntas 2 , población que ha planificado realizar una construcción o ampliar su vivienda)

$$
\begin{gathered}
\mathrm{MD}=217960.00 * 91 \% \\
\mathrm{MD}=198343.6 \approx 198344 \text { consumidores }
\end{gathered}
$$

\subsubsection{Mercado Efectivo.}

De acuerdo a Müller (n d.), el mercado efectivo es una parte del mercado disponible y está formado por el conjunto de consumidores que tienen además de la necesidad, la intención de comprar el bien o servicio que ofrece el proyecto. Este también es definido a través del resultado de la encuesta 
Para definir nuestro Mercado Efectivo hemos partido de nuestra población que deriva del Mercado Disponible obtenido, a través de la pregunta 9 del cuestionario aplicado, siendo este el $76 \%$.

Mercado Efectivo $=M D *($ pregunta $9 \%)$

(\% pregunta 9, población que si desearía comprar las bloquetas de plástico)

$$
\begin{gathered}
\mathrm{ME}=198344 * 76 \% \\
\mathrm{ME}=150741.14 \approx 150742 \text { consumidores }
\end{gathered}
$$

\subsubsection{Mercado Objetivo.}

De acuerdo a Kinner y Keller (2012), el mercado meta o mercado objetivo es la demanda la cual se pretende alcanzar, esta demanda es una parte del mercado efectivo y es seleccionada por los inversionistas. Por lo tanto, el mercado objetivo, es el mercado al cual se va a dirigir los esfuerzos y acciones de marketing,

El mercado objetivo deriva del mercado efectivo del cual se selecciona el mercado que se pretende captar o vender (\%)

Por lo tanto, se determinó seleccionar el $4.5 \%$ del mercado efectivo (150742 consumidores), esto se debe a que el sector ladrillero presentó esta tendencia (crecimiento del 7.5\%) que se, donde se analizó de acuerdo a la investigación realizada, factores internos y externos descritos en el Capítulo II, por lo tanto, se logra obtener un mercado meta de $6783.39 \approx 6784$ consumidores.

\subsection{Pronóstico de Ventas}

Para calcular el pronóstico de ventas se determinó la cantidad de productos que se espera ofrecer al mercado. El método seleccionado para el pronóstico es el de Juicio, es decir que después del análisis realizado en los puntos anteriores, se consideró un promedio anual de compras de ladrillo como mínimo por persona es de 0.40 millares/año, determinado de 
acuerdo al análisis de la investigación cualitativa, tomando la decisión de iniciar la demanda en una situación casi pesimista.

El horizonte del proyecto es de 5 años, en el primer año se determinó mantener la producción los siguientes años tendrán variaciones crecientes de 5\%, esto se debe a que el sector ladrillero tuvo un crecimiento del 7.5\% y hasta Mayo del 2016 el sector construcción el crecimiento fue de $5.55 \%$, debido al mayor consumo interno de cemento que creció en $2.35 \%$ (PERU21, 2016), como se muestra en la Figura 28 y Tabla 18 respectivamente, la cual tuvo que ser considerada para el análisis de la demanda que se muestra en la Tabla 19.

Cabe resaltar que se determinó el 5\% de crecimiento considerando que el sector construcción presenta un crecimiento desacelerado a partir del 2013 y si este llega realizar variaciones se pueda manejar la producción a través de la flexibilidad y la capacidad instalada.

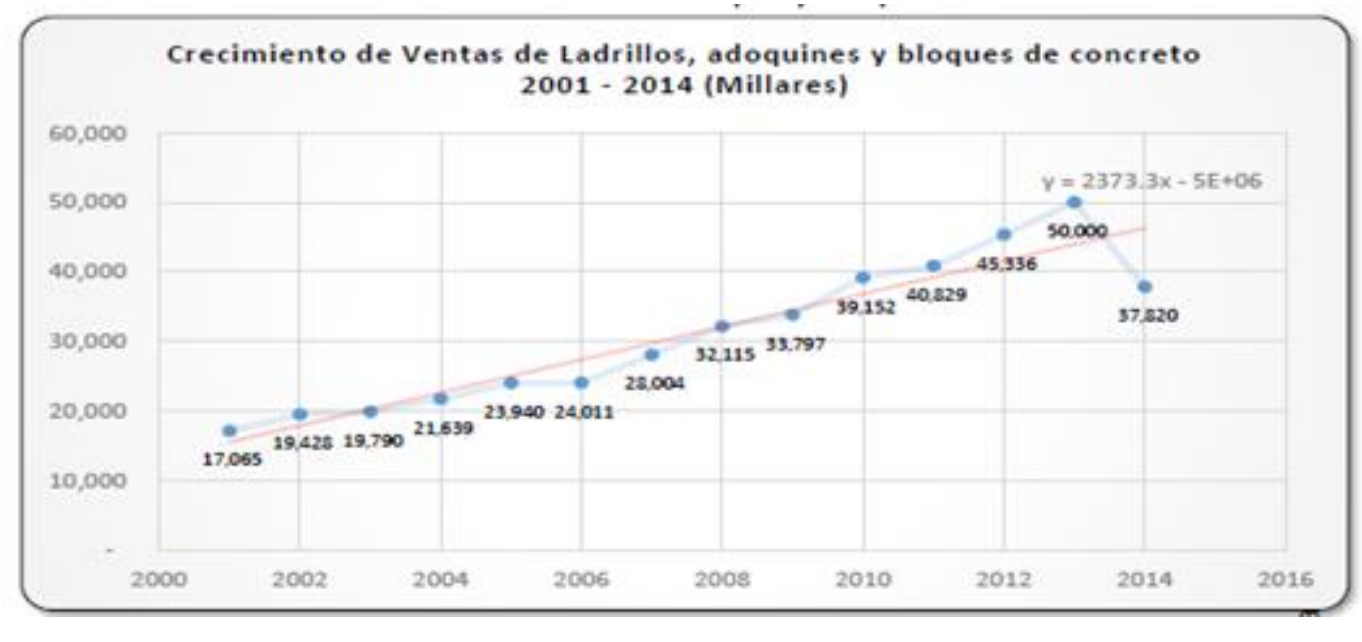

Figura 28 Tomado de Tesis plan de negocios para la fabricación ladrillos ecológicos en lima metropolitana., 2015, Pag 75. 
Tabla 18

Avance Productivo Sectorial, Mayo 2016 (Variacion \%)

\begin{tabular}{|c|c|}
\hline SECTORES PRODUCTIVOS & MAYO \\
\hline Agropecuario & $\mathbf{2 0 1 6}$ \\
\hline Agricola & $\mathbf{- 1 , 2 7}$ \\
Pecuario & $-3,39$ \\
Pesca & 3,89 \\
CH Directo & $\mathbf{- 6 6 , 9 8}$ \\
CH Indirecto & 2,75 \\
Electricidad & $-93,20$ \\
Minería e Hidrocarburos & $\mathbf{8 , 0 4}$ \\
Metálica & $\mathbf{3 3 , 2 4}$ \\
Hidrocarburos & 36,70 \\
Petróleo Crudo & 17,33 \\
Liquido Gas Natural & $-26,95$ \\
Gas Natural & 45,50 \\
Construcción & 40,87 \\
Consumo Interno de Cemento & $\mathbf{5 , 5 5}$ \\
Avance fisico de obras & 2,35 \\
& 19,62 \\
\hline
\end{tabular}

Nota. Avance Productivo Sectorial. Tomado de "INEI: Minería y Construcción registraron crecimiento en mayo de 2016". Peru.21, 2016.Recuperado de http://peru21.pe/economia/ineimineria-y-construccion-registran-crecimiento-mayo-2250870

Tabla 19

Pronóstico de la demanda (Método de Juicio)

\begin{tabular}{|c|c|c|c|c|c|c|c|c|c|}
\hline \multicolumn{10}{|c|}{ DEMANDA DE BLOQUETAS DE PLASTICO (MILLARES) } \\
\hline \multicolumn{2}{|c|}{ AÑO 1} & \multicolumn{2}{|c|}{ AÑO 2} & \multicolumn{2}{|c|}{ AÑO 3} & \multicolumn{2}{|c|}{ AÑO 4} & \multicolumn{2}{|c|}{ AÑO 5} \\
\hline MES 1 & 250 & MES 1 & 263 & MES 1 & 276 & MES 1 & 290 & MES 1 & 305 \\
\hline MES 2 & 250 & MES 2 & 263 & MES 2 & 276 & MES 2 & 290 & MES 2 & 305 \\
\hline MES 3 & 250 & MES 3 & 263 & MES 3 & 276 & MES 3 & 290 & MES 3 & 305 \\
\hline MES 4 & 250 & MES 4 & 263 & MES 4 & 276 & MES 4 & 290 & MES 4 & 305 \\
\hline MES 5 & 250 & MES 5 & 263 & MES 5 & 276 & MES 5 & 290 & MES 5 & 305 \\
\hline MES 6 & 250 & MES 6 & 263 & MES 6 & 276 & MES 6 & 290 & MES 6 & 305 \\
\hline MES 7 & 250 & MES 7 & 263 & MES 7 & 276 & MES 7 & 290 & MES 7 & 305 \\
\hline MES 8 & 250 & MES 8 & 263 & MES 8 & 276 & MES 8 & 290 & MES 8 & 305 \\
\hline MES 9 & 250 & MES 9 & 263 & MES 9 & 276 & MES 9 & 290 & MES 9 & 305 \\
\hline MES 10 & 250 & MES 10 & 263 & MES 10 & 276 & MES 10 & 290 & MES 10 & 305 \\
\hline MES 11 & 250 & MES 11 & 263 & MES 11 & 276 & MES 11 & 290 & MES 11 & 305 \\
\hline MES 12 & 250 & MES 12 & 263 & MES 12 & 276 & MES 12 & 290 & MES 12 & 305 \\
\hline TOTAL & 3000 & & 3156 & & 3312 & & 3480 & & 3660 \\
\hline
\end{tabular}

Nota. Adaptado de la proyección del mercado 


\subsection{Aspectos críticos que impactan el pronóstico de ventas}

Existen diversos aspectos que pueden impactar los pronósticos, estos se subdividen en Internos y Externos. Los externos no pueden ser controlados por la empresa.

1. Disminución del PBI del Sector Construcción.

2. Variaciones en la oferta del producto en el mercado.

3. Restricciones e incentivos del gobierno.

4. Tendencia de crecimiento de los últimos años.

Y a su vez podemos encontrar Aspectos críticos internos, que si podemos controlarlos como:

1. Cambio en los procesos operacionales.

2. Poca capacidad productiva de la empresa.

3. Inadecuada estrategia de comercialización y mercadeo. 


\section{Capítulo V: Ingeniería del Proyecto}

\subsection{Estudio de Ingeniería}

Para Padilla (2011), la ingeniería del proyecto tiene la responsabilidad de seleccionar el proceso de producción de un proyecto cuya disposición en planta conlleva a la adopción de una determinada tecnología y la instalación de obras físicas o servicios básicos de conformidad con los equipos y maquinarias elegidos. Las partes de la ingeniería del proyecto que se describe en en este capítulo se muestra en la Figura 29.

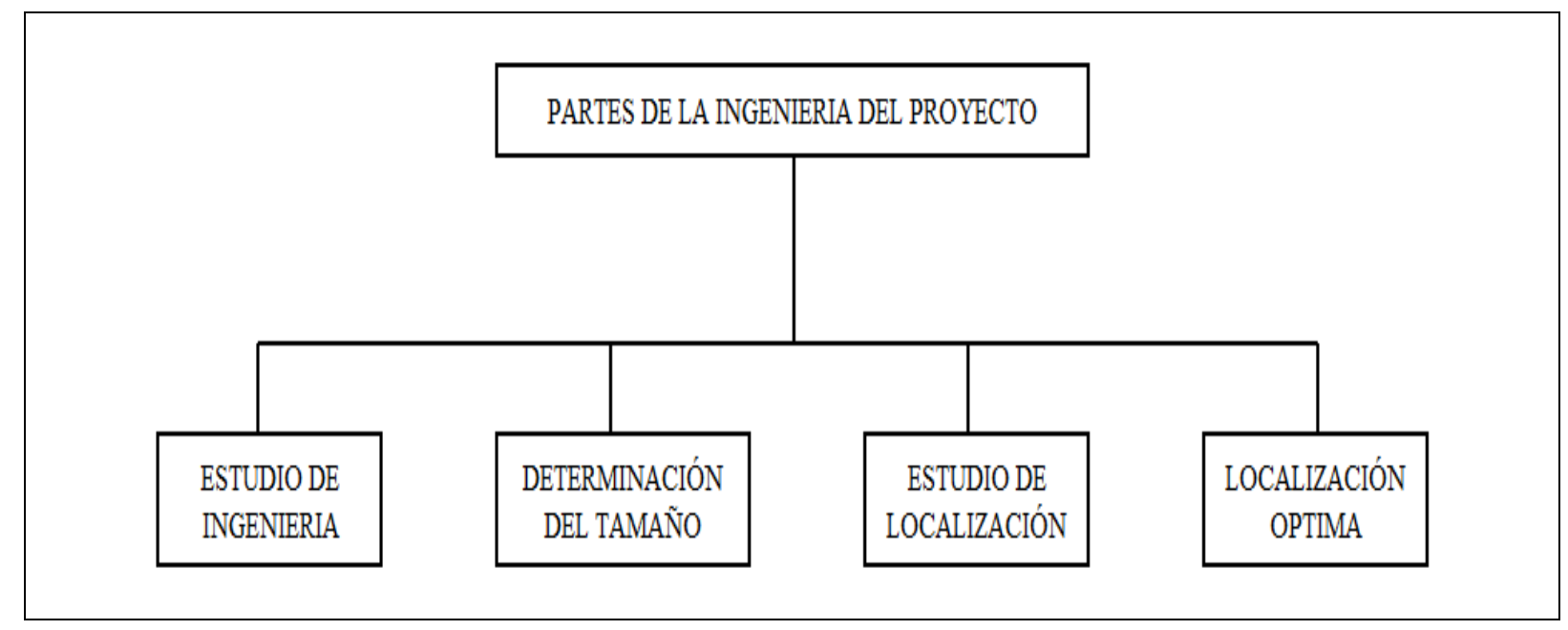

Figura 29. Partes contempladas en la Ingeniería del Proyecto

Según publicación de Ecured.cu (2016), la creación de los ladrillos ecológicos nace en 1999, donde Henry Liu se da cuenta que la contaminación se había incrementado. Viendo esta situación crea la idea de ladrillos ecológicos con la finalidad de disminuir los desechos. Los ladrillos del presente proyecto aprovechan los plásticos usados y desechados que generan gran impacto ambiental y que son reciclados, triturados y mezclamos con cemento y agua. Las ventajas radican en que es un producto con un impacto ambiental menor, que genera un proceso de producción limpia, ya que se eliminaría la etapa de cocido en el mismo. 


\subsubsection{Modelamiento y selección de procesos productivos.}

Como Krajewski, Ritzman y Malhorta (2013) lo establecen, los procesos de manufactura convierten materiales en bienes que tienen una forma física que llamamos productos. Por ejemplo, una fábrica de bloquetas de plástico como nuestro proyecto; la figura 30 muestra un proceso productivo básico que contempla un estado inicial, un proceso de transformación hasta el estado final. Los procesos de Transformación cambian los materiales en una o más de las siguientes dimensiones: Propiedades Físicas, Forma, Tamaño (largo, ancho, altura de un bloque rectangular), acabado de la superficie y unión de partes y materiales.

Las salidas del proceso de manufactura se pueden fabricar, almacenar y transportar, previniendo la demanda.

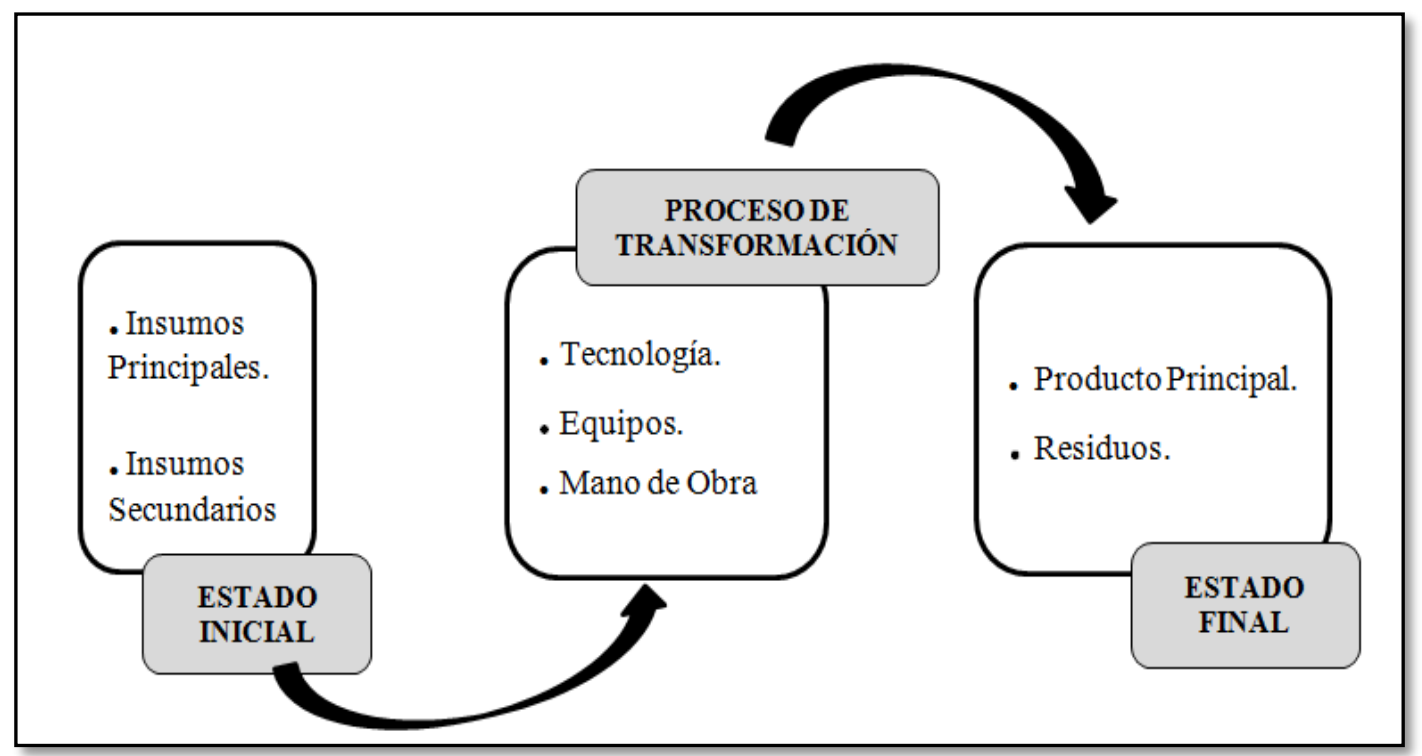

Figura 30. Proceso Productivo para la elaboración de Bloquetas de Plástico.

El estudio de Castell (2000), menciona que la población mundial está creciendo a un ritmo acelerado, y con ello la contaminación ambiental; en este punto el ser humano está preocupado por darles un mejor uso a estos residuos por medio del proceso del reciclaje, el cual consiste en aplicarle un proceso al material para que así este pueda ser reutilizado y disminuir el uso de los recursos naturales. 
Con las bloquetas de plástico se pretende tener una alternativa a la producción del ladrillo de barro, el cual requiere de mayor consumo de agua durante el proceso de curado y de producción, la propuesta promueve la protección del ambiente y del consumo de recursos disminuyendo la tala de árboles para la alimentación de hornos del ladrillo de barro.

Por otro lado, Gómez (2014), establece que se disminuyen elementos como cemento y arena, al reemplazarlos por plástico, uno de los grandes contaminantes, el cual es utilizado en muchos de los procesos y actividades de la vida cotidiana. Este material se conoce como tereftalato de polietileno (PET), que ofrece grandes ventajas además de los bajos costos de fabricación. No obstante, el tiempo que tarda en descomponerse es no menor a cien años, lo cual genera un alto nivel de contaminación. 


\section{Descripción técnica del proceso.}

La figura 31 muestra el diagrama para la elaboración del ladrillo de plástico.

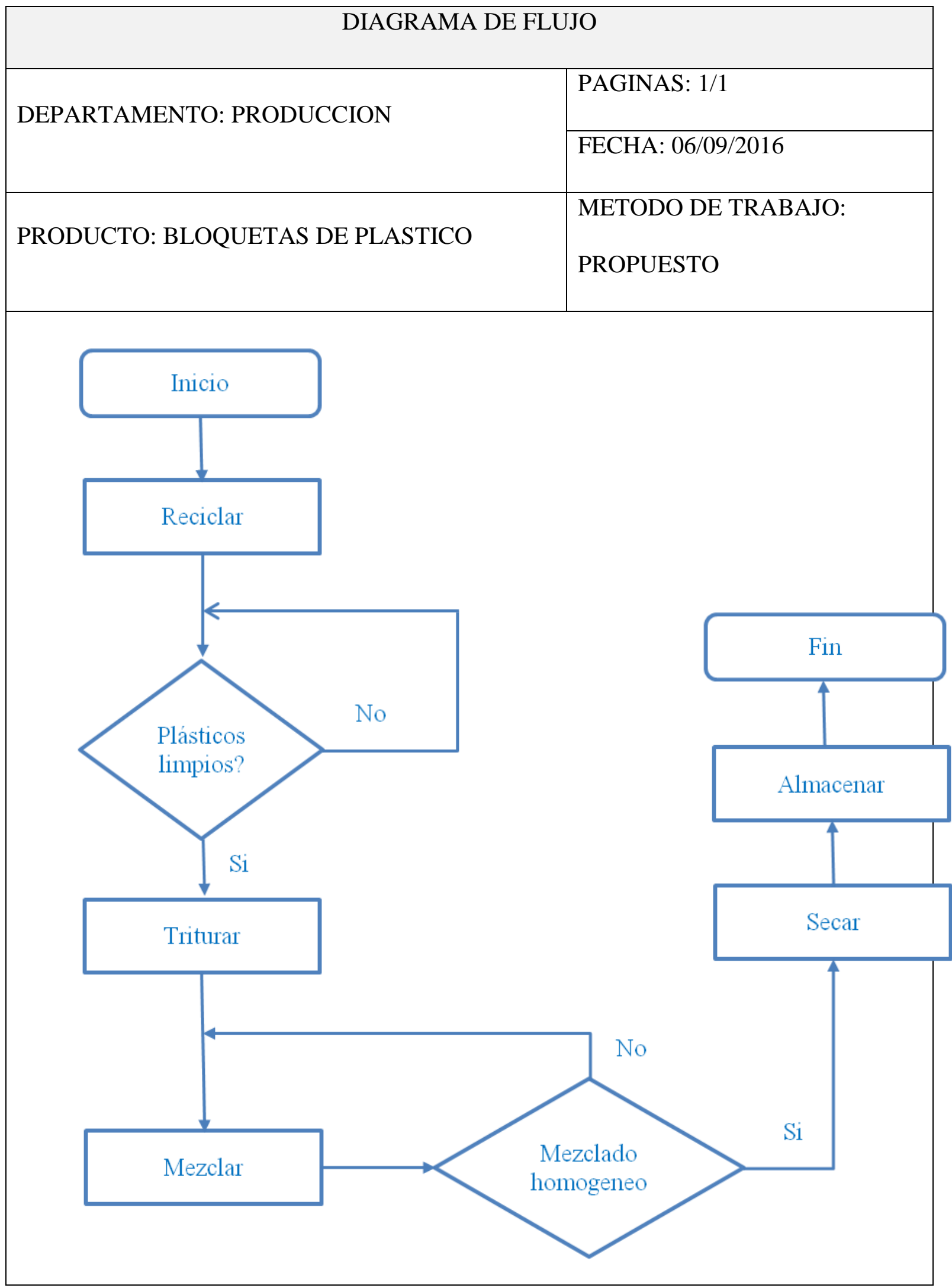

Figura 31. Diagrama de Flujo del Proceso Productivo. 


\section{Reciclado de Plástico}

La disposición de residuos en la ciudad de Arequipa constituye un problema de difícil solución. Actualmente sus residuos urbanos son en su mayor parte enterrados, lo cual no es una alternativa muy racional desde el punto de vista económico ni tampoco ambientalmente adecuado, puesto que gran parte de los residuos es no biodegradable.

Como lo detalla el Instituto de Vivienda (Universidad de Chile, 2008); el tiempo que demora el proceso de descomposición de los desechos es variable según el tipo de material, siendo sumamente lento en el caso de los plásticos. "Las botellas de polietileno-tereftalato (PET) tardan más de 500 años en descomponerse, y duran más si están enterradas. Las bolsas de polietileno de baja densidad (LDPE) se transforman recién a los 150 años en contacto con los agentes naturales".

Reciclar es una alternativa conveniente desde el punto de vista ambiental, puesto que se reducen los residuos que se acumulan en basurales al aire libre, se queman, o se entierran.

\section{Triturado del Plástico Reciclado}

Las piezas se rompen y desmenuzan a través un triturador de gran capacidad productiva, por medio de un juego de cuchillas giratorio, reduciéndolas a pequeños trozos según el diámetro requerido. Con el triturado logramos que la granulometría del plástico sea homogénea lo que nos facilita las posteriores labores. |

De acuerdo a lo explicado por Gaggino (2008) los plásticos triturados son incorporados a la mezcla cementicia, sin necesidad de un lavado previo (salvo en el caso que se utilicen residuos muy contaminados tomados de la basura, sin un acopio separado). 
El bajo requerimiento de limpieza se explica porque los desechos quedan confinados en la masa del cemento.

En el caso de los envases de PET, no es necesario sacarle etiquetas ni tapas previo al proceso de triturado.

No se pueden utilizar envases procedentes de la industria agroquímica y en general, aquellos que puedan haber estado en contacto con sustancias tóxicas.

\section{Mezclado del Plástico con el Cemento y el Agua}

De acuerdo a la investigación científica de Martínez (2014) se llegó a la conclusión que la mezcla que genera mayor resistencia y compresión son las que se componen de $50 \%$ de cemento y $50 \%$ de PET, logrando una mayor resistencia que los ladrillo comúnmente usados en la construcción. Adicional debe agregar $0.261 \mathrm{M}^{3}$ agua.

Lo que se debe considerar es el agua, de preferencia deberá contener lo necesario o menos ya que si se excede la humedad no resistirá la compresión, ya que frustra una compactación adecuada ocasionando ranuras.

\section{Moldeado}

Con la mezcla lista comienza la fabricación de los ladrillos de manera ipsofacta. Se fabrica el molde en madera con las dimensiones establecidas por el Ministerio de la Producción (2010), 23X10X4 (cm). Se ubica el molde en el espacio que se halla destinado para el secado del ladrillo; ya estando en este espacio se introduce la mezcla para darle la forma cuadrada y luego despegar el molde para dejarlos al sol durante un día para que se sequen. 


\section{Curado}

De acuerdo con Fraternalli, Spadea y Berardi (2014), luego de finalizado el día de secado se ponen los ladrillos en un tanque, que debe estar lleno de agua, donde pasarán 7 días aproximadamente en un proceso que se le hace al cemento, el cual se llama "curado", que brinda al ladrillo las características de cohesión.

Pasados los siete días del proceso anterior, se sacan los ladrillos del agua para pasarlos a un lugar fresco.

\section{Secado}

Según lo explica Martínez (2014) el Secado es el último paso del proceso de fabricación de la bloqueta de plástico, en el cual se sacan todas las muestras del agua y se llevan a un lugar bajo techo donde permanezcan a temperatura ambiente, son apilados uno encima de otro y no se pueden mover durante 28 días, lapso en el que tomarán las propiedades mecánicas; este tiempo es usado internacionalmente.

\section{Almacenado}

Los ladrillos deben ser almacenados en lugares ventilados y pueden formarse rumas de 1,000 ladrillos.

\subsubsection{Selección del equipamiento.}

Los principales equipos a considerar en el proyecto son los siguientes:

\section{Trituradora de Plástico}

Básicamente el Triturador se compone de una boca de entrada más o menos grande, que permite el acceso a las piezas de plástico y que está preparado para evitar, en la medida de lo posible, proyectar piezas al exterior. Un rotor incorpora 
varias cuchillas que, gracias a la potencia y velocidad de giro, cortan y trituran las piezas de plástico. La figura 32, muestra un triturador de plástico modelo SP800.

Después, pasa por un tamiz o por una rejilla que únicamente permite el paso a los trozos de un tamaño deseado. Por último, pasa por una cinta hasta un depósito donde se almacena el producto.

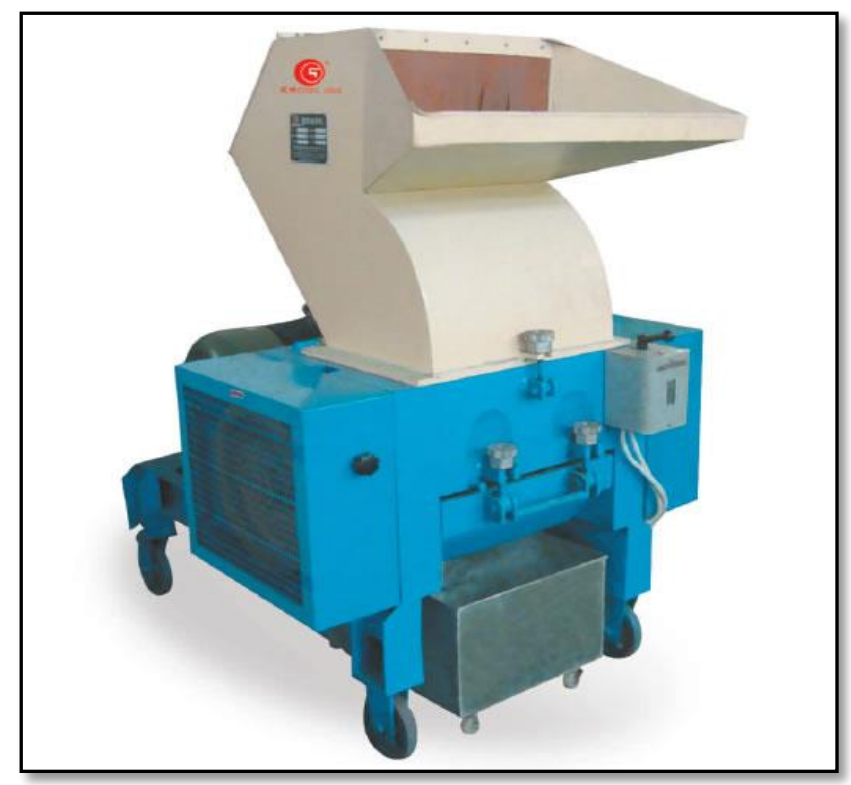

Figura 32. Trituradora de plástico modelo SP800. Tomado de productos machine: maquina auxiliar de procesamiento. Recuperado de http://chinainjection.es/4-1plastic-crusher.html/

\section{Mezcladora}

Tiene como función preparar la mezcla de cemento, plástico y agua. La ventaja de usar una mezcladora industrial, es que la mezcla de producto final queda más homogénea, mejorando su calidad.

El tiempo de mezclado depende del tipo de equipo empleado, pero en ningún caso este tiempo debe ser menor a dos minutos. El tiempo se toma en cuenta desde que todos los elementos han ingresado a la mezcladora.

En la figura 33 se muestra la mezcladora horizontal que tiene un eje conformado por dobles cintas helicoidales que se encuentran dentro de la tina. El 
elemento mezclador gira con el eje principal y por lo tanto pone el producto en movimiento. Guiado por las cintas helicoidales y soleras externas que impulsan el producto hacia las paredes de la tina, mientras que las soleras internas lo impulsan al centro logrando una mezcla en movimiento uniforme y homogéneo en cada esquina de la mezcladora.

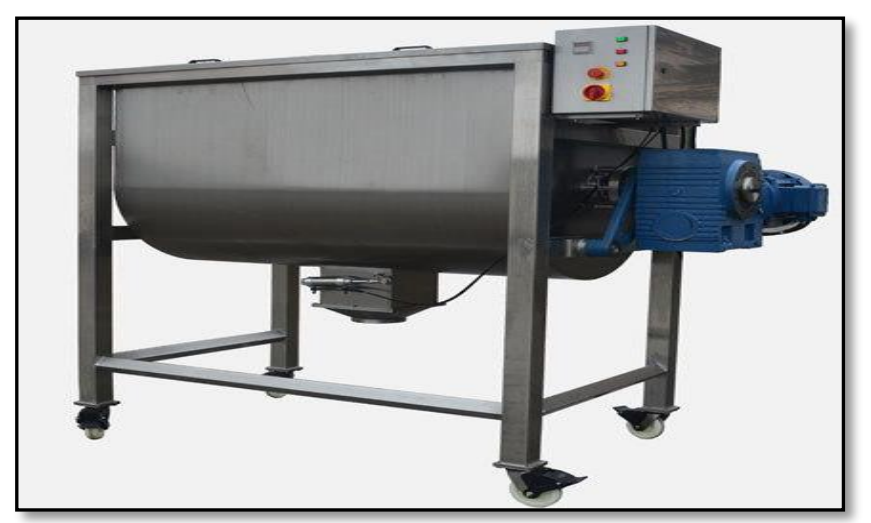

Figura 33. Licuadora de cemento y plástico modelo tdpm, con tornillo y paleta de agitación. Recuperado de https://spanish.alibaba.com/product-detail/plasticcement-blender-screw-stirring-paddle-blender-paste-mixer-wldh-serieshorizontal-ribbon-blender-60059154148.html

\section{Tornillo Helicoidal}

En ingeniería mecánica se denomina también transportador de tornillo sin fin; es un dispositivo que transmite el movimiento entre ejes que son perpendiculares entre sí, mediante un sistema de dos piezas: el "tornillo" (con dentado helicoidal), y un engranaje circular denominado "corona". La figura 34 muestra el tipo de tornillo helicoidal necesario para nuestro proyecto. 


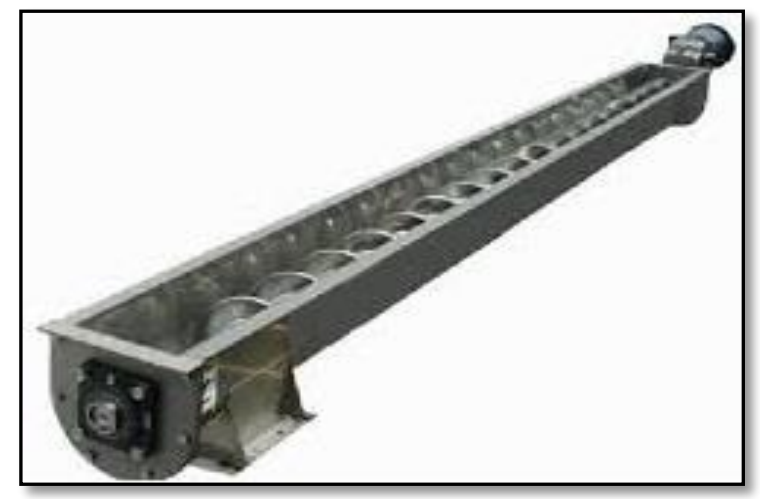

Figura 34. Transportadores de tornillo sin fin. Cálculo de Transportadores de tornillo sin fin. Recuperado de http://ingemecanica.com/tutorialsemanal/tutorialn143.html.

\section{Cinta Transportadora.}

Una cinta transportadora o transportador de banda, ver Figura 35, es un sistema de transporte continúo formado por una banda continua que se mueve entre dos tambores.

Por lo general, la banda es arrastrada por la fricción de sus tambores, que a la vez este es accionado por su motor. Esta fricción es la resultante de la aplicación de una tensión a la banda transportadora, habitualmente mediante un mecanismo tensor por husillo o tornillo tensor. El otro tambor suele girar libre, sin ningún tipo de accionamiento, y su función es servir de retorno a la banda. La banda es soportada por rodillos entre los dos tambores. Denominados rodillos de soporte. 


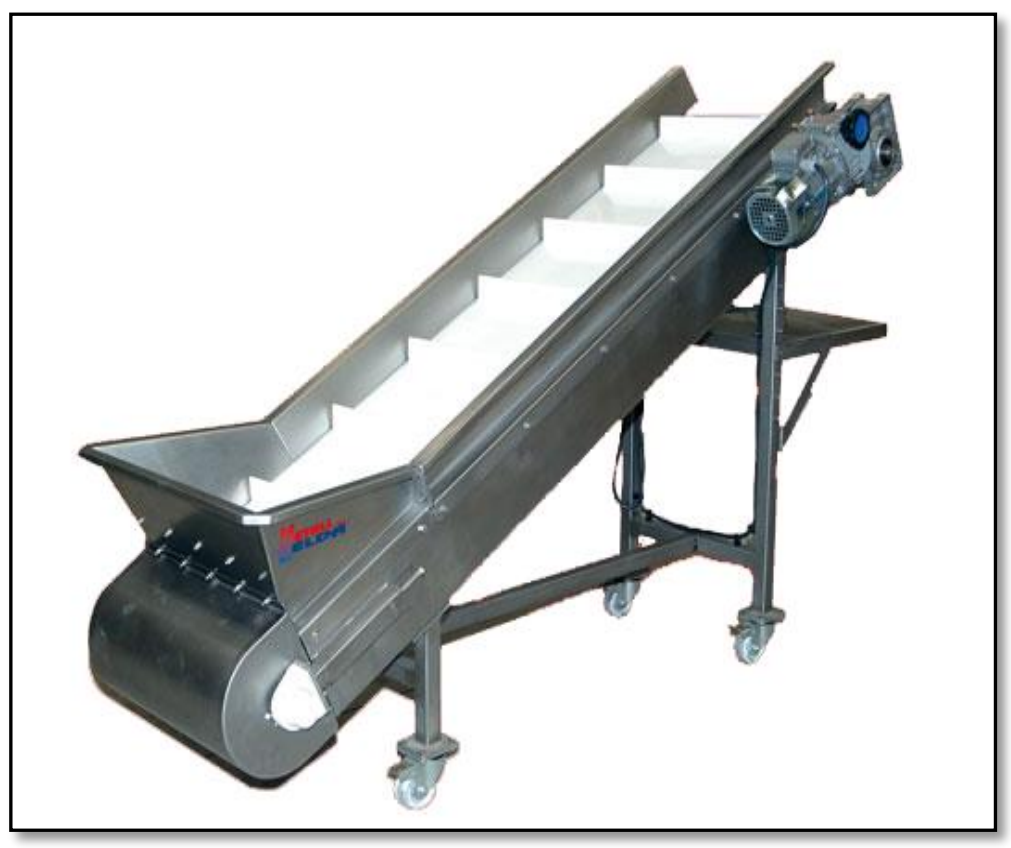

Figura 35.Cinta Transportadora de metal. Tomada de http://www.metallbelda.net/portfolio/cintas-transportadoras/\#prettyPhoto

\subsubsection{Layout}

Para poder realizar el layout de planta se ha calculado la necesidad del área que necesita el proyecto en sus diferentes ambientes de trabajo. La tabla 20 muestra el requerimiento de terreno que necesitamos para nuestro proyecto. 
Tabla 20

Requerimiento de Área de Terreno

\begin{tabular}{|c|c|c|c|c|c|c|c|c|c|}
\hline \multirow{2}{*}{ Elementos } & \multirow{2}{*}{ Cantidad } & \multicolumn{3}{|c|}{ Dimensiones } & \multirow{2}{*}{$\begin{array}{l}\mathrm{N}^{\circ} \mathrm{de} \\
\text { lados }\end{array}$} & \multirow{2}{*}{ Ss (m2) } & \multirow{2}{*}{$\mathrm{Sg}(\mathrm{m} 2)$} & \multirow{2}{*}{$\begin{array}{c}\text { St } \\
\text { (m2/unid) }\end{array}$} & \multirow{2}{*}{$\mathrm{St}(\mathrm{m} 2)$} \\
\hline & & $\mathrm{L}$ & A & $\mathrm{H}$ & & & & & \\
\hline \multicolumn{10}{|l|}{ Producción } \\
\hline Balanza electrónica & 2 & 0.39 & 0.35 & 0.75 & 3.00 & 0.14 & 0.41 & 0.55 & 1.09 \\
\hline Triturador de Plástico & 1 & 3.50 & 4.20 & 1.50 & 3.00 & 14.70 & 44.10 & 58.80 & 58.80 \\
\hline Mezcladora & 1 & 4.50 & 3.20 & 1.59 & 3.00 & 14.40 & 43.20 & 57.60 & 57.60 \\
\hline Tornillos helicoidales & 2 & 5.00 & 0.40 & 0.40 & 1.00 & 2.00 & 2.00 & 4.00 & 8.00 \\
\hline Cinta Transportadora & 1 & 5.00 & 0.60 & 0.40 & 1.00 & 3.00 & 3.00 & 6.00 & 6.00 \\
\hline Moldes x 24 unidades & 350 & 1.50 & 0.50 & 0.05 & 2.00 & 0.75 & 1.50 & 2.25 & 26.25 \\
\hline Tinas plásticas & 4 & 0.80 & 0.50 & 0.35 & 2.00 & 0.40 & 0.80 & 1.20 & 4.80 \\
\hline Mesa de trabajo & 4 & 2.50 & 1.50 & 0.90 & 4.00 & 3.75 & 15.00 & 18.75 & 75.00 \\
\hline Almacén de M.P. & - & - & - & - & - & $1,000.00$ & - & - & $1,000.00$ \\
\hline Almacén de P.T. & - & - & - & - & - & $1,000.00$ & - & - & $1,000.00$ \\
\hline Tina de Curado & - & - & - & - & - & 800.00 & - & - & 800.00 \\
\hline Control de calidad & - & - & - & - & - & 14.00 & - & - & 14.00 \\
\hline Mantenimiento & - & - & - & - & - & 40.00 & - & - & 40.00 \\
\hline Administración y ventas & - . & - & - & - . & - . & 16.00 &.- &.- & 16.00 \\
\hline Servicios higiénicos & - & - & - & - & - & 10.50 & - & - & 10.50 \\
\hline Áreas verdes & - & - & - & - & - & 150.00 & - & - & 150.00 \\
\hline Área de expansión & - & - & - & - & - & 653.61 & - & - & 653.61 \\
\hline Área Total & & & & & & & & & \\
\hline
\end{tabular}

Nota. Los guiones indican que no existe valor para esta celda. Adaptado del Estudio de Ingeniería del proyecto, Layout de Planta. 
El Layout correspondiente a los requerimientos de área de terreno, ver Figura 36 :

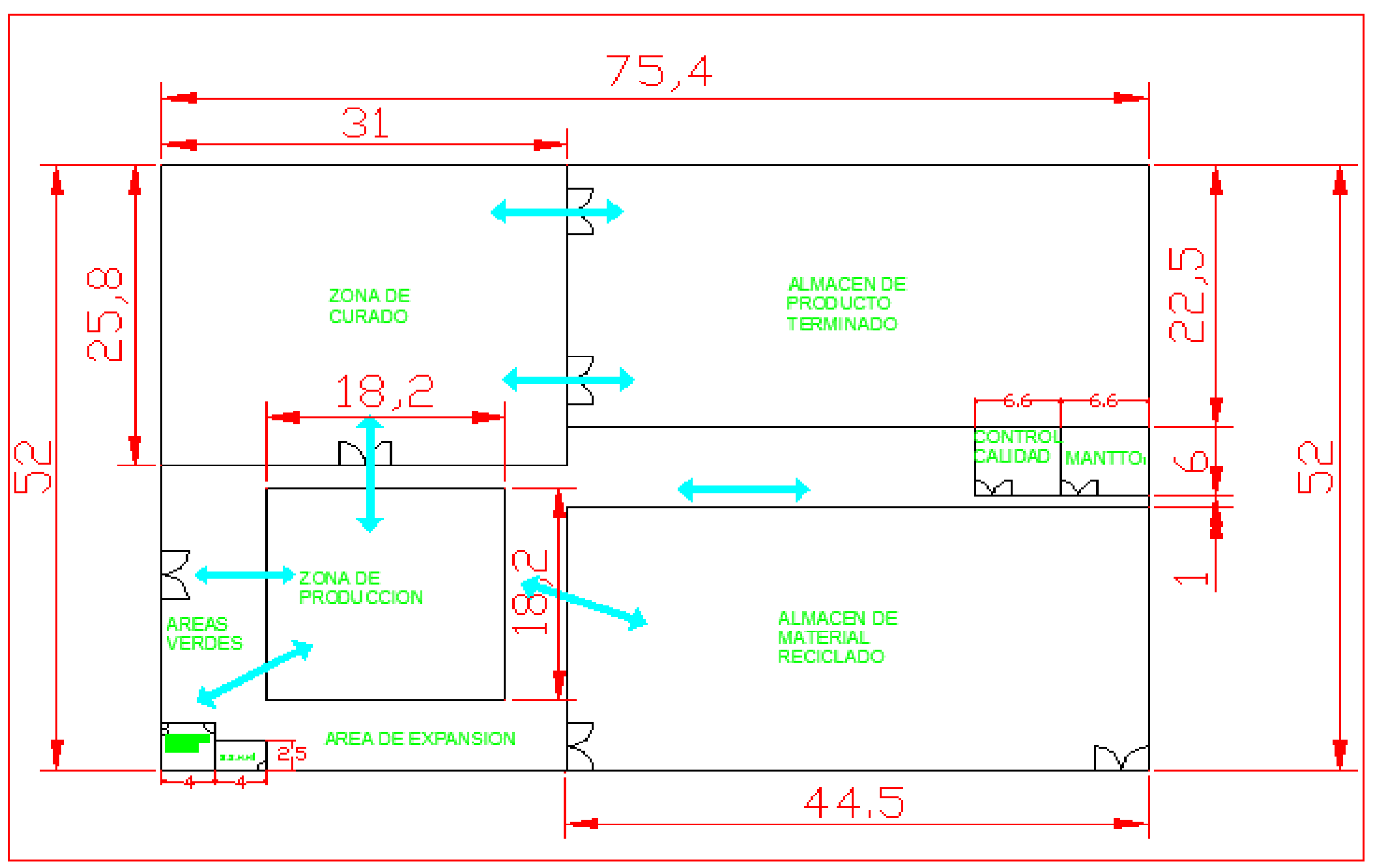

Figura 36. Layout de planta (metros) 


\subsubsection{Distribución de equipos y maquinarias}

Se ha definido la distribución de equipos y maquinarias del proyecto, así como las zonas de procesamiento, ver Figura 37.

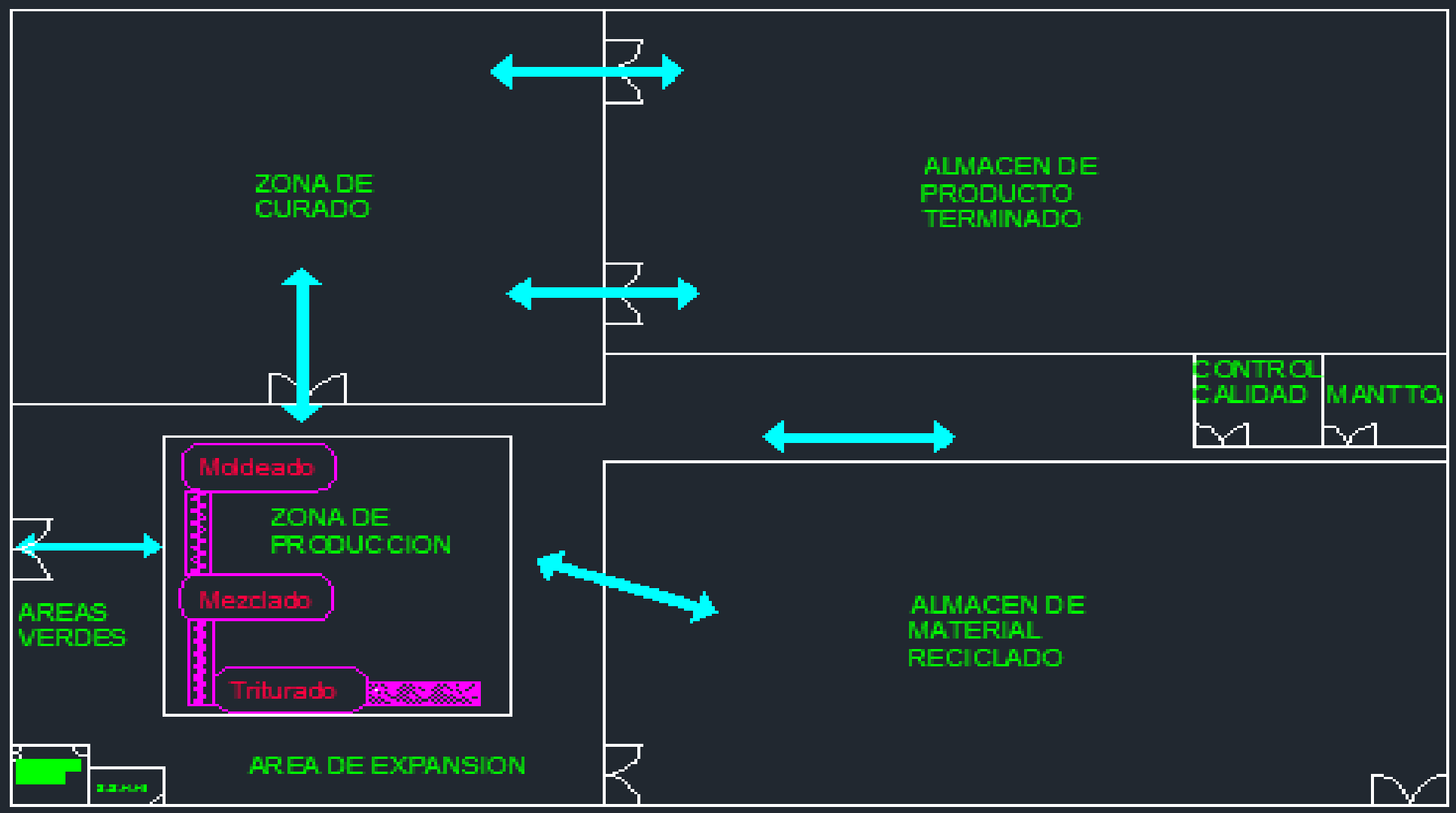

Figura 37. Distribución de equipos. 


\subsection{Determinación del Tamaño}

Se determinó el tamaño óptimo de la planta entre una serie de alternativas de tamaño. El tamaño quedará determinado por aquella que conduzca a obtener los máximos beneficios; es decir que cubra en lo posible la mayor parte de la demanda de nuestro producto, de acuerdo a la proyección de crecimiento del negocio, evitando incurrir en altos costos innecesarios y de capacidad ociosa.

\subsubsection{Proyección de crecimiento}

De acuerdo al estudio de mercado y a la demanda proyectada de del producto, se ha determinado una producción anual que muestra una tendencia positiva a través del tiempo, de acuerdo a la tabla 21:

Tabla 21

Proyección del Crecimiento del Proyecto

\begin{tabular}{cc}
\hline Año & $\begin{array}{c}\text { PRODUCCION } \\
\text { (Millares) }\end{array}$ \\
\hline Año 1 & 3,000 \\
Año 2 & 3,156 \\
Año 3 & 3,312 \\
Año 4 & 3,480 \\
Año 5 & 3,660 \\
\hline
\end{tabular}

Nota. Elaboración propia de acuerdo al crecimiento de 5\% anual. Ver anexo XII.

Medición del tamaño

Para determinar el tamaño óptimo de la planta se ha adaptado el método de planificación de la capacidad utilizando factores globales (como se cita en Chapman, 2006) de acuerdo a la capacidad de producción necesarios, según la proyección de ventas. 
Se ha considerado los siguientes parámetros:

$\mathrm{CP}=\mathrm{f}(\mathrm{A}, \mathrm{B}, \mathrm{C}, \mathrm{D})$

Dónde:

Variable

$\mathrm{CP}=$ Capacidad de Producción

$A=$ Días de Trabajo / año

$\mathrm{B}=$ Turnos de Trabajo/Día 1

$\mathrm{C}=$ Horas de Trabajo/Turno 10

$\mathrm{D}=\quad$ Unidad Producción/Hr. $\underline{\text { Valor }}$

En función de las variables de producción días laborales al año, a razón de días en promedio al mes turno de trabajo por día horas laborales por turno Acorde a la alternativa de tamaño 
1.

Alternativas de tamaño

El proyecto contempla tres alternativas de tamaño óptimo, que se muestran en la Tabla 22, y que toma como base para el desarrollo la

Tabla 23, donde se muestra la proyección del crecimiento del proyecto

Tabla 22

Alternativas para la obtención del tamaño óptimo de planta

\begin{tabular}{|c|c|c|c|c|c|c|}
\hline Variables & \multicolumn{2}{|c|}{ Alternativa 1} & \multicolumn{2}{|c|}{ Alternativa 2} & \multicolumn{2}{|c|}{ Alternativa 3} \\
\hline $\mathrm{CP}=$ & 3,000 & Millares/año & 4,000 & Millares/año & 5,000 & Millares/año \\
\hline $\mathrm{A}=$ & 300 & días/año & 300 & días/año & 300 & días/año \\
\hline $\mathrm{B}=$ & 1 & turno/día & 1 & turno/día & 1 & turno/día \\
\hline $\mathrm{C}=$ & 10 & horas/turno & 10 & horas/turno & 10 & horas/turno \\
\hline $\mathrm{D}=$ & 1.00 & Millar/hora & 1.33 & Millar/hora & 1.67 & Millar/hora \\
\hline
\end{tabular}

Nota. Las alternativas propuestas toman como base la Tabla de proyección del crecimiento del proyecto. 


\subsubsection{Recursos}

1. Recurso Humano.

De acuerdo a lo que menciona Chiavenato (2007) la planeación de personal es el proceso de decisión respecto a los recursos humanos necesarios para alcanzar los objetivos organizacionales en determinado tiempo. Se trata de anticipar cuál es la fuerza de trabajo y los talentos humanos necesarios para la realización de la actividad organizacional futura. La planeación de personal no siempre es responsabilidad del departamento de personal de la organización. El problema de anticipar la cantidad y calidad de personas necesarias para la organización es extremadamente importante.

La empresa requerirá personal directo, los cuales se subdividen en dos el Operativo destinado a la producción y el de Administración con funciones de Supervisión, Compras, Ventas y Dirección. La Tabla 23 muestra el personal necesario para el desarrollo de las actividades del proyecto, mostrando una variación anual de acuerdo a su crecimiento.

Tabla 23

Recursos Humanos que necesita el proyecto

\begin{tabular}{lccccc}
\hline \multicolumn{1}{c}{ PUESTO } & año 1 & año 2 & año 3 & año 4 & año 5 \\
\hline Administrador & 1 & 1 & 1 & 1 & 1 \\
Gerente de Operaciones & 1 & 1 & 1 & 1 & 1 \\
Operarios & 4 & 4 & 5 & 5 & 6 \\
Vendedores & 4 & 4 & 5 & 5 & 6 \\
Técnicos & 1 & 1 & 2 & 2 & 2 \\
Asistentes de Campo & 1 & 1 & 2 & 2 & 2 \\
Asistentes Administrativos & 0 & 1 & 1 & 1 & 1 \\
\hline Nota. Elaboración Propia de acuerdo al estudio de ingeniería del proyecto.
\end{tabular}

Nota. Elaboración Propia de acuerdo al estudio de ingeniería del proyecto. 


\section{Recursos Físicos.}

En la Tabla 24 se muestran las necesidades de maquinarias, equipos y herramientas del proyecto, destinados al proceso productivo, ventas y administración.

Tabla 24

Requerimiento de Maquinaria, Equipos y Herramientas

\begin{tabular}{|c|c|c|c|c|c|c|}
\hline Tipo & Equipos & Marca & Capac. & Cant. & $\begin{array}{l}\text { P.U. } \\
\text { (S/.) }\end{array}$ & $\begin{array}{l}\text { Total } \\
\text { (S/.) }\end{array}$ \\
\hline \multirow{9}{*}{$\begin{array}{c}\text { Maquinarias } \\
\text { y Equipos }\end{array}$} & $\begin{array}{l}\text { Balanza } \\
\text { electrónica }\end{array}$ & $\begin{array}{l}\text { Precisión } \\
\text { Perú }\end{array}$ & $100 \mathrm{Kg}$. & 2 & 250 & 500 \\
\hline & $\begin{array}{l}\text { Triturador de } \\
\text { Plástico }\end{array}$ & $\begin{array}{l}\text { Industria } \\
\text { nacional }\end{array}$ & $4 \mathrm{Tm} / \mathrm{H}$ & 1 & 8,250 & 8,250 \\
\hline & Mezcladora & $\begin{array}{l}\text { Industria } \\
\text { nacional }\end{array}$ & $10 \mathrm{Tm} / \mathrm{H}$ & 1 & 11,550 & 11,550 \\
\hline & $\begin{array}{l}\text { Tornillos } \\
\text { helicoidales }\end{array}$ & $\begin{array}{l}\text { Industria } \\
\text { nacional }\end{array}$ & $15 \mathrm{Tm} / \mathrm{H}$ & 2 & 6,600 & 13,200 \\
\hline & $\begin{array}{l}\text { Cinta } \\
\text { Transportadora }\end{array}$ & $\begin{array}{l}\text { Industria } \\
\text { nacional }\end{array}$ & $10 \mathrm{Tm} / \mathrm{H}$ & 1 & 8,250 & 8,250 \\
\hline & $\begin{array}{l}\text { Moldes para } \\
\text { bloquetas }\end{array}$ & $\begin{array}{l}\text { Industria } \\
\text { nacional }\end{array}$ & 24 unid. & 350 & 48 & 16,800 \\
\hline & Montacarga & Toyota & $3.0 \mathrm{TM}$ & 1 & 8,000 & 8,000 \\
\hline & Camión & $\mathrm{Jac}$ & $5.0 \mathrm{TM}$ & 1 & 38,000 & 38,000 \\
\hline & Computadora & $\begin{array}{c}\text { HP - Corel } \\
\text { i3 }\end{array}$ & $\begin{array}{c}4 \mathrm{~GB} \\
\text { RAM, } 1 \\
\text { TB }\end{array}$ & 1 & 2,000 & 2,000 \\
\hline \multirow{12}{*}{ Herramienta } & Herramientas & Marca & Capac. & Cant. & $\begin{array}{l}\text { P.U. } \\
\text { (S/.) }\end{array}$ & $\begin{array}{l}\text { Total } \\
\text { (S/.) }\end{array}$ \\
\hline & Tinas plásticas & Rey & $50 \mathrm{Lt}$. & 6 & 13 & 78 \\
\hline & Jarras plásticas & Rey & $1 \mathrm{Lt}$. & 12 & 2 & 24 \\
\hline & Coladores & Rey & Mediana & 12 & 1.50 & 18 \\
\hline & $\begin{array}{l}\text { Tablas de } \\
\text { Muestreo }\end{array}$ & Rey & Mediana & 6 & 5 & 30 \\
\hline & Lampas & Incoresa & $\begin{array}{l}\text { Tipo } \\
\text { cuchara }\end{array}$ & 6 & 40 & 240 \\
\hline & $\begin{array}{l}\text { Dinos - Envases } \\
\text { Plásticos }\end{array}$ & Rey & $200 \mathrm{Lt}$ & 3 & 90 & 270 \\
\hline & Recogedor & Rey & Mediana & 12 & 4 & 48 \\
\hline & Paletas & Rey & Mediana & 12 & 8 & 96 \\
\hline & $\begin{array}{l}\text { Materiales de } \\
\text { laboratorio }\end{array}$ & Varios & & 1 & 1,000 & 1,000 \\
\hline & $\begin{array}{l}\text { Herramientas de } \\
\text { Mantenimiento }\end{array}$ & Varios & & 1 & 1,000 & 1,000 \\
\hline & Mesa de trabajo & $\begin{array}{l}\text { Industria } \\
\text { nacional }\end{array}$ & $3 \times 3 \mathrm{~m}$. & 3 & 50 & 150 \\
\hline
\end{tabular}


3. Insumos.

El estudio requerirá de materias primas y elementos diversos para la fabricación de las bloquetas de plástico. La Tabla 25 muestra el requerimiento de materia prima y la Tabla 26 los precios de las mismas.

\section{Tabla 25}

Requerimiento de Materia Prima

\begin{tabular}{lcc}
\hline \multicolumn{2}{c}{ Materia prima } & \multicolumn{2}{c}{ Requerimiento/Millar } \\
\hline Agua $\left(\mathrm{M}^{3}\right)$ & 0.261 & $\mathrm{M} 3$ \\
Plástica $(\mathrm{Kg})$ & 220.50 & $\mathrm{Kg}$ \\
Cemento $(\mathrm{Kg})$ & 661.50 & $\mathrm{Kg}$
\end{tabular}

$\overline{\text { Nota. Adaptado del estudio de ingeniería del proyecto }}$

Tabla 26

Precios de la Materia Prima

\begin{tabular}{ccc}
\hline \multicolumn{3}{c}{ Precios (S/.) } \\
\hline Agua (M3) & Plástico (Kg) & Cemento (Kg) \\
\hline 4.27 & 0.35 & 0.33 \\
\hline \multicolumn{2}{l}{ Nota. Adaptado del estudio de ingeniería del proyecto }
\end{tabular}

\subsubsection{Tecnología}

Según Padilla (2013) la tecnología es un factor crítico en los proyectos, por la selección de la misma, la cual consta de dos pasos:

Selección de la tecnología desde el punto de vista técnico, que considera la capacidad de producción y el año que tiene la maquinaria.

Selección de la alternativa desde el punto de vista económico, que considera los costos de las maquinarias.

En consecuencia, el tipo de tecnología utilizada en un proyecto depende del precio de la maquinaria y del rendimiento técnico de cada alternativa. Si el aumento técnico en el rendimiento que genera una opción tecnológicamente más avanzada no 
compensa los mayores costos de su adquisición y operación, entonces será económicamente más conveniente optar por la alternativa técnicamente menos avanzada.

La tecnología de los equipos para nuestro proyecto será adaptada a la Industria Nacional, de acuerdo a las especificaciones o modelos necesarios. Existen diversos talleres encargados de fabricar la maquinaria de acuerdo a los requerimientos deseados por el cliente, por lo que vamos a confeccionar los tornillos helicoidales, fajas transportadoras, mezcladoras, etc., las cuales se han cotizado de acuerdo a los diseños propuestos, como la Empresa Jhonny Burgos S.A, Servicios INCLAN S.R.L, y otros.

\subsubsection{Flexibilidad}

La empresa está diseñada para poder afrontar diversos volúmenes de producción, iniciando con una demanda de alrededor al 30\% para luego ir creciendo hasta llegar al quinto año al 75\% de su capacidad instalada total (5,000 millares/año), para lo cual se han considerado áreas de expansión en caso se requiera (ver layout de planta).

Cuando las demandas oscilen en forma decreciente se realizará una gestión de equilibrio en los recursos y uso de la capacidad instalada, sin afectar o desinstalar activos, ya que la inversión inicial contempla la adquisición de activos que cubran la capacidad demandada al quinto año.

\subsubsection{Selección del tamaño ideal}

Como Díaz, Jarufe y Noriega (2007), lo indican el tamaño óptimo de la planta se determina seleccionando una serie de alternativas determinadas por aquella que 
conduzca a obtener los máximos beneficios; es decir que cubra en lo posible la mayor parte de la demanda de nuestro producto, evitando incurrir en altos costos innecesarios y de capacidad ociosa.

Los criterios o relación para la selección del tamaño óptimo, se tomaron de acuerdo a los siguientes criterios:

1. Relación tamaño - mercado.

Para definir el tamaño de la planta es importante tener en cuenta los requerimientos del mercado, ya que tenemos que empezar la producción con el mínimo requerido para no afectar la viabilidad del negocio; para esto, se necesita proyectar la demanda que se va a dar a lo largo del horizonte del proyecto según Stucchi (2010).

Conclusión. - De acuerdo a la relación Tamaño - Mercado que podemos observar en la Tabla 27, las opciones más convenientes son la alternativa 2 y alternativa 3 , debido a que el porcentaje de demanda cubierta es mayor. 
Tabla 27

Cálculo para la selección del tamaño óptimo en relación al mercado.

\begin{tabular}{|c|c|c|c|c|c|c|c|c|c|c|}
\hline \multirow{3}{*}{ Año } & \multirow{3}{*}{$\begin{array}{c}\text { Demanda } \\
\text { (Millar) }\end{array}$} & \multicolumn{3}{|c|}{ Alternativa 1} & \multicolumn{3}{|c|}{ Alternativa 2} & \multicolumn{3}{|c|}{ Alternativa 3} \\
\hline & & \multirow{2}{*}{$\begin{array}{r}3,000 \\
\text { Producción } \\
\text { (Millar) }\end{array}$} & \multicolumn{2}{|c|}{ Millar/año } & \multirow{2}{*}{$\begin{array}{l}4,000 \\
\text { Producción } \\
\text { (Millar) }\end{array}$} & \multicolumn{2}{|c|}{ Millar/año } & \multirow{2}{*}{$\begin{array}{r}5,000 \\
\text { Producción } \\
\text { (Millar) }\end{array}$} & \multicolumn{2}{|c|}{ Millar/año } \\
\hline & & & $\begin{array}{l}\text { Demanda } \\
\text { cubierta }\end{array}$ & $\begin{array}{c}\mathrm{CP} \\
\text { utilizada }\end{array}$ & & $\begin{array}{l}\text { Demanda } \\
\text { cubierta }\end{array}$ & $\begin{array}{c}\mathrm{CP} \\
\text { utilizada }\end{array}$ & & $\begin{array}{l}\text { Demanda } \\
\text { cubierta }\end{array}$ & $\begin{array}{c}\mathrm{CP} \\
\text { utilizada }\end{array}$ \\
\hline Año 1 & 3,000 & 3,000 & $100 \%$ & $100 \%$ & 3,000 & $100 \%$ & $75 \%$ & 3,000 & $100 \%$ & $60 \%$ \\
\hline Año 2 & 3,156 & 3,000 & $95 \%$ & $100 \%$ & 3,156 & $100 \%$ & $79 \%$ & 3,156 & $100 \%$ & $63 \%$ \\
\hline Año 3 & 3,312 & 3,000 & $91 \%$ & $100 \%$ & 3,312 & $100 \%$ & $83 \%$ & 3,312 & $100 \%$ & $66 \%$ \\
\hline Año 4 & 3,480 & 3,000 & $86 \%$ & $100 \%$ & 3,480 & $100 \%$ & $87 \%$ & 3,480 & $100 \%$ & $70 \%$ \\
\hline Año 5 & 3,660 & 3,000 & $82 \%$ & $100 \%$ & 3,660 & $100 \%$ & $92 \%$ & 3,660 & $100 \%$ & $73 \%$ \\
\hline
\end{tabular}

Nota. Los cálculos se realizaron tomando en cuenta la Tabla 19, Alternativas para la obtención del tamaño óptimo de planta. 
2. Relación tamaño - inversión.

El tamaño de la planta está fuertemente ligado al nivel de inversión, lo cual definirá la tecnología y los recursos pertinentes para el nivel de producción que se quiere alcanzar. Hay que tener mucho cuidado al momento de dimensionar la planta ya que no se quiere sobrepasar los volúmenes productivos, y de esta manera se estaría sobre costeando. Como se muestra en la tabla 28, para la inversión inicial se consideran equipos principales para el proceso productivo como también algunos importantes para servicios auxiliares.

De acuerdo a la relación Tamaño - Mercado podemos observar que las opciones más convenientes son la alternativa II y alternativa III, debido a que el porcentaje de demanda cubierta es mayor.

Tabla 28

Selección del Tamaño óptimo en relación a la inversión.

\begin{tabular}{ccccc}
\hline Alternativa de Tamaño & $\begin{array}{c}\text { Inversión } \\
\text { (US\$) }\end{array}$ & $\begin{array}{c}\text { Aporte propio } \\
(50 \%)\end{array}$ & $\begin{array}{c}\text { Financiamiento } \\
(50 \%)\end{array}$ \\
\hline \multirow{2}{*}{3,000} & Millares & 250,000 & 125,000 & 125,000 \\
4,000 & Millares & 300,334 & 150,167 & 150,167 \\
5,000 & Millares & 350,000 & 175,000 & 175,000 \\
\hline
\end{tabular}

Nota. Adaptado del estudio de ingeniería del proyecto

La capacidad financiera de los inversionistas es de 50 mil dólares (US\$. 150,000). Por lo que por los resultados obtenidos podemos descartar la alternativa 3 ya que se aleja demasiado de al límite de inversión.

Por lo tanto, el análisis final indica que el tamaño óptimo para el proyecto Fabricación de Bloquetas de Plástico al mercado arequipeño es de: 4,000 Millares/año. Debido al limitante de Inversión, además de considerar las demandas cubiertas en la relación Tamaño - Mercado. 


\subsection{Estudio de localización}

El propósito del capítulo de localización es determinar cuál será el lugar óptimo para ubicar la planta para la fabricación de bloquetas de plástico que se plantea Macrolocalizar en la Provincia de Arequipa. La localización óptima lo vamos a determinar de acuerdo a lo planteado por Krajewski (2013) y quedara determinada por aquella alternativa que nos muestre el mínimo costo de producción, siguiendo el proceso de Microlocalización.

\subsubsection{Microlocalización}

Definición de factores de localización.

Factores relacionados con la gestión

1. Cercanía a la Materia Prima

2. Factor Energía Eléctrica

3. Factor Agua

4. Factor mano de obra

5. Cercanía a la Vía de Exportación

Alternativas de localización

\section{Alternativa I: Distrito de Characato}

Se considera esta alternativa debido a que la población reconoce al distrito por la cantidad de fábricas artesanales y mecanizadas de ladrillos.

\section{Alternativa II: Distrito de Yarabamba}

Se considera esta alternativa debido a su cercanía con poblados emergentes y demanda en crecimiento, existe una dinámica inmobiliaria positiva y la población busca alternativas económicas para sus construcciones.

\section{Alternativa III: Distrito de Cerro Colorado}

Se considera esta alternativa debido a la presencia de gran número de hornos de ladrillos convencionales. 


\subsubsection{Consideraciones legales.}

\subsubsection{Identificación del marco legal.}

Para el presente estudio se analizó las normas y reglamentos que intervienen 1 en la actividad ladrillera, la Tabla 29, muestra el marco legal de referencia para nuestro proyecto:

Tabla 29

Marco Legal de la empresa

Constitución Política del Perú”. $\quad$ Tiene un nivel jerárquico mayor en el área legal, otorga 1993. expresamente la categoría de derecho fundamental de la persona a gozar de un ambiente equilibrado y adecuado al desarrollo de su vida (Art. 2 inc. 22). A través de ella se otorga el Estado la política nacional del ambiente e incentiva el adecuado uso de recursos naturales

Décimo Novena Política de En el Acuerdo Nacional se menciona el compromiso para

Estado: Desarrollo Sostenible y incluir la política ambiental a los demás sectores, con la Gestión Ambiental finalidad de contribuir al desarrollo del Perú.

A su vez el compromiso de institucionalizar la gestión ambiental, pública y privada.

Ley $\mathrm{N}^{\circ}$ 28611: Ley General del A través de esta ley se define el derecho que una persona Ambiente posee para tener un ambiente conforme a su necesidad es decir saludable además este deberá contar con todas las características para el desarrollo de la vida y la preservación del paisaje y la naturaleza. Naturales.

D. S. N 001-97-ITINCI: “... las Promueve procedimientos y plazos con la finalidad de empresas industriales desarrollar el programa de manejo ambiental, en cada una manufactureras se adecuen a las 
normas de Protección Ambiental de las empresas dependiendo del lugar de ubicación de su a ser aprobadas por el respectiva municipalidad.

MITINCI”. 05/01/1997

Cumpliendo su programa de manejo ambiental las empresas no podrán paralizar sus actividades por este tema., art. 103 de la Ley $\mathrm{N}^{\circ} 23407$.

D. S. N 019-97-ITINCI: $\quad$ El reglamento menciona que se debe realizar la política "Reglamento de Protección ambiental propuesta por el MINTINCI, el cual señala la Ambiental para el Desarrollo de importancia de la gestión ambiental. las Actividades de la Industria Dicha gestión tendrá que verse reflejada en las actividades Manufacturera”. 26/09/1997 que busquen la reducción de contaminantes.

Decreto Supremo $\mathrm{N}^{\circ}$ 057-2004 Dentro del reglamento se hace referencia sobre el PCM .Reglamento de la Ley almacenamiento, recolección y distribución final de General de Residuos Sólidos residuos sólidos que no pertenecen a alguna institución del №27314. 24/07/2004 estado (Título III, Capítulo II).

Reglamento de Estándares de $\quad$ EA través del reglamento se establece los horarios de Calidad Ambiental para Ruido atención los cuales deberán ser 07:00 a 22:00 horas en las D.S.Nº85-2003-PCM mañanas y viceversa en las noches . 


\subsubsection{Ordenamiento jurídico de la empresa.}

Dentro del ordenamiento jurídico de la empresa se consideró los puntos para la constitución legal.

1. Para la constitución de la empresa se tomó en cuenta una Sociedad Anónima Cerrada (S.A.C.), conforme se señala el Título Primero de la Ley General de Sociedades.

2. Para las empresas constituidas como S.A.C., se tendrá que considerar como máximo 20 accionistas y mínimo 2.

3. Para la presente empresa se consideró tres accionistas de manera inicial. Ya que progresivamente esta cantidad puede ir acrecentado conforme el crecimiento de la empresa.

Cabe resaltar que los accionistas no tendrán responsabilidad personalmente, sino que quien representara es una persona denominada “jurídica”, para lo cual tendrán que poseer una Junta General de Accionistas, y a su vez contar con un Gerente General, la cual es la persona encargada de la empresa y su gestión.

4. Se tendrá que buscar los servicios de una Notaria para que se proceda con la constitución de la empresa; la cual tendrá que elaborar la minuta de constitución y la escritura pública.

Con la Escritura pública lista, se tendrá que realizar los trámites en la Superintendencia de Nacional de Registros Públicos, concluido dicho trámite y ya con la Partida Registral de Inscripción se realizara los 
tramites en la Superintendencia Nacional de Aduanas y de

Administración Tributaria (SUNAT).

- Lo que se pretende lograr en la SUNAT es obtener el Registro Único de Contribuyentes (RUC)., el cual registrara la información de la empresa, respecto a la identificación, actividades económicas, domicilio fiscal, tributos a los que la empresa se encuentra afecta, etc. El trámite podrá realizarse por el representante legal establecido en Registros Públicos, para lo cual se requerirán los documentos señalados como: Documento de Identidad del Representante Legal, recibo de luz, teléfono, televisión, o última declaración jurada de predio o autoevaluó donde se localizará la empresa, la partida registral certificada por los Registros Públicos (antigüedad no mayor a 30 días calendario).

Asimismo, la empresa se acogerá al Régimen General, puesto que los otros Regímenes tales como RUS y RER imponen limitaciones como no poseer otro centro de operaciones o no superar los 10 trabajadores, respectivamente.

5. Registro en el MYPE El Decreto Legislativo $\mathrm{N}^{\circ}$ 1086, tiene por objetivo la promoción de la competitividad, formalización y desarrollo de las Micro y Pequeñas Empresas. La empresa, dentro de la Mype pertenecerá al grupo de la "Pequeña Empresa", ya que cumple con el requisito de tener de uno hasta 100 trabajadores y un monto de ventas anuales no mayor a 1700 UIT como lo indica la Ley de Promoción y Formalización de la Micro y Pequeña empresa (2003). Para ello, será 
necesaria la inscripción en la página web del Ministerio de Trabajo. Una vez registrada, la empresa podrá acceder a los beneficios laborales, tributarios, financieros y tecnológicos que brinda la Ley Mype.

6. Es necesario presentar la Autorización Municipal y Licencia de funcionamiento.

7. Para el proyecto será necesario considerar lo que norma el Régimen General, como es el Impuesto a la Renta (30\% de la utilidad) al finalizar el año y a su vez el Impuesto General a las Ventas (IGV equivale 18\%)

8. Otro punto importante es el registro de marca y logo diseñado para la empresa Instituto Nacional de Defensa de la Competencia y de la Protección de la Propiedad Intelectual (INDECOPI) antes de iniciar el negocio. El nombre de la marca será "LadriPlastAQP”.

\subsection{Determinación de la localización óptima}

Para encontrar la mejor alternativa se empleó el Método de los Factores Ponderados, de acuerdo a lo planteado por Krajewski (2013).

\subsubsection{Estratificación de los factores.}

Tabla 30

Factores de Micro localización

\begin{tabular}{lc}
\hline Estratificación del Factor de Terreno & \\
\hline Atributo & Puntaje \\
\hline Alta disponibilidad de terrenos & 15 \\
Regular disponibilidad de terreno & 10 \\
No se dispone de terreno & 5 \\
\hline
\end{tabular}

Estratificación de Factor de Construcción

\begin{tabular}{lc}
\hline Atributo & Puntaje \\
\hline Bajos costos de construcción & 15 \\
Regular costo de construcción & 10 \\
Altos costos de construcción & 5 \\
\hline
\end{tabular}


Estratificación del Factor de Cercanía a Materia Prima

\begin{tabular}{lc}
\hline \multicolumn{1}{c}{ Atributo } & Puntaje \\
\hline $\begin{array}{l}\text { Cerca de la fuente de materia } \\
\text { prima }\end{array}$ & 15 \\
$\begin{array}{l}\text { No tan cerca a la fuente de } \\
\text { materia prima }\end{array}$ & 10 \\
$\begin{array}{l}\text { Lejos de la fuente de materia } \\
\text { prima }\end{array}$ & 5 \\
\hline
\end{tabular}

Estratificación del Factor de Energía Eléctrica

\begin{tabular}{lc}
\hline \multicolumn{1}{c}{ Atributo } & Puntaje \\
\hline Buena disponibilidad de energía & 15 \\
Regular disponibilidad de energía & 10 \\
Mala disponibilidad de energía & 5 \\
\hline \multicolumn{1}{c}{ Atributo } & \\
Estratificación del Factor de Agua & Puntaje \\
\hline \multicolumn{1}{c}{$\begin{array}{l}\text { Buena disposición de agua y } \\
\text { bajos costos }\end{array}$} & 15 \\
$\begin{array}{l}\text { Regular disposición de agua y } \\
\text { costos }\end{array}$ & 10 \\
$\begin{array}{l}\text { Mala disposición de agua y altos } \\
\text { costos }\end{array}$ & 5 \\
\hline
\end{tabular}

Estratificación del Factor Mano de Obra

\begin{tabular}{lc}
\hline \multicolumn{1}{c}{ Atributo } & Puntaje \\
\hline Alta oferta y bajos costos & 15 \\
Regular oferta y costos regulares & 10 \\
Poco oferta y altos costos & 5 \\
\hline
\end{tabular}

Estratificación del Factor de cercanía a vías de expansión

\begin{tabular}{lc}
\hline \multicolumn{1}{c}{ Atributo } & Puntaje \\
\hline Cerca de las vías de exportación & 15 \\
Regularmente lejos a las vías de & 10 \\
exportación & 5 \\
Lejos a las vías de exportación & Nota: Adaptado del estudio de ingeniería del proyecto
\end{tabular}


En la Tabla 30, de acuerdo al método de factores ponderados se establecen los puntajes de microlocalización afectos, del factor terreno, construcción, cercanía de materias primas, factor energía eléctrica, agua, mano de obra y cercanía a vías de expansión.

Estos factores serán determinantes para la elección de la alternativa más óptima de ubicación del proyecto.

Como se puede observar en la Tabla 31, la alternativa que obtuvo el mayor puntaje en la evaluación fue el Distrito de Cerro Colorado con 1200 puntos, muy de cerca de los distritos de Yarabamba y Characato con 1150 puntos cada uno, por lo que se concluye que esta es la localización óptima para nuestro proyecto es el Distrito de Cerro Colorado. 
Tabla 31

Evaluación de Factores de Micro localización

\begin{tabular}{|c|c|c|c|c|c|c|c|}
\hline \multirow{2}{*}{ Factores de locación } & \multirow{2}{*}{ Ponderación } & \multicolumn{3}{|c|}{ Estratificación } & \multicolumn{3}{|c|}{ Evaluación } \\
\hline & & Cerro Colorado & Yarabamba & Characato & Cerro Colorado & Yarabamba & Characato \\
\hline Terrenos & 10 & 15 & 10 & 10 & 150 & 100 & 100 \\
\hline Construcciones & 10 & 10 & 10 & 10 & 100 & 100 & 100 \\
\hline Materia Prima & 30 & 10 & 15 & 15 & 300 & 450 & 450 \\
\hline Energía & 10 & 15 & 10 & 10 & 150 & 100 & 100 \\
\hline Agua & 10 & 10 & 10 & 10 & 100 & 100 & 100 \\
\hline Mano de obra & 10 & 10 & 10 & 10 & 100 & 100 & 100 \\
\hline C. vías de Exportación & 20 & 15 & 10 & 10 & 300 & 200 & 200 \\
\hline Total & 100 & & & & 1200 & 1150 & 1150 \\
\hline
\end{tabular}

Nota. Adaptado del estudio de ingeniería del proyecto. 


\section{Capítulo VI: Aspectos Organizacionales}

\subsection{Caracterización de la cultura organizacional deseada}

\subsubsection{Visión}

Thompson, Peteraf, Gamble y Strickland (2012) definen el concepto de visión estratégica, como la ruta trazada por la organización en el largo plazo, teniendo como premisas el "lugar a donde vamos" y las razones por las que sería beneficioso para el negocio, todo esto avalado por las opiniones y aspiraciones de los altos directivos.

Señalan los autores, que la comunicación de esta visión dentro de la organización debe ser tan convincente para los niveles jerárquicos inferiores, de tal manera que se sientan comprometidos y no ofrezcan resistencia al cambio.

Las características que se deben cumplir al elaborar una visión son: (a) breve y concisa, no mayor a dos párrafos, (b) fácil de explicar y (c) fácil de recordar.

Los beneficios que se obtienen al redactar una clara declaración de visión son:

1. Puntos de vista bien definidos de los directivos, con respecto al rumbo en el largo plazo de la organización.

2. Toma de decisiones acertadas

3. Es una herramienta de soporte para todos los miembros de la organización ante cambios futuros.

4. Se usa como referencia por jefaturas inferiores, para diseñar objetivos y estrategias específicas las cuales deben estar alineadas con los objetivos y estrategias globales

5. La organización está mejor preparada de cara al futuro.

Se define la visión para el proyecto:

Ser la opción número uno en comercialización de bloquetas plásticas a nivel regional, logrando establecer un nuevo sistema de construcción, que promueva la protección del medio ambiente. 


\subsubsection{Misión}

Thompson et al. (2012) sostienen que una declaración de misión se redacta en tiempo presente, de forma breve y concisa.

La misión debe ser bastante descriptiva, para que de esta forma se fácil identificar el producto y servicios de la empresa, el segmento de mercado que busca atender, las necesidades del consumidor y el brand marketing que desarrollará.

En síntesis, la declaración de misión de una empresa responde a las siguientes interrogantes ¿Quiénes somos, qué hacemos? ¿Por qué estamos aquí?, lo cual define el propósito y el negocio de la empresa.

Se define la misión para el proyecto:

Brindar al cliente de la provincia de Arequipa una bloqueta plástica con el más alto estándar de calidad para la construcción de su vivienda; basados en un trato justo, integridad, conducta ética, sentido innovador, trabajo en equipo, calidad suprema, servicio superior al cliente, responsabilidad social; ofrecer precios razonables, tecnología de punta, capacitación en métodos de construcción; generar una relación de confianza perdurable en el tiempo con los clientes.

\subsubsection{Principios}

Según Thompson et al. (2012) la declaración de principios son creencias y normas conductuales que están orientadas al cumplimiento de la visión y misión de la empresa, ya que así lo establece la administración.

Señalan los autores, que los directores ejecutivos que asumen el compromiso de integrar los principios a la cultura organizacional de su empresa, conectan con mayor facilidad en la búsqueda de la visión y misión

Las empresas suelen identificar de cuatro a 8 valores esenciales y estos están relacionados con las siguientes características: 
1. Trato justo

2. Integridad

3. Conducta ética

4. Sentido Innovador

5. Trabajo en equipo

6. Calidad suprema

7. Servicio Superior al cliente

8. Responsabilidad social

9. Ciudadanía comunitaria

Se establecen los siguientes principios organizacionales para el proyecto de negocio:

1. Comprometerse con el cliente

Con la finalidad de brindar lo que el cliente necesita, ponemos a su disposición un innovador material de construcción como son los ladrillos de plástico, los cuales poseen una alta calidad.

2. Comprometerse con las personas

Contribuir con el cliente interno y toda la sociedad el desenvolvimiento de sus capacidades logrando que sean potencializadas logrando así un ambiente de solidaridad e integración.

3. Comprometerse con el ambiente

Priorizando el cuidado del medio ambiente se busca el compromiso no solo de la empresa sino de la sociedad a través de la preservación del ecosistema.

4. Compromiso empresarial 
Es de suma importancia para nuestra organización ganarse el respeto de la gente, clientes e inversionistas todos los días, en todo lo que se hace.

\subsection{Formulación de Estrategias del Negocio}

Thompson et al. (2012) señala que la formulación y también de la ejecución para el desarrollo de una estrategia es una prioridad máxima en la administración. Una estrategia bien definida, establece una ventaja competitiva, tiene clientes contentos y mejora las finanzas de la organización. En gran medida el rumbo correcto de la organización está definido por dos puntos clave una buena estrategia y una buena ejecución, los cuales son los signos más fiables de una buena administración.

A su vez describe cinco estrategias competitivas frecuentes, la diferencia entre ellas es que tratan de obtener una posición de mercado diferente. Estas son:

1. Estrategia de costos bajos: el enfoque es conseguir una gran cantidad de cliente, teniendo como premisa base manejando bajos costos con respecto a los rivales.

2. Estrategia de diferenciación amplia: consiste en atraer la mayor cantidad posible de compradores, diferenciando al producto a ofrecer con atributos atractivos para el consumidor.

3. Estrategia dirigida de bajo costo: se determina la mejor competencia frente a los rivales ofreciendo productos de bajo costo y se enfoca en obtener un pequeño segmento de consumidores.

4. Estrategia dirigida de diferenciación: se enfoca en conseguir un segmento específico de compradores, y la ventaja frente a los rivales es ofrecer un producto que satisfaga gustos y necesidades específicas del segmento escogido.

5. Estrategia de mejores costos del proveedor: esta estrategia trata de brindar mayor valor por el monto que está adquiriendo el bien o el servicio esto se puede dar a 
través del incremento de atributos o características adicionales al producto que no generen costos elevados en comparación de la competencia.

La estrategia a emplear en el plan de negocios es por diferenciación y estará sostenida por los siguientes lineamientos:

a) Alto nivel de servicio al cliente reflejado en: venta personal, capacitaciones y asesoría, cumplimiento de tiempos de entrega.

b) Fuerte inversión en adquisición de materia prima, planta de operaciones, maquinarias, promoción y publicidad para conseguir el posicionamiento deseado en el mercado.

c) Generar alianzas con las instituciones que fomenten innovaciones constructivas y construcciones verdes.

\subsection{Determinación de las ventajas competitivas críticas}

Según Thompson et al. (2012), la ventaja competitiva es generada por la capacidad para lograr satisfacer las necesidades de los consumidores, siempre que sea de manera más eficaz.

Se deben considerar cuatro planteamientos estratégicos para ganar una ventaja competitiva sustentable:

1. Tener los costos más bajos del sector, para así lograr una ventaja competitiva de basada en costos.

2. Lograr estar por arriba de la competencia brindando atributos relacionados a la calidad.

3. Concentrar las estrategias a un nicho de mercado logrando satisfacer las necesidades con más exactitud.

4. Tener menor costo con las mismas características del bien en comparación con la competencia. Tal como se menciona en el capítulo de ingeniería, al disminuir 
elementos como cemento y arena, reemplazados por plástico, se obtienen bajos costos de fabricación.

Las ventajas competitivas que se contemplan en el proyecto, sobre el producto a ofrecer son las siguientes:

1. Producto Ecológico

2. Nuevo sistema constructivo Sismo resistentes nivel S3 y S4 en ladrillos

3. Brinda mayor protección térmica

4. Brinda mayor protección acústica

5. Genera menor riesgo sanitario para el obrero

6. Capacitación pre y post compra

\subsection{Diseño de la estructura organizacional deseada}

Louffat (2010) señala que el diseño organizacional está representado en la estructura orgánica y que está constituida por unidades orgánicas (y dentro de cada unidad orgánica hay personas que ocupan cargos y/o puestos de trabajo), se constituye en el punto de partida para la administración de potencial humano.

Define el diseño organizacional como el proceso técnico especializado de la administración del potencial humano encargado de definir, estructurar, ordenar y distribuir las diversas unidades orgánicas que constituyen una organización, así como el personal que ocupará los diversos cargos o puestos que forman dicha estructura orgánica.

El autor sustenta las bases del diseño organizacional en tres modelos: Modelo Organizacional, Organigrama y Manuales organizacionales. 


\section{Modelo Organizacional}

El modelo organizacional, representa las estrategias principales adoptadas como antecedencia en el planeamiento empresarial y posibilitar que estas se ejecuten posteriormente.

a) El modelo funcional

b) El modelo geográfico

c) El modelo por clientes

d) El modelo por productos

e) El modelo por turnos

f) El modelo por proceso productivo

g) El modelo por cantidad de subordinados

h) El modelo por división

i) $\mathrm{El}$ modelo por proyectos

j) El modelo matricial

k) El modelo por redes

\section{Organigramas}

Louffat (2010) menciona que un elemento necesario para el diseño organizacional, también son conocidos como orgonograma, o gráfico organizacional, el cual es la representación gráfica del modelo organizacional adoptado. Se considera una fotografía de la institución, ya que muestra cómo se distribuyen las diversas unidades orgánicas que la constituyen y las relaciones entre ellas. 
Las unidades orgánicas están representadas dentro del organigrama de la organización y por lo general suele ser:

a) Unidades de dirección: se ubican en la cúspide jerárquica, donde se ejerce el poder y se toman las decisiones principales. Se ubican en la parte superior del organigrama

b) Unidades de control: son las encargadas de verificas el cumplimiento eficaz del desempeño de las otras unidades. Se ubican en la parte lateral izquierda del organigrama y arriba de las unidades de apoyo.

c) Unidades consultivas: está constituida por expertos en el área y sector donde se desempeña la empresa. Se ubican en la parte lateral derecha del organigrama y arriba de las unidades de asesoría.

d) Unidades de apoyo: son las que administran los recursos humanos, materiales y financieros, garantizan el desarrollo de las funciones y operaciones de diversas unidades orgánicas de la institución. Se ubican en la parte lateral izquierda del organigrama.

e) Unidades asesoras: son las encargadas de brindar sugerencias, opiniones y consejos a las unidades de línea sobre diversos temas, pero no tienen potestad para ejecutar acciones administrativas. Se ubican en la parte lateral derecha del organigrama.

f) Unidades de línea: son las que ejecutan las operaciones propias de la empresa, aquellas que le dan la razón de ser y hacen que funciones de acuerdo con la misión y objetivos estratégicos en sus diferentes niveles jerárquicos. Se ubican en el parte central medular del organigrama.

De acuerdo a lo mencionado por Enrique Louffat (2010), la estructura organizacional propuesta sería bajo el modelo funcional como se muestra en la figura 38. 


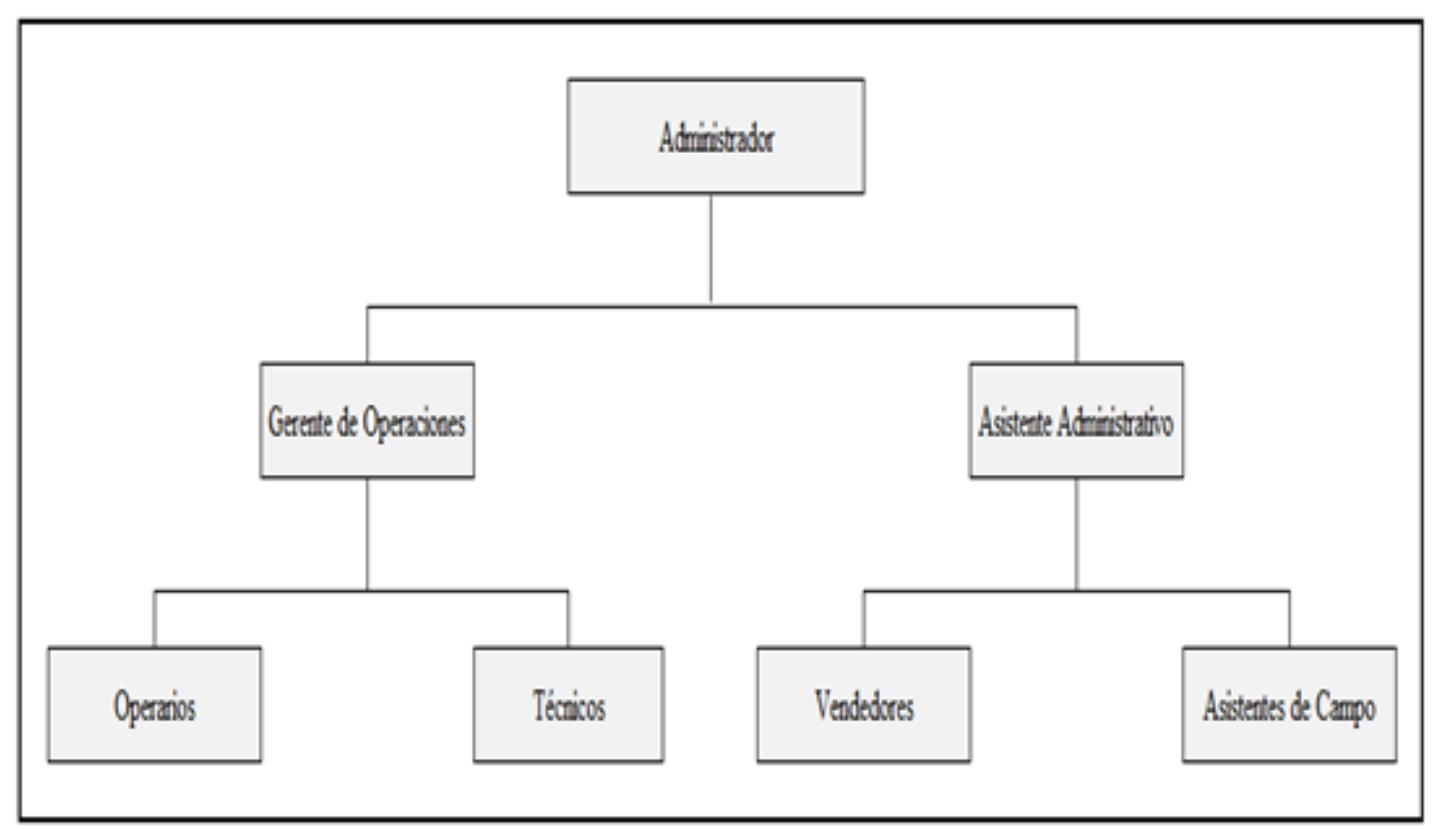

Figura 38. Organigrama de empresa.

\section{Manuales}

Louffat (2010) establece este elemento como necesario para redondear integralmente el concepto de diseño organizacional, y menciona dos tipos de manuales específicamente: el Manual de organización y funciones y el Manual de Puestos, los cuales se elaboran por separado y en algunos casos se tratan de integrar. Se precisa que el contenido de ambos es diferente.

El manual de organizaciones y funciones, sirve para contextualizar las atribuciones de cada unidad orgánica que forme parte de un organigrama. Básicamente consigna la siguiente información:
a) Nombre de la unidad orgánica
b) Finalidad de la unidad orgánica
c) Funciones ponderadas de la unidad orgánica
d) Cuadro de personal asignado a la unidad orgánica 
El manual de puestos, se refiere a las descripciones y especificaciones técnicas en los diversos puestos que serán ocupados por los diversos funcionarios que pertenecen a dicha unidad orgánica. Este manual consigna la siguiente información:
a) Nombre de la unidad a la que pertenece este puesto
b) Nombre del puesto que está adscrito a la unidad orgánica.
c) Finalidad del puesto
d) Funciones ponderadas del puesto
e) Relación de mando
f) Relación de subordinación
g) Relación de coordinación
h) Requisitos de competencias

\subsection{Diseño de los perfiles de puestos clave}

Louffat (2010) define lo siguiente, el diseño de puestos es el proceso por el cual se determina el perfil de cada uno de los puestos o cargos que se establecen en las diversas unidades orgánicas que constituyen un organigrama"

El análisis del puesto, se entiende como el proceso metodológico que permite recopilar información primaria o secundaria, sobre las características que deben considerarse en cada puesto. Las técnicas para recopilación de información son técnicas universales como la revisión de documentos, observación, cuestionarios y/o entrevistas.

La descripción de puestos, es el componente que describe las características del puesto en sí y responde a las siguientes preguntas en general:

i) ¿Qué hace? : Identifica las tareas o actividades a realizar 
j) ¿Cómo lo hace?: Se refiere a la prioridad de cada actividad o tarea a realizar de acuerdo al puesto.

k) ¿Cómo lo hace?: Son las responsabilidades que se le asignan a las funciones de cada puesto, en cuanto a recursos financieros, materiales y de personal.

1) ¿Dónde lo hace?: Describe el ambiente de trabajo en cuanto a condiciones de seguridad, en detalle tales como luz, ventilaciones, decoraciones, etc.

m) ¿Por qué lo hace?: Define la finalidad del puesto y que objetivos o metas se pretende lograr.

La especificación de puestos, describe las características que debe tener el ocupante del puesto, es decir el perfil en cuanto a requisitos de competencias, dimensiones de conocimientos, habilidades y de actitudes necesarias para el puesto.

La evaluación de puestos, componente utilizado como insumo en el proceso de técnicas de remuneraciones y compensaciones. Consiste en realizar un ranking basado en el valor que tiene cada puesto según criterios previamente establecidos para luego categorizarlos y dar sustento a las estructuras salariales basadas en los principios de equidad interna.

Tarcica \& Gonzales (2010) desarrollan un manual con 120 descripciones de puestos, para el caso del proyecto de investigación solo, se consideran los siguientes puestos: 
Tabla 32

Administrador

\begin{tabular}{|c|c|}
\hline $\begin{array}{l}\text { Jefe Directo: } \\
\text { Supervisión a Ejercer: } \\
\text { Formación Académica: }\end{array}$ & $\begin{array}{l}\text { Todo el personal de la sucursal o departamento } \\
\text { Bachillerato en Administración de Empresas }\end{array}$ \\
\hline $\begin{array}{l}\text { Años de Experiencia: } \\
\text { Idiomas: }\end{array}$ & $\begin{array}{l}\text { 2-4 años } \\
\text { Inglés: Básico }\end{array}$ \\
\hline $\begin{array}{l}\text { Conocimientos o Competencias } \\
\text { obligatorias: }\end{array}$ & $\begin{array}{l}\text { Mantener la dirección de la sucursal o } \\
\text { departamento en todas las áreas. Mantener el flujo } \\
\text { de información a las jefaturas y a sus subalternos. } \\
\text { Conocimiento indispensable en el área de manejo } \\
\text { de personal, contabilidad y estrategias de } \\
\text { mercado. Debe manejar herramientas tecnológicas } \\
\text { como el paquete Office e Internet. Debe tener } \\
\text { liderazgo, ser analitico y abierto a escuchar. Debe } \\
\text { ser una persona con alto grado de responsabilidad } \\
\text { y enfocada a resultados. De igual forma, debe ser } \\
\text { una persona que sepa resolver problemas. }\end{array}$ \\
\hline Habilidades deseables: & $\begin{array}{l}\text { Deseable conocimiento de la legislación laboral y } \\
\text { conocimiento de técnicas de clima organizacional } \\
\text { y de entrenamiento. }\end{array}$ \\
\hline $\begin{array}{l}\text { Funciones Principales del puesto } \\
\text { (responsabilidades primordiales del } \\
\text { puesto): }\end{array}$ & $\begin{array}{l}\text { 1) Realizar los reportes de asistencia del personal } \\
\text { a cargo. Realizar los cambios necesarios para } \\
\text { cubrir al personal libre, en caso de ser necesario. } \\
\text { 2) Realizar el análisis de los resultados diarios, } \\
\text { semanales y mensuales de la sucursal. } \\
\text { 3) Controlar los costos y los egresos de la } \\
\text { sucursal, realizando los informes } \\
\text { correspondientes. } \\
\text { 4) Llevar el control y el manejo de la Caja Chica. } \\
\text { 5) Realizar reuniones informativas y } \\
\text { motivacionales con su personal a cargo. } \\
\text { 6) Elaborar los análisis de la producción y crear } \\
\text { los reportes de resultados para su jefe directo. } \\
\text { 7) Supervisar y reentrenar a su personal a cargo de } \\
\text { forma periódica para velar por el buen } \\
\text { funcionamiento de la sucursal. } \\
\text { 8) Realizar el control de inventarios de materia } \\
\text { prima y de suministros de la sucursal. } \\
\text { 9) Realizar el pago a proveedores y llevar el } \\
\text { control de la entrada de productos o suministros al } \\
\text { inventario. } \\
\text { 10) Elaborar los reportes de cierres diarios de la } \\
\text { operación. } \\
\text { Cubrir los diferentes puestos de la sucursal ante } \\
\text { una posible ausencia. }\end{array}$ \\
\hline
\end{tabular}

Nota. Tomado de "120 descripciones de puestos" Tarcica \&Gonzales (2010) pag.01 
Tabla 33

Gerente De Operaciones

\begin{tabular}{|c|c|}
\hline $\begin{array}{l}\text { Jefe directo } \\
\text { Supervisión a ejercer }\end{array}$ & $\begin{array}{l}\text { Administrador } \\
\text { Asistentes y Supervisores de Operaciones }\end{array}$ \\
\hline $\begin{array}{l}\text { Formación académica } \\
\text { Años de experiencia }\end{array}$ & $\begin{array}{l}\text { Licenciatura en Ingenieria Industrial o carrera afin. } \\
10-15 \text { años }\end{array}$ \\
\hline Idiomas: & Inglés: Avanzado \\
\hline Objetivos del puesto & $\begin{array}{l}\text { Velar porque las operaciones de la empresa se } \\
\text { produzcan de forma efectiva y cumpliendo con los } \\
\text { estándares de calidad y con lo previamente estipulado } \\
\text { por la Gerencia General. }\end{array}$ \\
\hline $\begin{array}{l}\text { Conocimientos o competencias } \\
\text { obligatorias: }\end{array}$ & $\begin{array}{l}\text { Indispensable experiencia en el manejo de personal } \\
\text { operativo. Debe tener facilidad de palabra y de } \\
\text { entendimiento. Debe manera normativas de } \\
\text { seguridad y de desempeño de producción. Debe ser } \\
\text { ordenado, organizado, proactivo, dinámico y } \\
\text { enfocado a resultados. }\end{array}$ \\
\hline Habilidades deseables: & $\begin{array}{l}\text { Deseable carrera adicional en administración de } \\
\text { empresas. Además, el conocimiento en maquinaria } \\
\text { de producción. }\end{array}$ \\
\hline $\begin{array}{l}\text { Funciones principales del } \\
\text { puesto (responsabilidades } \\
\text { primordiales del puesto): }\end{array}$ & $\begin{array}{l}\text { 1) Revisar y aprobar los planes de producción y su } \\
\text { respectiva planificación. } \\
\text { 2) Verificar el correcto almacenamiento de los } \\
\text { productos producidos o ingresados a las bodegas de } \\
\text { la empresa. } \\
\text { 3) Desarrollar planes estratégicos de producción para } \\
\text { la solución de incidentes. } \\
\text { 4) Supervisar el seguimiento de los controles de } \\
\text { mantenimientos preventivos de los equipos de } \\
\text { producción. } \\
\text { 5) Realizar y controlar los presupuestos de } \\
\text { maquinaria y personal del departamento. } \\
\text { 6) Coordinar y verificar el cumplimiento de los } \\
\text { planes de seguridad establecidos. } \\
\text { 7) Realizar y coordinar simulacros de emergencias. } \\
\text { 8) Supervisar y controlar la operación diaria velando } \\
\text { por el cumplimiento de los controles de calidad. } \\
\text { 9) Verificar la calidad de los ingresos de la materia } \\
\text { prima. } \\
\text { 10) Elaborar los reportes de resultados mensuales de } \\
\text { actividad, quejas e incidentes. }\end{array}$ \\
\hline $\begin{array}{l}\text { Funciones adicionales del } \\
\text { puesto }\end{array}$ & $\begin{array}{l}\text { Participar en capacitaciones o talleres de } \\
\text { entrenamiento. Asistir a reuniones con } \\
\text { Administrador. }\end{array}$ \\
\hline
\end{tabular}

Nota. Tomado de "120 descripciones de puestos" Tarcica \&Gonzales (2010) pag.56 
Tabla 34

Operario De Producción

\begin{tabular}{|c|c|}
\hline $\begin{array}{l}\text { Jefe directo: } \\
\text { Supervisión a ejercer: }\end{array}$ & $\begin{array}{l}\text { Gerente de Operaciones } \\
\text { No cuenta con personal a su cargo }\end{array}$ \\
\hline $\begin{array}{l}\text { Formación académica: } \\
\text { Años de experiencia: }\end{array}$ & $\begin{array}{l}\text { Primaria concluida } \\
0-1 \text { años }\end{array}$ \\
\hline $\begin{array}{l}\text { Idiomas: } \\
\text { Objetivos del puesto: }\end{array}$ & $\begin{array}{l}\text { N/A } \\
\text { Mantener el buen funcionamiento de la linea de } \\
\text { producción diaria de la empresa para evitar los } \\
\text { desperdicios y los errores de planta. }\end{array}$ \\
\hline $\begin{array}{l}\text { Conocimientos o competencias } \\
\text { obligatorias: }\end{array}$ & $\begin{array}{l}\text { Indispensable que sepa manejar maquinaria de } \\
\text { producción y que conozca términos técnicos de la } \\
\text { maquinaria. Debe ser ordenado y enfocado a } \\
\text { resultados y a seguir procedimientos de producción. }\end{array}$ \\
\hline Habilidades deseables: & $\begin{array}{l}\text { Deseable que tenga mayor escolaridad y que cuente } \\
\text { con experiencia laboral en cadenas de producción. }\end{array}$ \\
\hline $\begin{array}{l}\text { Funciones principales del } \\
\text { puesto (responsabilidades } \\
\text { primordiales del puesto): }\end{array}$ & $\begin{array}{l}\text { 1) Realizar las asignaciones otorgadas dentro de la } \\
\text { cadena de producción. } \\
\text { 2) Asistir a los compañeros en el ciclo de producción. } \\
\text { 3) Elaborar los reportes de fallas de la maquinaria o } \\
\text { de los productos hechos durante el turno de trabajo. } \\
\text { 4) Revisar la calidad de los productos que esté } \\
\text { elaborando la cadena de producción y detectar los } \\
\text { errores antes de finalizar el producto. } \\
\text { 5) Revisar diariamente que el equipo y materiales } \\
\text { que utiliza se encuentren en buen estado. Reportar } \\
\text { cualquier defecto o problema inmediatamente. } \\
\text { 6) Encargarse de los desechos de materiales } \\
\text { utilizados durante el turno depositándolos donde } \\
\text { corresponda. } \\
\text { 7) Controlar y revisar las medidas de seguridad de la } \\
\text { planta periódicamente y reportar cualquier problema } \\
\text { inmediatamente. }\end{array}$ \\
\hline $\begin{array}{l}\text { Funciones adicionales del } \\
\text { puesto: }\end{array}$ & $\begin{array}{l}\text { Participar en reuniones informativas o capacitaciones } \\
\text { de la empresa cuando se le requiera. Velar por el uso } \\
\text { correcto de los implementos de protección de cada } \\
\text { colaborador. }\end{array}$ \\
\hline
\end{tabular}

Nota. Tomado de “120 descripciones de puestos” Tarcica \&Gonzales (2010) pag.90 
Tabla 35

Técnicos

\begin{tabular}{|ll|}
\hline Jefe directo: & Gerente de Operaciones \\
Supervisión a ejercer: & No cuenta con personal a su cargo \\
\hline Formación académica: & Primaria concluida \\
Arios de experiencia: & 0-1 arios \\
Idiomas: & N/A \\
Objetivos del puesto: & Mantener el buen funcionamiento de la linea de \\
producción diaria de la empresa para evitar los \\
desperdicios y los errores de planta.
\end{tabular}

Nota. Tomado de “120 descripciones de puestos” Tarcica \&Gonzales (2010) pag.110 
Tabla 36

Asistentes Administrativos

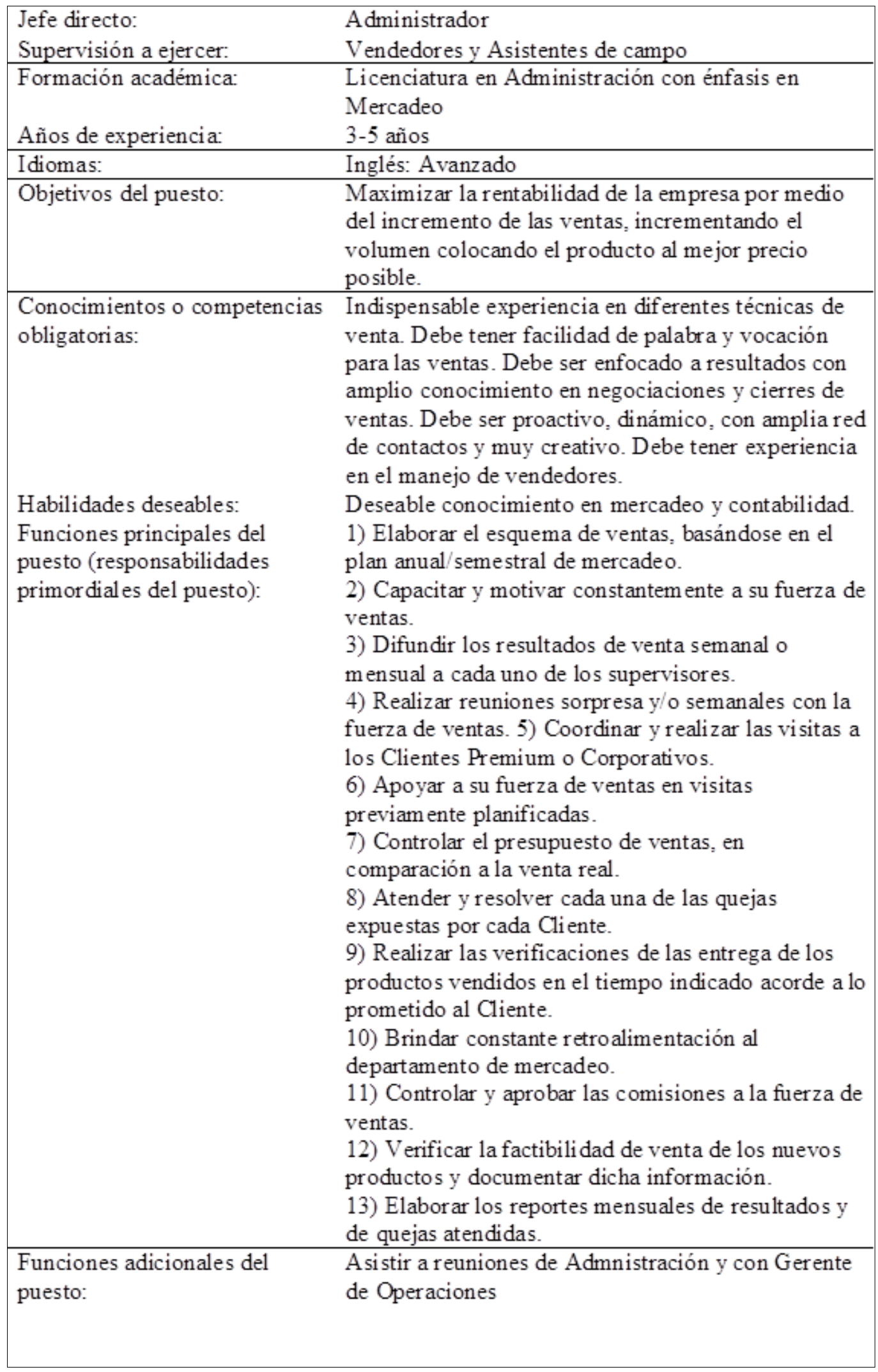

Nota. Tomado de “120 descripciones de puestos" Tarcica \&Gonzales (2010) pag.09. 
Tabla 37

Vendedores

\begin{tabular}{|c|c|}
\hline $\begin{array}{l}\text { Jefe directo: } \\
\text { Supervisión a ejercer: }\end{array}$ & $\begin{array}{l}\text { A si stente administrativo } \\
\text { Sin personal a cargo }\end{array}$ \\
\hline Formación académica: & Secundaria completa o estudios técnicos incompletos \\
\hline Años de experiencia: & $3-5$ años \\
\hline Idiomas: & \\
\hline Objetivos del puesto: & $\begin{array}{l}\text { Maximizar la rentabilidad de la empresa por medio } \\
\text { del incremento de las ventas, incrementando el } \\
\text { volumen colocando el producto al mejor precio } \\
\text { posible. }\end{array}$ \\
\hline $\begin{array}{l}\text { Conocimientos o competencias } \\
\text { obligatorias: }\end{array}$ & $\begin{array}{l}\text { Indispensable experiencia en diferentes técnicas de } \\
\text { venta. Debe tener facilidad de palabra y vocación } \\
\text { para las ventas. Debe ser enfocado a resultados con } \\
\text { amplio conocimiento en negociaciones y cierres de } \\
\text { ventas. Debe ser proactivo, dinámico, con amplia red } \\
\text { de contactos y muy creativo. Debe tener experiencia } \\
\text { en el manejo de vendedores. }\end{array}$ \\
\hline Habilidades deseables: & Deseable conocimiento en mercadeo y contabilidad. \\
\hline $\begin{array}{l}\text { Funciones principales del } \\
\text { puesto (responsabilidades } \\
\text { primordial es del puesto): }\end{array}$ & $\begin{array}{l}\text { 1) Elaborar el esquema de ventas, basándose en el } \\
\text { plan anual/semestral de mercadeo. } \\
\text { 2) Capacitar y motivar constantem ente a su fuerza de } \\
\text { ventas. } \\
\text { 3) Difundir los resultados de venta semanal o } \\
\text { mensual a cada uno de los supervisores. } \\
\text { 4) Realizar reuniones sorpresa y/o semanales con la } \\
\text { fuerza de ventas. 5) Coordinar y realizar las visitas a } \\
\text { los Clientes Premium o Corporativos. } \\
\text { 6) Apoyar a su fuerza de ventas en visitas } \\
\text { previamente planificadas. } \\
\text { 7) Controlar el presupuesto de ventas, en } \\
\text { comparación a la venta real. } \\
\text { 8) Atender y resolver cada una de las quejas } \\
\text { expuestas por cada Cliente. } \\
\text { 9) Realizar las verificaciones de las entrega de los } \\
\text { productos vendidos en el tiempo indicado acorde a lo } \\
\text { prometido al Cliente. } \\
\text { 10) Brindar constante retroalimentación al } \\
\text { departamento de mercadeo. } \\
\text { 11) Controlar y aprobar las comisiones a la fuerza de } \\
\text { ventas. } \\
\text { 12) Verificar la factibilidad de venta de los nuevos } \\
\text { productos y documentar dicha información. } \\
\text { 13) Elaborar los reportes mensuales de resultados y } \\
\text { de quejas atendidas. }\end{array}$ \\
\hline $\begin{array}{l}\text { Funciones adicionales del } \\
\text { puesto: }\end{array}$ & $\begin{array}{l}\text { Asistir a reuniones con administrador y asistente } \\
\text { administrativo }\end{array}$ \\
\hline
\end{tabular}

Nota. Tomado de "120 descripciones de puestos" Tarcica \&Gonzales (2010) pag114. 
Tabla 38

Asistentes de Campo

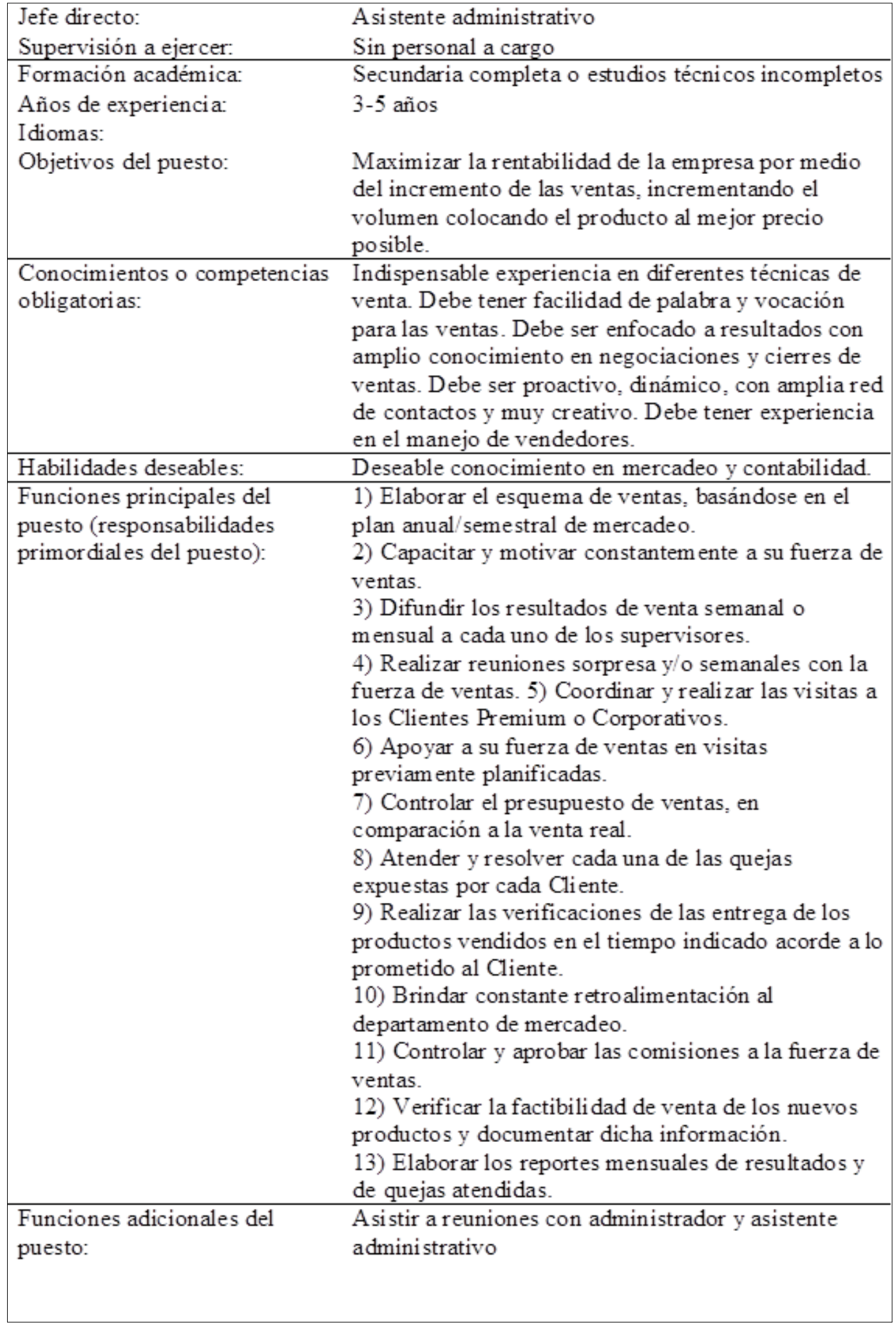

Nota. Tomado de “120 descripciones de puestos” Tarcica \&Gonzales (2010) pag.09 


\subsection{Remuneraciones, compensaciones e incentivos}

Chiavenato (2009) define las remuneraciones, como el pago adecuado por la dedicación, esfuerzo, conocimiento y habilidades invertidos en el tiempo trabajo de parte de cada colaborador. En algunas organizaciones esta representa el $60 \%$ de los costos totales de empresas de servicios o manufactureras.

El autor señala que la remuneración tiene tres componentes:

1. El sueldo básico: este puede ser mensual o por hora.

2. Incentivos salariales: programas diseñados para recompensar empleados con buen desempeño, bonos, participación en resultado, etc.

3. Beneficios: considerados también como las remuneraciones indirectas y contemplan varios programas (vacaciones, seguro de vida, seguro de salud, restaurantes, transporte, etc)

Según Chiavenato (2009) las compensaciones se pueden clasificar como financieras y no financieras pueden ser directas e indirectas.

La compensación financiera puede ser directa e indirecta.

La compensación financiera directa es el pago que cada empleado recibe como salario, bonos, premios y comisiones.

El salario puede ser directo o indirecto. El directo se percibe como contraprestación del servicio en el cargo ocupado; se puede referir al mes o a las horas trabajadas. Los empleados por meses reciben el valor de su salario mensual. El pago de salario por hora. Los empleados por meses reciben el valor de su salario mensual.

La compensación financiera indirecta es el salario indirecto derivado de cláusulas de la convención colectiva de trabajo y del plan de beneficios y servicios sociales ofrecidos por la organización. El salario indirecto incluye vacaciones, primas, propinas, adicionales, la suma del salario directo y del salario indirecto constituye la remuneración. La remuneración 
constituye todo lo que el empleado recibe como fruto del trabajo que realiza en una organización.

Para el proyecto se tiene establecida una estructura salarial definida de acuerdo al cargo que desempeñen, ver figura 39.

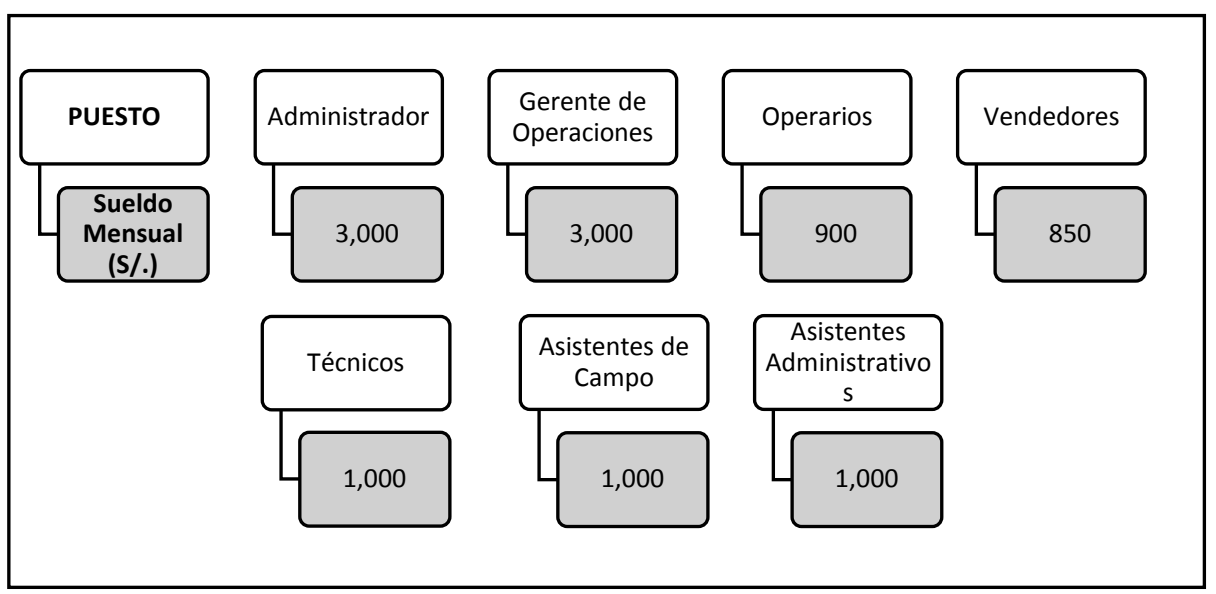

Figura 39. Sueldos asignados a trabajadores del proyecto. Tomado de Ingeniería del proyecto.

\subsection{Política de recursos humanos}

Para el recurso humano, se establecerán políticas para la gestión del mismo Las cuales estarán fraccionadas en tres, como se muestran a continuación:

1. Selección de personal

El objetivo de este proceso es tener el personal conforme a los puestos, para lo cual se tendrá que tomar en cuenta la siguiente guía:

a) Diseñar los puestos y la cantidad de personal por cada uno de ellos.

b) Determinar la técnica para la selección de personal.

c) Definir el proceso de convocatoria y el medio a través del cual se llevará a cabo.

d) Determinar el proceso para la evaluación del futuro colaborador de la empresa.

e) Elegir al personal que cumpla con el perfil del puesto. 
2. Plan de inducción y formación

Con el personal seleccionado, se inicia la etapa de inducción a través de la cual se le brindara las herramientas y conocimientos necesarios para que pueda desempeñarse en el puesto obtenido.

Mediante el plan el personal se encontrará con todo el conocimiento para poder compartir los valores, política de la empresa.

3. Plan de capacitación

La empresa desarrollará un plan de capacitación para potencializar las competencias de sus clientes internos y a su vez incrementar el valor de la empresa- A través del plan se contemplará los puestos que se tiene y sus requerimientos de cada uno de ellos.

Al elaborar el plan de capacitación se analizarán y desarrollarán los siguientes procesos:

a) Buscar la relación entre las necesidades de la empresa y del personal, aunque previamente se tendrá que ver la necesidad de cada uno de ellos.

b) Definir la necesidad de capacitación ya que puede ser interna o externa.

c) Ejecutar el plan de capacitación aprobado.

d) Evaluar y analizar los resultados del plan. 


\section{Capítulo VII: Plan De Marketing}

\subsection{Estrategias de marketing}

Kotler y Armstrong (2012) explican que la función del plan de marketing está enfocada en alcanzar los objetivos propuestos de la organización, haciendo uso de las herramientas del marketing, teniendo como foco de atención al cliente. Los objetivos y los argumentos desarrollados en un plan de marketing tienen una cobertura limitada.

De acuerdo a los autores para diseñar una estrategia impulsada por el cliente se siguen 4 pasos fundamentales: (a) Segmentación de mercado, (b) mercado meta, (c) la diferenciación y (d) el posicionamiento. (Kotler \& Armstrong, 2012).

El perfil de consumidor al que se dirige este producto son hombres y mujeres, que pertenecen a la población económicamente activa (PEA), cuya necesidad sea la construcción y/o ampliación de vivienda. El segmento se describe por geografía: Provincia de Arequipa, demográficamente por edad: entre 30 y 50 años que pertenecen al PEA. Al tener definido el mercado objetivo la estrategia de marketing será por diferenciación.

Los objetivos del plan son los siguientes:

a) Posicionar la marca de bloquetas plásticas LADRIPLAST AQP.

b) Lograr una cuota de mercado del $4.5 \%$ el primer año con un crecimiento anual del $5 \%$.

c) Durante el primer año se espera lograr un volumen de ventas de 3000 millares de bloquetas de plástico.

d) Para el tercer año se plantea la venta meta 3312 millares de bloquetas plásticas y alcanzar el punto de equilibrio en de dicho periodo. 


\subsubsection{Estrategia de Producto}

Kotler y Armstrong (2012) indican que la oferta de mercado general está centrada sobre el producto y las estrategias de marketing que se desarrollan sobre este; Las mismas que se enfocan en brindar una propuesta de valor al cliente, lo cual es el punto de partida de las relaciones redituables.

El producto sobre el que se desarrollará la oferta y las mezclas de marketing serán las bloquetas plásticas.

Los autores señalan que los encargados de la planeación de productos consideran tres niveles que brindan valor al cliente y estos son:

a) Nivel 1 o básico: ¿Qué adquiere realmente el consumidor?, considerado el valor fundamental para el cliente.

Para el caso del proyecto en desarrollo, el cliente busca satisfacer la necesidad de vivir en un mejor hábitat.

b) Nivel 2 o intermedio: El producto real; que es la materialización del beneficio del producto.

LadriplastAQP, la bloqueta plástica, son ladrillos ecológicos.

c) Nivel 3 o superior: El producto aumentado; teniendo ya un producto final, este debe contar con beneficios y servicios adicionales, que sean atractivos para el consumidor final. (Kotler \& Armstrong, 2012).

LadriplastAQP, es más que sólo material de construcción, es un producto que reúne características ecológicas, brinda gran resistencia y cumple con todos los estándares y especificaciones técnicas que exigen las normas peruanas con un servicio de post venta que brinda asesoría técnica. 
La estrategia de marketing de LadriplastAQP se enfoca en un posicionamiento de diferenciación de producto. La propuesta de valor estaría enfocada en ofrecer Más por lo mismo; un producto de calidad, pero a un precio más bajo. (Kotler \& Armstrong, 2012). Ver Figura 40.

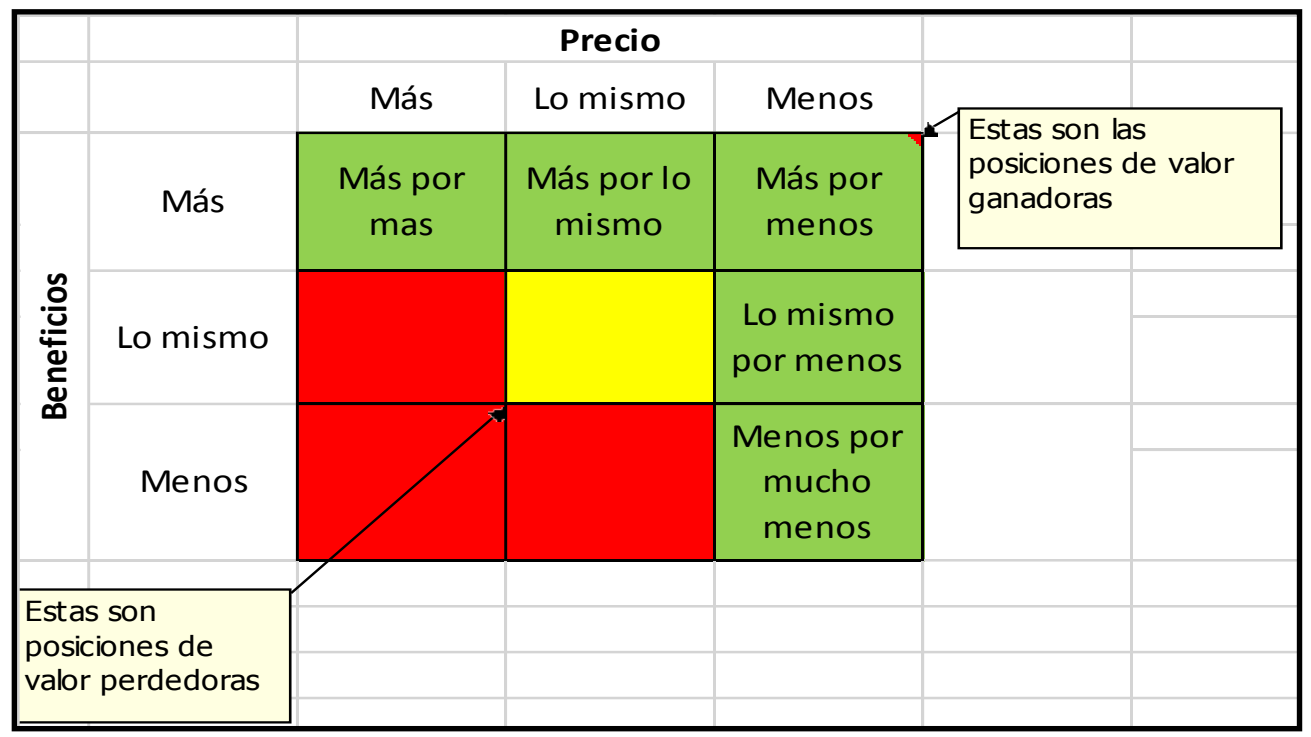

Figura 40. Propuestas de valor de empresa para posicionar producto. Tomado de "Marketing", por Kotler \& Armstrong, 2012

Se ofrece el producto de Bloqueta de plástico, con las siguientes características:

a) Descripción del producto:

1. Las bloquetas de plástico son ladrillos ecológicos en forma rectangular que cuentan con 10 cavidades ovaladas en las caras superior e inferior para permitir el mayor agarre al momento de su utilización. Utiliza el plástico reciclado como principal componente, lo cual hace de este producto un bien ecológico y amigable con el medio ambiente.

2. Livianos porque están compuestos por plástico que tiene un bajo peso específico

3. Excelente aislador térmico, superior a otros.

4. Similar resistencia a la de los ladrillos comunes.

5. Igual absorción del agua que los ladrillos comunes.

6. Fáciles de clavar y aserrar. 
7. Muy buena resistencia al fuego.

8. Tiene una resistencia acústica que supera al ladrillo común.

b) Usos del producto:

1. Construcción de viviendas

2. Edificios

3. Muros

4. Vías

5. Recubrimientos o cercos perimétricos, etc.

Se establece como nombre de la empresa: LadriplastAQP.

Al trabajar con un solo producto se pretende que la marca establezca una relación de largo plazo con el cliente. Se busca que este se familiarice con el producto, de tal manera que se logre un posicionamiento del mercado con gran visibilidad y notoriedad. El objetivo de esta estrategia es a largo plazo reducir los costos de publicidad

Se tiene como diseño de logotipo:

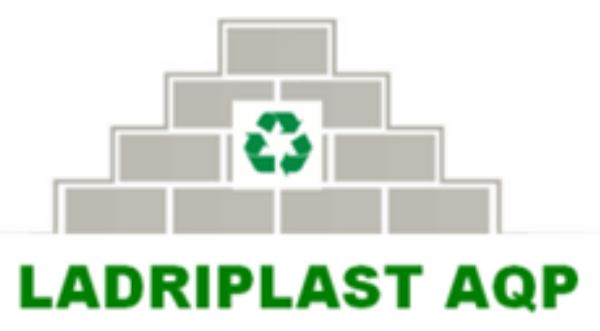

Isotipo: El modelo y color mostrado asemeja al color de la Bloqueta plástica, donde el diseño es el generador palpable de la innovación en el mercado de la construcción.

\subsubsection{Estrategia de Precio}

Kotler y Armstrong (2012) mencionan que la determinación del precio es una de las decisiones de la mezcla de marketing más importantes. Los factores limitantes son la demanda y los costos. Los factores de la demanda, como la fijación de precios basados en el 
valor, establecen el precio máximo; los costos de la compañía establecen el precio mínimo.

Entre estos dos factores, los mercadólogos deben considerar los precios de los competidores y otros elementos como los requisitos de los distribuidores, las leyes gubernamentales y los objetivos de la empresa.

La Bloqueta de Plástico, se lanzará con un precio de S/. 432.9 el millar (AnexoXIV). Este precio refleja una estrategia que sirve para atraer clientes y ganar participación de mercado en la Provincia de Arequipa.

Como las bloquetas plásticas son considerados como productos nuevos en el mercado y nuestra oferta será a empresas, consumidores finales, mediante una estrategia de marketing business to business (B2B), donde se aplicará la estrategia de precio de valor, basado en los atributos del producto, complementado con un estudio del mercado de la competencia, elasticidad del precio, incremento de precios en el transcurso del tiempo, servicio externo que afecta al precio, y productos complementarios. (Kotler \& Armstrong, 2012). Ver figura 41.

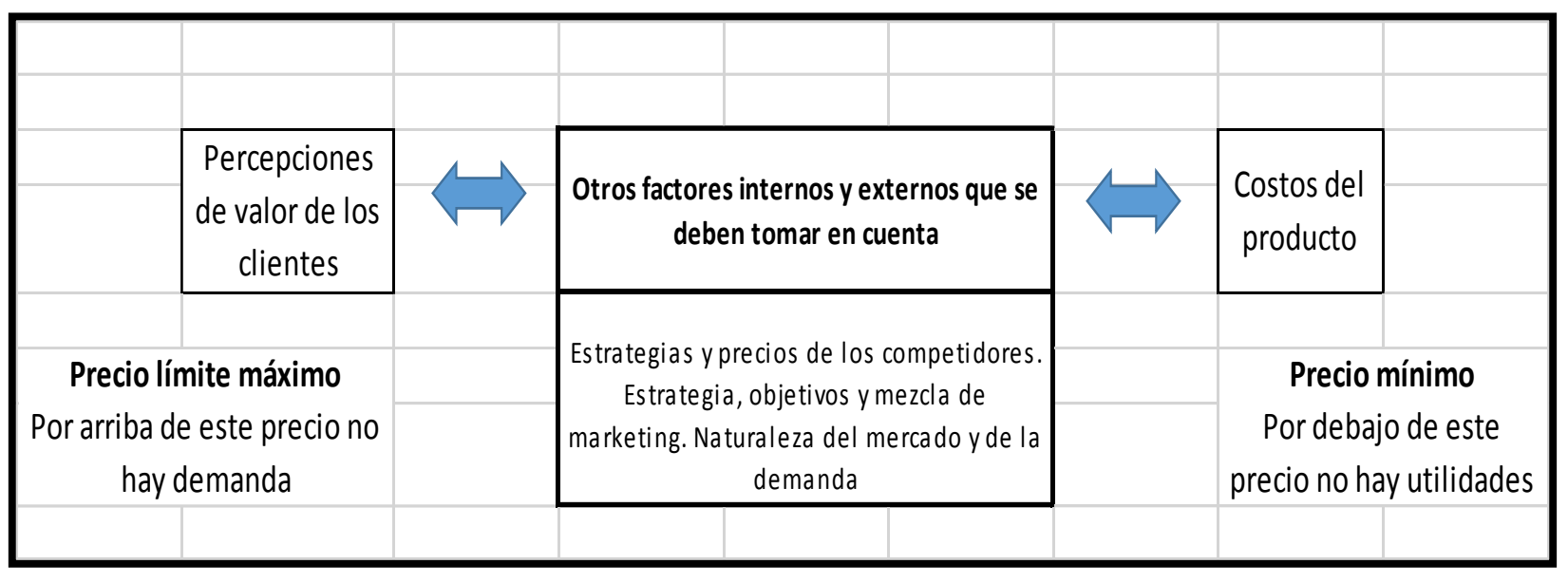

Figura 41. Factores que se toman en cuenta al fijar los precios. Tomado de "Marketing", por Kotler \& Armstrong, 2012

Este precio refleja una estrategia que sirve para atraer clientes y ganar participación de mercado en la Provincia de Arequipa. 
La estrategia de precios que se aplicará estará enfocada en los siguientes puntos:

a) Se trabajará con descuentos por volúmenes de compra, buscando que no se afecte la rentabilidad del negocio.

b) Se establece como política de crédito a 15 días máximo, solo a aquellas empresas que sean compradores continuos, previa firma de contrato de compromiso.

c) Los vendedores podrán negociar precios de venta hasta ciertos topes establecidos, más allá de ello ya se requerirá autorización.

d) El Asistente Administrativo elevará propuestas sobre precios y descuentos de forma anual, al Administrador y al Gerente de Operaciones, usando como base la información recopilada por los vendedores de campo, ya que esto últimos tienen la información directa de los clientes y de los proyectos constructivos programados.

\subsubsection{Estrategia de distribución}

Los autores Kotler y Armstrong (2012) señalan que pocos productores venden sus artículos directamente a los usuarios finales; la mayoría utiliza intermediarios para llevar sus productos al mercado. Ellos buscan crear un canal de marketing (o canal de distribución), que consiste en un conjunto de organizaciones interdependientes que participan en el proceso de poner un producto o servicio a disposición del consumidor o usuario de negocios.

Las compañías diseñan sus canales de distribución para poner sus productos y servicios a disposición de los consumidores de distintas maneras. Cada capa de intermediarios de marketing que desempeñe algún trabajo para acercar el producto y su posesión al comprador final es un nivel de canal. Como el productor y el consumidor final realizan ciertas funciones, también forman parte de cada canal. 
El llamado canal de marketing directo, no tiene niveles de intermediarios; la compañía vende directamente a los consumidores. Los canales de marketing indirecto son los que incluyen a uno o más intermediarios.

El plan de negocios utilizará dos estrategias, la distribución de canal directo e indirecto. La primera consiste en la venta directa al cliente objetivo, desde la misma fábrica y la segunda estrategia consiste en emplear intermediarios y estos pueden ser mayoristas o minoristas. Para la aplicación de la estrategia se diseñan los siguientes procesos:

a) Almacenaje: La producción estará agrupada en lotes listo para la venta, de esta manera se ahorrará tiempo y espacio con respecto a las solicitudes de compra de los clientes.

b) Despacho: Los encargados de las ventas serán el Asistente Administrativo, los vendedores y los asistentes de campo, cayendo sobre ellos la responsabilidad del despacho de las bloquetas plásticas. Para ello deben cumplir con el siguiente procedimiento

1. El responsable de la venta será quien envié el comprobante de pago y/o el compromiso de pago.

2. Validación: El área de ventas será la encargada de validar el pago de cliente en las cuentas de la empresa, verificando con la copia del depósito realizado.

c) Distribución: La distribución de la mercadería se hará haciendo uso de unidad propia.

d) Entrega final: La carga o descarga de bloquetas plásticas se hará por servicio tercerizado de estibadores, los cuales deben estar previamente identificados y registrados en la empresa. 


\subsubsection{Estrategia de promoción y publicidad}

Kotler y Armstrong (2012), definen la mezcla de promoción o también llamada la mezcla de comunicación de marketing, como la combinación de las siguientes herramientas: a) publicidad, b) promoción de ventas, c) ventas personales, d) relaciones públicas y e) marketing directo.

Cada una de las categorías antes mencionadas, cuenta con herramientas de comunicación específicas para los clientes. Los anuncios televisivos, volantes impresos, la internet y todo que se usa en exteriores, forman parte de la publicidad. Los cupones, vales de descuento, exhibidores, etc., son herramientas de la promoción de ventas. Los programas de incentivos, exhibiciones y presentaciones de ventas, son parte de las ventas personales. Las relaciones públicas, incluyen boletines de prensa, patrocinios, eventos especiales y sitios web. Para el marketing directo, se trabaja con marketing telefónico, marketing móvil, catálogos, internet, quioscos, etc.

La promoción de las bloquetas plásticas se hará usando la estrategia de Venta personal y la estrategia de Atracción:

a) Venta Personalizada:

Los encargados de ventas tendrán que promover la imagen de la empresa, generando el interés de potenciales consumidores, es por ello que serán capacitados por especialistas externos y recibirán entrenamiento por parte de la empresa.

Los vendedores y asistentes de campo, deben ser capaces de cerrar las ventas de manera efectiva, haciendo uso de los argumentos medioambientales, características del producto y de responsabilidad social propuestos por la empresa.

b) Estrategia de atracción.

Con la estrategia atracción, el negocio contará con un enfoque adecuado a nuestras actividades comerciales que ayudarán a que el cliente objetivo conozca, acepte el producto, la 
marca y el concepto de LadriplastAQP generando un mayor contacto y facilitando a nuestra fuerza de venta que el cliente objetivo identifique los atributos y los beneficios como la mejor opción en Bloquetas plásticas, para sus proyectos de construcción.

Las principales actividades de relaciones públicas a realizar tenemos:

1. Se realizará un despliegue inicial promocional, con un cóctel de presentación y la inauguración de locales.

2. Se hará entrega de Brochure y Catálogos sobre las bloquetas plásticas, donde se detalla información de la empresa, ficha técnica del producto, modelo y sus funcionalidades. Los responsables de ventas se encargarán de la entrega de los mismos a los potenciales compradores, siendo estas herramientas de apoyo en su labor de introducción del producto.

3. Diseño de WebSite corporativa, describiendo a la empresa, datos, ubicación, contacto, atributos de los productos, proceso de fabricación, distribución, innovaciones de productos, responsabilidad social, etc.

4. Souvenirs: Se contará para la distribución de los mismos, con lapiceros, libretas, llaveros, etc. con el respectivo logotipo de la empresa y una tarjeta de contacto de la empresa, para conseguir mayor recordación de la marca.

5. Publicidad en periódicos locales: Basándonos en el hecho que la prensa escrita, la publicidad y anuncios en los periódicos es el segundo medio más recurrido para buscar información de adquisiciones de viviendas y terrenos, podemos incluir como estrategia la publicación de anuncios en el diario el Pueblo y el Correo que tienen bastante difusión local.

6. Anuncios radiales: Para obtener la mayor cantidad posible de compradores se transmitirá un anuncio en "Radio Melodía" emisora local de amplia difusión a nivel 
provincial los días Lunes, Miércoles, Viernes y Domingos de cada mes por todo el año entre los horarios de 06:00 hasta las 22:00 horas.

\subsection{Estrategia de ventas}

\subsubsection{Plan de ventas}

Los autores Kotler y Armstrong (2012), definen las ventas personales como el brazo interpersonal de la mezcla de comunicación de marketing o también conocida como la mezcla promocional. La finalidad de la fuerza de ventas de una empresa es crear y comunicar valor para el consumidor final, a través de las interacciones personales. Las relaciones que establecen las fuerzas de ventas son el vínculo fundamental entre una compañía y sus clientes. La coordinación del marketing y las ventas son sumamente importantes para crear valor para el cliente.

De acuerdo a los autores los nuevos vendedores no se limitan a un territorio, remuneración y capacitación, requieren de supervisión y motivación. El objetivo de la supervisión es inducirlos a trabajar de manera eficiente y correcta. La motivación los incentiva a trabajar duro y con energía para alcanzar las metas establecidas.

Cada compañía trabaja de manera diferente estableciendo herramientas de supervisión tales como planes de visitas (semanal, mensual o anual), análisis de tiempo y obligaciones. Las herramientas para la motivación de los vendedores usados por algunas compañías es establecer cuotas de ventas. También se usan las reuniones de ventas como oportunidades de interacción social, para tener un mayor conocimiento de sus requerimientos.

Para realizar una correcta evaluación del desempeño de la fuerza de ventas, la gerencia requiere de información para una correcta retroalimentación, para ello se hace uso de herramientas como son los reportes de ventas, informes de visitas e informes de gastos. 
El proyecto cuenta con la siguiente proyección de ventas, de acuerdo al crecimiento de $5 \%$ anual del sector. Ver Figura 42.

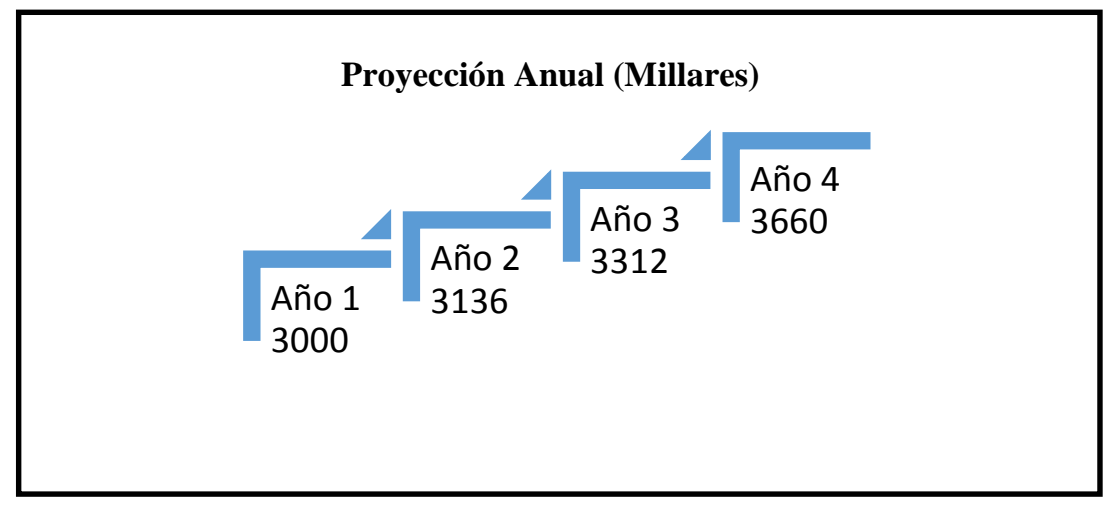

Figura 42. Proyección de ventas. Tomado de la proyección de crecimiento del proyecto.

Para cumplir con la proyección de ventas se cuenta con un equipo de cuatro vendedores y un asistente de campo a quienes se les diseñó un plan de trabajo basado en los siguientes puntos:

a) Establecer una cuota de ventas basada en presupuesta de ventas.

b) Tener un cuadro de control de ventas actualizado para que se pueda validar con lo reportado por los vendedores.

c) Programar visitas y reuniones sorpresas con la fuerza de ventas.

d) Hacer seguimiento y visitas a los mejores clientes de la cartera.

e) Realizar comparaciones entre el presupuesto de ventas y las ventas reales.

f) Verificar que las entregas de los productos vendidos sean en el tiempo pactado con el cliente.

g) Realizar feedback constante con el departamento de administración.

Dentro del plan de ventas se considera como punto de equilibrio de ventas, la comercialización 1,919 millares, esto quiere decir que si se venden más de la cantidad proyectada se generarán utilidades para la empresa y ventas por debajo del punto de equilibrio serán perdidas. 


\subsubsection{Políticas de servicios y garantías.}

El proyecto tiene planeado desarrollar una estrategia de servicio en el pre y post compra, considerando los siguientes elementos:

1. Asesoría Técnica Gratuita:

Teniendo en consideración que la Bloquetas Plásticas son un producto nuevo en el mercado Arequipeño, se ha optado por asesorar a los potenciales cliente y compradores de manera totalmente gratuita, aplicando una metodología teórico práctico. La asesoría abarcará los siguientes temas: (a) diseño, (b) evaluación, (c) métodos y técnicas, (d) herramientas, que se utilizan para los proyectos de construcción con las bloquetas plásticas. Todo ello con el acompañamiento del personal técnico de esta manera, nuestros potenciales clientes puedan sacar el mayor provecho del producto y puedan evaluar sus beneficios.

Las capacitaciones están dirigidas al público en general, tanto como a profesionales y técnicos de la construcción. Se hará entrega de material didáctico, las clases teóricas se realizan con un video proyector. La parte práctica se hará con herramientas de la empresa.

La duración de las capacitaciones se proyecta como máximo hasta de 4 horas. Al finalizar la capacitación se hará entrega una certificación de capacitación y participación de la empresa.

2. Asesoramiento en Diseño Arquitectónico:

Teniendo como objetivo tener un posicionamiento de mercado, y una demanda establecida de bloquetas plásticas es que se les brinda a los clientes asesoría en diseño arquitectónico en sus proyectos de construcción, a fin de que tenga óptimos resultados y logre sus objetivos. Se les orienta en cuanto al diseño de sus planos considere las medidas correctas de fierros y ubicaciones adecuadas de puertas y ventanas. 


\section{Capítulo VIII: Planificación Financiera.}

\subsection{La Inversión.}

El objetivo del presente capítulo es valorar los recursos reales y financieros que requiere el proyecto en una unidad de tiempo a fin de poder producir los servicios del mismo.

Las inversiones según Llanos (n. d), son aquellos gastos que se efectúan en una unidad de tiempo, en la adquisición de determinados recursos para la implementación de una nueva unidad de producción, los mismos que en el transcurso del tiempo van a permitir flujos de beneficios netos.

\subsubsection{Inversión Preoperativa}

Llanos (n. d), define la inversión preoperativa, como la inversión que se genera antes de la operación o del inicio de las actividades de la empresa, la denominan también inversión inicial.

Para el presente proyecto se calculó la inversión preoperativa como se muestra en la Tabla 39, obteniendo una inversión inicial de S/.191,145.00 soles. 
Tabla 39

Inversión Pre operativa

\begin{tabular}{|c|c|c|c|c|c|c|c|c|}
\hline \multirow[b]{2}{*}{ INVERSION TOTAL } & \multicolumn{2}{|c|}{ Trimestre 1} & \multicolumn{2}{|c|}{ Trimestre 2} & \multicolumn{2}{|c|}{ Trimestre 3} & \multicolumn{2}{|c|}{ Trimestre 4} \\
\hline & Monto (S/.) & $\begin{array}{l}\text { Monto } \\
\text { (USD) }\end{array}$ & $\operatorname{Monto}(\mathrm{S} /)$. & $\begin{array}{l}\text { Monto } \\
\text { (USD) }\end{array}$ & Monto (S/.) & $\begin{array}{l}\text { Monto } \\
\text { (USD) }\end{array}$ & Monto (S/.) & $\begin{array}{l}\text { Monto } \\
\text { (USD) }\end{array}$ \\
\hline 1. INVERSION FIJA & & & & & & & & \\
\hline Terrenos & - & - & - & - & - & - & 12,941 & 3,886 \\
\hline Construcciones & - & - & - & - & - & - & 27,325 & 8,206 \\
\hline Muebles y Enseres & - & - & - & - & - & - & 14,096 & 4,233 \\
\hline Equipos y herramientas & - & - & - & - & - & - & 109,504 & 32,884 \\
\hline Imprevistos $(5 \%)$ & - & - & - & - & - & - & 8,361 & 2,511 \\
\hline 2. INVERSION INTANGIBLE & - & - & - & - & - & - & - & - \\
\hline Estudios de Pre inversión & 2,500 & 751 & - & - & - & - & - & - \\
\hline Estudios Definitivos & - & - & 4,623 & 1,388 & - & - & - & - \\
\hline Organización & - & - & - & - & 1,400 & 420 & - & - \\
\hline Pruebas & - & - & - & - & - & - & 3,500 & 1,051 \\
\hline Intereses Pre operativos & - & - & - & - & - & - & 5,977 & 1,795 \\
\hline Imprevistos $(5 \%)$ & - & - & - & - & - & - & 918 & 276 \\
\hline 3. SUBTOTAL & 2,500 & 751 & 4,623 & 1,388 & 1,400 & 420 & 182,622 & 54,8427 \\
\hline
\end{tabular}

Nota. Ver detalles de costos en anexo XIII 


\subsubsection{Inversión en capital de trabajo}

De acuerdo a Sapag (2011), el proyecto debe contemplar todos los activos fijos para poder operar de manera adecuada, si no se contempla el capital para financiar los desfases de caja durante la operación pueda que fracase la empresa. Es por ello que para el proyecto se realizó el cálculo de la inversión de capital como se puede visualizar en la Tabla 40, siendo este de S/109, 189.00 soles. 
Tabla 40

Inversión en capital de trabajo

\begin{tabular}{|c|c|c|c|c|c|c|c|c|c|c|c|c|}
\hline CONCEPTO & Enero & Febrero & Marzo & Abril & Mayo & Junio & Julio & Agosto & Septiem & Octubre & Noviem & Diciem \\
\hline \multicolumn{13}{|l|}{ INGRESOS } \\
\hline Ventas & & 108,225 & 108,225 & 108,225 & 108,225 & 108,225 & 108,225 & 108,225 & 108,225 & 108,225 & 108,225 & 108,225 \\
\hline Total ingresos & - & 108,225 & 108,225 & 108,225 & 108,225 & 108,225 & 108,225 & 108,225 & 108,225 & 108,225 & 108,225 & 108,225 \\
\hline \multicolumn{13}{|l|}{ EGRESOS } \\
\hline Mano de Obra Directa & 5,693 & 5,693 & 5,693 & 5,693 & 5,693 & 5,693 & 5,693 & 5,693 & 5,693 & 5,693 & 5,693 & 5,693 \\
\hline $\begin{array}{l}\text { Insumos directos (Mat. } \\
\text { Prima) }\end{array}$ & 74,697 & 74,697 & 74,697 & 74,697 & 74,697 & 74,697 & 74,697 & 74,697 & 74,697 & 74,697 & 74,697 & 74,697 \\
\hline Mano Obra Indirecta & 7,117 & 7,117 & 7,117 & 7,117 & 7,117 & 7,117 & 7,117 & 7,117 & 7,117 & 7,117 & 7,117 & 7,117 \\
\hline Insumos indirectos & 3,633 & 3,633 & 3,633 & 3,633 & 3,633 & 3,633 & 3,633 & 3,633 & 3,633 & 3,633 & 3,633 & 3,633 \\
\hline Gastos Administrativos & 5,227 & 5,227 & 5,227 & 5,227 & 5,227 & 5,227 & 5,227 & 5,227 & 5,227 & 5,227 & 5,227 & 5,227 \\
\hline Gastos de Ventas & 7,816 & 7,816 & 7,816 & 7,816 & 7,816 & 7,816 & 7,816 & 7,816 & 7,816 & 7,816 & 7,816 & 7,816 \\
\hline Total egresos & 104,182 & 104,182 & 104,182 & 104,182 & 104,182 & 104,182 & 104,182 & 104,182 & 104,182 & 104,182 & 104,182 & 104,182 \\
\hline FLUJO DE CAJA & $-104,182$ & 4,043 & 4,043 & 4,043 & 4,043 & 4,043 & 4,043 & 4,043 & 4,043 & 4,043 & 4,043 & 4,043 \\
\hline \multicolumn{2}{|c|}{ Margen de seguridad (5\%) } & 5,007 & & & & & & & & & & \\
\hline \multicolumn{2}{|l|}{ CAPITAL DE TRABAJO } & 109,189 & & & & & & & & & & \\
\hline
\end{tabular}

Nota. Ver detalles de costos en anexo XIV. 


\subsubsection{Costo del proyecto.}

Se realizó el análisis de todos los costos para realizar la inversión total del proyecto entre los cuales se consideró la Inversión Fija, Inversión Intangible y el Capital de Trabajo. (Ver Tabla 41), obteniendo así un Costo Total de S/ 300,334 soles.

Tabla 41

\begin{tabular}{|c|c|c|c|c|}
\hline Inversión total & $\begin{array}{c}\text { Monto } \\
\text { (S/.) }\end{array}$ & $\%$ & $\begin{array}{l}\text { Monto } \\
\text { (USD) }\end{array}$ & $\%$ \\
\hline Inversión Fija & 172,227 & $57 \%$ & 51,720 & $57 \%$ \\
\hline Inversión Intangible & 18,918 & $6 \%$ & 5,681 & $6 \%$ \\
\hline Capital de Trabajo & 109,189 & $36 \%$ & 32,790 & $36 \%$ \\
\hline Total de la inversión & 300,334 & $100 \%$ & 90,191 & $100 \%$ \\
\hline
\end{tabular}

Nota. Adaptado de anexo XII, XIII y XIV.

\subsubsection{Inversiones futuras.}

El proyecto no ha contemplado invertir a corto ni mediano plazo. Las proyecciones debido a que se han calculado para una operación de cinco años sin agregar activos adicionales.

\subsection{Financiamiento.}

Como lo define Stickney, Weil, Schipper, Francis \& Avolio (2012), el financiamiento es la toma de decisiones acerca de la obtención de la proporción de los fondos que brindaran los propietarios, los acreedores a largo plazo y los acreedores a corto plazo.

El financiamiento se ocupa de la búsqueda de capital a través de los diferentes mecanismos de obtención de recursos financieros y de la especificación de los diferentes flujos de origen y uso de fondos para el período de tiempo estipulado afín de satisfacer la inversión requerida.

En la fase de ejecución, los recursos financieros son requeridos para inversiones fijas; mientras que en la fase de operación, éstos son requeridos para el capital de trabajo. 


\subsubsection{Endeudamiento y condiciones.}

Para el proyecto se han considerado las siguientes fuentes externas de financiamiento:

1. Aporte propio

Los aportes serán canalizados mediante la participación equitativa de los mismos. De esta manera, los socios gozarán de los mismos beneficios y de los excedentes económicos generados por el proyecto y su gestión financiera.

El aporte propio constituirá el 50\% de la inversión total.

2. Intermediario financiero

Las entidades o intermediarios financieros tienen, entre otras, la responsabilidad de la recepción de las solicitudes de financiamiento, evaluar la viabilidad de la operación de crédito solicitada, aprobar el financiamiento, desembolsar los recursos financieros y efectuar las labores de recuperación de los créditos aprobados.

Son estas instituciones las que asumen el riesgo del préstamo y fijan la tasa de interés al prestatario.

El intermediario financiero seleccionado es el Banco Continental por ser la que mejores facilidades de crédito ofrece en el mercado.

La tabla 42, muestra la composición del financiamiento del proyecto, el monto de préstamo de Banco Continental será del 50\% de la inversión total. Dicho financiamiento se encuentra destinado a solventar inversión fija y capital de trabajo. 
Tabla 42

Composición del financiamiento del proyecto

\begin{tabular}{lcccccc}
\hline \multicolumn{2}{c}{$\begin{array}{c}\text { Fuentes de } \\
\text { financiamiento }\end{array}$} & \multicolumn{2}{c}{ Aporte Propio } & \multicolumn{2}{c}{ Préstamo } & \multicolumn{2}{c}{ Total } \\
& Soles & Dólares & Soles & Dólares & Soles & Dólares \\
\hline Inversión Fija & 131,249 & 39,414 & 40,978 & 12,306 & 172,227 & 51,720 \\
Inversión Intangible & 18,918 & 5,681 & - & - & 18,918 & 5,681 \\
Capital de Trabajo & - & - & 109,189 & 32,790 & 109,189 & 32,790 \\
\hline Total & 150,167 & 45,095 & 150,167 & 45,095 & 300,334 & 90,191 \\
Composición & \multicolumn{2}{c}{$50 \%$} & \multicolumn{2}{c}{$50 \%$} & \multicolumn{2}{c}{$100 \%$} \\
\hline
\end{tabular}

Nota. El aporte propio es el capital que disponen los socios para el proyecto.

Es necesario identificar la fuente específica de financiamiento y el uso al cual está destinado dentro de los rubros de inversión del proyecto, en la Tabla 43, se encuentra detallado las fuentes y usos de la composición del financiamiento.

Tabla 43

Fuentes y usos de la composición del financiamiento

\begin{tabular}{|c|c|c|c|c|c|c|}
\hline \multirow{2}{*}{ Rubro de Inversión } & \multicolumn{2}{|c|}{ Aporte Propio } & \multicolumn{2}{|c|}{ Préstamo } & \multicolumn{2}{|c|}{ Total } \\
\hline & Soles & $\%$ & Soles & $\%$ & $\mathrm{~S} /$. & $\%$ \\
\hline Inversión Fija Tangible & 131,249 & $76 \%$ & 40,978 & $24 \%$ & 172,227 & $100 \%$ \\
\hline Terrenos & 12,941 & $100 \%$ & - & - & 12,941 & $100 \%$ \\
\hline Construcciones & 27,325 & $100 \%$ & - & $0 \%$ & 27,325 & $100 \%$ \\
\hline Muebles y Enseres & 14,096 & $100 \%$ & - & - & 14,096 & $100 \%$ \\
\hline Equipos y herramientas & 68,526 & $63 \%$ & 40,978 & $37 \%$ & 109,504 & $100 \%$ \\
\hline Imprevistos $(2 \%)$ & 8,361 & $100 \%$ & - & - & 8,361 & $100 \%$ \\
\hline Inversión fija Intangible & 18,918 & $100 \%$ & - & - & 18,918 & $100 \%$ \\
\hline Estudios de Pre inversión & 2,500 & $100 \%$ & - & - & 2,500 & $100 \%$ \\
\hline Estudios Definitivos & 4,623 & $100 \%$ & - & - & 4,623 & $100 \%$ \\
\hline Organización y Capacitación & 1,400 & $100 \%$ & - & - & 1,400 & $100 \%$ \\
\hline Pruebas y Puestas en Marcha & 3,500 & $100 \%$ & - & - & 3,500 & $100 \%$ \\
\hline Intereses Pre operativos & 5,977 & $100 \%$ & - & - & 5,977 & $100 \%$ \\
\hline Imprevistos $(5 \%)$ & 918 & $100 \%$ & - & - & 918 & $100 \%$ \\
\hline Capital de Trabajo & - & - & 109,189 & $100 \%$ & 109,189 & $100 \%$ \\
\hline
\end{tabular}

Nota. El financiamiento se centrará en el capital de trabajo y en equipos y herramientas. 


\subsubsection{Capital y costo de oportunidad}

La importancia del costo de oportunidad del capital radica en que toda empresa toma sus decisiones de inversión. Se entiende el Costo de Oportunidad del Capital (COK) como la tasa de retorno de la inversión mínima que permitirá a la empresa generar valor partir de esta. El costo de oportunidad según LLadó y Concha (n. d), es el costo que se origina al tomar una determinación que provoca la renuncia de otro tipo de alternativa que pudiera ser considerada al llevar a cabo la decisión, esto es así porque cuando se toma una decisión para empeñarse en determinada alternativa, se abandonan los beneficios de otras opciones. En este caso el costo de oportunidad son los beneficios perdidos al descartar la siguiente mejor alternativa.

Para determinar el COK, es necesario determinar la tasa libre de riesgo y la tasa de rendimiento de mercado, la cual se muestra en la Tabla 44, que está dada para los años 2006-2015.

Tabla 44

Tasa Libre de Riesgo, Tasa de Rendimiento de Mercado

\begin{tabular}{lccc}
\hline Año & S\&P500 & Stocks - T.Bills & Stocks - T.Bonds \\
\hline $1928-2015$ & $11.41 \%$ & $3.49 \%$ & $5.23 \%$ \\
$1966-2015$ & $11.01 \%$ & $4.97 \%$ & $7.12 \%$ \\
$2006-2015$ & $9.03 \%$ & $1.16 \%$ & $5.16 \%$ \\
\hline
\end{tabular}

Rf $\quad 9.03 \% \quad$ Rm $5.16 \%$

Nota: Tomado de http://www.stern.nyu.edu/ adamodar/pc/datasets/indname.xls

Rf $9.03 \% \quad \mathrm{Rm}=15,0 \%$

$\mathrm{Rm} \quad 15,00 \%$

b) Estimación de Beta

Beta: 1.18 (Ver anexo XXI)

c) Estimación del Riesgo País

Riesgo país: 1.54 (Ver anexo XXII) 
d) Estimación prima de riesgo

Prima de riesgo: 2.53 (Ver anexo XXIII)

e) Estimación del COK

En la Tabla 45 se muestra el cálculo del costo de oportunidad del capital, el cual nos muestra que $14,7 \%$ será la tasa de retorno de la inversión mínima que permitirá a la empresa generar valor para los accionistas.

Tabla 45

Calculo del COK

$\mathrm{COK}=\mathrm{Rf}+\beta(\mathrm{Rm}-\mathrm{Rf})+\mathrm{RP}+\mathrm{PR}$

\begin{tabular}{lll} 
Rf: & 9.03 \\
$\beta:$ & 1.18 \\
Rm: & $15.00 \quad$ COK $=$ & \\
RP: & 1.54 \\
PR: & 2.53 & \\
\hline
\end{tabular}

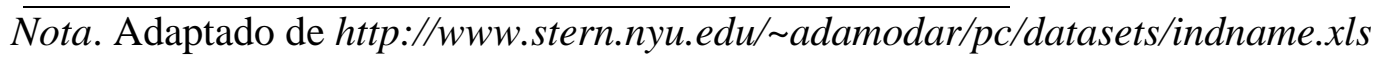

\subsubsection{Costo de capital promedio ponderado}

El Costo de Capital Promedio Ponderado (CCPP), según el Boletín de Investigación de la Comisión de Desarrollo Finanzas y Sistema Financiero (2014) es una medida financiera, la cual tiene el propósito de englobar en una sola cifra expresada en términos porcentuales, el costo de las diferentes fuentes de financiamiento que usará una empresa para fondear algún proyecto en específico.

Para calcular el CCPP, como lo muestra la Tabla 46, se requiere conocer los montos, tasas de interés y efectos fiscales de cada una de las fuentes de financiamiento seleccionadas. 
Tabla 46

Datos necesarios para el CCPP

\begin{tabular}{lrrr}
\hline \multicolumn{1}{c}{ Concepto } & $\%$ & $\mathrm{~K}$ & $\mathrm{~K} *(1-\mathrm{t})$ \\
\hline$\%$ Deuda & $50.00 \%$ & $7.10 \%$ & $4.90 \%$ \\
$\%$ Capital & $50.00 \%$ & $13.21 \%$ & $13.21 \%$ \\
\hline $\mathrm{KO}=\% \mathrm{C} * \mathrm{KE}+\% \mathrm{D} * \mathrm{Ki}^{*}(1-\mathrm{t})$ & $\mathrm{KO}(\mathrm{CPPC})$ & $7.39 \%$ \\
\hline
\end{tabular}

Nota. Adaptado de Análisis previo al punto 8.2.3 del presente estudio.

\subsection{Presupuestos Base}

Diaz (2009), indica que se basa en fases que el proyecto utilizará para medir y monitorear la ejecución del presupuesto. Esta base será utilizada para compararla con los costos reales incurridos por el proyecto y ver su progreso, cada mes nuevos datos provienen de gastos en personal, compras de bienes y servicios y otros gastos del proyecto tales como beneficios y costos compartidos. El presupuesto base será utilizado para controlar el presupuesto mediante cálculos del valor ganado para determinar cómo se está desarrollando el presupuesto de acuerdo con el progreso alcanzado. Usualmente todo el proyecto se divide por el total de meses/años de duración del proyecto.

\subsubsection{Presupuesto de ventas}

Jaramillo (2011), define a un presupuesto de ventas como el cálculo planificado de las ventas y que es utilizado para tomar las decisiones de compras, producción y flujos de efectivo. Para el presente proyecto se realizó el análisis de los costos a presupuestar, ver la Tabla 47. 
Tabla 47

Presupuesto de ventas

\begin{tabular}{|c|c|c|c|c|c|c|c|c|}
\hline \multirow[t]{2}{*}{ Año } & \multirow[t]{2}{*}{ Remuner. } & \multirow{2}{*}{$\begin{array}{c}\text { Bonos por } \\
\text { ventas } \\
\text { S/. } 10 \mathrm{x} \\
\text { Millar }\end{array}$} & \multirow[t]{2}{*}{$\begin{array}{l}\text { Alquiler } \\
\text { Locales } \\
\text { ventas }\end{array}$} & \multirow{2}{*}{$\begin{array}{l}\text { Servic. } \\
\text { Telef. e } \\
\text { Internet } \\
\quad(\mathrm{S} / .)\end{array}$} & \multirow{2}{*}{$\begin{array}{c}\text { Útiles } \\
\text { escritor. } \\
\text { Papeler. } \\
\text { (S/.) }\end{array}$} & \multirow{2}{*}{$\begin{array}{c}\text { Imprev } \\
5 \% \\
(\mathrm{~S} / .)\end{array}$} & \multicolumn{2}{|c|}{$\begin{array}{c}\text { Total de gastos de } \\
\text { venta }\end{array}$} \\
\hline & & & & & & & Año (S/.) & $\operatorname{Mes}(\mathrm{S} /)$. \\
\hline Año 1 & 58,071 & $30,000.0$ & 2,700 & 2400 & 472.5 & 143.6 & $93,786.8$ & 7816 \\
\hline Año 2 & 58,071 & $31,560.0$ & 2,700 & 2400 & 1914 & 215.7 & $96,860.3$ & 8072 \\
\hline Año 3 & 72,588 & $33,120.0$ & 2,700 & 2400 & 1914 & 215.7 & $112,938.0$ & 9412 \\
\hline Año 4 & 72,588 & $34,800.0$ & 2,700 & 2400 & 1914 & 215.7 & $114,618.0$ & 9552 \\
\hline Año 5 & 87,106 & $36,600.0$ & 2,700 & 2400 & 1914 & 215.7 & $130,935.7$ & 10911 \\
\hline
\end{tabular}

Nota: Tomado del anexo XIV

\subsubsection{Presupuesto de costo de producción}

Para los costos de producción se consideraron los costos directos e indirectos para los cinco años del proyecto, entre ellos tenemos el de mano de obra (ver Tabla 48) y materia prima (Ver Tabla 49)

Tabla 48

Costo de mano de obra directa

\begin{tabular}{cccccccc}
\hline Año & $\begin{array}{c}\text { Cant. } \\
\text { Oper. }\end{array}$ & $\begin{array}{c}\text { Costo } \\
\text { Operario }\end{array}$ & CTS & Gratificac. & ESSALUD & Vacaciones & $\begin{array}{c}\text { Costo } \\
\text { total }\end{array}$ \\
\hline Año 1 & 4 & 48,000 & $3,998.4$ & $8,001.6$ & $4,320.0$ & $3,998.4$ & $68,318.4$ \\
Año 2 & 4 & 48,000 & $3,998.4$ & $8,001.6$ & $4,320.0$ & $3,998.4$ & $68,318.4$ \\
Año 3 & 5 & 60,000 & $4,998.0$ & $10,002.0$ & $5,400.0$ & $4,998.0$ & $85,398.0$ \\
Año 4 & 5 & 60,000 & $4,998.0$ & $10,002.0$ & $5,400.0$ & $4,998.0$ & $85,398.0$ \\
Año 5 & 6 & 72,000 & $5,997.6$ & $12,002.4$ & $6,480.0$ & $5,997.6$ & $102,477.6$ \\
\hline
\end{tabular}

Nota. Tomado del anexo XVI. 
Tabla 49

Costo de materia prima

\begin{tabular}{cccccc}
\hline & \multicolumn{3}{c}{ Costo de materia prima } & \multicolumn{2}{c}{ Costo total } \\
Año & Agua & Plástico & Cemento & $(\mathrm{S} /)$. & $(\$)$ \\
\hline Año 1 & 3,344 & 231,525 & 661,500 & $896,369.3$ & $269,180.0$ \\
Año 2 & 3,518 & 243,564 & 695,898 & $942,980.5$ & $283,177.3$ \\
Año 3 & 3,692 & 255,604 & 730,296 & $989,591.7$ & $297,174.7$ \\
Año 4 & 3,879 & 268,569 & 767,340 & $1,039,788.4$ & $312,248.8$ \\
Año 5 & 4,080 & 282,461 & 807,030 & $1,093,570.6$ & $328,399.6$ \\
\hline
\end{tabular}

Nota. Tomado del anexo XVIII

En la Tabla 50 se muestra el costo total directo que integra los costos de mano de obra y materia prima, para los cinco primeros años del proyecto.

Tabla 50

Costo total directo

\begin{tabular}{ccccc}
\hline \multirow{2}{*}{ Año } & $\begin{array}{c}\text { Mano Obra Directa } \\
(\mathrm{S} / .)\end{array}$ & $(\mathrm{S} /)$. & $(\mathrm{S} /)$. & $(\$)$ \\
\hline Año 1 & $68,318.4$ & $896,369.3$ & $964,687.7$ & $289,696.0$ \\
Año 2 & $68,318.4$ & $942,980.5$ & $1,011,298.9$ & $303,693.4$ \\
Año 3 & $85,398.0$ & $989,591.7$ & $1,074,989.7$ & $322,819.7$ \\
Año 4 & $85,398.0$ & $1,039,788.4$ & $1,125,186.4$ & $337,893.8$ \\
Año 5 & $102,477.6$ & $1,093,570.6$ & $1,196,048.2$ & $359,173.6$ \\
\hline
\end{tabular}

Nota. Adaptado del anexo XVI y anexo XVIII.

El costo de mano de obra indirecta que se muestra en la Tabla 51 y Tabla 52, evidencia una necesidad de recursos de personal administrativos, asistentes y técnicos. Existe una diferencia de requerimiento en los diferentes años, de acuerdo a la proyección de crecimiento del proyecto. 
Tabla 51

Costo de mano de obra indirecta

\begin{tabular}{|c|c|c|c|c|c|c|c|}
\hline $\begin{array}{l}\text { Puesto de } \\
\text { trabajo }\end{array}$ & Cant. & $\begin{array}{c}\text { Remun } \\
\text { anual } \\
(\mathrm{S} / .)\end{array}$ & $\begin{array}{c}\text { CTS } \\
8.33 \%\end{array}$ & $\begin{array}{c}\text { Gratific. } \\
16.67 \%\end{array}$ & $\begin{array}{l}\text { Essalud } \\
9.00 \%\end{array}$ & $\begin{array}{l}\text { Vacac. } \\
8.33 \%\end{array}$ & $\begin{array}{c}\text { Costo } \\
\text { total } \\
(\mathrm{S} / .)\end{array}$ \\
\hline $\begin{array}{l}\text { Gerente de } \\
\text { Producción }\end{array}$ & 1 & 36,000 & $2,998.8$ & 6,001 & 3,240 & 2,998 & 51,238 \\
\hline $\begin{array}{l}\text { Asistente } \\
\text { Campo }\end{array}$ & 1 & 12,000 & 999.6 & 2,000 & 1,080 & 999 & 17,079 \\
\hline $\begin{array}{l}\text { Técnicos (Año } \\
1 \text { y } 2 \text { ) }\end{array}$ & 1 & 12,000 & 999.6 & 2,000 & 1,080 & 999 & 17,079 \\
\hline $\begin{array}{l}\text { Técnicos (Año } \\
3,4 \text { y } 5 \text { ) }\end{array}$ & 2 & 24,000 & $1,999.2$ & 4,000 & 2,160 & 1,999 & 34,159 \\
\hline \multirow{2}{*}{\multicolumn{4}{|c|}{ Total }} & \multicolumn{2}{|c|}{ año 1 y 2} & & $85,398.0$ \\
\hline & & & & \multicolumn{2}{|c|}{ año 3,4 y 5} & & 102,478 \\
\hline
\end{tabular}

Nota. Tomado del anexo XVI.

Tabla 52

Costo de mano de obra indirecta para todo el proyecto

\begin{tabular}{ccc}
\hline AÑO & $\begin{array}{c}\text { Costo Total } \\
(\text { S./ })\end{array}$ & $\begin{array}{c}\text { Costo Total } \\
(\$)\end{array}$ \\
\hline Año 1 & 85,398 & $25,645.05$ \\
Año 2 & 85,398 & $25,645.05$ \\
Año 3 & 102,478 & $30,774.05$ \\
Año 4 & 102,478 & $30,774.05$ \\
Año 5 & 102,478 & $30,774.05$ \\
\hline
\end{tabular}

Nota. Tomado de la tabla 51

En la Tabla 53 se identifican los costos de insumos indirectos para el proyecto.

Tabla 53

Costo de insumos indirectos

\begin{tabular}{ccccc}
\hline Año & $\begin{array}{c}\text { Higiene y segur. } \\
\text { industrial }\end{array}$ & Limpieza & Mantenim. & $\begin{array}{c}\text { Costo total } \\
(\mathrm{S} / .)\end{array}$ \\
\hline Año 1 & $2,343.0$ & $41,250.0$ & $13,558.5$ & $57,151.5$ \\
Año 2 & $2,343.0$ & $43,395.0$ & $13,558.5$ & $59,296.5$ \\
Año 3 & $3,243.0$ & $45,540.0$ & $13,558.5$ & $62,341.5$ \\
Año 4 & $3,243.0$ & $47,850.0$ & $13,558.5$ & $64,651.5$ \\
Año 5 & $3,408.0$ & $50,325.0$ & $13,558.5$ & $67,291.5$ \\
\hline
\end{tabular}

Nota. Adaptado del anexo XIV. 
Para el cálculo de la depreciación del proyecto se utilizó el método de depreciación de la suma de los dígitos de los años, en la Tabla 54 se muestra el costo de depreciación, en donde las cuotas de depreciación reflejan una disminución progresiva hacia los últimos años de la vida útil del proyecto.

Tabla 54

Costo de depreciación en soles

\begin{tabular}{ccccc}
\hline $\begin{array}{c}\text { Valor del activo } \\
\text { Vida útil (V) }\end{array}$ & $\begin{array}{r}109,504.00 \\
5 \text { años }\end{array}$ & \multicolumn{2}{c}{$\begin{array}{c}\text { Método: de la suma de los } \\
\text { dígitos del año }\end{array}$} \\
\hline Año & FACTOR & $\begin{array}{c}\text { Cuota } \\
\text { depreciación } \\
\text { Valor Activo } \\
\text { Factor }\end{array}$ & $\begin{array}{c}\text { Valor neto en } \\
\text { Depreciación } \\
\text { acumulada }\end{array}$ & $\begin{array}{c}\text { Valor Activo } \\
\text { - Dep. Acum. }\end{array}$ \\
\hline Año 0 & $33.33 \%$ & $36,501.33$ & $36,501.33$ & $73,002.67$ \\
Año 1 & $26.67 \%$ & $29,201.07$ & $65,702.40$ & $43,801.60$ \\
Año 2 & $20.00 \%$ & $21,900.80$ & $87,603.20$ & $21,900.80$ \\
Año 3 & $13.33 \%$ & $14,600.53$ & $102,203.73$ & $7,300.27$ \\
Año 4 & $6.67 \%$ & $7,300.27$ & $109,504.00$ & 0.00 \\
Año 5 & $0.00 \%$ & 0.00 & $109,504.00$ & 0.00 \\
\hline
\end{tabular}

\begin{tabular}{ccccc}
\hline Año & $\begin{array}{c}\text { Maquinaria y } \\
\text { equipo }\end{array}$ & Imprevistos & $\begin{array}{c}\text { Monto anual } \\
(\mathrm{S} / .)\end{array}$ & $\begin{array}{c}\text { Monto anual } \\
(\$)\end{array}$ \\
\hline Año 1 & $36,501.33$ & 418.03 & $36,919.36$ & $11,086.89$ \\
Año 2 & $29,201.07$ & 418.03 & $29,619.09$ & $8,894.62$ \\
Año 3 & $21,900.80$ & 418.03 & $22,318.83$ & $6,702.35$ \\
Año 4 & $14,600.53$ & 418.03 & $15,018.56$ & $4,510.08$ \\
Año 5 & $7,300.27$ & 418.03 & $7,718.29$ & $2,317.81$ \\
\hline
\end{tabular}

Nota. Costos de depreciación calculados para un horizonte de 5 años.

En la Tabla 55 se muestran los costos de amortización de cargas diferidas, los cuales deben ser amortizados en la medida en que se van utilizando, en la media en que se van gastando o consumiendo. 
Tabla 55

Costo de amortizaciones de cargas diferidas

\begin{tabular}{|c|c|c|c|}
\hline Rubro & $\begin{array}{c}\text { Valor Inicial } \\
(\mathrm{S} / .)\end{array}$ & $\begin{array}{c}\text { Tasa } \\
\text { Anual }\end{array}$ & $\begin{array}{c}\text { Monto anual } \\
\text { (S/.) }\end{array}$ \\
\hline Estudios de Pre inversión & $2,500.0$ & $20 \%$ & 500.0 \\
\hline Estudios Definitivos & $4,623.0$ & $20 \%$ & 924.6 \\
\hline Organización & $1,400.0$ & $20 \%$ & 280.0 \\
\hline $\begin{array}{l}\text { Pruebas y Puesta en } \\
\text { Marcha }\end{array}$ & $3,500.0$ & $20 \%$ & 700.0 \\
\hline Intereses Pre operativos & $5,977.0$ & $20 \%$ & $1,195.4$ \\
\hline Imprevistos $(5 \%)$ & 918.4 & $20 \%$ & 183.7 \\
\hline Total & $18,918.4$ & & $3,783.7$ \\
\hline
\end{tabular}

Nota. Costos tomados del anexo XV

En la Tabla 56 se muestra el valor de los gastos indirectos de producción que es la suma de los costos de depreciación y el costo de amortizaciones de las cargas diferidas.

Tabla 56

Gastos indirectos de producción

\begin{tabular}{ccccc}
\hline \multirow{2}{*}{ Año } & Depreciación & Amortización & \multicolumn{2}{c}{ Total gastos directos } \\
& & & $(\mathrm{S} /)$. & $(\$)$ \\
\hline Año 1 & $36,919.4$ & $3,783.7$ & $40,703.0$ & $12,223.1$ \\
Año 2 & $29,619.1$ & $3,783.7$ & $33,402.8$ & $10,030.9$ \\
Año 3 & $22,318.8$ & $3,783.7$ & $26,102.5$ & $7,838.6$ \\
Año 4 & $15,018.6$ & $3,783.7$ & $18,802.2$ & $5,646.3$ \\
Año 5 & $7,718.3$ & $3,783.7$ & $11,502.0$ & $3,454.0$ \\
\hline
\end{tabular}

Nota. Adaptado de las tablas 51 Y 52

De acuerdo al análisis anterior realizado, se obtiene el costo total indirecto de producción (ver Tabla 57) y el costo total de producción (ver Tabla 58). 
Tabla 57

Costos totales indirectos de producción

\begin{tabular}{ccccc}
\hline Año & $\begin{array}{c}\text { Mano de Obra } \\
\text { Indirecta }\end{array}$ & $\begin{array}{c}\text { Materiales } \\
\text { Indirectos }\end{array}$ & $\begin{array}{c}\text { Gastos } \\
\text { Indirectos }\end{array}$ & $\begin{array}{c}\text { Costo total } \\
\text { indirecto } \\
\text { (S/.) }\end{array}$ \\
\hline Año 1 & $85,398.0$ & $57,151.5$ & $40,703.0$ & $183,252.5$ \\
Año 2 & $85,398.0$ & $59,296.5$ & $33,402.8$ & $178,097.3$ \\
Año 3 & $102,477.6$ & $62,341.5$ & $26,102.5$ & $190,921.6$ \\
Año 4 & $102,477.6$ & $64,651.5$ & $18,802.2$ & $185,931.3$ \\
Año 5 & $102,477.6$ & $67,291.5$ & $11,502.0$ & $181,271.1$ \\
\hline
\end{tabular}

Nota. Adaptado de los anexos XIV y XVI

Tabla 58

Costo total de producción

\begin{tabular}{ccccc}
\hline \multirow{2}{*}{ Año } & Costo Directo & $\begin{array}{c}\text { Costo } \\
\text { Indirecto }\end{array}$ & \multicolumn{2}{c}{ Costo total de producción } \\
& & $(\mathrm{S} /)$. & $(\$)$ \\
\hline Año 1 & $964,687.7$ & $183,252.5$ & $1,147,940.3$ & $344,726.8$ \\
Año 2 & $1,011,298.9$ & $178,097.3$ & $1,189,396.2$ & $357,176.0$ \\
Año 3 & $1,074,989.7$ & $190,921.6$ & $1,265,911.3$ & $380,153.6$ \\
Año 4 & $1,125,186.4$ & $185,931.3$ & $1,311,117.8$ & $393,729.1$ \\
Año 5 & $1,196,048.2$ & $181,271.1$ & $1,377,319.3$ & $413,609.4$ \\
\hline
\end{tabular}

Nota. Adaptado del anexo XVII.

\subsubsection{Presupuesto de compras}

La Tabla 59 muestra el presupuesto que necesitamos considerar en el proyecto para la compra de materias primas e insumos indirectos, para los cinco primeros años del proyecto. 
Tabla 59

Costo total de compras en materia prima e insumos indirectos

\begin{tabular}{ccccc}
\hline Año & $\begin{array}{c}\text { Materia prima } \\
(\mathrm{S} / .)\end{array}$ & $\begin{array}{c}\text { Ins. } \\
\text { Indirectos } \\
(\mathrm{S} / .)\end{array}$ & Total $(\mathrm{S} /)$. & $\begin{array}{c}\text { Total } \\
(\mathrm{US} \$)\end{array}$ \\
\hline Año 1 & 896,369 & 43,593 & 939,962 & 282,271 \\
Año 2 & 942,981 & 45,738 & 988,719 & 296,912 \\
Año 3 & 989,592 & 48,783 & $1,038,375$ & 311,824 \\
Año 4 & $1,039,788$ & 51,093 & $1,090,881$ & 327,592 \\
Año 5 & $1,093,571$ & 53,733 & $1,147,304$ & 344,536 \\
\hline
\end{tabular}

Nota. Adaptado del anexo XVIII y anexo XIV.

\subsubsection{Presupuesto de costo de ventas}

En la Tabla 60 se muestra el presupuesto que se consideró en el proyecto como costos de ventas que incluye las remuneraciones del personal de ventas, los bonos o comisiones por ventas, los alquileres, servicios básicos del área, etc. y que tienen un impacto en el desarrollo de las actividades del proyecto.

Tabla 60

Costo de ventas

\begin{tabular}{|c|c|c|c|c|c|c|c|}
\hline Año & $\begin{array}{c}\text { Remuner. } \\
\text { Ventas }\end{array}$ & $\begin{array}{c}\text { Bonos } \\
\text { por } \\
\text { ventas } \\
\text { (S/. } 10 \mathrm{x} \\
\text { Millar) } \\
\end{array}$ & $\begin{array}{l}\text { Alquiler } \\
\text { Locales } \\
\text { ventas }\end{array}$ & $\begin{array}{l}\text { Servicios } \\
\text { Teléfono } \\
\mathrm{e} \\
\text { Internet }\end{array}$ & $\begin{array}{c}\text { Útiles de } \\
\text { escritorio } \\
\text { y } \\
\text { papelería }\end{array}$ & $\begin{array}{c}\text { Imprev. } \\
5 \%\end{array}$ & $\begin{array}{c}\text { Total de } \\
\text { gastos de } \\
\text { venta } \\
(\mathrm{S} / .)\end{array}$ \\
\hline Año 1 & & 30,000 & 2,700 & 2100 & 472.5 & 143.6 & $93,786.8$ \\
\hline Año 2 & 58,071 & 31,560 & 2,700 & 2400 & 1914 & 215.7 & $96,860.3$ \\
\hline Año 3 & 72,588 & 33,120 & 2,700 & 2400 & 1914 & 215.7 & $112,938.0$ \\
\hline Año 4 & 72,588 & 34,800 & 2,700 & 2400 & 1914 & 215.7 & $114,618.0$ \\
\hline Año 5 & 87,106 & 36,600 & 2,700 & 2400 & 1914 & 215.7 & $130,935.7$ \\
\hline
\end{tabular}

Nota. Tomado del anexo XIV. 


\subsubsection{Presupuesto de gastos administrativos}

La Tabla 61 muestra los gastos administrativos, que incluye las remuneraciones del personal administrativos, servicios básicos del área, etc. que impactan en el desarrollo del proyecto para los cinco primeros años.

Tabla 61

Total de Gastos administrativos

\begin{tabular}{|c|c|c|c|c|c|c|c|}
\hline \multirow[t]{2}{*}{ Año } & \multirow[t]{2}{*}{ Remunerac. } & \multicolumn{2}{|c|}{ Servicios Básicos } & \multirow{2}{*}{$\begin{array}{l}\text { Servicios } \\
\text { teléfono e } \\
\text { Internet }\end{array}$} & \multirow{2}{*}{$\begin{array}{c}\text { Útiles } \\
\text { escritor. y } \\
\text { papeler. }\end{array}$} & \multirow{2}{*}{$\begin{array}{c}\text { Imprev. } \\
5 \%\end{array}$} & \multirow{2}{*}{$\begin{array}{c}\text { Total gastos } \\
\text { administrat. } \\
\text { (S/.) }\end{array}$} \\
\hline & & Agua & Luz & & & & \\
\hline Año 1 & 51,239 & $2,856.1$ & 2,835 & 3,600 & 1,914 & 275.7 & $62,719.6$ \\
\hline Año 2 & 68,318 & $3,004.6$ & 3,014 & 3,600 & 1,914 & 275.7 & $80,126.2$ \\
\hline Año 3 & 68,318 & $3,153.1$ & 3,210 & 3,600 & 1,914 & 275.7 & $80,471.0$ \\
\hline Año 4 & 68,318 & $3,313.0$ & 3,426 & 3,600 & 1,914 & 275.7 & $80,847.0$ \\
\hline Año 5 & 68,318 & $3,484.4$ & 3,663 & 3,600 & 1,914 & 275.7 & $81,255.9$ \\
\hline
\end{tabular}

Nota. Tomado del anexo XIV.

\subsubsection{Presupuesto de marketing y ventas}

Se determinó el nivel de ventas real y proyectado de la empresa, para determinar límite de tiempo. El presupuesto marketing y ventas es el punto de apoyo del cual dependen todas las fases del plan de utilidades, la responsabilidad de establecer este presupuesto está a cargo del departamento de ventas tomando en cuenta factores que afecta las ventas como pueden ser las políticas de precio, el grado de competencia, el ingreso disponible, la actitud de los compradores, la aparición de nuevos productos, las condiciones económicas, etc.

La tabla 62 muestra el presupuesto de marketing y ventas del proyecto, que va ligado a la estrategia de ventas de nuestro producto. 
Tabla 62

Presupuesto Marketing y Ventas (S/.)

\begin{tabular}{|c|c|c|c|c|c|c|}
\hline $\mathrm{N}^{\circ}$ & Material & Tipo & Frecuencia & $\begin{array}{l}\text { Costo } \\
\text { Mes }\end{array}$ & $\begin{array}{l}\text { Costo } \\
\text { Anual }\end{array}$ & $\%$ \\
\hline 1 & Brouchure & \multirow{4}{*}{$\begin{array}{c}\text { Venta } \\
\text { Directa }\end{array}$} & Mensual & 120 & 1,440 & $3.6 \%$ \\
\hline 2 & Polos & & Mensual & 250 & 3,000 & $7.5 \%$ \\
\hline 3 & Gorros & & Mensual & 250 & 3,000 & $7.5 \%$ \\
\hline 4 & $\begin{array}{l}\text { (Lapicero, libreta, Llavero, } \\
\text { etc.) }\end{array}$ & & Mensual & 200 & 2,400 & $6.0 \%$ \\
\hline 5 & Hosting (Plan Avanzado) & \multirow{4}{*}{ Web } & Anual & - & 250 & $0.6 \%$ \\
\hline 6 & Registro de dominio & & Anual & - & 120 & $0.3 \%$ \\
\hline 7 & Internet (banners) & & Mensual & 200 & 2,400 & $6.0 \%$ \\
\hline 9 & Correo Directo & & Anual & - & 2,000 & $5.0 \%$ \\
\hline 10 & Banners & \multirow{4}{*}{$\begin{array}{c}\text { Capacita- } \\
\text { ciones }\end{array}$} & Semestral & 500 & 1,000 & $2.5 \%$ \\
\hline 11 & Trípticos & & Mensual & 200 & 2,400 & $6.0 \%$ \\
\hline 12 & Paleógrafos & & Mensual & 50 & 600 & $1.5 \%$ \\
\hline 13 & Plumones & & Mensual & 20 & 240 & $0.6 \%$ \\
\hline 14 & Anuncio en periódico local & \multirow{2}{*}{$\begin{array}{l}\text { Publici- } \\
\text { dad }\end{array}$} & Bimensual & 1000 & 6,000 & $15.1 \%$ \\
\hline 15 & Anuncio en radio local & & Mensual & 500 & 6,000 & $15.1 \%$ \\
\hline 16 & Inauguración de locales & \multirow{3}{*}{$\begin{array}{l}\text { Promo- } \\
\text { ción }\end{array}$} & Inauguración & - & 3,000 & $7.5 \%$ \\
\hline 17 & Presentación del producto & & Inauguración & - & 3,000 & $7.5 \%$ \\
\hline 18 & $\begin{array}{l}\text { Despliegue Inicial } \\
\text { promocional }\end{array}$ & & Inauguración & - & 3,000 & $7.5 \%$ \\
\hline & TOTAL & & & & 39,850 & $100 \%$ \\
\hline
\end{tabular}

Nota. Adaptado del estudio del proyecto

\subsubsection{Presupuesto de gastos financieros}

De acuerdo a la Superintendencia de banca, seguros y AFP se evidencio las diferentes tasas activas anuales de las operaciones en moneda nacional realizadas en los últimos 30 días útiles por tipo de crédito, para medianas y pequeñas empresas. La tabla 63 muestra un resumen de las principales tasas de interés de las entidades financieras más sólidas del mercado y que brindan el financiamiento para diferentes proyectos nacionales: 
Tabla 63

Tasas de interés promedio del sistema bancario

\begin{tabular}{lcccc}
\hline Tasa Anual (\%) & Continental & Crédito & Scotiabank & Interbank \\
\hline Medianas Empresas & 11.62 & 10.13 & 11.65 & 10.54 \\
Descuentos & 13.39 & 8.46 & 10.02 & 8.77 \\
Préstamos hasta 30 días & 11.05 & 9.47 & 11.54 & 10.21 \\
Préstamos de 31 a 90 días & 11.65 & 9.99 & 10.43 & 11.42 \\
Préstamos de 91 a 180 días & 12.19 & 11.87 & 10.72 & 9.75 \\
Préstamos de 181 a 360 días & 11.59 & 11.50 & 11.78 & 10.42 \\
Préstamos a más de 360 días & 9.58 & 10.13 & 14.62 & 12.28 \\
Pequeñas Empresas & 16.83 & 18.26 & 23.77 & 18.24 \\
Descuentos & 17.43 & 8.15 & 13.06 & 10.30 \\
Préstamos hasta 30 días & 17.05 & 8.41 & 17.66 & - \\
Préstamos de 31 a 90 días & 17.32 & 13.87 & 18.83 & 16.89 \\
Préstamos de 91 a 180 días & 17.67 & 22.93 & 16.65 & 15.99 \\
Préstamos de 181 a 360 días & 20.18 & 23.19 & 20.31 & 20.76 \\
Préstamos a más de 360 días & 13.40 & 15.80 & 25.02 & 18.95 \\
\hline
\end{tabular}

Nota: Adaptado de http://www.sbs.gob.pe/app/pp/EstadisticasSAEEPortal/Paginas/ TIActivaTipoCreditoEmpresa.aspx?tip=B, 03 octubre del 2016.

\section{Gatos financieros de la inversión fija}

El presupuesto de gasto financiero por inversión fija del proyecto se muestra en la Tabla 64 y es calculado de acuerdo a las tasas de interés correspondiente del Banco Continental mostrado en la Tabla 65. Se considera un periodo de gracia de un trimestre y veinte trimestres de amortización. 
Tabla 64

Inversión fija

\begin{tabular}{|c|c|c|c|c|c|}
\hline \multicolumn{2}{|c|}{ Monto en Soles } & \multicolumn{2}{|l|}{40,978} & \multirow[t]{2}{*}{ TEA } & \multirow[t]{2}{*}{$9.58 \%$} \\
\hline \multicolumn{2}{|c|}{ Periodo de gracia } & 1 & trimestre & & \\
\hline \multicolumn{2}{|c|}{ Plazo de amortización } & 20 & trimestres & & \\
\hline \multicolumn{2}{|c|}{ Tasa efectiva trimestral } & $2.31 \%$ & & & \\
\hline \multicolumn{2}{|c|}{ Periodo } & Saldo & Intereses & & Pago \\
\hline Año & Trimestre & deudor & Trim. & Amortiz. & $(\mathrm{S} /)$. \\
\hline \multirow{2}{*}{$\mathbf{0}$} & 3 & 40,978 & & & \\
\hline & 4 & 41,926 & 948 & -948 & - \\
\hline \multirow{4}{*}{1} & 1 & 40,254 & 970 & 1,672 & 2,642 \\
\hline & 2 & 38,543 & 931 & 1,711 & 2,642 \\
\hline & 3 & 36,792 & 892 & 1,751 & 2,642 \\
\hline & 4 & 35,001 & 851 & 1,791 & 2,642 \\
\hline \multirow{4}{*}{2} & 1 & 33,169 & 810 & 1,833 & 2,642 \\
\hline & 2 & 31,294 & 767 & 1,875 & 2,642 \\
\hline & 3 & 29,375 & 724 & 1,918 & 2,642 \\
\hline & 4 & 27,413 & 680 & 1,963 & 2,642 \\
\hline \multirow{4}{*}{3} & 1 & 25,405 & 634 & 2,008 & 2,642 \\
\hline & 2 & 23,350 & 588 & 2,055 & 2,642 \\
\hline & 3 & 21,248 & 540 & 2,102 & 2,642 \\
\hline & 4 & 19,097 & 492 & 2,151 & 2,642 \\
\hline \multirow{4}{*}{4} & 1 & 16,897 & 442 & 2,200 & 2,642 \\
\hline & 2 & 14,645 & 391 & 2,251 & 2,642 \\
\hline & 3 & 12,342 & 339 & 2,303 & 2,642 \\
\hline & 4 & 9,985 & 286 & 2,357 & 2,642 \\
\hline \multirow{4}{*}{5} & 1 & 7,574 & 231 & 2,411 & 2,642 \\
\hline & 2 & 5,107 & 175 & 2,467 & 2,642 \\
\hline & 3 & 2,583 & 118 & 2,524 & 2,642 \\
\hline & 4 & -0 & 60 & 2,583 & 2,642 \\
\hline
\end{tabular}

$\overline{\text { Nota. Adaptado de acuerdo a la tasa de interés correspondiente del Banco }}$ Continental, http://www.sbs.gob.pe/app/pp/EstadisticasSAEEPortal/Paginas/ TIActivaTipoCreditoEmpresa.aspx?tip=B, del 03 octubre del 2016. 


\section{Gastos financieros del capital de trabajo}

El presupuesto de gasto financiero por capital de trabajo del proyecto se muestra en la Tabla 65, que es calculado con las tasas de interés correspondientes del Banco Continental:

Tabla 65

Características de la inversión física

\begin{tabular}{|c|c|c|c|c|c|}
\hline \multicolumn{6}{|c|}{ Monto en Soles } \\
\hline & & \multirow{2}{*}{$\begin{array}{l}109,189 \\
1 \text { mes }\end{array}$} & \multicolumn{2}{|c|}{ TEA } & $13.40 \%$ \\
\hline Periodo & cia & & \multicolumn{2}{|c|}{ Plazo amortización } & 24 meses \\
\hline \multicolumn{6}{|c|}{ Tasa efectiva trimestral $1.05 \%$} \\
\hline \multicolumn{2}{|c|}{ Periodo } & \multirow{2}{*}{\multicolumn{2}{|c|}{ Saldo deudorIntereses mes }} & \multirow{2}{*}{ Amortiz. } & \multirow{2}{*}{ Pago (S/.) } \\
\hline Año & Mes & & & & \\
\hline $\mathbf{0}$ & 12 & 109,189 & & & \\
\hline \multirow{12}{*}{1} & 1 & 110,339 & 1,150 & $-1,150$ & \\
\hline & 2 & 106,274 & 1,162 & 4,065 & 5,227 \\
\hline & 3 & 102,167 & 1,120 & 4,108 & 5,227 \\
\hline & 4 & 98,016 & 1,076 & 4,151 & 5,227 \\
\hline & 5 & 93,821 & 1,033 & 4,195 & 5,227 \\
\hline & 6 & 89,583 & 988 & 4,239 & 5,227 \\
\hline & 7 & 85,299 & 944 & 4,283 & 5,227 \\
\hline & 8 & 80,970 & 899 & 4,329 & 5,227 \\
\hline & 9 & 76,596 & 853 & 4,374 & 5,227 \\
\hline & 10 & 72,176 & 807 & 4,420 & 5,227 \\
\hline & 11 & 67,709 & 760 & 4,467 & 5,227 \\
\hline & 12 & 63,195 & 713 & 4,514 & 5,227 \\
\hline \multirow{11}{*}{2} & 1 & 58,634 & 666 & 4,561 & 5,227 \\
\hline & 2 & 54,024 & 618 & 4,609 & 5,227 \\
\hline & 3 & 49,366 & 569 & 4,658 & 5,227 \\
\hline & 4 & 44,659 & 520 & 4,707 & 5,227 \\
\hline & 5 & 39,903 & 470 & 4,757 & 5,227 \\
\hline & 6 & 35,096 & 420 & 4,807 & 5,227 \\
\hline & 7 & 30,238 & 370 & 4,857 & 5,227 \\
\hline & 8 & 25,330 & 319 & 4,909 & 5,227 \\
\hline & 9 & 20,369 & 267 & 4,960 & 5,227 \\
\hline & 10 & 15,357 & 215 & 5,013 & 5,227 \\
\hline & 11 & 10,291 & 162 & 5,065 & 5,227 \\
\hline
\end{tabular}


Monto en Soles
109,189
TEA
$13.40 \%$

Periodo de gracia 1 mes

Plazo amortización 24 meses

Tasa efectiva trimestral $1.05 \%$

\begin{tabular}{|c|c|c|c|c|c|}
\hline \multicolumn{2}{|c|}{ Periodo } & \multirow{2}{*}{\multicolumn{2}{|c|}{ Saldo deudorIntereses mes }} & \multirow{2}{*}{ Amortiz. } & \multirow{2}{*}{ Pago (S/.) } \\
\hline Año & Mes & & & & \\
\hline & 12 & 5,173 & 108 & 5,119 & 5,227 \\
\hline 3 & 1 & 0 & 54 & 5,173 & 5,227 \\
\hline
\end{tabular}

Nota. Adaptado de Cálculos con tasa de interés correspondiente del Banco

Continental,

http://www.sbs.gob.pe/app/pp/EstadisticasSAEEPortal/Paginas/TIActivaTipoCredito Empresa.aspx?tip=B, del 03 octubre del 2016.

\section{Resumen del presupuesto del gasto financiero}

El resumen del servicio a la deuda por año se muestra en la Tabla 66.

Tabla 66

Resumen del servicio a la deuda anual

\begin{tabular}{cccccc}
\hline & Añorsión & \multicolumn{2}{c}{$\begin{array}{c}\text { Capital } \\
\text { de } \\
\text { Trabajo } \\
(\text { S/.) }\end{array}$} & $\begin{array}{c}\text { Pago } \\
\text { fija } / .)\end{array}$ & $\begin{array}{c}\text { (S/.) } \\
\text { anual }\end{array}$ \\
\hline 1 & 10,569 & 57,499 & 68,068 & 20,441 \\
2 & 10,569 & 62,726 & 73,295 & 22,011 \\
3 & 10,569 & 5,227 & 15,796 & 4,744 \\
4 & 10,569 & - & 10,569 & 3,174 \\
5 & 10,569 & - & 10,569 & 3,174 \\
\hline
\end{tabular}

Nota. Adaptado de Tabla 64 y 65

\subsection{Presupuestos de Resultados}

\subsubsection{Estado de ganancias y pérdidas proyectado}

Es un estado financiero que muestra los ingresos de una organización así como sus gastos, durante un determinado periodo. También se llama estado de ingresos y egresos, estado de resultados, estado de ingresos y gastos, estado de rendimientos. En 
la Tabla 67 se muestra el estado de pérdidas y ganancias con financiamiento del proyecto.

Según el reglamento de información financiera CONASEV en su artículo $25^{\circ}$ :

El estado de ganancias y pérdidas comprende las cuentas de ingresos, costos y gastos, presentados según el método de función de gasto. En su formulación se debe observar lo siguiente:

1. Debe incluirse todas las partidas que representen ingresos o ganancias y gastos o pérdidas originados durante el periodo.

2. Solo debe incluirse las partidas que afecten la determinación de los resultados netos.

Tabla 67

Estado de pérdidas y ganancias con financiamiento (S/.)

\begin{tabular}{lrrrrr}
\hline \multicolumn{1}{c}{ Rubro } & \multicolumn{1}{c}{ Año 1 } & \multicolumn{1}{c}{ Año 2 } & Año 3 & Año 4 & Año 5 \\
\hline (+) Ventas & $1,298,700$ & $1,502,856$ & $1,734,855$ & $2,005,141$ & $2,319,741$ \\
(-) Costo de Producción & $1,147,940$ & $1,189,396$ & $1,265,911$ & $1,311,118$ & $1,377,319$ \\
(=) Utilidad bruta & 150,760 & 313,459 & 468,944 & 694,023 & 942,421 \\
(-) Gastos Administrativos & 137,870 & 137,870 & 137,870 & 137,870 & 137,870 \\
(-) Gastos Ventas & 39,850 & 39,850 & 39,850 & 39,850 & 39,850 \\
(=) Utilidad Operativa & $-26,960$ & 135,740 & 291,224 & 516,303 & 764,701 \\
(-) Gastos Financieros & 68,068 & 73,295 & 15,796 & 10,569 & 10,569 \\
(-) Depreciación & 36,919 & 29,619 & 22,319 & 15,019 & 7,718 \\
(-) Amortización Intangibles & 3,784 & 3,784 & 3,784 & 3,784 & 3,784 \\
(=) Utilidad Antes de & & & & & \\
Impuestos & $-135,731$ & 29,042 & 249,325 & 486,932 & 742,630 \\
(-) Impuestos a la renta & & & & & \\
(30\%) & $-40,719$ & 8,713 & 74,798 & 146,080 & 222,789 \\
(=) UTILIDAD NETA & $-95,012$ & 20,329 & 174,528 & 340,852 & 519,841 \\
\hline
\end{tabular}

Nota: Adaptado del punto 8.1 ,8.2 y 8.3 del Capítulo de Planificación Financiera del presente estudio. 


\subsubsection{Balance proyectado}

El balance general del proyecto también llamado estado de situación financiera muestra una información resumen de todo lo que tiene la empresa, de lo que debe, lo que le deben y de lo que realmente le pertenece a su propietario a una fecha determinada, en la Tabla 68 se muestra el activo corriente y el pasivo corriente del proyecto, que ha sido adaptado del punto 8.1 ,8.2 y 8.3 del Capítulo de Planificación Financiera del presente estudio.

Tabla 68

Balance general del proyecto $(\mathrm{S} /$.)

\begin{tabular}{|c|c|c|c|}
\hline \multicolumn{2}{|l|}{ Activo } & \multicolumn{2}{|l|}{ Pasivo } \\
\hline ACTIVO CORRIENTE & & PASIVO CORRIENTE & \\
\hline Caja y Bancos & $109,189.0$ & Crédito & $150,167.2$ \\
\hline Total activo corriente & $109,189.0$ & & \\
\hline Activo no corriente & & Total pasivo corriente & $150,167.2$ \\
\hline Activos fijos & & Patrimonio & \\
\hline Maquinaria y equipo & $109,504.0$ & Capital Social & $150,167.2$ \\
\hline Muebles y enseres & $14,096.0$ & Total patrimonio & $150,167.2$ \\
\hline Terrenos & $12,941.45$ & & \\
\hline Construcciones & $27,325.04$ & & \\
\hline Imprevistos $(5 \%)$ & $8,360.5$ & & \\
\hline Total Activo Fijo & $172,227.0$ & & \\
\hline Activos intangibles & & & \\
\hline Estudios de Pre-Inversión & $2,500.0$ & & \\
\hline Estudios definitivos o particulares & $4,623.0$ & & \\
\hline Organización y Capacitación & $1,400.0$ & & \\
\hline Pruebas y puestas en marcha & $3,500.0$ & & \\
\hline Intereses Pre - Operativos & $5,977.0$ & & \\
\hline Imprevistos $(5 \%)$ & 918.4 & & \\
\hline Total Activo Intangible & $18,918.4$ & & \\
\hline
\end{tabular}




\begin{tabular}{rccc}
\hline Activo & \multicolumn{2}{c}{ Pasivo } \\
\hline Total activo no corriente & $\mathbf{1 9 1 , \mathbf { 1 4 5 . 4 }}$ & & \\
\hline Total activo & $300,334.4$ & $\begin{array}{c}\text { Total pasivo y } \\
\text { patrimonio }\end{array}$ & $300,334.4$ \\
\hline
\end{tabular}

Nota: Adaptado del punto 8.1 ,8.2 y 8.3 del Capítulo de Planificación Financiera del presente estudio.

\subsubsection{Flujo de caja proyectado}

El estado de flujo de efectivo proyectado muestra el plan de ingresos, egresos y saldos de efectivo proyectados.

El flujo de efectivo proyectado es una herramienta básica para la administración financiero, con ello se planifica el uso eficiente de efectivo, manteniendo saldos razonablemente cercanos a las permanentes necesidades de efectivo. Generalmente los flujos de efectivo proyectados ayudan a evitar cambios arriesgados en la situación de efectivo que pueden poner en peligro el crédito de la empresa hacia sus acreedores o excesos de capital durmiente en efectivo. En la Tabla 69 se muestra el flujo de caja con financiamiento para los cinco primeros años de vida del proyecto. 
Tabla 69:

Flujo de caja con financiamiento (S/.)

\begin{tabular}{|c|c|c|c|c|c|c|}
\hline Rubro & Año (0) & Año 1 & Año 2 & Año 3 & Año 4 & Año 5 \\
\hline \multicolumn{7}{|l|}{ Ingresos } \\
\hline Ventas & 0 & $1,298,700$ & $1,502,856$ & $1,734,855$ & $2,005,141$ & $2,319,741$ \\
\hline Valor de Recupero & 0 & 0 & 0 & 0 & 0 & 0 \\
\hline Recuperación del C.T. & 0 & 0 & 0 & 0 & 0 & 0 \\
\hline Préstamo & 150,167 & 0 & 0 & 0 & 0 & 0 \\
\hline Subtotal de Ingresos & 150,167 & $1,298,700$ & $1,502,856$ & $1,734,855$ & $2,005,141$ & $2,319,741$ \\
\hline \multicolumn{7}{|l|}{ Egresos } \\
\hline Costos de Producción & 0 & $1,147,940$ & $1,189,396$ & $1,265,911$ & $1,311,118$ & $1,377,319$ \\
\hline Gastos de Operación & 0 & 177,720 & 177,720 & 177,720 & 177,720 & 177,720 \\
\hline Gastos Financieros & 0 & 68,068 & 73,295 & 15,796 & 10,569 & 10,569 \\
\hline Impuesto a la Renta & 0 & $-40,719$ & 8,713 & 74,798 & 146,080 & 222,789 \\
\hline Subtotal de Egresos & 0 & $1,353,009$ & $1,449,124$ & $1,534,225$ & $1,645,486$ & $1,788,397$ \\
\hline \multicolumn{7}{|l|}{ Inversiones } \\
\hline Inversión Fija Tangible & 172,227 & 0 & 0 & 0 & 0 & 0 \\
\hline Inversión Fija Intangible & 18,918 & 0 & 0 & 0 & 0 & 0 \\
\hline Capital de Trabajo & 109,189 & 0 & 0 & 0 & 0 & 0 \\
\hline Subtotal de Inversiones & 300,334 & 0 & 0 & 0 & 0 & 0 \\
\hline $\begin{array}{l}\text { Flujo de Caja } \\
\text { Económico }\end{array}$ & 150,167 & $-54,309$ & 53,732 & 200,630 & 359,655 & 531,343 \\
\hline
\end{tabular}

Nota: Adaptado del punto 8.1 ,8.2 y 8.3 del Capítulo de Planificación Financiera del presente estudio. 


\section{Capítulo IX: Evaluación Económica Financiera.}

\subsection{Evaluación Financiera}

\subsubsection{Tasa Interna de Retorno (TIR)}

A través del valor presente neto (VPN), se obtiene la ganancia de manera monetaria del proyecto, trayendo los ingresos y egresos programados durante el horizonte del proyecto a la actualidad.

Tabla 70

Cálculo del VAN y TIR económico

\begin{tabular}{|c|c|c|c|c|c|}
\hline Año & $\begin{array}{l}\text { Flujo de caja } \\
\text { económico } \\
(\mathrm{S} / .)\end{array}$ & $\begin{array}{c}\text { f.s.a. } \\
(29.06)\end{array}$ & Costos & $\begin{array}{l}\text { VAN } \\
(\mathrm{S} / .)\end{array}$ & $\begin{array}{c}\text { VAN } \\
\text { acumulado } \\
(\mathrm{S} / .)\end{array}$ \\
\hline Año 0 & $-300,334.4$ & 1.000 & $\begin{array}{c}- \\
300,334.4\end{array}$ & $\begin{array}{c}- \\
300,334.4\end{array}$ & $-300,334.4$ \\
\hline Año 1 & $-6,661.1$ & 0.872 & & $-5,807.3$ & $-306,141.7$ \\
\hline Año 2 & $105,038.6$ & 0.760 & & $79,835.7$ & $-226,306.0$ \\
\hline Año 3 & $211,687.7$ & 0.663 & & $140,271.1$ & $-86,034.9$ \\
\hline Año 4 & $367,053.0$ & 0.578 & & $212,043.7$ & $126,008.8$ \\
\hline Año 5 & $538,741.6$ & 0.504 & & $271,332.2$ & $397,340.9$ \\
\hline TIR & $42.57 \%$ & & & & \\
\hline
\end{tabular}

Nota. Tomado del anexo XXV.

Tabla 71

Cálculo del VAN y TIR financiero

\begin{tabular}{|c|c|c|c|c|c|}
\hline Año & $\begin{array}{c}\text { Flujo de caja } \\
\text { financiero } \\
(\mathrm{S} / .)\end{array}$ & $\begin{array}{c}\text { f.s.a. } \\
(29.06)\end{array}$ & Costos & $\begin{array}{l}\text { VAN } \\
(\mathrm{S} / .)\end{array}$ & $\begin{array}{c}\text { VAN } \\
\text { acumulado (S/.) }\end{array}$ \\
\hline Año 0 & $-150,167.2$ & 1.0 & $-150,167.2$ & $\begin{array}{c}- \\
150,167.2\end{array}$ & $-150,167.2$ \\
\hline Año 1 & $-54,308.6$ & 0.9 & & $-47,836.2$ & $-198,003.4$ \\
\hline Año 2 & $53,732.1$ & 0.8 & & $41,687.8$ & $-156,315.6$ \\
\hline Año 3 & $200,630.3$ & 0.7 & & $137,107.0$ & $-19,208.6$ \\
\hline Año 4 & $359,654.6$ & 0.6 & & $216,489.3$ & $197,280.7$ \\
\hline Año 5 & $531,343.2$ & 0.5 & & $281,717.4$ & $478,998.1$ \\
\hline TIR & $57.89 \%$ & & & & \\
\hline
\end{tabular}

Nota. Tomado del anexo XXV. 
Como se observa en las Tablas 71 y 72, el cálculo realizado dio como resultado un TIR Financiero de $57.89 \%$. Esta tasa se basó en el flujo de los próximos 5 años que se programó el proyecto. A su vez se comparó el TIR Financiero con el COK (14.7\%), siendo el primero mayor por lo tanto se acepta el proyecto. (Ver anexo XXV).

\subsubsection{Valor Actual Neto (VAN)}

Este método sirve para calcular la ganancia o pérdida monetaria neta esperada del proyecto mediante el descuento hasta el presente de todos los flujos futuros esperados de entradas y salidas de efectivo. Los valores del VPN Económico y Financiero obtenidos para nuestro proyecto son:

\begin{tabular}{|l|r|}
\hline VAN Económico & $397,340.9$ \\
\hline VAN Financiero & $478,998.1$ \\
\hline
\end{tabular}

Tomado el COK del 14.7\% y con un valor presente neto económico de S/.397,340.9, se determina realizar el proyecto.(Ver anexo XXV).

\subsubsection{Rentabilidad Financiera (ROE)}

Mide la rentabilidad que obtienen los propietarios de un proyecto, para lo cual compara el resultado del ejercicio (beneficio neto) con los fondos propios.

Tabla 72

Cálculo del ROE

\begin{tabular}{|c|c|c|c|c|c|c|}
\hline ROE & ROE & Año 1 & Año 2 & Año 3 & Año 4 & Año 5 \\
\hline $\begin{array}{c}\text { Retorno Sobre } \\
\text { el Capital }\end{array}$ & $\frac{\text { Utilidad Neta }}{\text { Capital de }} \begin{array}{c}\text { Accionistas } \\
\text { Aclons }\end{array}$ & $-0.63 \%$ & $0.14 \%$ & $1.16 \%$ & $2.27 \%$ & $3.46 \%$ \\
\hline
\end{tabular}

Nota. Adaptado del análisis Financiero del proyecto. 
En la Tabla 72, se observa que el ROE tiene una tendencia positiva a través del tiempo, lo que demuestra que el proyecto se vuelve atractivo para los inversionistas que tienen una alternativa para la rentabilidad de su dinero.

\subsubsection{Ratios}

\section{Beneficio - Costo}

Contrario al VAN, cuyos resultados están expresados en términos absolutos, este indicador financiero expresa la rentabilidad en términos relativos. Mide la relación entre los costos y beneficios asociados a un proyecto de inversión con el fin de evaluar su rentabilidad. La interpretación de tales resultados es en centavos por cada "Sol" que se ha invertido.

Tabla 73

Cálculo del costo/beneficio

\begin{tabular}{cccccc}
\hline Año & $\begin{array}{c}\text { Flujo de } \\
\text { caja } \\
\text { económico } \\
(\mathrm{S} / .)\end{array}$ & f.s.a. & Costos & Beneficios & $\begin{array}{c}\text { Actualización } \\
\text { de beneficios }\end{array}$ \\
\hline Año 0 & $-300,334.4$ & 1.0 & - & & \\
Año 1 & $3,501.2$ & 0.9 & & $3,052.4$ & $2,661.1$ \\
Año 2 & $115,200.9$ & 0.8 & & $87,559.7$ & $66,550.7$ \\
Año 3 & $221,850.1$ & 0.7 & & $147,005.0$ & $97,410.2$ \\
Año 4 & $377,215.3$ & 0.6 & & $217,914.4$ & $125,887.5$ \\
Año 5 & $548,904.0$ & 0.5 & & $276,450.4$ & $139,231.6$ \\
\hline
\end{tabular}

\section{$. \mathrm{B} / \mathrm{C}=\quad \Sigma$ Actualización de beneficios $/$ Costos}

Beneficio/Costo Económico 1.44

Nota. Adaptado del anexo XXV

Entonces, de acuerdo a la Tabla 62 se puede evidenciar que por cada Sol que se invierte, se obtiene una ganancia de S/. 0.44 centavos de Sol. 


\subsection{Análisis de riesgo}

\subsubsection{Análisis de punto de equilibrio}

\section{Qo $=$ Cantidad en el punto de equilibrio}

$\begin{array}{ccl}\mathrm{CF}=\mathrm{S} / . & 395,382.4 & \\ \mathrm{P}=\mathrm{S} / . & 523.8 & Q_{0}=\frac{C F}{(P-C V u)} \\ \mathrm{CVu}=\mathrm{S} / . & 317.8 & \text { Millares } \\ \mathrm{Qo}= & 1,919.6 & \end{array}$

Esto quiere decir que, si se fabrican y venden más de 1,919 millares de bloquetas de plástico al año, el producto generará utilidades, si se fabrican y venden menos de 1,919 millares producirá pérdidas.

\begin{tabular}{ccc}
\hline $\mathbf{Q 1 0 0}=\begin{array}{l}\text { Cantidad en el punto de } \\
\text { equilibrio en \% }\end{array}$ & \\
\hline $\mathrm{CF}=$ & $395,382.4$ & $Q 100=\frac{C F}{(V-C V)} \times 100$ \\
$\mathrm{~V}=$ & $1,734,855.4$ & \\
$\mathrm{CV}=$ & $1,051,933.2$ & $\%$ \\
$\mathrm{Q} 100=$ & 57.9 & \\
\hline
\end{tabular}

Esto quiere decir que, de las ventas totales, el $57.9 \%$ es empleado para el pago de los costos fijos y variables y el $42.1 \%$ restante, es la utilidad neta que obtiene la empresa.

\subsubsection{Análisis de sensibilidad}

Para evaluar el proyecto y medir cuan accesible es realizarlo a las variaciones que se presentan. A continuación, se presentan los supuestos considerados para realizar el análisis y los cambios que se generan en el valor actual económico y financiero. 
Las variables utilizadas para los supuestos son: la materia prima, la mano de obra y la demanda del proyecto.

El supuesto considerado es la variación $-20 \%$ hasta $+20 \%$ aumentando de $5 \%$ en 5\%. Para cada una de las variables. Cabe resaltar que para el análisis solo se consideró la variación de una de las variables mientras que las otras continúan en el mismo estado.

\section{Análisis de la variable costo de mano de obra}

En la Tabla 74, se evidencia las variaciones del VAN y el TIR en función al cambio de los costos de mano de obra.

Tabla 74

Variación del VAN y TIR en función al cambio de los costos de mano de obra

\begin{tabular}{ccccccccc}
\hline $\begin{array}{c}\% \text { de } \\
\text { Cambio }\end{array}$ & Año 0 & Año 1 & Año 2 & Año 3 & Año 4 & Año 5 & VAN & TIR \\
\hline$-20 \%$ & $-150,167$ & $-40,645$ & 42,986 & 160,504 & 287,724 & 425,075 & 355,633 & $50.5 \%$ \\
$-15 \%$ & $-150,167$ & $-44,061$ & 45,672 & 170,536 & 305,706 & 451,642 & 386,474 & $52.5 \%$ \\
$-10 \%$ & $-150,167$ & $-47,477$ & 48,359 & 180,567 & 323,689 & 478,209 & 417,316 & $54.4 \%$ \\
$-5 \%$ & $-150,167$ & $-50,893$ & 57,148 & 204,900 & 363,924 & 536,467 & 492,862 & $59.3 \%$ \\
$0 \%$ & $-150,167$ & $-54,309$ & 53,732 & 200,630 & 359,655 & 531,343 & 478,998 & $57.9 \%$ \\
$5 \%$ & $-150,167$ & $-57,725$ & 50,316 & 196,360 & 355,385 & 526,219 & 465,134 & $56.5 \%$ \\
$10 \%$ & $-150,167$ & $-61,140$ & 46,900 & 192,091 & 351,115 & 521,095 & 451,270 & $55.1 \%$ \\
$15 \%$ & $-150,167$ & $-64,556$ & 43,484 & 187,821 & 346,845 & 515,972 & 437,406 & $53.8 \%$ \\
$20 \%$ & $-150,167$ & $-67,972$ & 40,068 & 183,551 & 342,575 & 510,848 & 423,542 & $52.4 \%$ \\
\hline
\end{tabular}

Nota. Tomado del anexo XXV.

En los resultados podemos observar que la variable de mano de obra es sensible al proyecto, teniendo una relación inversa con el VAN financiero. 


\section{Análisis de la variable materia prima}

Es importante analizar los nuevos ratios financieros cuando existe una variación en los costos de la materia prima. En la Tabla 75, se observa el nuevo flujo de caja financiero a diferentes porcentajes de variación.

Tabla 75

Variación del VAN y TIR en función al cambio de los costos de materia prima.

\begin{tabular}{ccccccccc}
\hline $\begin{array}{c}\text { \% de } \\
\text { Cambio }\end{array}$ & Año 0 & Año 1 & Año 2 & Año 3 & Año 4 & Año 5 & VAN & TIR \\
\hline$-20 \%$ & $-150,167$ & 124,965 & 242,328 & 398,549 & 567,612 & 750,057 & $1,159,621$ & $139.5 \%$ \\
$-15 \%$ & $-150,167$ & 80,147 & 195,179 & 349,069 & 515,623 & 695,379 & 989,465 & $117.0 \%$ \\
$-10 \%$ & $-150,167$ & 35,328 & 148,030 & 299,589 & 463,633 & 640,700 & 819,309 & $95.9 \%$ \\
$-5 \%$ & $-150,167$ & $-9,490$ & 100,881 & 250,110 & 411,644 & 586,022 & 649,154 & $76.2 \%$ \\
$0 \%$ & $-150,167$ & $-54,309$ & 53,732 & 200,630 & 359,655 & 531,343 & 478,998 & $57.9 \%$ \\
$5 \%$ & $-150,167$ & $-99,127$ & 6,583 & 151,151 & 307,665 & 476,665 & 308,842 & $41.0 \%$ \\
$10 \%$ & $-150,167$ & $-143,946$ & $-40,566$ & 101,671 & 255,676 & 421,986 & 138,687 & $25.4 \%$ \\
$15 \%$ & $-150,167$ & $-188,764$ & $-87,715$ & 52,192 & 203,686 & 367,308 & $-31,469$ & $10.9 \%$ \\
$20 \%$ & $-150,167$ & $-233,583$ & $-134,864$ & 2,712 & 151,697 & 312,629 & $-201,625$ & $-2.8 \%$ \\
\hline
\end{tabular}

Nota. Tomado del anexo XXV.

El análisis que se obtiene de los siguientes resultados es que tienen una relación inversa ya que si aumenta el costo de materia prima el VAN Financiero se reduce, al punto de hacer inviable el proyecto cuando el porcentaje de cambio llega al $20 \%$ de incremento.

\section{Análisis de la demanda del proyecto}

A continuación, en la Tabla 76, se observa los cambios efectuados en el flujo de caja financiero al cambiar la demanda de proyecto, para hallar los nuevos VAN Financieros. Los escenarios que se han calculado son en una variación de 5\% con un alcance $-20 \%$ y $20 \%$. 
Tabla 76

Cálculo de VAN y TIR al cambio de la demanda del proyecto

\begin{tabular}{ccccccccc}
\hline $\begin{array}{c}\text { \% de } \\
\text { Cambio }\end{array}$ & Año 0 & Año 1 & Año 2 & Año 3 & Año 4 & Año 5 & VAN & TIR \\
\hline$-20 \%$ & $-150,167$ & $-43,447$ & 42,986 & 160,504 & 287,724 & 425,075 & 353,165 & $50.1 \%$ \\
$-15 \%$ & $-150,167$ & $-46,162$ & 45,672 & 170,536 & 305,706 & 451,642 & 384,623 & $52.2 \%$ \\
$-10 \%$ & $-150,167$ & $-48,878$ & 48,359 & 180,567 & 323,689 & 478,209 & 416,082 & $54.2 \%$ \\
$-5 \%$ & $-150,167$ & $-51,593$ & 51,045 & 190,599 & 341,672 & 504,776 & 447,540 & $56.1 \%$ \\
$0 \%$ & $-150,167$ & $-54,309$ & 53,732 & 200,630 & 359,655 & 531,343 & 478,998 & $57.9 \%$ \\
$5 \%$ & $-150,167$ & $-57,024$ & 56,419 & 210,662 & 377,637 & 557,910 & 510,456 & $59.6 \%$ \\
$10 \%$ & $-150,167$ & $-59,740$ & 59,105 & 220,693 & 395,620 & 584,478 & 541,915 & $61.3 \%$ \\
$15 \%$ & $-150,167$ & $-62,455$ & 61,792 & 230,725 & 413,603 & 611,045 & 573,373 & $62.9 \%$ \\
$20 \%$ & $-150,167$ & $-65,170$ & 64,478 & 240,756 & 431,585 & 637,612 & 604,831 & $64.5 \%$ \\
\hline
\end{tabular}

Nota. Tomado del anexo XXV.

De la tabla se obtiene que la demanda al disminuir más del 20\%, no genera la inviabilidad del proyecto. Adicionalmente, si la variable se incrementa en $20 \%$ el VAN Financiero se eleva a los 600,000 soles.

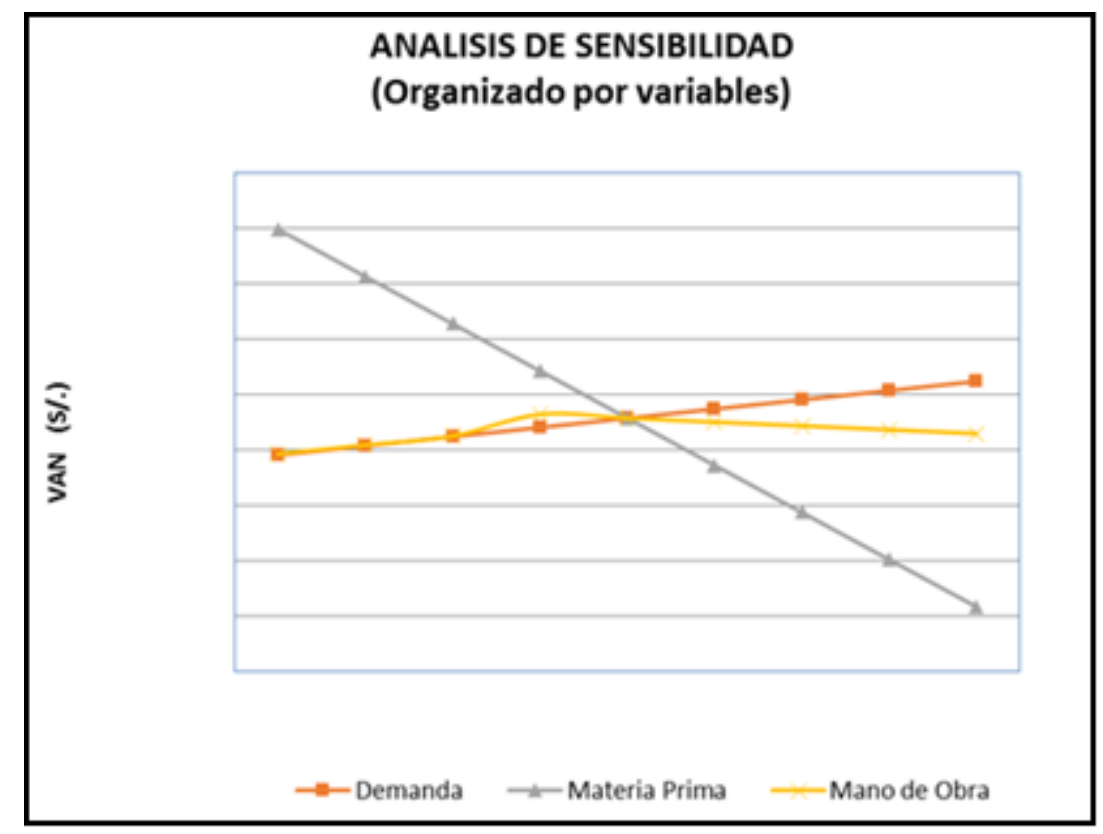

Figura 43. Adaptado de Análisis de sensibilidad de las variaciones de mano de obra, materia prima y demanda del producto. 
Como se muestra en la Figura 43, el proyecto es más sensible a un incremento en los precios de la materia prima. Si se incrementa alrededor de $15 \%$, el proyecto ya no se acepta. Por otro lado, presenta una menor sensibilidad en la mano de obra. Finalmente, se puede apreciar el grado de sensibilidad de cada una de las variables mostrado en la pendiente de su recta.

\subsubsection{Análisis de escenarios}

A continuación, se presentan los escenarios a los cuales se sometió el proyecto.

1.- Escenario Pesimista

Tabla 77

Flujo de caja en un escenario pesimista

\begin{tabular}{|c|c|c|c|c|c|c|}
\hline Rubro & Año (0) & Año 1 & Año 2 & Año 3 & Año 4 & Año 5 \\
\hline \multicolumn{7}{|l|}{ Ingresos } \\
\hline Ventas & 0.0 & $1,298,700.0$ & $1,428,570.0$ & $1,571,427.0$ & $1,728,569.7$ & $1,901,426.7$ \\
\hline Subtotal de Ingresos & 0.0 & $1,298,700.0$ & $1,428,570.0$ & $1,571,427.0$ & $1,728,569.7$ & $1,901,426.7$ \\
\hline \multicolumn{7}{|l|}{ Egresos } \\
\hline Costos de Producción & 0 & $1,192,759$ & $1,187,603$ & $1,217,507$ & $1,212,517$ & $1,224,936$ \\
\hline Gastos de Operación & 0 & 163,202 & 163,202 & 163,202 & 163,202 & 163,202 \\
\hline Impuesto a la Renta & 0 & $-49,810$ & $-8,680$ & 44,646 & 97,044 & 147,365 \\
\hline Subtotal de Egresos & 0 & $1,306,151$ & $1,342,126$ & $1,425,355$ & $1,472,763$ & $1,535,504$ \\
\hline \multicolumn{7}{|l|}{ Inversiones } \\
\hline $\begin{array}{l}\text { Inversión Fija } \\
\text { Tangible }\end{array}$ & 172,227 & 0 & 0 & 0 & 0 & 0 \\
\hline $\begin{array}{l}\text { Inversión Fija } \\
\text { Intangible }\end{array}$ & 18,918 & 0 & 0 & 0 & 0 & 0 \\
\hline Capital de Trabajo & 109,189 & 0 & 0 & 0 & 0 & 0 \\
\hline $\begin{array}{l}\text { Subtotal de } \\
\text { Inversiones }\end{array}$ & 300,334 & 0 & 0 & 0 & 0 & 0 \\
\hline $\begin{array}{l}\text { Flujo de Caja } \\
\text { Económico }\end{array}$ & $-300,334$ & $-7,451$ & 86,444 & 146,072 & 255,807 & 365,923 \\
\hline
\end{tabular}




\begin{tabular}{rrrrrrr}
\hline AÑO & $\begin{array}{l}\text { Flujo de } \\
\text { caja (S/.) }\end{array}$ & f.s.a. & Costos & Beneficios & $\begin{array}{c}\text { Actualización } \\
\text { de beneficios }\end{array}$ & $\begin{array}{c}\text { VAN } \\
\text { Acumulado }\end{array}$ \\
\hline Año 0 & $-300,334.4$ & 1.0 & $-300,334.4$ & & & $-300,334.4$ \\
Año 1 & $-7,451.3$ & 0.9 & & $-6,496.2$ & $-5,663.5$ & $-306,830.6$ \\
Año 2 & $86,444.4$ & 0.8 & & $65,703.0$ & $49,938.3$ & $-241,127.6$ \\
Año 3 & $146,071.9$ & 0.7 & $96,791.9$ & $64,137.4$ & $-144,335.7$ \\
Año 4 & $255,806.7$ & 0.6 & $147,777.6$ & $85,370.0$ & $3,441.9$ \\
Año 5 & $365,923.0$ & 0.5 & & $184,293.7$ & $92,817.8$ & $187,735.5$ \\
\hline
\end{tabular}

\begin{tabular}{|l|c|}
\hline VAN $=$ & $187,735.54$ \\
\hline TIR $=$ & $30 \%$ \\
\hline BENEFICIO $/$ COSTO $=$ & 0.95 \\
\hline
\end{tabular}

Nota. Adaptado del estudio de ingeniería del proyecto

2.- Escenario Esperado

Tabla 78

Flujo de caja en un escenario esperado

\begin{tabular}{|c|c|c|c|c|c|c|}
\hline Rubro & Año (0) & Año 1 & Año 2 & Año 3 & Año 4 & Año 5 \\
\hline \multicolumn{7}{|l|}{ Ingresos } \\
\hline Ventas & 0.0 & $1,298,700.0$ & $1,502,855.6$ & $1,734,855.4$ & $2,005,140.9$ & $2,319,740.5$ \\
\hline Subtotal de Ingresos & 0.0 & $1,298,700.0$ & $1,502,855.6$ & $1,734,855.4$ & $2,005,140.9$ & $2,319,740.5$ \\
\hline \multicolumn{7}{|l|}{ Egresos } \\
\hline Costos de Producción & 0.0 & $1,147,940.3$ & $1,189,396.2$ & $1,265,911.3$ & $1,311,117.8$ & $1,377,319.3$ \\
\hline Gastos de Operación & 0.0 & $163,202.1$ & $163,202.1$ & $163,202.1$ & $163,202.1$ & $163,202.1$ \\
\hline Impuesto a la Renta & 0.0 & $-15,943.6$ & $35,056.4$ & $83,891.8$ & $153,605.6$ & $230,315.2$ \\
\hline Subtotal de Egresos & 0.0 & $1,295,198.8$ & $1,387,654.7$ & $1,513,005.3$ & $1,627,925.5$ & $1,770,836.6$ \\
\hline \multicolumn{7}{|l|}{ Inversiones } \\
\hline Inversión Fija Tangible & $172,227.0$ & 0.0 & 0.0 & 0.0 & 0.0 & 0.0 \\
\hline $\begin{array}{l}\text { Inversión Fija } \\
\text { Intangible }\end{array}$ & $18,918.4$ & 0.0 & 0.0 & 0.0 & 0.0 & 0.0 \\
\hline Capital de Trabajo & $109,189.0$ & 0.0 & 0.0 & 0.0 & 0.0 & 0.0 \\
\hline Subtotal de Inversiones & $300,334.4$ & 0.0 & 0.0 & 0.0 & 0.0 & 0.0 \\
\hline $\begin{array}{l}\text { Flujo de Caja } \\
\text { Económico (\$) }\end{array}$ & 300,334. & $3,501.2$ & $115,200.9$ & $221,850.1$ & $377,215.3$ & $548,904.0$ \\
\hline
\end{tabular}




\begin{tabular}{ccccccc}
\hline AÑO & $\begin{array}{c}\text { Flujo de } \\
\text { caja (S/.) }\end{array}$ & f.s.a. & Costos & Beneficios & $\begin{array}{c}\text { Actualización } \\
\text { beneficios }\end{array}$ & $\begin{array}{c}\text { VAN } \\
\text { Acumulado }\end{array}$ \\
\hline Año 0 & $-300,334.4$ & 1.000 & $-300,334.4$ & & & $-300,334.4$ \\
Año 1 & $3,501.2$ & 0.872 & & $3,052.4$ & $2,661.1$ & $-297,282.0$ \\
Año 2 & $115,200.9$ & 0.760 & & $87,559.7$ & $66,550.7$ & $-209,722.3$ \\
Año 3 & $221,850.1$ & 0.663 & & $147,005.0$ & $97,410.2$ & $-62,717.3$ \\
Año 4 & $377,215.3$ & 0.578 & $217,914.4$ & $125,887.5$ & $155,197.1$ \\
Año 5 & $548,904.0$ & 0.504 & & $276,450.4$ & $139,231.6$ & $431,647.5$ \\
\hline
\end{tabular}

\begin{tabular}{|l|c|}
\hline $\mathrm{VAN}=$ & $431,647.46$ \\
\hline $\mathrm{TIR}=$ & $45.08 \%$ \\
\hline BENEFICIO $/$ COSTO $=$ & 1.44 \\
\hline
\end{tabular}

Nota. Adaptado del estudio de ingeniería del proyecto.

3.- Escenario Optimista

Tabla 79

Flujo de caja en un escenario optimista

\begin{tabular}{|c|c|c|c|c|c|c|}
\hline Rubro & Año (0) & Año 1 & Año 2 & Año 3 & Año 4 & Año 5 \\
\hline \multicolumn{7}{|l|}{ Ingresos } \\
\hline Ventas & 0.0 & $1,298,700.0$ & $1,535,712.8$ & $1,815,980.3$ & $2,147,396.7$ & $2,539,296.6$ \\
\hline Subtotal de Ingresos & 0.0 & $1,298,700.0$ & $1,535,712.8$ & $1,815,980.3$ & $2,147,396.7$ & $2,539,296.6$ \\
\hline \multicolumn{7}{|l|}{ Egresos } \\
\hline $\begin{array}{l}\text { Costos de } \\
\text { Producción }\end{array}$ & 0 & $1,103,122$ & $1,161,833$ & $1,260,393$ & $1,329,208$ & $1,420,969$ \\
\hline Gastos de Operación & 0 & 163,202 & 163,202 & 163,202 & 163,202 & 163,202 \\
\hline Impuesto a la Renta & 0 & $-360,326$ & $-303,099$ & $-255,367$ & $-172,900$ & $-84,394$ \\
\hline Subtotal de Egresos & 0 & 905,998 & $1,021,936$ & $1,168,228$ & $1,319,511$ & $1,499,777$ \\
\hline \multicolumn{7}{|l|}{ Inversiones } \\
\hline $\begin{array}{l}\text { Inversión Fija } \\
\text { Tangible }\end{array}$ & 172,227 & 0 & 0 & 0 & 0 & 0 \\
\hline $\begin{array}{l}\text { Inversión Fija } \\
\text { Intangible }\end{array}$ & 18,918 & 0 & 0 & 0 & 0 & 0 \\
\hline Capital de Trabajo & 109,189 & 0 & 0 & 0 & 0 & 0 \\
\hline $\begin{array}{l}\text { Subtotal de } \\
\text { Inversiones }\end{array}$ & 300,334 & 0 & 0 & 0 & 0 & 0 \\
\hline $\begin{array}{l}\text { Flujo de Caja } \\
\text { Económico }\end{array}$ & 300,334 & 392,702 & 513,776 & 647,753 & 827,886 & $1,039,520$ \\
\hline
\end{tabular}




\begin{tabular}{lcccccc}
\hline AÑO & $\begin{array}{c}\text { Flujo de caja } \\
(\text { S/. })\end{array}$ & f.s.a. & Costos & Beneficios & $\begin{array}{c}\text { Actualización } \\
\text { de beneficios }\end{array}$ & $\begin{array}{c}\text { VAN } \\
\text { Acumulado }\end{array}$ \\
\hline Año 0 & $-300,334.4$ & 1.0 & $-300,334.4$ & & & $-300,334.4$ \\
Año 1 & $392,701.8$ & 0.9 & $342,363.2$ & $298,477.2$ & $42,028.7$ \\
Año 2 & $513,776.3$ & 0.8 & $390,501.2$ & $296,804.6$ & $432,529.9$ \\
Año 3 & $647,752.5$ & 0.7 & $429,221.6$ & $284,416.0$ & $861,751.5$ \\
Año 4 & $827,886.2$ & 0.6 & $478,263.5$ & $276,289.2$ & $1,340,015.1$ \\
Año 5 & $1,039,519.7$ & 0.5 & $523,544.4$ & $263,678.2$ & $1,863,559.4$ \\
\hline
\end{tabular}

\begin{tabular}{|l|c|}
\hline VAN $=$ & $1,863,559.4$ \\
\hline TIR $=$ & $155 \%$ \\
\hline BENEFICIO $/$ COSTO $=$ & 4.73 \\
\hline
\end{tabular}

Nota. Adaptado del estudio de ingeniería del proyecto

Para este análisis se han considerado los escenarios de cambio en la demanda del producto y en la materia prima que es la variable más sensible para el proyecto. En la Tabla 77, se consideró un escenario pesimista de no crecer en demanda y que se incremente el costo de materia prima en 5\%.

Para el escenario optimista de la Tabla 79, se ha considerado un crecimiento del $7.5 \%$ en la demanda del producto y una baja en el precio de la materia prima del $5 \%$.

Con estos resultados podemos observar que ante un escenario pesimista el proyecto no es viable, generando una pérdida de 0.05 soles por cada sol que se invierte tal como lo demuestra el ratio de beneficio costo del proyecto. Los otros escenarios tanto el optimista, como el esperado mostrado en la Tabla 78, son provechosos para los inversionistas. 


\section{Conclusiones y Recomendaciones}

Conclusiones:

PRIMERO.- A través del plan se observa que existen perspectivas favorables para este sector en tema económico para los siguientes años, además del apoyo político del Estado Peruano en relación a temas económicos y ambientales. La tecnología presentada en este estudio y la informalidad de los competidores, generan una potencial oportunidad la cual se pretende aprovechar.

SEGUNDO.- EL producto que se presenta al entorno de la construcción es novedoso, ayuda a la protección del medio ambiente, ya que no se utiliza la arcilla, promueve el menos uso del agua, y evita el incremento de tala de árboles destinados para los hornos de cocción y secado de ladrillo tradicional, a su vez se disminuye la emanación de gases que contaminan el medio ambiente.

TERCERO: Mediante la investigación de mercado se pudo definir el perfil del consumidor: hombres y mujeres en el rango de edad entre los 30 a 50 años que se encuentran dentro de la población económicamente activa ,pertenecientes a los distritos de: Arequipa, Cayma, Characato, José Luis Bustamante y Rivero, Mariano Melgar, Miraflores, Mollebaya, Paucarpata, Polobaya, Quequeña, Sabandía, Sachaca, Socabaya, Tiabaya, Uchumayo, Yanahuara e Yarabamba y con mayor atención a los distritos de Cerro Colorado, Alto Selva Alegre y Jacobo Hunter ,estos últimos demandaran las bloquetas de plástico en mayor cantidad., que tienen la meta de tener una vivienda propia y si en caso la posee, desea buscar su crecimiento. Se siente motivado por un buen precio y un producto que contribuya con el ambiente.

CUARTO: El Mercado Objetivo está compuesto por 6784 personas (consumidores), sobre las cuales se basó la proyección de la demanda de bloquetas de 
plástico para los cinco años, siendo el primer y quinto año de 3000 y 3660 millares respectivamente.

QUINTO .- El plan conseguirá el posicionamiento esperado a través de las estrategias a utilizar como son la diferenciación en la capacitación, venta, publicidad y las alianzas con los medios de comunicación las cuales permitirán llegar al consumidor.

SEXTO.-Los indicadores de rentabilidad positivos evidencian la viabilidad de la propuesta de plan de negocio; con un VAN Económico de S/. 397, 340.9 y una TIR de $42.57 \%$, que supera el costo ponderado del capital, la idea de negocio representa una atractiva oportunidad de inversión.

Recomendaciones:

PRIMERO.-Se recomienda realizar estudios semestrales sobre las nuevas tecnologías paras el proceso de fabricación, esto brindara una mejor utilización de los recursos.

SEGUNDO.- Realizar el análisis para una posible diversificación de productos, así se podrá atender mayores preferencias de consumo y hacerlo más rentable.

TERCERO.-Realizar alianzas estratégicas con las municipalidades de Arequipa para la recolección de residuos plásticos de la población y así disminuir los costos de materia prima, a cambio de bloquetas de plástico para sus obras sociales.

CUARTO.- Generar relaciones y presentación del producto con las alcaldías de Arequipa y la Región y así poder vincular nuestras bloquetas de plástico a futuros proyectos de construcción de viviendas de interés social que genere el estado.

Definir programas de responsabilidad social empresarial relacionadas con nuestro producto. 


\section{Índice de Figuras}

Figura 1. Evolución mensual de la actividad del sector construcción (Pbi Construcción):

2011-2016, variación porcentual mensual. Tomado de estadísticas del Ministerio de

Vivienda Construcción y Saneamiento.

Figura 2. Evolución del PBI año 2000 al 2015, Tomado de Instituto Nacional de Estadística e Informática - Dirección Nacional de Cuentas Nacionales. .11

Figura 3. Comparativo entre situación esperada y real del nivel de las operaciones en las empresas constructoras (segundo bimestre 2016 vs segundo bimestre 2015), tomado de informe económico de la construcción (IEC) № 9, por la Cámara Peruana de Construcción (CAPECO), Julio 2016.

Figura 4. Participación de mercado de empresas nacionales, productores formales de Ladrillos de Arcilla - 2014 (En Facturación), tomado de informe económico de la construcción (IEC) $\mathrm{N}^{\circ}$ 9, por la Cámara Peruana de Construcción (CAPECO), Julio 2016 .

Figura 5. Tipo de Construcción que más crecerá el 2016.Perspectivas sobre el desempeño de los diferentes tipos de construcción en el 2016. Tomado del "Informe Económico de la Construcción” (IEC) Julio 2016, por Cámara Peruana de la Construcción (CAPECO) .19

Figura 6. Perspectivas sobre el desempeño de los diferentes tipos de construcción en el 2016.

Tomado del "Informe Económico de la Construcción” (IEC) Julio 2016, por Cámara

Peruana de la Construcción (CAPECO) 19

Figura 7. Tipos de proyectos susceptibles a ser desarrollados por iniciativas privadas.

Tomado del "Informe Económico de la Construcción” (IEC) Julio 2016, por Cámara

Peruana de la Construcción (CAPECO) .20 
Figura 8. Expectativas sobre la variación del nivel de inversión en nuevos proyectos.

Tomado del “Informe Económico de la Construcción (IEC)” Julio 2016, por Cámara

Peruana de la Construcción (CAPECO) .21

Figura 9. Expectativas sobre la variación de precios de materiales de construcción. Tomado del "Informe Económico de la Construcción (IEC)" Julio 2016, por Cámara Peruana de la Construcción (CAPECO) .21

Figura 10. Nivel de oferta informal de materiales de construcción por industria. Tomado del “Informe Económico de la Construcción (IEC)” Julio 2016, por Cámara Peruana de la Construcción (CAPECO). .22

Figura 11.Participación de mercado de empresas nacionales, productores formales de

Ladrillos de Arcilla - 2014 (En Facturación), de informe económico de la construcción

(IEC) N 9, por la Cámara Peruana de Construcción (CAPECO), Julio 2016. 31

Figura 12. Zonas de producción de ladrillo artesanal en Arequipa. Adaptado de "Diagnóstico

Nacional del Sector Ladrillero Artesanal” por Mercadeando S.A 2012. .32

Figura 13. Número de empresas que fabrican ladrillo en Mollebaya. Adaptado de

“Diagnóstico Nacional del Sector Ladrillero Artesanal” por Mercadeando S.A 2012 ....33

Figura 14.Evolución del Producto Bruto Interno y Demanda Interna 2008 al 2017, por el Instituto Nacional de Estadística (INEI), 2017. .39

Figura 15. Inflación y meta de Inflación 2007 al 2017, por el Banco Central de Reserva del

Perú (BCRP), setiembre 2017.

Figura 16. Distritos incluidos en la segmentación. Tomado de https://www.google.com.pe/maps .50

Figura 17. Pregunta 1. Adaptado de la Recolección de datos del Cuestionario .62

Figura 18. Pregunta 2. Adaptado de la Recolección de datos del Cuestionario .63

Figura 19. Pregunta 3. Adaptado de la Recolección de datos del Cuestionario .63 
Figura 20. Pregunta 4. Adaptado de la Recolección de datos del Cuestionario .64

Figura 21. Pregunta 5. Adaptado de la Recolección de datos del Cuestionario .65

Figura 22. Pregunta 6. Adaptado de la Recolección de datos del Cuestionario .65

Figura 23. Pregunta 7. Adaptado de la Recolección de datos del Cuestionario .66

Figura 24. Pregunta 8. Adaptado de la Recolección de datos del Cuestionario .66

Figura 25. Pregunta 9. Adaptado de la Recolección de datos del Cuestionario 67

Figura 26. Pregunta 10. Adaptado de la Recolección de datos del Cuestionario 67

Figura 27. Tendencia: datos que aumentan o disminuyen en forma constante. Tomado de Administración de Operaciones Procesos y Cadena de Suministro (p.466), Krajewski, et al., 2013, Décima Edición, Pearson Educación. .72

Figura 28 Tomado de Tesis plan de negocios para la fabricación ladrillos ecológicos en lima metropolitana., 2015, Pag 75. .75

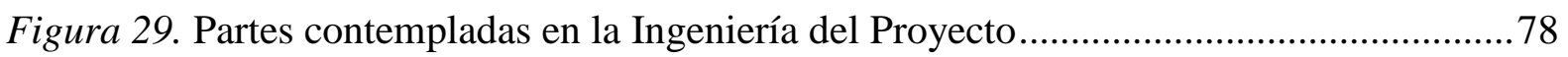

Figura 30. Proceso Productivo para la elaboración de Bloquetas de Plástico .79

Figura 31. Diagrama de Flujo del Proceso Productivo. 81

Figura 32. Trituradora de plástico modelo SP800. Tomado de productos machine: maquina auxiliar de procesamiento. Recuperado de http://chinainjection.es/4-1-plasticcrusher.html/ .85

Figura 33. Licuadora de cemento y plástico modelo tdpm, con tornillo y paleta de agitación. Recuperado de https://spanish.alibaba.com/product-detail/plastic-cement-blender-screwstirring-paddle-blender-paste-mixer-wldh-series-horizontal-ribbon-blender60059154148.html .86

Figura 34. Transportadores de tornillo sin fin. Cálculo de Transportadores de tornillo sin fin. Recuperado de http://ingemecanica.com/tutorialsemanal/tutorialn143.html. 87 
Figura 35.Cinta Transportadora de metal. Tomada de http://www.metallbelda.net/portfolio/cintas-transportadoras/\#prettyPhoto .88

Figura 36. Layout de planta (metros) .90

Figura 37. Distribución de equipos. 91

Figura 38. Organigrama de empresa. 119

Figura 39. Sueldos asignados a trabajadores del proyecto. Tomado de Ingeniería del proyecto. 130

Figura 40. Propuestas de valor de empresa para posicionar producto. Tomado de

“Marketing”, por Kotler \& Armstrong, 2012

Figura 41. Factores que se toman en cuenta al fijar los precios. Tomado de "Marketing", por

Kotler \& Armstrong, 2012 136

Figura 42. Proyección de ventas. Tomado de la proyección de crecimiento del proyecto... 142 Figura 43. Adaptado de Análisis de sensibilidad de las variaciones de mano de obra, materia prima y demanda del producto. 


\section{Índice de Tablas}

Tabla 1. Clasificación Industrial Internacional Uniforme .................................................

Tabla 2. Perú: Oferta y demanda Global 2000-2015 ........................................................ 11

Tabla 3. Indicadores de Construcción Arequipa................................................................... 13

Tabla 4. Descripción de las zonas de producción y número de ladrilleras en Arequipa......... 16

Tabla 5. Zonas de mayor producción de ladrillo artesanal .................................................. 16

Tabla 6. Proyección de gastos por app del sector no financiero del 2014 al 2018 ................. 18

Tabla 7. Participación de mercado de las principales empresas productoras de ladrillo de

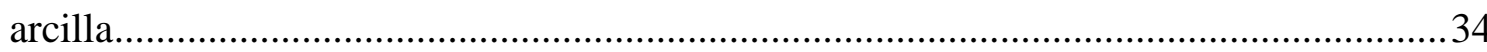

Tabla 8. Matriz de perfil competitivo, de empresa ladrillera y proyecto.................................35

Tabla 9. Índice de la Democracia 2016 para América Latina y el Caribe...............................37

Tabla 10. Principales proyectos de inversión al 2019...................................................... 41

Tabla 11. Población seleccionada de los Distritos de Arequipa ............................................51

Tabla 12. Población de Distritos de Arequipa por edades ...................................................52

Tabla 13. Perú: Población Económicamente Activa, Según Departamento

Tabla 14. Población Económicamente Activa de los Distritos de Arequipa ...........................54

Tabla 15. Perfil de participante de las entrevistas a expertos ..............................................56

Tabla 16. Muestra perteneciente al Segmento del Mercado para el Cuestionario ....................61

Tabla 17. Producción Mensual del ladrillo en Arequipa ...................................................... 71

Tabla 18. Avance Productivo Sectorial, Mayo 2016 (Variacion \%) ...................................... 76

Tabla 19. Pronóstico de la demanda (Método de Juicio) ....................................................... 76

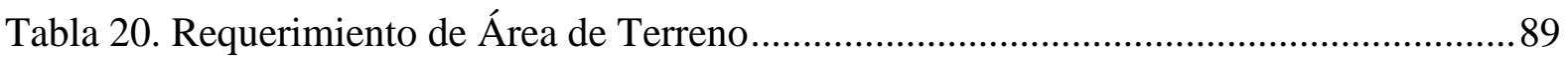

Tabla 21. Proyección del Crecimiento del Proyecto ..................................................................92

Tabla 22. Alternativas para la obtención del tamaño óptimo de planta...................94 
Tabla 23. Recursos Humanos que necesita el proyecto ........................................................95

Tabla 24. Requerimiento de Maquinaria, Equipos y Herramientas ......................................96

Tabla 25. Requerimiento de Materia Prima ......................................................................... 97

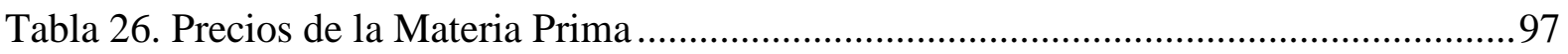

Tabla 27. Cálculo para la selección del tamaño óptimo en relación al mercado.................... 100

Tabla 28. Selección del Tamaño óptimo en relación a la inversión. ....................................... 101

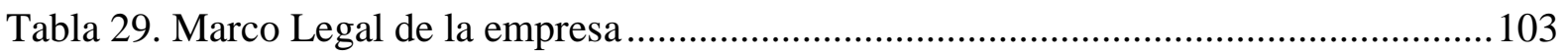

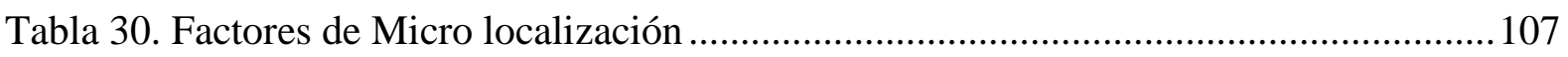

Tabla 31. Evaluación de Factores de Micro localización ...................................................... 110

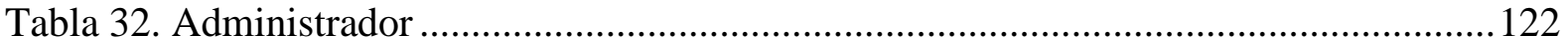

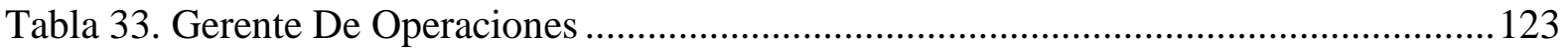

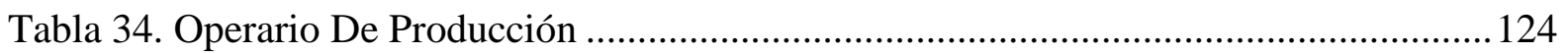

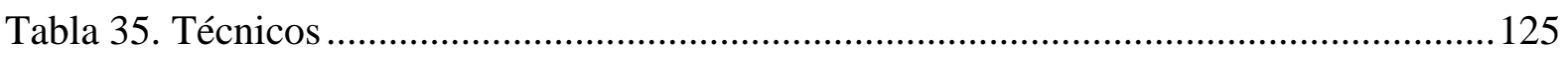

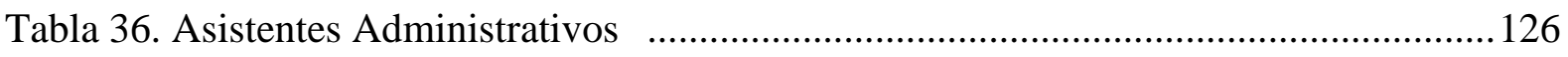

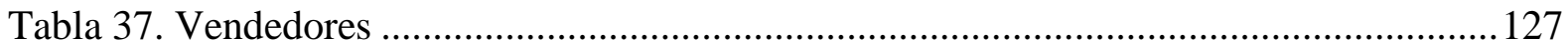

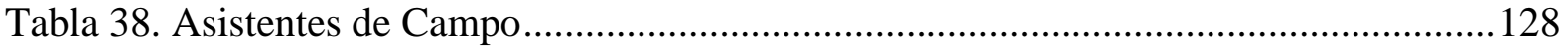

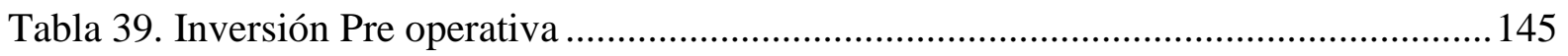

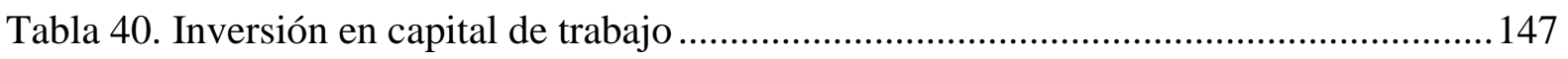

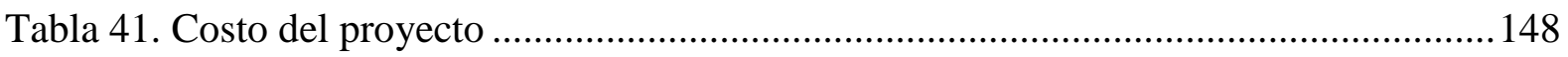

Tabla 42. Composición del financiamiento del proyecto ................................................... 150

Tabla 43. Fuentes y usos de la composición del financiamiento.........................150

Tabla 44. Tasa Libre de Riesgo, Tasa de Rendimiento de Mercado .................................... 151

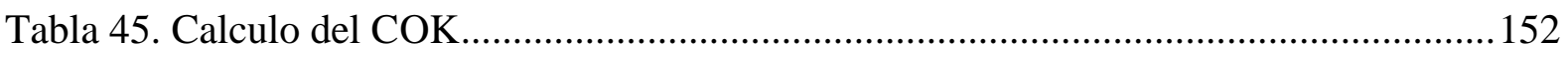

Tabla 46.. Datos necesarios para el CCPP.....................................153 


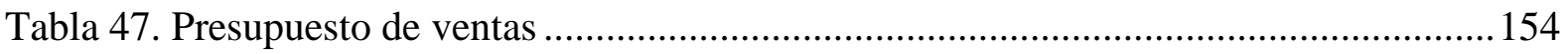

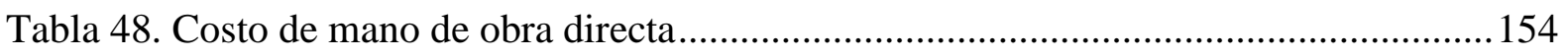

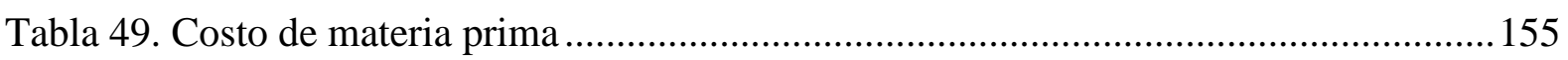

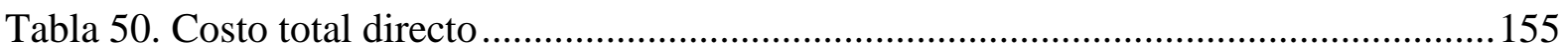

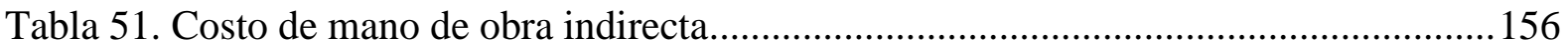

Tabla 52. Costo de mano de obra indirecta para todo el proyecto..........................................156

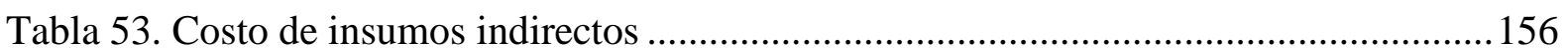

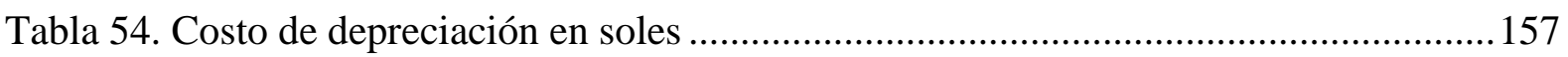

Tabla 55. Costo de amortizaciones de cargas diferidas ........................................................ 158

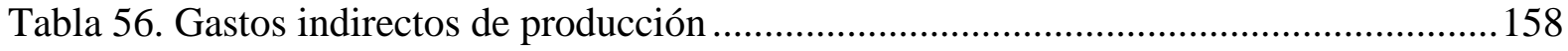

Tabla 57. Costos totales indirectos de producción.................................................................159

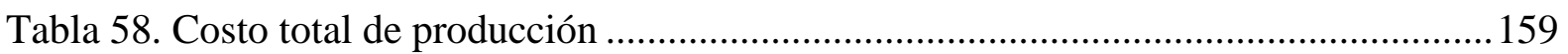

Tabla 59. Costo total de compras en materia prima e insumos indirectos................................ 160

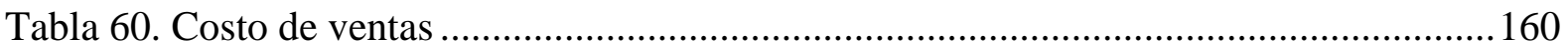

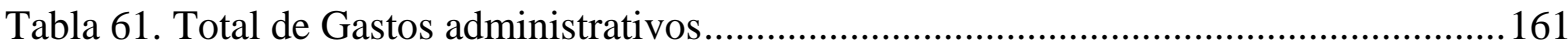

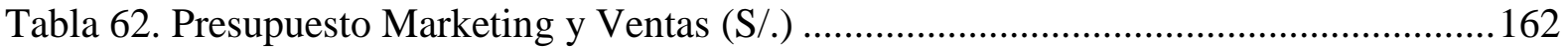

Tabla 63. Tasas de interés promedio del sistema bancario ...................................................163

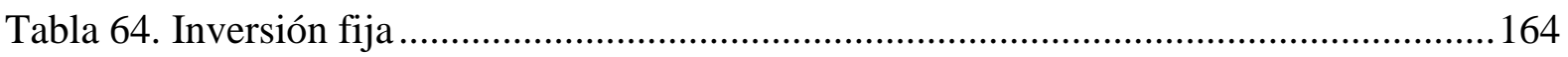

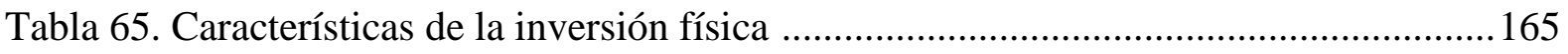

Tabla 66. Resumen del servicio a la deuda anual ................................................................... 166

Tabla 67. Estado de pérdidas y ganancias con financiamiento (S/.)........................................167

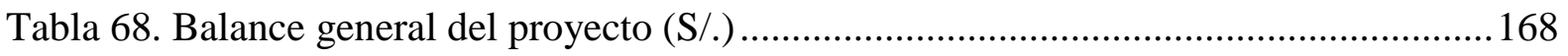

Tabla 69. Flujo de caja con financiamiento (S/.) ……………………………………......... 170

Tabla 70. Cálculo del VAN y TIR económico ………………………………………........171

Tabla 71. Cálculo del VAN y TIR financiero ......................................................................... 171 
Tabla 72. Cálculo del ROE 172

Tabla 73. Cálculo del costo/beneficio 173

Tabla 74.Variación del VAN y TIR en función al cambio de los costos de mano de obra ... 175

Tabla 75. Variación del VAN y TIR en función al cambio de los costos de materia prima. 176

Tabla 76. Cálculo de VAN y TIR al cambio de la demanda del proyecto 177

Tabla 77. Flujo de caja en un escenario pesimista.... 178

Tabla 78. Flujo de caja en un escenario esperado. 179

Tabla 79. Flujo de caja en un escenario optimista 180 


\section{Anexos}

\section{ANEXO I: FICHA TÉCNICA FOCUS GROUP}

\section{Objetivos de investigación:}

Objetivo General:

Conocer el grado de aceptación o rechazo por parte de los posibles consumidores frente a las bloquetas de plástico.

Objetivos Específicos:

1. Identificar las características que los consumidores consideran más relevantes al momento de elegir el material de construcción.

2. Determinar las promociones a ofrecer y sus respectivos puntos de ventas.

3. Establecer los factores importantes para la decisión de compra del consumidor.

4. Conocer las expectativas del consumidor respecto al nuevo producto.

\section{2. - Perfil del Participante:}

Los participantes serán de focus group, hombres y mujeres de los distritos de Arequipa, Alto selva Alegre, Cayma, Cerro Colorado, Characato, Jacobo Hunter, José Luis Bustamante y Rivero, Mariano Melgar, Miraflores, Mollebaya, Paucarpata, Polobaya, Quequeña, Sabandía, Sachaca, Socabaya, Tiabaya, Uchumayo, Yanahuara e Yarabamba con edades entre 30 a 50 años que se encuentren dentro de los NSE A/B, C y D.

\section{3. - Guía de Pautas:}

Guía del moderador (Guía de Pautas) para la sesión de entrevista en grupo de enfoque sobre el producto bloquetas de plástico.

\section{BIENVENIDA A LOS PARTICIPANTES}

Buenas tardes, mi nombre es , y el día de hoy voy a acompañarlos como moderador en este Focus Group, en el cual se les presentará un nuevo producto : bloquetas de plástico, lo que se espera es que cada uno de Uds. exprese lo que siente y emita opiniones en todos los temas que se tratarán en esta reunión, les pido que brinden sus opiniones con toda naturalidad. 


\section{CALENTAMIENTO}

Antes de iniciar me gustaría que nos presentemos, formemos un círculo y diremos cada uno nuestro nombre, empecemos por el lado derecho.

Ahora haremos un juego, "Cantaremos el ritmo A gogo, usando tipos de materiales de construcción de vivienda", por ejemplo "yo mencionare sillar, la siguiente persona mencionará el material que dije y dirá uno nuevo, así sucesivamente".

Ya que acabamos el juego y antes de iniciar con los temas, debo decirles que todos estamos dando un poco de nuestro tiempo para participar, así que realmente valoramos sus opiniones y su participación.

Para ello se realizarán las siguientes preguntas, donde cada uno tendrá oportunidad de intervenir.

\section{TEMA 1: CARACTERISTICAS QUE CONSIDERA EL CONSUMIDOR PARA LA CONSTRUCCION DE SU VIVIENDA.}

Arequipa está creciendo hay varios lugares que han pasado a ser zonas pobladas como es el caso de las partes altas de Alto Selva Alegre, Miraflores, entre otros.

Y en las zonas que ya están construidas se ven que se hacen ampliaciones, se incrementan niveles, por ello surge la pregunta ¿quiénes de Uds. quieren construir o realizar ampliaciones de su vivienda?

A. ¿Qué material elegirían para realizar las ampliaciones y/o construcciones de nuevas viviendas?

B. ¿Es importante para Uds., la textura del material, su color, etc.?

IV. TEMA 2: FACTORES IMPORTANTES PARA LA DECISIÓN DE COMPRA DEL CONSUMIDOR.

Existen diversos materiales de construcción de viviendas en Arequipa, como lo mencionamos en la dinámica, el sillar es uno de ellos, también tenemos al ladrillo y ahora último vemos que existen otros materiales más livianos.

Piensen en como las personas toman sus decisiones para comprar estos materiales "Qué factores considerarían importantes cuando deciden comprar materiales para la construcción"
A. ¿Cuáles son los materiales de construcción que conocen?
B. Para Uds., ¿Cuál sería la característica del material de construcción por el cual lo compraría? 
C. Si escuchara el término "LadriplastAQP” ¿Qué idea le viene a la mente?

\section{TEMA 3: LA BLOQUETA DE PLASTICO}

(Se presenta la bloqueta de plástico a los participantes.)

Este es el material que quiero que observen, es una bloqueta de plástico, que posee características similares al ladrillo.

Si tuvieran esta bloqueta disponible en las ferreterías ¿Consideraría en comprarlo?

A. ¿Por qué motivos no lo compraría?

B. ¿Por qué motivos si lo compraría?

C. Si estuviera a la venta ¿Le gustaría recibir su pedido en el lugar de la construcción?

D. ¿Se acercarían a comprarlo? ¿Lo comprarían a través de pedidos por la web?

E. ¿Qué esperaría del producto?

\section{CIERRE LA SESION CON SUGERENCIAS E IDEAS FINALES}

Teniendo en cuenta nuestra conversación, ¿Qué acciones sugerirían o recomendarían para las bloquetas de plástico fuera el mejor producto?

¿Pueden brindarnos las ultimas ideas, sentimientos o comentarios? (pregunte sonde a cada participante)

\section{FIN DE LA SESION DE ENFOQUE}

Gracias a todos por haber asistido a este Focus Group, sus ideas, comentarios y en general sus respuestas, son un gran aporte.

(Se, entregara el presente a los participantes). Gracias por su asistencia. 


\section{ANEXO II: FICHA TECNICA DE ENTREVISTAS A EXPERTO EN MARKETING}

\section{Objetivo de investigación:}

Conocer aspectos de marketing relevantes para un nuevo producto en el sector.

\section{Perfil del Participante:}

Experto en Marketing

a. Profesional y /o técnico de la Carrera de Administración de empresas, Ing. Industrial entre otras.

b. Con Experiencia en el marketing mayor a 2 años en el área de marketing del sector ladrillero.

c. Edad entre 30 años a más.

d. Conocimiento de estrategias de marketing de empresa.

\section{Guía de Entrevista:}

\begin{tabular}{|l|l|}
\hline \multicolumn{2}{|c|}{ GUIA DE ENTREVISTA N ${ }^{\circ}$} \\
\hline Lugar : & \\
\hline Fecha: & \\
\hline Hora : & Conocer aspectos de marketing \\
\hline Tema: & relevantes para un nuevo producto en \\
& el sector. \\
\hline 1. Presentación & \\
\hline Buenas tardes, queremos mostrarle agradecimiento por recibirnos y sobre todo el \\
tiempo brindado para poder realizar esta entrevista. Mencionarle a su vez que la \\
información y comentarios brindados serán muy valorados para el proyecto de \\
tesis que vamos a realizar.
\end{tabular}




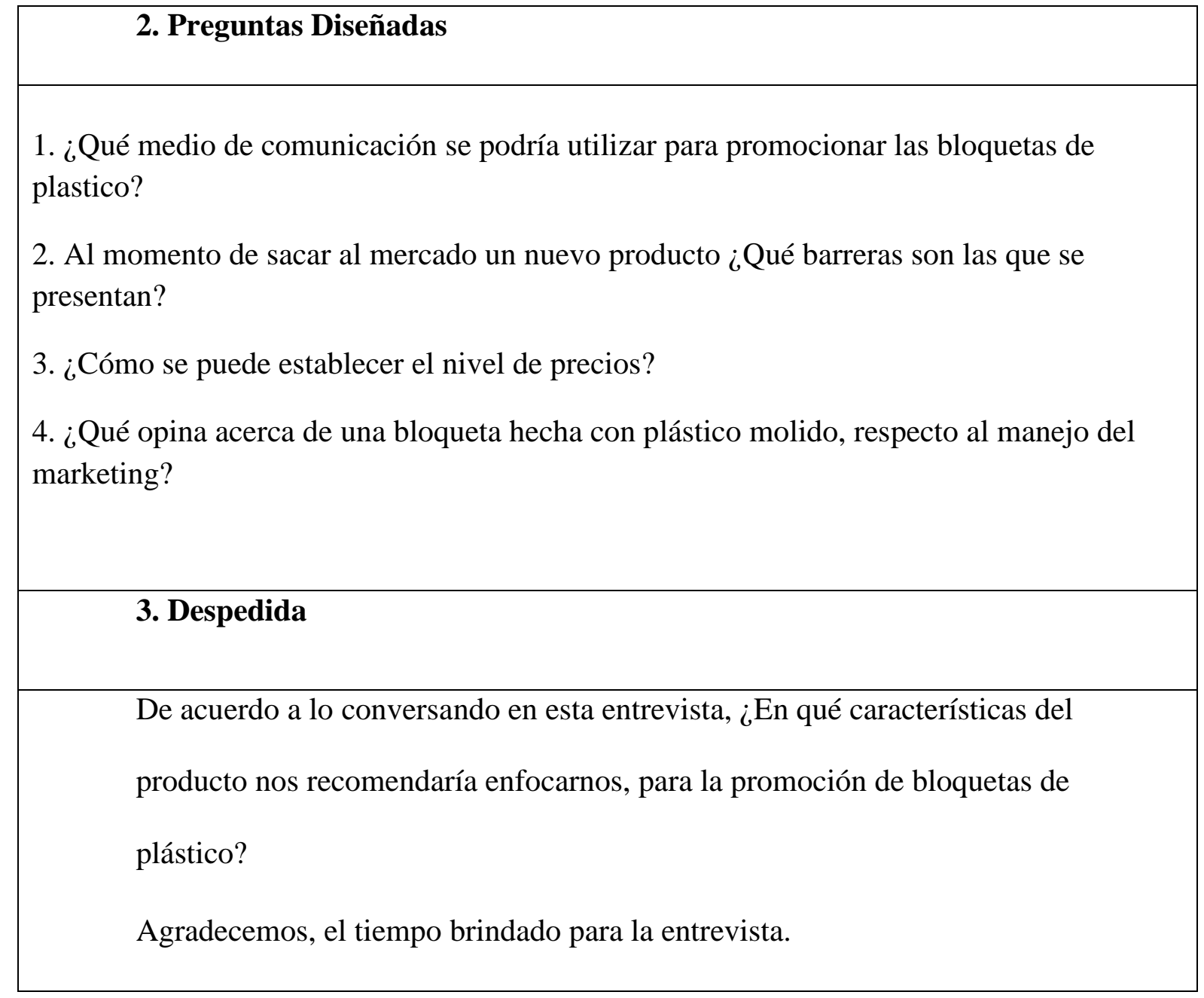




\section{ANEXO III: FICHA TECNICA DE ENTREVISTA A EXPERTO EN CONSTRUCCIÓN}

\section{Objetivo de investigación:}

Conocer las perspectivas del sector construcción en relación a las bloquetas de plástico.

\section{Perfil de los Participantes:}

Experto de Construcción

a. Profesional de la Carrera de, Ing. Civil o Arquitectura.

b. Con Experiencia en el rubro de la construcción mayor a 6 años.

c. Edad entre 35 a 45 años.

d. Con conocimiento en:

- Normas Técnicas de Construcción vigentes

-Supervisión de la calidad de los materiales de construcción.

-Sistemas constructivos más adecuados para el tipo de tareas a ejecutar en las obras.

\section{Guía de Entrevista:}

\begin{tabular}{|c|c|}
\hline \multicolumn{2}{|r|}{ GUIA DE ENTREVISTA $\mathbf{N}^{\circ} 2$} \\
\hline Lugar & \\
\hline Fecha: & \\
\hline Hora : & \\
\hline Tema: & $\begin{array}{l}\text { Conocer las perspectivas del sector construcción en relación a } \\
\text { las bloquetas de plástico. }\end{array}$ \\
\hline \multicolumn{2}{|c|}{ 1. Presentación } \\
\hline \multicolumn{2}{|c|}{$\begin{array}{l}\text { Buenas tardes, queremos mostrarle agradecimiento por recibirnos y sobre todo el } \\
\text { tiempo brindado para poder realizar esta entrevista. Mencionarle a su vez que la } \\
\text { información y comentarios brindados serán muy valorados para el proyecto de } \\
\text { tesis que vamos a realizar. }\end{array}$} \\
\hline
\end{tabular}




\section{Preguntas Diseñadas}

1. ¿Qué tipo de ladrillo para la construcción es el que Ud. selecciona con frecuencia?

2. De su experiencia, ¿Qué tipo de ladrillo es el más solicitado en las construcciones?

3. ¿Qué características del ladrillo toma en cuenta para las edificaciones que realiza?

4. ¿Suele sugerir materiales de construcciones con características ecológicas en sus construcciones?

5. ¿Ud. Ha oído a hablar respecto la venta de ladrillos y/o bloquetas de material reciclado?

5. ¿Qué opina acerca de una bloqueta hecha con plástico molido?

6. ¿Cuáles cree usted que podrían ser los pros y los contras de este ladrillo?

(Restricciones según el reglamento de construcción, normas, características, etc.)

7. ¿Qué recomendaciones daría a este nuevo producto? (ladrillo y/o elaborado con plástico)

\section{Despedida}

De acuerdo a su experiencia, ¿Qué sugerencias podría brindarnos, con respecto al producto de bloquetas de plástico, considerando la situación actual y las perspectivas a futuro del sector ladrillero? Agradecemos, el tiempo brindado para la entrevista. 


\section{ANEXO IV: FICHA TECNICA DE ENTREVISTAS A EXPERTO DEL SECTOR LADRILLERO}

\section{Objetivo de investigación:}

Conocer aspectos dentro de la industria del sector ladrillero.

\section{Perfil de los Participantes:}

Experto de la Industria

a. Representante de alguna empresa del sector.

b.Estar laborado durante la industria más de 6 años.

c.Edad entre 40 a 56 años.

d.Con conocimiento del movimiento del sector ladrillero, en los últimos años.

\section{Guía de Entrevista:}

\begin{tabular}{|c|c|}
\hline \multicolumn{2}{|r|}{ GUIA DE ENTREVISTA $\mathbf{N}^{\circ} 3$} \\
\hline Lugar: & \\
\hline Fecha: & \\
\hline Hora : & \\
\hline Tema: & $\begin{array}{l}\text { Conocer aspectos dentro de la industria del sector } \\
\text { ladrillero. }\end{array}$ \\
\hline \multicolumn{2}{|c|}{ 1. Presentación } \\
\hline \multicolumn{2}{|c|}{$\begin{array}{l}\text { Buenas tardes, queremos mostrarle agradecimiento por recibirnos y sobre todo el } \\
\text { tiempo brindado para poder realizar esta entrevista. Mencionarle a su vez que la } \\
\text { información y comentarios brindados serán muy valorados para el proyecto de } \\
\text { tesis que vamos a realizar. }\end{array}$} \\
\hline \multicolumn{2}{|c|}{ 2. Preguntas Diseñadas } \\
\hline \multicolumn{2}{|c|}{$\begin{array}{l}\text { 1. ¿Cómo ve la situación del sector ladrillero, en el contexto actual? } \\
\text { 2. ¿Qué márgenes de rentabilidad manejan los productores de ladrillo? } \\
\text { 3. ¿Qué tipos de ladrillo son los que ofrecen mayor margen de ganancia a los } \\
\text { productores? } \\
\text { 4. ¿Qué monto mínimo de inversión se requiere para incursionar en la industria } \\
\text { ladrillera? } \\
\text { 5. ¿Cuánto es la inversión en permisos para el desarrollo de esta actividad? } \\
\text { 6. ¿Cuánto es el gasto en recursos humanos, en este sector? } \\
\text { 7. ¿Cuánto se invierte en materia prima en promedio en la producción de } \\
\text { ladrillo? }\end{array}$} \\
\hline
\end{tabular}




\section{Despedida}

Teniendo en cuenta nuestra conversación, ¿Qué acciones sugeriría o

recomendarían para las bloquetas de plástico fuera el mejor producto posible?

Agradecemos, el tiempo brindado para la entrevista. 


\section{ANEXO V: FICHA TECNICA DE LA ENCUESTA}

\section{Objetivos de la investigación:}

\section{Objetivo General}

Descubrir el mercado de los consumidores de bloquetas de plástico en la ciudad de Arequipa.

Objetivos Específicos

- Identificar los posibles consumidores de bloquetas de plástico.

- Determinar las zonas dentro de la provincia de Arequipa que tienen mayor consumo de producto sustituto.

- Determinar los competidores del mercado objetivo.

- Determinar los canales de comercialización en este tipo de empresas.

- Determinar el precio de las bloquetas de plástico en el mercado que se pretende ingresar.

\section{Perfil de los Participantes:}

Población pertenecientes a los distritos de Arequipa, Alto selva Alegre, Cayma, Cerro Colorado, Characato, Jacobo Hunter, José Luis Bustamante y Rivero, Mariano

Melgar, Miraflores, Mollebaya, Paucarpata, Polobaya, Quequeña, Sabandía, Sachaca, Socabaya, Tiabaya, Uchumayo, Yanahuara e Yarabamba, que se encuentren dentro de la población económicamente activa, que oscilen entre 30 y50 años , pertenecientes al segmento $\mathrm{A} / \mathrm{B}, \mathrm{C}$ y D . 


\section{Cuestionario:}

\section{CUESTIONARIO}

Buenos días (Tardes/Noches), somos alumnos de Maestría en Ciencias Empresariales de la USIL, estamos realizando una investigación relacionada con los materiales de construcción para viviendas. Agradeceremos su colaboración respondiendo las siguientes preguntas.

Le rogamos usted responda con absoluta sinceridad los resultados de esta encuesta; serán tratados de forma confidencial.

1. Marque el distrito donde vive:
( ) Arequipa
( ) Cayma
( ) Cerro Colorado
( ) Chacarato
( ) José Luis Bustamante y Rivero
( ) Mariano Melgar
( ) Miraflores
( ) Mollebaya
( ) Quequeña
( ) Polobaya
( ) Alto Selva Alegre
( ) Sabandía
( ) Sachaca
( ) Jacobo Hunter
( ) Socabaya
( ) Tiabaya
( ) Uchumayo
( ) Paucarpata
( ) Yarabamba
( ) Yanahura

2. ¿Ud. tiene planificado la construcción y/o ampliación de vivienda?

( ) $\mathrm{Si}$

( ) No (Pase a la pregunta 4)

3. ¿Qué estrategia utilizará Ud. para la construcción y/o ampliación de su vivienda?

( ) Lo construye Ud. mismo

( ) Contrata a una persona

4. En su distrito ¿Qué materiales predominan para la construcción?

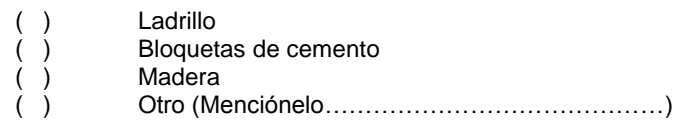

5. ¿Cuál es el material de su preferencia para la construcción?

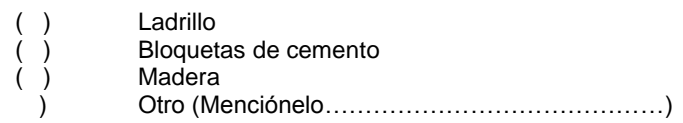

6. ¿A cuál de las característica de ladrillo, bloquetas de cemento u otros, le da más importancia a la hora de Comprarlo?

$\begin{array}{ll}\text { ( ) } & \text { Resistencia } \\ \text { ( ) } & \text { Peso } \\ \text { ( ) } & \text { Amigable con el Medio Ambiente }\end{array}$

7. ¿En qué lugar compra los ladrillos, bloquetas de cemento u otros?

$\begin{array}{ll}\text { ( ) } & \text { Distribuidora } \\ \text { ( ) } & \text { Ferretería } \\ \text { ( ) } & \text { Fabrica }\end{array}$

8. ¿De qué empresa de ladrillos u otro material solicita, cuando va a adquirirlos?

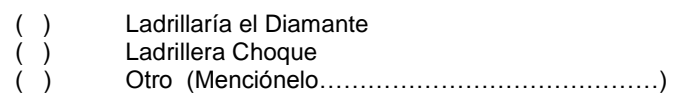

9. ¿Compraría un material de construcción ("bloqueta de plástico" o "ladrillo de plástico" que contiene cemento) que tenga características similares a un ladrillo convencional?

$$
\text { ( ) } \mathrm{Si}
$$

10. ¿Cuánto estaría dispuesto a pagar si existirá una bloqueta de plástico con las características similares a un ladrillo convencional?(Precio por unidad) 

(7) $\mathrm{De} / .0 .40$ a S/ 0.49
( ) De S/. 0.50 a S/.0.59
( ) $\mathrm{De} S / .0 .60$ a S/.0.79
( ) De $S / .0 .80$ a S/. 0.89
( ) De $S / .0 .90$ a S/,1.10

\section{DATOS DE CONTROL}

11. Sexo: Masculino ( )

12. Edad :
Femenino ( )

Gracias. 


\section{ANEXO VI: FOCUS GROUP SESION I}

\section{BIENVENIDA A LOS PARTICIPANTES}

Moderador: Buenas noches, mi nombre es Stefhanie, y el día de hoy voy a acompañarlos como moderador en este Focus Group, en el cual se les presentará un nuevo producto: bloquetas de plástico, lo que se espera es que cada uno de Uds. exprese lo que siente y emita opiniones en todos los temas que se tratarán en esta reunión, les pido que brinden sus opiniones con toda naturalidad.

\section{CALENTAMIENTO}

Moderador: Antes de iniciar me gustaría que nos presentemos, formemos un círculo y diremos cada uno nuestro nombre, empecemos por el lado derecho.

Ahora haremos un juego, "Cantaremos el ritmo Agogo, usando tipos de materiales de construcción de vivienda", por ejemplo "yo mencionare sillar, la siguiente persona mencionará el material que dije y dirá uno nuevo, así sucesivamente”.

Ya que acabamos el juego y antes de iniciar con los temas, debo decirles que todos estamos dando un poco de nuestro tiempo para participar, así que realmente valoraremos sus opiniones y su participación.

Para ello se realizarán las siguientes preguntas, donde cada uno tendrá oportunidad de intervenir.

\section{TEMA 1: CARACTERISTICAS QUE CONSIDERA EL CONSUMIDOR PARA LA CONSTRUCCION DE SU VIVIENDA.}

Moderador: Arequipa está creciendo hay varios lugares que han pasado a ser zonas pobladas como es el caso de las partes altas de Alto Selva Alegre, Miraflores, entre otros.

$\mathrm{Y}$ en las zonas que ya están construidas se ven que se hacen ampliaciones, se incrementan niveles, por ello surge la pregunta ¿quiénes de Uds. quieren construir o realizar ampliaciones de su vivienda?

Carmen: Yo tengo un terreno en Alto Selva Alegre y si me gustaría poder empezar a construir aunque sea cercarlo y hacer una habitación por lo menos para asegurarlo. En la casa que vivo aun no pensé en alguna modificación que de seguro lo hare más adelante. 
Erika: Si quisiera construir en mi casa somos cinco, mi último hijo tiene cuatro años y ya tiene que tener su propia habitación la casa nos quedó chica, por eso quisiera empezar a construir de una vez.

Luz: Yo también tengo un pequeño terreno que quiero construir porque vivimos con mis padres y hermanos porque la casa es grande, pero con mi esposo ya lo hemos conversado y queremos vivir en nuestra propia casa.

Renzo: Yo por el momento no pienso en construir una casa, lo que si haría es comprar una ya hecha. Tampoco he pensado ampliar mi actual vivienda

Maria: Bueno si quiero construir justo ahora estamos haciendo una pequeña construcción en nuestro jardín. Creo que la mayoría de personas si quieren construir una vivienda.

Noemi: Si quiero realizar la ampliación de mi vivienda y también tengo un terreno que quiero construir, eso ya está planeado el próximo año empezare si Dios me lo permite.

Justina: Pienso igual que Luz porque tengo un terrenito en Cerro Colorado y quiero construir para alquilarlo.

Jonel: Si quisiera ampliar mi casa, pero por ahora no puedo porque estoy sin tiempo y lo que me aconsejaron es hacer divisiones con trupan o triplay, más o menos me indicaron eso porque es rápido. Pero ya para el próximo año si me animare a construir un tercer piso.

Wilber: Yo si construiré, ahora vivo en una parte de la casa que me dieron mis padres y solo es de piso por eso quiero empezar a construir.

Rodrigo: Yo no tengo una casa propia que pueda ampliar, lo que sí quiero hacer es comprarme un lote para construir o un departamento o una casita.

Fernando: Si tengo planificado la construcción de mi vivienda, bueno la ampliación en si porque ya tengo una casa de un piso y quiero hacer su segundo piso.

Cinthya: Yo no tengo planeado hacer construcciones porque acabo de comprar una casa y estoy con el pago del banco, quizás de aquí a tres años.

A. ¿Qué material elegirían para realizar las ampliaciones y/o construcciones de nuevas viviendas? 
Carmen: El ladrillo es lo que más se utiliza, escuche también de bloquetas de cemento así que entre esos dos, pero el cerco si quiero hacerlo de ladrillo.

Erika : De ladrillo o también como es el último piso hay prefabricados tengo que averiguar bien sobre el prefabricado.

Luz : Solo construiría de ladrillo como es una casa nueva.

Mari : que sea de ladrillo

Wilber: Depende del espacio que se desea construir para mi seria el ladrillo si voy a hacer una casa desde cero, pero para ampliaciones podría ser otro material, no se quizás madera, bloquetas.

Justina: La casa que construiré está hecha de ladrillos el arquitecto nos dijo que era mejor así, aunque nos dio otras opciones, pero el precio era más elevado.

Fernando: Por economía lo haría de bloquetas.

Jonel: Yo utilizaría el ladrillo para hacer un piso, pero como les dije solo hare divisiones y utilizare el triplay.

Cinthya: De ladrillo para que sea más resistente.

Rodrigo: Lo construiría con ladrillo, como dice Cinthya es más resistente.

Noemi: También utilizaría el ladrillo.

Renzo: Si construiría la haría de ladrillo o lo que me aconseje un arquitecto o especialista en el tema, haría algo moderno.

B. ¿Es importante para Uds., la textura del material, su color, etc.?

Noemi: No, eso no es tan importante porque al final el ladrillo se estuca.

Erika: Yo pienso que, si es importante para que el estuque agarre mejor, el color no me parece importante porque al final se pinta, así sea ladrillo caravista.

Jonel: El tamaño si me parece importante, porque depende de eso la cantidad de ladrillos a comprar, también su peso, el color no me parece importante.

Justina: Esas características no me parecen importantes creo que lo compramos por precio o por si son resistentes.

Luz: El físico no es tan importante como sus propiedades para la construcción, de ahí varia el estuque, pintura.

Cinthya: Si es para interior y se va a estucar no, pero eso sí, no se debe de desgranar. La otra vez vi ladrillos artesanales que fácilmente se desmoronaba.

Renzo: Las características físicas no son importantes quizás el ello si es más liso o no eso si afecta a la fijación entre cada ladrillo. Pero el color no es importante. 
Wilber: Creo que es importante la resistencia, el precio también porque un ladrillo con mejores propiedades puede ser que cueste más.

Rodrigo: Definitivamente tiene razón Wilber porque depende también rl precio del ladrillo.Ahh! y sobre las propiedades de color , textrua es relastivo porque si quieren caravista hay un ladrillo especializado, y asi para cada cosa.

Fernando: Esas características si son importantes si vamos a querer que no se estuque o pinte, pero para las paredes interiores siempre se estucan y eso no afecta, lo que si afecta es sus propiedades, que sea resistente a los sismos.

Carmen: El color la textura no es importante a mi parecer lo importante es la calidad del material, y ya algunos lo han mencionado, creo que el resultado es lo importante

\section{TEMA 2: FACTORES IMPORTANTES PARA LA DECISIÓN DE COMPRA DEL CONSUMIDOR.}

Moderador: Existen diversos materiales de construcción de viviendas en Arequipa, como lo mencionamos en la dinámica, el sillar es uno de ellos, también tenemos al ladrillo y ahora último vemos que existen otros materiales más livianos.

Piensen en como las personas toman sus decisiones para comprar estos materiales “QQué factores considerarían importantes cuando deciden comprar materiales para la construcción?"

Moderador: Vamos a hacer una lluvia de ideas, les voy a dar cinco papeles a cada uno y van a escribir las características que creen que son necesarias para que ustedes tomen la decisión de comprar un tipo o marca de ladrillo.

Tienen cinco minutos.

¿Ya todos tienen listos todos sus papeles? (Dos personas aún no terminan)

Se les dará dos minutos más para que concluyan.

Ahora sí! ¿Todos listos, verdad?

Todos: Si

Vamos a continuar como todos van a mostrar sus papeles, vamos a trabajar en grupos de seis y después de que ordenen los factores en orden de prioridad tomaremos los cinco primeros y los compararemos con el otro grupo.

Tienen seis minutos, si terminan antes me avisan.

Luz : Ya terminamos

Moredador : y el otro grupo cómo va? 
Jonel : Ya acabamos.

Moredador: Bien, entonces ahora uniremos los 3 primeros de cada grupo y los ordenaremos, si se repite no o consideremos.

Tienen 10 minutos para que dialoguen y me indiquen el orden de preferencia.

Erika : Listo ya lo tenmos listo!

Moredador: Haber cuál es el orden que han considerado. Wilber menciona el primero.

Wilber : Creemos que es importante el precio ya que se repitió en los grupos y porque depende de eso la compra, si es muy caro no podremos construir.

Moderador: Muy bien ahora el segundo factor, Mari nos puedes indicar.

Mari: Si la resistencia es el segundo porque queremos casas seguras y como Arequipa está considerado como Zona sísmica por eso lo seleccionamos como el número dos. La resistencia también lo pusieron el otro grupo.

Moderarador : El tercero? Jonel.

Jonel : El tercero es que no contamine el ambiente, que sea algo ecológico. Por lo que hablábamos de la contaminación de las ladrilleras por los hornos.

Moredador : Bien, y el cuarto lo mencionara ,Cinthya .

Cinthya. Si el cuarto es el peso. Porque nos comentaron que influye para poder construir otros niveles y eso es importante para los que tenemos un terreno pequeño y se quiera hacer varios pisos.

D. ¿Cuáles son los materiales de construcción que conocen?

Moderador: Recuerdan el juego para conocernos, el "Ritmo Agogo", ¿verdad?. Bueno ahora quiero que me indiquen detenidamente cuales son:

Noemi: el ladrillo, el sillar, las bloquetas

Erika : El ladrillo y el sillar

Luz: Aparte de los que ya mencionaron yo conozco el trupan, hacen estructuras y en base a ello colcoan laminas

Rodrigo: Si también la Madera, y el ladrillo

Justina: Yo ladrillo pandereta, el king kong.

Renzo: Los mismos, ladrillo, sillar, madera.

Mari: Aca también construyen con adobe y a veces hacen casitas de material aligerado. 
Jonel: Yo lei sobre ladrillos ecológicos, creo que en Lima se hacen con residuos.

Wilber: Si hay esos ladrillos, vi edificios ecológicos en Lima, pero supongo que tienen estos ladrillos reciclados.

Rodrigo: ladrillo, ladrillo caravista pandereta hay varios tipos con los que se puede construir, también está el ladrillo artesanal o mecanizado.

Carmen: Ladrillo, madera y aligerado

Fernando: madera, ladrillo, bloquetas de cemento.

E. Si escuchara el término "LadriplastAQP” ¿Qué idea le viene a la mente?

Carmen: Mmm un Ladrillo de plástico de Arequipa

Erika: Si como ya lo menciono el nombre es claro, ladrillos de plástico, pero no sabría si todo es de plástico o tiene otro material adicional.

Todos: Ladrillos de pastico en Arequipa

\section{TEMA 3: LA BLOQUETA DE PLASTICO}

(Se presentó a través de imágenes la bloqueta de plástico a los participantes.)

Este es el material que quiero que observen, es una bloqueta de plástico, que posee características similares al ladrillo.

A. Si tuvieran esta bloqueta disponible en las ferreterías ¿Consideraría en comprarlo? ¿Por qué motivos no o si lo compraría?

Carmen: Si tiene las mismas propiedades si lo compraría

Erika: Bueno tendría que ver con que material se uniría, de repente es más caro.

Luz: Claro que sí si es más económico que el ladrillo y tiene lo mismo, sí.

Fernando: Si, pero tendría que saber bien, que tenga garantía

Renzo:Si , si es resistente a sismos y cuesta igual o menos que el ladrillo si lo compraría para mi casa.

Justina:No lo compraría porque no conozco como se usaría y nose si hay personas que construyan con ese material

Cinthya: Yo si lo compraría, si no contaminara el medio ambiente.

Jonel: Si compraría si es igual que el ladrillo

Wilber Si también lo compraría siempre y cuando me aseguren que mi casa no se ca a acaer.

Rodrigo: si, si compraría

Mari: Si lo compraría quizás para una medianera y si me va bien seguiría comprando. 
Noemi: No lo compraría porque no conozco de sus características y que tal si construyo y se cae.

B. Si estuviera a la venta ¿Le gustaría recibir su pedido en el lugar de la construcción? ¿Se acercarían a comprarlo? ¿Lo comprarían a través de pedidos por la web?

Carmen: Claro pero que sea menor el costo, por la web es un poco difícil.

Erika: Yo iría a comprarlo pero que me brinden el servicio de envío gratis.

Luz: Por la web me parece perfecto pero que incluya el envío y sea económico.

Fernando: Sobre todo que sea económico, porque a veces se gasta en ir y venir y encima se paga el envió.

Renzo: A mi si me gustaría ir a comprar porque asi puedo ver que sea un buen material.

Justina: Si iría a comprar como dicen a veces dan gato por liebre en especial en el ladrillo artesanal que es más económico.

Cinthya si me parece genial que lo entreguen en tu casa y hagas el pedido o la compra por internet.

Jonel: Cualquiera de las opciones es buena, en especial comprarlo por internet.

Wilber: Yo iría a ver el material.

Rodrigo: Si cotizaría precios y recién compraría. Pedidos por internet sería un poco difícil, para ver la calidad del producto.

Noemi : Yo compraría por intenet, pero siempre y cuando este verificado que es un buen material.

Renzo: Creo que no todos dominamos las compras por internet, así que yo prefiero ir al lugar.

C. ¿Qué esperaría del producto?

Maria: Que sea un buen producto que resista en caso de sismos

Noemi: que dure bastante, que me permita construir

Luz: que sea económico y que brinde la seguridad cuando haya terremotos

Fernando: Que sea un buen producto, que tenga garantía.

Erika: Que sea un producto de calidad, y si es bueno que haya también tipos.

Camen: El producto a mi parecer debe brindar confianza estar respaldado

Renzo: Que tenga algo que lo respalde para que se pueda comprar con confianza. 
Jonel: Si a mí me gustaría comprar, he escuchado, pero como le digo no hay información entonces eso deberían difundirlo.

Wilber: Que el producto sea seguro, que no vayamos a tener problemas en el futuro. Rodrigo: Seguridad, ante todo.

Justina: pienso que debería ser resistente, que este avalado, como la mencionaba la señora como Arequipa es zona sísmica. que nos de esa seguridad.

Cinthya: bueno yo espero que sea un producto resistente y que tenga la mejor calidad

\section{CIERRE LA SESION CON SUGERENCIAS E IDEAS FINALES}

Teniendo en cuenta nuestra conversación, ¿Qué acciones sugerirían o recomendarían para las bloquetas de plástico fuera el mejor producto? ¿Pueden brindarnos las ultimas ideas, sentimientos o comentarios? (pregunte sonde a cada participante)

Carmen: Me encantaría utilizar esas bloquetas, quizás probar para ver que tales son.

Erika Yo les recomendaría que divulguen la información porque me parece una buena forma de reciclaje

Luz La recomendación es que brinden buena información del producto.

Mari: como lo mencionaron, que lo certifiquen.

Rodrigo: Bueno que informen de estos ladrillos o bloquetas.

Cinthya: Quizás que hagan una buena campaña de publicidad, letreros.

Fernando: Si también se podrían repartir volantes donde haya más crecimiento

Jonel: Creo que las recomendaciones de los demás son muy buenas, quizás agregarle, que tenga varios lugares donde comprar

Wilber: Que pueda tener un precio bajo, para que sea accesible a todos.

Renzo: Que tengan para pagar a crédito

Noemi : Que nos den información de esas bloquetas o que hagan una casa para que se vea a demostración

Justina: Seria bueno que a los clientes se hagan charlas de los beneficios de construir con las bloquetas con plástico 


\section{FIN DE LA SESION DE ENFOQUE}

Moredador: Gracias a todos por haber asistido a este Focus Group, sus ideas, comentarios y en general sus respuestas, son un gran aporte.

(Se, entregara el presente a los participantes). Gracias por su asistencia. 


\section{ANEXO VII: FOCUS GROUP SESION II}

\section{BIENVENIDA A LOS PARTICIPANTES}

Moderador: Buenas noches, mi nombre es Stefhanie, y el día de hoy voy a acompañarlos como moderador en este Focus Group, en el cual se les presentará un nuevo producto: bloquetas de plástico, lo que se espera es que cada uno de Uds. exprese lo que siente y emita opiniones en todos los temas que se tratarán en esta reunión, les pido que brinden sus opiniones con toda naturalidad.

\section{CALENTAMIENTO}

Moderador: Antes de iniciar me gustaría que nos presentemos, formemos un círculo y diremos cada uno nuestro nombre, empecemos por el lado derecho.

Ahora haremos un juego, "Cantaremos el ritmo Agogo, usando tipos de materiales de construcción de vivienda", por ejemplo "yo mencionare sillar, la siguiente persona mencionará el material que dije y dirá uno nuevo, así sucesivamente".

Ya que acabamos hemos terminado el juego y antes de iniciar con los temas, debo decirles que todos estamos dando un poco de nuestro tiempo para participar, así que realmente valoraremos sus opiniones y su participación.

Para ello se realizarán las siguientes preguntas, donde cada uno tendrá oportunidad de intervenir.

\section{TEMA 1: CARACTERISTICAS QUE CONSIDERA EL CONSUMIDOR PARA LA CONSTRUCCION DE SU VIVIENDA.}

Moderador: Nuestra ciudad está creciendo hay varios distritos que han crecido de manera rápida como es el caso de las partes altas de Alto Selva Alegre, Miraflores, Cerro Colorado, etc.

Y no solo hablamos de crecimiento de población por distrito sino, el crecimiento de cada una de las viviendas, se incrementan niveles, por quiero realizarles la pregunta ¿quiénes de Uds. quieren construir o realizar ampliaciones de su vivienda?

Carlos: Yo si realizare la construcción de mi vivienda, ya tengo los planos estoy buscando quien me construya.

Lourdes: Bueno yo ahora no pienso construir aquí, pero en mi casa de playa si, ya para el verano he hecho algunos cambios.

Mirian: Si yo pienso construir, pero ahora no, de repente el próximo año. 
Manuel: Yo por el momento no, el año pasado hice algunas modificaciones a la casa así que no.

Claudia: Vivo en un departamento así que no he planificado nada de eso.

Patricia: En enero espero construir una casita por Characato.

Laura: En mi casa realizare ampliaciones, por mis hijitos.

Ronal: También ampliar mi casa, lo que no se es cuando iniciare eso.

Aron: Yo si construiré, o quiero empezar a construir una casa en Cerro Colorado.

Arturo: Yo me comprare un lote el cual cercare.

Alejandra: Yo no tengo planificado la construcción de mi vivienda, pero mi esposa me insiste que sí.

Karla Yo no tengo planeado hacer construcciones porque acabo de comprar una casa y estoy con el pago del banco, quizás de aquí a tres años.

Pierina: Yo he planificado construir en mi casa el segundo piso

C. ¿Qué material elegirían para realizar las ampliaciones y/o construcciones de nuevas viviendas?

Lourdes: El ladrillo.

Manuel: También ladrillo para una casa nueva.

Carlos: Ladrillo o bloqueta.

Miriam: También de ladrillo por su resistencia

Claudia: Para ampliación podría ser otro material, madera, bloqueta.

Laura: De ladrillo de arcilla, bloquetas no acá usan más el ladrillo

Ronal: Ladrillo cien porciento.

Arturo: Bueno para el cerco podría utilizar bloquetas

Karla: De ladrillo para que sea más resistente.

Aron: Ladrillo También

Alejandra: También utilizaría el ladrillo.

Pierina : Definitivamente el ladrillo, porque es más seguro.

D. ¿Es importante para Uds., la textura del material, su color, etc.?

Pierina: No, eso no es tan importante porque al final el ladrillo se estuca.

Carlos: Yo pienso que, si es importante para que el estuque agarre mejor, el color no me parece importante porque al final se pinta, así sea ladrillo caravista. Aron: El tamaño si me parece importante, porque depende de eso la cantidad de ladrillos a comprar, también su peso, el color no me parece importante. 
Miriam: Esas características no me parecen importantes creo que lo compramos por precio o por si son resistentes.

Claudia: El físico no es tan importante como sus propiedades para la construcción, de ahí varia el estuque, pintura.

Cinthya: Si es para interior y se va a estucar no, pero eso si, no se debe de desgranar. La otra vez vi ladrillos artesanales que fácilmente se desmoronaba.

Renzo: Las características físicas no son importantes quizás el ello si es más liso o no eso si afecta a la fijación entre cada ladrillo. Pero el color no es importante. Arturo: Creo que es importante la resistencia, el precio también porque un ladrillo con mejores propiedades puede ser que cueste más.

Manuel: Definitivamente tiene razón Wilber porque depende también el precio del ladrillo.Ahh! y sobre las propiedades de color, textura es relativo porque si quieren caravista hay un ladrillo especializado, y así para cada cosa.

Ronal: Esas características si son importantes si vamos a querer que no se estuque o pinte, pero para las paredes interiores siempre se estucan y eso no afecta, lo que si afecta es sus propiedades, que sea resistente a los sismos.

Laura: El color la textura no es importante a mi parecer lo importante es la calidad del material, y ya algunos lo han mencionado, creo que el resultado es lo importante.

\section{TEMA 2: FACTORES IMPORTANTES PARA LA DECISIÓN DE COMPRA DEL CONSUMIDOR.}

Moderador: Existen diversos materiales de construcción de viviendas en Arequipa, como lo mencionamos en la dinámica, el sillar es uno de ellos, también tenemos al ladrillo y ahora último vemos que existen otros materiales más livianos.

Piensen en como las personas toman sus decisiones para comprar estos materiales “QQué factores considerarían importantes cuando deciden comprar materiales para la construcción?"

Moderador: Vamos a hacer una lluvia de ideas, les voy a dar cinco papeles a cada uno y van a escribir las características que creen que son necesarias para que ustedes tomen la decisión de comprar un tipo o marca de ladrillo.

Tienen cinco minutos.

¿Ya todos tienen listos todos sus papeles? (tres personas aún no terminan)

Se les dará tres minutos más para que concluyan. 
¡Ahora sí! ¿Todos están listos?

Todos: $\mathrm{Si}$

Vamos a continuar como todos van a mostrar sus papeles, vamos a trabajar en grupos de seis y después de que ordenen los factores en orden de prioridad tomaremos los cinco primeros y los compararemos con el otro grupo.

Tienen seis minutos, si terminan antes me avisan.

Carlos: Ya acabamos

Moderador: ¿y el otro grupo cómo va?

Lourdes: Ya estamos listos.

Moredador: Bien, entonces ahora uniremos los 3 primeros de cada grupo y los ordenaremos, si se repite no o consideremos.

Tienen 10 minutos para que dialoguen y me indiquen el orden de preferencia.

Miriam: ¡Listo ya lo tenemos!

Moredador: Haber cuál es el orden que han considerado. Manuel menciona el primero.

Manuel: Para nosotros en su mayoría lo importante es la calidad y seguridad que brinda para la construcción no podemos arriesgar nuestras vidas con cualquier material que no sea de buena calidad.

Moderador: Muy bien ahora el segundo factor, Claudia nos puedes indicar.

Claudia: El segundo factor seria el precio, pero sin descuidar la calidad y garantía del producto, creo que la mayoría de personas busca economizar los costos y no elevarlos.

Moderador: El tercero? Laura.

Laura: Todo actualmente se basa en la contaminación sería bueno considerar que estos materiales puedan ser reutilizados o que ayuden a la preservación de nuestro planeta.

Moredador: Bien, y el cuarto lo mencionara ,Ronal .

Ronal. Otro factor importante es que sean resistentes a los diferentes climas que soporta la ciudad y además de agentes que puedan dañarlos.

F. ¿Cuáles son los materiales de construcción para muros portantes y no portantes que conocen? 
Moderador: Recuerdan el juego para conocernos, el "Ritmo Agogo", ¿verdad?. Bueno ahora quiero que me indiquen detenidamente cuales son:

Aron: Ladrillo, Sillar, adobe también se usa, pero solo para dos pisos.

Claudia: Ladrillo, Bloques de concreto.

Laura: Existen diferentes tipos de ladrillo, además el sillar, también muros prefabricados de concreto.

Arturo: Ladrillo, Sillar, bloquetas

Alejandra: Sillar, ladrillo,

Karla: Ladrillos, saben hacer paneles de madera y también eh visto las placas de yeso prefabricado.

Pierina: Eh visto que usan la madera como casas prefabricadas hasta de dos pisos, y lo clásico es el ladrillo y sillar.

Carlos: En internet vi que se está empezando a fabricar ladrillos con plástico reciclado.

Manuel: Si en Perú ya existen proyectos donde se usa estos ladrillos, un amigo es ingeniero y me dijo que es rentable y son de buena calidad también resisten a los climas extremos.

Lourdes: Solo conozco ladrillos mecanizados y artesanales, también ladrillo.

Ronal: Ladrillo, placas de concreto y fierro, de madera.

Miriam: Bloquetas, ladrillo, prefabricados.

G. Si escuchara el término "LadriplastAQP” ¿Qué idea le viene a la mente?

Ronal: Ladrillos de plástico

Laura: Pues su nombre lo dice ladrillos hechos a base de platico y en Arequipa.

Todos: Ladrillos de pastico en Arequipa.

\section{TEMA 3: LA BLOQUETA DE PLASTICO}

(Se presentó a través de imágenes la bloqueta de plástico a los participantes.)

Este es el material que quiero que observen, es una bloqueta de plástico, que posee características similares al ladrillo.

D. Si tuvieran esta bloqueta disponible en las ferreterías ¿Consideraría en comprarlo? ¿Por qué motivos no o si lo compraría?

Carlos: $\mathrm{Si}$, para ayudar al reciclaje

Lourdes: Si, si es que es más económico y cumple las normas. 
Miriam: No, quisiera saber más sobre sus propiedades y ver que lo usen otras personas.

Manuel: Si, pero tendría que investigar sus propiedades y hasta cuanto de resistencia soportaría.

Claudia: Si, pero debería entrar al mercado explicando sus bondades y defectos para que todos sepamos donde usarlo y como usarlo.

Laura: Supongo que al comprarlo nos explicarían como se usa y además que personal lo sabe colocar, porque si se necesita un especialista pueda ser que me salga más caro que colocar un ladrillo típico.

Ronal: No, no soy de las personas que confían en algo nuevo hasta ver su uso en otros lugares.

Aron: Si, pero si es que cuesta menos que los ladrillos normales y rinde mas en cuanto a avance también debe ser mejor.

Arturo: No, hasta lograr investigar sus propiedades y desventajas es muy importante, por otro lado, ayuda a reciclar los plásticos, quizá para viviendas de dos pisos como máximo.

Alejandra: No, no me arriesgo

Karla: Si, ayudamos al medio ambiente si se tiene este material disponible

Pierina: si, si compraría para probar

\section{E. Si estuviera a la venta ¿Le gustaría recibir su pedido en el lugar de la construcción? ¿Se acercarían a comprarlo? ¿Lo comprarían a través de pedidos por la web?}

Carlos: Como siempre se hace en todos los materiales de construcción cuando los compramos por más de 1 millar, si es por web sería más fácil.

Lourdes: Si, Todos los medios de comunicación son válidos, pero siempre y cuando que lo que se oferte sea igual a lo que se recibe.

Miriam: si, para comprarlos siempre es necesario ver el producto, si ya lo conozco solo lo pido.

Manuel: para el ladrillo común siempre es gratis el envió, por primera vez si iría a conocer el producto pero después lo pediría por internet.

Claudia: si; es más practico pero que sea de calidad.

Laura: $\mathrm{Si}$, pero la primera vez quisiera verlos antes de comprarlos. 
Ronal: siempre que compre ladrillo me lo trajeron al lugar sin algún costo adicional, todas las nuevas tecnologías deben ser usadas y aprovechadas.

Aron: bueno siempre es bueno saber los precios en diferentes puntos de venta, pero al conocer un lugar donde me haga precio solo los pediría.

Arturo: Si el producto es el único en el mercado lo pediría directamente a la fábrica por cualquier medio.

Alejandra: No, no me arriesgo quisiera verlos antes que me den gato por liebre.

Karla: Si, a todos nos resulta mejor que esos productos sean puestos en obra sin costo adicional, por internet lo compraría después de varias veces que ya conozca el producto

Pierina: para la primera compra iría a ver el producto antes de comprarlo y debe ser puesto en obra como se sabe de los ladrillos, por internet también, pero es lo de menos.

F. ¿Qué esperaría del producto?

Carlos: Que sea bueno, barato.

Lourdes: que este a un precio asequible y que sea de calidad.

Miriam: que sea durable, aunque el plástico tarda bastante en degradarse.

Manuel: Que sea de buena calidad y fácil instalación, podríamos ahorrar en especialistas.

Claudia: que sea barato y que se use más que los ladrillos comunes.

Laura: que sean productos de calidad y duraderos.

Ronal: Que se siga investigando y a lo mejor se incorpore aditivos que mejoren sus propiedades.

Aron: que sea asequible a toda clase de público y que asegure la vida de las personas que vivirán en esas casas.

Arturo: Debe de estar garantizado antes de su comercialización y si aún no pasa los requerimientos mínimos se siga investigando.

Alejandra: que sea económico pero seguro

Karla: que se adapte a todos los lugares de uso

Pierina: todos coincidimos en lo mismo que sea bueno, barato y seguro 


\section{CIERRE LA SESION CON SUGERENCIAS E IDEAS FINALES}

Teniendo en cuenta nuestra conversación, ¿Qué acciones sugerirían o recomendarían para las bloquetas de plástico fuera el mejor producto? ¿Pueden brindarnos las ultimas ideas, sentimientos o comentarios? (pregunte sonde a cada participante)

Carlos: sería bueno que se construya una vivienda de prueba donde se explique al público sus propiedades.

Lourdes: que haya bastantes puntos de distribución.

Miriam: que se dé a conocer más las propiedades y que sea cierto lo que se dice.

Manuel: el gobierno debe invertir para investigar más estos productos y mejorarlos

Claudia: si realmente cumple sus propiedades debe hacerse campañas para que se expanda su uso en todo el país.

Laura: algunas familias no cuentan con mucho dinero sería bueno que el gobierno invierta y lo paguen poco a poco.

Ronal: debe hacerse saber más las propiedades de estos bloques

Aron: bueno siempre no se puede confiar así de fácil en algo que no conoces, asi que debe hacerse campañas de demostración.

Arturo: Que se haga campañas de publicidad.

Alejandra: deben ser hechos por una empresa de prestigio

Karla: investigar más sobre sus posibles mejoras

Pierina: siempre debe tener una certificación o que el estado financie la investigación más profunda de este producto

\section{FIN DE LA SESION DE ENFOQUE}

Moredador: Gracias a todos por haber asistido a este Focus Group, sus ideas, comentarios y en general sus respuestas, son un gran aporte.

(Se, entregara el presente a los participantes). Gracias por su asistencia. 


\section{ANEXO VIII: ENTREVISTA AL EXPERTO DE MARKETING}

\section{Participante:}

Nombre:Jose Paredes Romero

Edad:33 años

Profesion: Cs. De la Comunicación

\section{Guía de Entrevista:}

\begin{tabular}{|c|c|}
\hline \multicolumn{2}{|c|}{ GUIA DE ENTREVISTA $\mathbf{N}^{\circ} 1$} \\
\hline Lugar: & Urb. Asvea A-15 \\
\hline Fecha: & 25 de Octubre del 2016 \\
\hline Hora : & 6:00pm \\
\hline Tema: & $\begin{array}{l}\text { Conocer aspectos de marketing } \\
\text { relevantes para un nuevo producto en } \\
\text { el sector. }\end{array}$ \\
\hline \multicolumn{2}{|c|}{ 1. Presentación } \\
\hline \multicolumn{2}{|c|}{$\begin{array}{l}\text { Buenas tardes , queremos mostrarle agradecimiento por recibirnos y sobre todo el } \\
\text { tiempo brindado para poder realizar esta entrevista. Mencionarle a su vez que la } \\
\text { información y comentarios brindados serán muy valorados para el proyecto de } \\
\text { tesis que vamos a realizar. }\end{array}$} \\
\hline \multicolumn{2}{|c|}{ 2. Preguntas Diseñadas } \\
\hline \multicolumn{2}{|c|}{$\begin{array}{l}\text { 1. ¿Qué medio de comunicación se podría utilizar para promocionar las bloquetas de } \\
\text { plástico? }\end{array}$} \\
\hline \multicolumn{2}{|c|}{$\begin{array}{l}\text { Lo primordial es hacer el análisis de lo que requiere el cliente, el producto debe cubrir esos } \\
\text { requisitos y a lo largo del tiempo se debe ir actualizando al producto para que cumpa con } \\
\text { ello. Para un producto como es el ladrillo, bueno e este caso bloquetas de plástico, la } \\
\text { promoción esta en las condiciones que pueda brindar al consumidor, quizás resistencia } \\
\text { ante sismos, mayor seguridad, entre otras características que pueden ser importantes para } \\
\text { que el consumidor adquiera el producto. }\end{array}$} \\
\hline \multicolumn{2}{|c|}{$\begin{array}{l}\text { Pienso que siendo un producto de uso en poblaciones emergentes se podría contar con } \\
\text { vendedores de campo, quienes deberán tener a su cargo llevar la información de las } \\
\text { necesidades de los clientes para ir mejorando el producto, ello permitirá también crear la } \\
\text { fidelización con los clientes. }\end{array}$} \\
\hline
\end{tabular}


Se debería participar en ferias, exposiciones que permitan llevar a la empresa a tener reconocimiento por parte de los consumidores.

2. Al momento de sacar al mercado un nuevo producto ¿Qué barreras son las que se presentan?

La romper con la cultura que posee el consumidor respecto a las construcciones con ladrillo de arcilla si me parece una parte complicada, no difícil, ya que dar a conocer las propiedades, ventajas de las bloquetas de plástico. Habría que analizar qué es lo que mueve al consumidor para comprar algún tipo de material, de repente es el precio entonces, es fácil de eliminar esa barrera, por lo demás yo creo que es accesible.

3. ¿Cómo se puede establecer el nivel de precios?

Ya que posee varios productos sustitutos podría establecerse de acuerdo al precio de la competencia, eso sí siempre hay que pensar en la rentabilidad de la empresa.

4. ¿Qué opina acerca de una bloqueta hecha con plástico molido, respecto al manejo del marketing?

Me parece una idea muy interesante el hecho de hacer un producto en base a deshechos plásticos y creo que es una gran oportunidad explotar el impacto que va a tener al medio ambiente, y darlo a conocer.

Respecto al marketing, bueno como ya lo mencioné se debe tomar en cuenta a que consumidor se quiere llegar. Por ser un producto nuevo se debe hacer un plan de introducción al mercado, para dar a conocer el producto.

Respecto a los canales de distribución se podría considerar también las compras por internet que actualmente está teniendo gran acogida por la gente joven, de repente a una parte del segmento si les gustaría comprar a través de este medio. También deben considerar constar con distribuidoras hasta donde tengo entendido las empresas como la "Ladrillera el diamante" cuentan con clientes que se encargan de la distribución, de repente enfocarse en crear alianzas o tener un segmento orientado a ello.

\section{Despedida}

De acuerdo a lo conversando en esta entrevista, ¿En qué características del producto nos recomendaría enfocarnos, para la promoción de bloquetas de plástico?

Bueno si aún no han realizado su estudio cuantitativo, quizás hacer un cuestionario de acuerdo a las características más importantes para el consumidor o cliente, para determinar las características. Lo que si les podría recomendar que usen el tema ambiental para promocionar el producto ya que actualmente este se está haciendo parte de la cultura.

Agradecemos, el tiempo brindado para la entrevista. 


\section{ANEXO IX: ENTREVISTA A EXPERTO DEL SECTOR CONSTRUCCION}

\section{Participante:}

Nombre:Arturo Medina Añari

Edad:46 años

Profesion:Arquitecto

2. Guía de Entrevista:

\begin{tabular}{|c|c|}
\hline \multicolumn{2}{|r|}{ GUIA DE ENTREVISTA $\mathbf{N}^{\circ} 2$} \\
\hline Lugar : & Calle Virgen del Pilar 1007-Cercado \\
\hline Fecha: & 27 de Octubre del 2016 \\
\hline Hora : & $3.00 \mathrm{pm}$ \\
\hline Tema: & $\begin{array}{l}\text { Conocer las perspectivas del sector construcción en relación a las } \\
\text { bloquetas de plástico. }\end{array}$ \\
\hline \multicolumn{2}{|c|}{ 1. Presentación } \\
\hline \multicolumn{2}{|c|}{$\begin{array}{l}\text { Buenas tardes, queremos mostrarle agradecimiento por recibirnos y sobre todo el tiempo } \\
\text { brindado para poder realizar esta entrevista. Mencionarle a su vez que la información y } \\
\text { comentarios brindados serán muy valorados para el proyecto de tesis que vamos a } \\
\text { realizar. }\end{array}$} \\
\hline \multicolumn{2}{|c|}{ 2. Preguntas Diseñadas } \\
\hline \multicolumn{2}{|c|}{$\begin{array}{l}\text { Agradecerle a Ud. Por pensar en mí y bueno poderles brindar la información que } \\
\text { requieren. }\end{array}$} \\
\hline \multicolumn{2}{|c|}{ 1.¿Qué tipo de ladrillo para la construcción es el que Ud. selecciona con frecuencia? } \\
\hline \multicolumn{2}{|c|}{$\begin{array}{l}\text { Normalmente, seleccionó el ladrillo King Kong para muros portantes y tabiquerías, en } \\
\text { cambio para acabados uso el ladrillo caravista, a veces el pastelero como complementos } \\
\text { para acabados y generalmente. También el acanalado. }\end{array}$} \\
\hline \multicolumn{2}{|c|}{ 2. De su experiencia, ¿Qué tipo de ladrillo es el más solicitado en las construcciones? } \\
\hline \multicolumn{2}{|c|}{$\begin{array}{l}\text { Bueno eso depende de la función que vaya a cumplir, quizás sea muros portantes ahí si se } \\
\text { utiliza ladrillos estructurales y para muros de tabiquería se utiliza los ladrillos con } \\
\text { perforaciones. }\end{array}$} \\
\hline \multicolumn{2}{|c|}{$\begin{array}{l}\text { Ahora, el tipo puede variar dependiendo del constructor, a veces cuando se hacen con los } \\
\text { "maestros" para muros de tabiquería utilizan los ladrillos artesanales. }\end{array}$} \\
\hline \multicolumn{2}{|c|}{ 3. ¿Qué características del ladrillo toma en cuenta para las edificaciones que realiza? } \\
\hline $\begin{array}{l}\text { Bueno } \\
\text { las con }\end{array}$ & $\begin{array}{l}\text { reglamento con ciertas características que debe cumplir, para mí en } \\
\text { de viviendas utilizo el pandereta liso y acanalado. }\end{array}$ \\
\hline
\end{tabular}


4. ¿Suele sugerir materiales de construcciones con características ecológicas en sus construcciones?

$\mathrm{Si}$, especialmente el mecanizado (local) por el proceso de fabricación que utilizan pero que utilicen materiales ecológicos o que contribuyan al medio ambiente, no.

5. ¿Ud. Ha oído a hablar respecto la venta de ladrillos y/o bloquetas de material reciclado?

A través de páginas web, bueno en realidad por investigación propia, lo oí en una charla del colegio de Arquitectos y de ahí me nació la curiosidad. Pero información oficial que se dé a través de reglamentos o normas de uso, con ese material, no.

5. ¿Qué opina acerca de una bloqueta hecha con plástico molido?

Bueno como le indique averigüe un poco y me parece una idea muy sostenible, porque permite utilizar elementos de reciclaje para poder construir viviendas, me parece una idea muy innovadora y que, si podría utilizarse siempre y cuando este validado por Colegios profesionales, Universidades y que cumpla el reglamento de nacional de Edificaciones.

Además de que se publiquen las pruebas de ese nuevo material, hará que nos den el respaldo para su aplicación.

6. ¿Cuáles cree usted que podrían ser los pros y los contras de este ladrillo?

(Restricciones según el reglamento de construcción, normas, características, etc.)

Las restricciones quedaran determinadas una vez que se realicen los ensayos y estos no cumplan con las normas técnicas exigidas, si esto no sucede el material será totalmente aprobado y además podría ser respaldado y promovido por los Colegios profesionales e instituciones que tengan relación con el sector construcción.

\section{Despedida}

De acuerdo a su experiencia, ¿Qué sugerencias podría brindarnos, con respecto al producto de bloquetas de plástico, considerando la situación actual y las perspectivas a futuro del sector construcción?

La recomendación que les daré es de buscar tener respaldo quizás los ensayos que encontraron darles validez, de repente existe una patente que puedan comprarla y usarla aquí. Una vez que tenga validez, realizar conferencias, capacitaciones, charlas, foros, debates entre otras actividades que posibiliten la difusión del producto, una idea que se me ocurre es quizás realizar una obra pequeña la cual sirva de modelo para los clientes.

Entrevistador: Agradeceremos, el tiempo brindado para la entrevista.

No tienen porque, gracias a Uds. Por solicitar mi apoyo, espero haberle podido ayudar lo suficiente. 
ANEXO X: FICHA TECNICA DE ENTREVISTAS A EXPERTOS DEL SECTOR LADRILLERO

\section{Objetivo de investigación:}

Conocer aspectos dentro de la industria del sector ladrillero.

\section{Participante:}

Nombre: H. Gómez

Edad: 40 años

Cargo: Administrador

\section{Guía de Entrevista:}

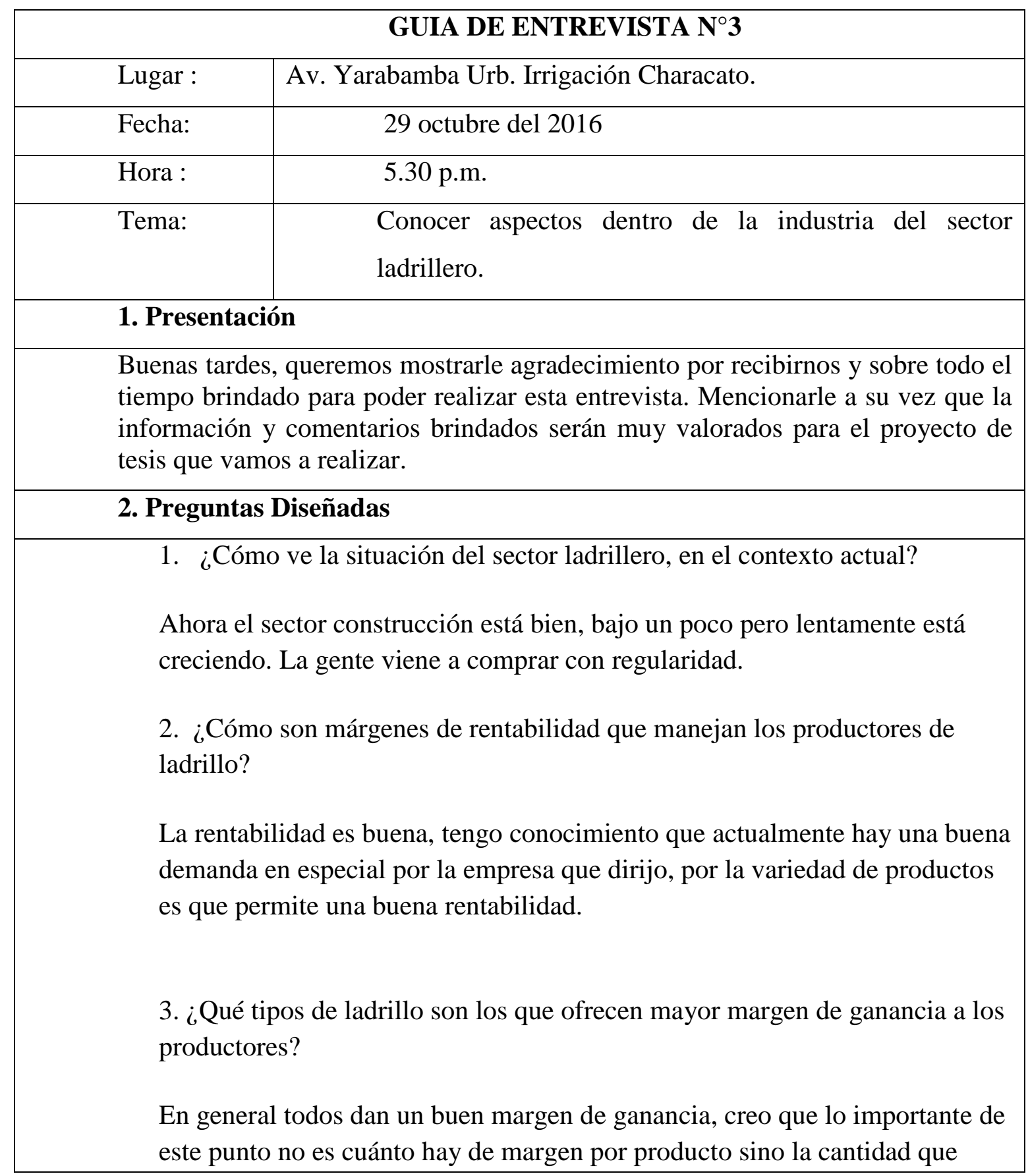




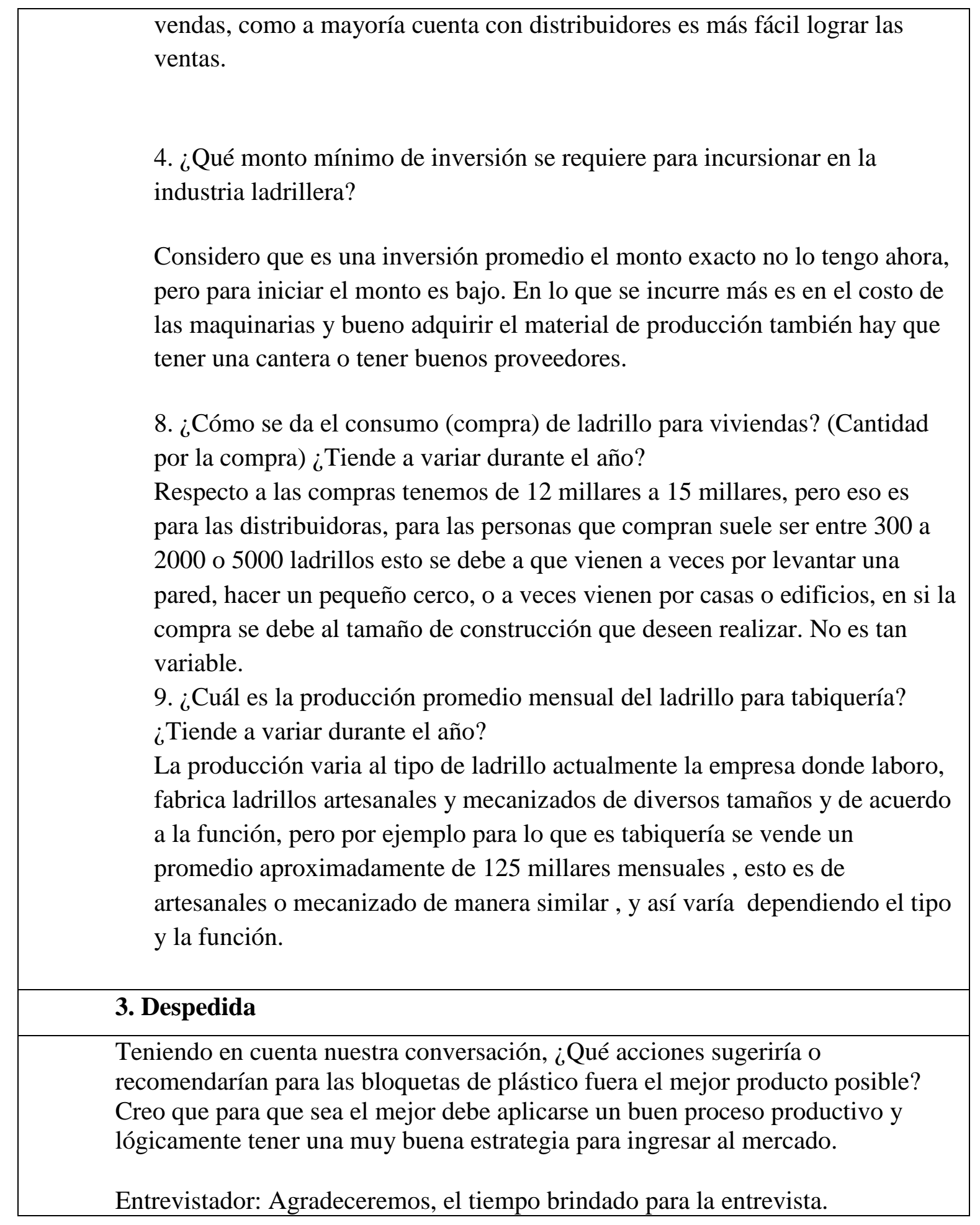




\section{ANEXO XI: FICHA TECNICA DE ENTREVISTAS A EXPERTOS DEL SECTOR}

\section{Objetivo de investigación:}

Conocer los factores competitivos en el Sector ladrillero, en relación a las bloquetas Plásticas.

\section{Perfil de los Participantes:}

a. Trabajador de alguna empresa del sector (área de ventas, marketing o administración).

b. Estar laborado durante la industria más de 4 años.

c. Edad desde 33 años a más.

d. Con conocimiento del sector ladrillero, en los últimos años.

\section{Guía de Entrevista:}

\subsection{Participante:}

Nombre: E. Zamora

Edad:33 años

Área: Ventas

\begin{tabular}{|c|c|}
\hline & GUIA DE ENTREVISTA $\mathbf{N}^{\circ} 1$ \\
\hline Lugar: & Jacinto Ibañez, Parque Industrial Arequipa -Arequipa \\
\hline Fecha: & 29/01/2018 \\
\hline Hora : & $2.30 \mathrm{pm}$ \\
\hline Tema: & Identificar las Factores Competitivos en el sector ladrillero. \\
\hline \multicolumn{2}{|c|}{ 1. Presentación } \\
\hline \multicolumn{2}{|c|}{$\begin{array}{l}\text { Buenas tardes, queremos mostrarle agradecimiento por recibirnos y sobre todo el } \\
\text { tiempo brindado para poder realizar esta entrevista. Mencionarle a su vez que la } \\
\text { información y comentarios brindados serán muy valorados para el proyecto de } \\
\text { tesis que vamos a realizar. }\end{array}$} \\
\hline \multicolumn{2}{|c|}{ 2. Preguntas Diseñadas } \\
\hline
\end{tabular}


1. ¿Qué empresa considera Ud. que sería un competidor principal para las bloquetas de plástico?

Al tratarse de una empresa nueva la que están emprendiendo, podrían competir directamente con ladrillera Choque, la cual es una microempresa bastante formal y con un proceso productivo establecido. Otras de las empresas con las que podrían entrar en competencia serían Sr. De los Milagros y Virgen de Chapi, pero estas empresas manejan su proceso productivo por quema tradicional.

2. ¿Qué factores competitivos considera que son importantes en este sector? ¿Por favor menciónelos de mayor o menor de acuerdo al grado de importancia?

Consideró en primer lugar la ubicación de la planta y también los lugares de venta, la maquinaria para la producción, es importante que el personal esté capacitado, cumplir con las normas de seguridad requeridas, enfocarse en la calidad del producto, tener diseñado un plan de ventas, manejar políticas de precios, contar con una adecuada logística, este punto es importante también por el periodo de tiempos de producción y definitivamente la publicidad necesaria, las promociones también es un factor necesario.

3. ¿Del uno al 10 podría indicarnos su calificación para cada uno de estos factores?

La calificación de factores que me solicitas es indistinta, ya que para cada empresario puede ser indistinta, en mi caso yo lo valoraría con 10 puntos a la calidad del producto, 9 puntos a la capacidad productiva, 8 puntos para logística, 7 puntos para la ubicación de la planta, 6 puntos para precios, 5 puntos para maquinaria, 4 puntos para lo que es personal, 3 puntos normas de seguridad, 2 puntos para la ubicación y 1 punto para la propaganda.

4. ¿De los factores que considera Ud. importantes, podría calificar las bloquetas plásticas, del 1al 10?

Es un producto novedoso el cual debería enfocarse en la calidad de producto (10 ptos), proceso productivo (9 ptos), deben trabajar en propaganda de las bloquetas (8ptos), ubicación de planta (7ptos), calidad de maquinaria (6ptos), precios (5ptos), plan de ventas (4), logística (3), normas de seguridad (2) y personal capacitado (1).

\section{Despedida}

De acuerdo a su experiencia, habiendo conversado con anterioridad sobre la propuesta de una bloqueta plástica para competir con el ladrillo tradicional ¿Qué sugerencias podría brindarnos, para poder hacerle frente a esta empresa?

Les sugeriría que definan adecuadamente sus capacidad productiva, esto va a conllevar que definan una ubicación estratégica para el proyecto, tengan muy en cuenta la calidad del producto que van a ofrecer, el cual debe ir acompañado de un precio competitivo, no olviden trabajar en los aspectos de publicidad para su producto, enfóquense en brindar un buen servicio de venta y post-venta para que sus clientes los sigan recomendando. 
3.2. Participante:

Nombre: E. Mollo

Edad:41 años

Área: Ventas

\begin{tabular}{|c|c|}
\hline \multicolumn{2}{|r|}{ GUIA DE ENTREVISTA $\mathrm{N}^{\circ} 2$} \\
\hline Lugar & Av. Aviación Km.6-Cerro Colorado \\
\hline Fecha: & $30 / 01 / 2018$ \\
\hline Hora: & $5.00 \mathrm{pm}$ \\
\hline Tema: & $\begin{array}{l}\text { Identificar las fortalezas y debilidades de la empresa } \\
\text { propuesta en el plan de Negocios con relación a Ladrillera } \\
\text { Choque. }\end{array}$ \\
\hline \multicolumn{2}{|c|}{ 1. Presentación } \\
\hline \multicolumn{2}{|c|}{$\begin{array}{l}\text { Buenas tardes, queremos mostrarle agradecimiento por recibirnos y sobre todo el } \\
\text { tiempo brindado para poder realizar esta entrevista. Mencionarle a su vez que la } \\
\text { información y comentarios brindados serán muy valorados para el proyecto de } \\
\text { tesis que vamos a realizar. }\end{array}$} \\
\hline \multicolumn{2}{|c|}{ 2. Preguntas Diseñadas } \\
\hline \multicolumn{2}{|c|}{$\begin{array}{l}\text { 1. ¿Qué empresa considera Ud. que sería un competidor principal para las } \\
\text { bloquetas de plástico? } \\
\text { Podrían iniciar compitiendo con algunas empresas medianas de Mollebaya como } \\
\text { Alcosa, Virgen de Chapi, ellos manejan producción artesanal a mediana escala, } \\
\text { por otro lado su producto es industrializado podría compararse con la Ladrillera } \\
\text { Choque o caso contrario la Ladrillera el Diamante, pero por el prestigio y la } \\
\text { capacidad que posee es un poco idealista. }\end{array}$} \\
\hline \multicolumn{2}{|c|}{$\begin{array}{l}\text { 2. ¿Qué factores competitivos considera que son importantes en este } \\
\text { sector?¿Porfavor menciónelos de mayor o menor de acuerdo al grado de } \\
\text { importancia? }\end{array}$} \\
\hline \multicolumn{2}{|c|}{ En mi experiencia yo consideraría solo 5 factores: } \\
\hline \multicolumn{2}{|c|}{$\begin{array}{l}\text { 1. La calidad del producto, al que yo asocio a los avances tecnológicos por } \\
\text { resistencia, comprensión, absorción, etc. } \\
\text { 2. La practicidad del producto, esto concierne al diseño con el que ofrecen } \\
\text { el producto } \\
\text { 3. La competitividad en precios, el ahorro que brindan al cliente. } \\
\text { 4. El posicionamiento de la marca } \\
\text { 5. La garantía del producto, cuan eficiente es y que se ofrece como servicio } \\
\text { post-venta. }\end{array}$} \\
\hline \multicolumn{2}{|c|}{$\begin{array}{l}\text { 3. ¿Del uno al } 10 \text { podría indicarnos su calificación para cada uno de estos } \\
\text { factores? }\end{array}$} \\
\hline
\end{tabular}


Todos los factores que te he mencionado son importantes, deben conjugarse para que una empresa pueda tener éxito, pero si habría que asignarles una puntuación a cada uno de ellos, desde mi punto de vista yo los calificaría

1. Calidad del producto ( 10 puntos)

2. La practicidad del producto (3 puntos)

3. La competitividad en precios, ( 8 puntos )

4. El posicionamiento de la marca ( 6 puntos)

5. La garantía del producto ( 5 puntos)

Estoy seguro que otros especialistas del sector podrían brindarte mayores factores competitivos, pero se interrelacionan con los que yo te he mencionado, mencionar más no te aseguran el éxito sino se conjugan.

4. ¿De los factores que considera Ud. importantes, podría calificar las bloquetas plásticas, del 1al 10?

Te asigno la misma puntuación, como te lo repito nuevamente para mí los factores competitivos de esta industria, no varían, depende de cada empresa como desarrollar cada uno de ellos dependiendo de sus recursos.

1. Calidad del producto ( 10 puntos)

2. La practicidad del producto ( 3 puntos)

3. La competitividad en precios, ( 8 puntos )

4. El posicionamiento de la marca ( 6 puntos)

5. La garantía del producto ( 5 puntos)

\section{Despedida}

De acuerdo a su experiencia, habiendo conversado con anterioridad sobre la propuesta de una bloqueta plástica para competir con el ladrillo tradicional ¿Qué sugerencias podría brindarnos, para que el proyecto sea competitivo frente a la industria tradicional?

Trabajen en conjugar los factores competitivos que les he mencionado, no olviden resaltar cada una de las características que brinda cada factor en sus productos, si se refieren a la calidad, refieran a su proceso productivo, los beneficios de su producto, por ser ecológico, a la presentación de su producto, establezcan un servicio de post-venta con el cliente. 


\section{ANEXO XII: PROYECCION DEMANDA DE BLOQUETAS DE PLASTICO}

La data ha sido elaborada tomando en cuenta el $7.5 \%$ de crecimiento de la demanda anual, según información proporcionada en el Capítulo IV, Fig. 38, crecimiento de ventas de ladrillos, adoquines y bloques de concreto. Para nuestro proyecto, siendo conservadores tomamos un crecimiento de 5,0\%.

\begin{tabular}{lcllllllll}
\hline \multicolumn{2}{c}{ A NO 1 } & \multicolumn{2}{c}{ AÑO 2 } & \multicolumn{2}{c}{ AÑ O } & \multicolumn{2}{c}{ AÑO 4 } & \multicolumn{2}{c}{ AÑO 5 } \\
\hline Mes 1 & 250 & Mes 1 & 263 & Mes 1 & 276 & Mes 1 & 290 & Mes 1 & 305 \\
Mes 2 & 250 & Mes 2 & 263 & Mes 2 & 276 & Mes 2 & 290 & Mes 2 & 305 \\
Mes 3 & 250 & Mes 3 & 263 & Mes 3 & 276 & Mes 3 & 290 & Mes 3 & 305 \\
Mes 4 & 250 & Mes 4 & 263 & Mes 4 & 276 & Mes 4 & 290 & Mes 4 & 305 \\
Mes 5 & 250 & Mes 5 & 263 & Mes 5 & 276 & Mes 5 & 290 & Mes 5 & 305 \\
Mes 6 & 250 & Mes 6 & 263 & Mes 6 & 276 & Mes 6 & 290 & Mes 6 & 305 \\
Mes 7 & 250 & Mes 7 & 263 & Mes 7 & 276 & Mes 7 & 290 & Mes 7 & 305 \\
Mes 8 & 250 & Mes 8 & 263 & Mes 8 & 276 & Mes 8 & 290 & Mes 8 & 305 \\
Mes 9 & 250 & Mes 9 & 263 & Mes 9 & 276 & Mes 9 & 290 & Mes 9 & 305 \\
Mes 10 & 250 & Mes 10 & 263 & Mes 10 & 276 & Mes 10 & 290 & Mes 10 & 305 \\
Mes 11 & 250 & Mes 11 & 263 & Mes 11 & 276 & Mes 11 & 290 & Mes 11 & 305 \\
Mes 12 & 250 & Mes 12 & 263 & Mes 12 & 276 & Mes 12 & 290 & Mes 12 & 305 \\
\hline TOTAL & $\mathbf{3 0 0 0}$ & & $\mathbf{3 1 5 6}$ & & $\mathbf{3 3 1 2}$ & & $\mathbf{3 4 8 0}$ & & $\mathbf{3 6 6 0}$ \\
\hline
\end{tabular}


ANEXO XIII: INVERSION FIJA

\section{Inversión en Terrenos}

\begin{tabular}{lr}
\hline \multicolumn{1}{c}{ Descripción } & Área $(\mathbf{m} 2)$ \\
\hline Producción & 237.5 \\
Almacén de M.P. & $1,000.0$ \\
Almacén de P.T. & $1,000.0$ \\
Tina de Curado & 800.0 \\
Control de calidad & 40.0 \\
Mantenimiento & 40.0 \\
Administración y ventas & 16.0 \\
Servicios higiénicos & 10.5 \\
Áreas verdes o libres & 124.0 \\
Área de expansión & 653.6 \\
\hline \multicolumn{1}{c}{ Total área } & $\mathbf{3 , 9 2 1 . 7}$ \\
\hline Costo por m2 (Alquiler) & 3.3 \\
\multicolumn{1}{c}{ Total costo terreno } & $\mathbf{1 2 , 9 4 1 . 4}$ \\
\hline
\end{tabular}

2. Inversión en construcciones

\begin{tabular}{|l|}
\hline \multicolumn{1}{|c|}{ Descripción } \\
\hline Cerco perimétrico \\
\hline Cimentación, columnas, muros y techo \\
\hline Instalaciones sanitarias \\
\hline Instalaciones eléctricas \\
\hline Acondicionamiento de áreas verdes y libres \\
\hline
\end{tabular}

\begin{tabular}{|c|c|}
\hline Total área por construir & $\mathbf{1 , 1 0 4 . 0 4}$ \\
\hline Costo por $\mathrm{m} 2$ & 24.75 \\
\hline Total costo construcción & $\mathbf{2 7 , 3 2 5 . 0 4}$ \\
\end{tabular}


3. Inversión en muebles y enseres

\begin{tabular}{|c|c|c|c|c|c|}
\hline \multirow{2}{*}{ Área } & \multirow{2}{*}{ Muebles y Enseres } & \multirow{2}{*}{ Cantidad } & C. Unitario & C. Total & C. Total \\
\hline & & & $(\mathrm{S} /)$. & $(\mathrm{S} /)$. & (\$) \\
\hline \multirow{14}{*}{ Gerencia } & $\begin{array}{l}\text { Escritorio para } \\
\text { gerencia }\end{array}$ & 1 & 400 & 400 & 120.1 \\
\hline & Computadora & 1 & 2000 & 2000 & 600.6 \\
\hline & Impresora & 1 & 700 & 700 & 210.2 \\
\hline & Sillón para gerencia & 1 & 210 & 210 & 63.1 \\
\hline & Escritorio para oficina & 1 & 200 & 200 & 60.1 \\
\hline & Silla giratoria & 3 & 160 & 480 & 144.1 \\
\hline & Archivador & 1 & 15 & 15 & 4.5 \\
\hline & Estante & 1 & 210 & 210 & 63.1 \\
\hline & Basurero & 3 & 7 & 21 & 6.3 \\
\hline & Juego de Cortinas & 1 & 40 & 40 & 12.0 \\
\hline & Macetas & 1 & 12 & 12 & 3.6 \\
\hline & Ventilador & 1 & 80 & 80 & 24.0 \\
\hline & Extintor & 1 & 60 & 60 & 18.0 \\
\hline & Reloj & 1 & 20 & 20 & 6.0 \\
\hline \multirow{10}{*}{$\begin{array}{c}\text { Administración } \\
\text { y Ventas }\end{array}$} & Escritorio para oficina & 2 & 200 & 400 & 120.1 \\
\hline & Computadora & 2 & 2000 & 4000 & $1,201.2$ \\
\hline & Impresora & 1 & 700 & 700 & 210.2 \\
\hline & Silla giratoria & 2 & 160 & 320 & 96.1 \\
\hline & Archivador & 2 & 15 & 30 & 9.0 \\
\hline & Estante & 2 & 210 & 420 & 126.1 \\
\hline & Reloj & 1 & 20 & 20 & 6.0 \\
\hline & Juego de Cortinas & 1 & 40 & 40 & 12.0 \\
\hline & Sillas & 4 & 50 & 200 & 60.1 \\
\hline & Macetas & 2 & 12 & 24 & 7.2 \\
\hline \multirow{10}{*}{ Producción } & Escritorio para oficina & 3 & 200 & 600 & 180.2 \\
\hline & Silla giratoria & 3 & 160 & 480 & 144.1 \\
\hline & Archivador & 3 & 15 & 45 & 13.5 \\
\hline & Extintor & 3 & 60 & 180 & 54.1 \\
\hline & Basurero & 3 & 7 & 21 & 6.3 \\
\hline & Botiquín de madera & 3 & 20 & 60 & 18.0 \\
\hline & Reloj & 3 & 20 & 60 & 18.0 \\
\hline & Juego de Cortinas & 6 & 40 & 240 & 72.1 \\
\hline & Macetas & 6 & 12 & 72 & 21.6 \\
\hline & Sillas & 12 & 50 & 600 & 180.2 \\
\hline
\end{tabular}




\begin{tabular}{|l|l|r|r|r|r|}
\hline \multirow{4}{*}{ Otros } & Escritorio de reunión & 1 & 220 & 220 & 66.1 \\
\cline { 2 - 6 } & Sillas & 6 & 50 & 300 & 90.1 \\
\cline { 2 - 6 } & Ventilador & 1 & 80 & 80 & 24.0 \\
\cline { 2 - 6 } & Juego de Cortinas & 2 & 40 & 80 & 24.0 \\
\cline { 2 - 6 } & Pizarra acrílica & 2 & 210 & 420 & 126.1 \\
\cline { 2 - 6 } & Macetas & 3 & 12 & 36 & 10.8 \\
\hline \multicolumn{2}{|c|}{ Total } & & $14,096.00$ & $4,233.0$ \\
\hline
\end{tabular}

\section{Inversión en maquinas, equipos y herramientas}

\begin{tabular}{|c|c|c|c|c|c|c|}
\hline Tipo & Equipos & Marca & Capacidad & Cant. & $\begin{array}{l}\text { P.U. } \\
\text { (S/.) }\end{array}$ & $\begin{array}{l}\text { Total } \\
\text { (S/.) }\end{array}$ \\
\hline \multirow{10}{*}{$\begin{array}{c}\text { Maquinarias } \\
\text { y Equipos }\end{array}$} & Balanza electrónica & $\begin{array}{l}\text { Precisión } \\
\text { Perú }\end{array}$ & $100 \mathrm{Kg}$. & 2 & 250.0 & 500.0 \\
\hline & Triturador de Plástico & $\begin{array}{l}\text { Industria } \\
\text { nacional }\end{array}$ & $4 \mathrm{Tm} / \mathrm{H}$ & 1 & $8,250.0$ & $8,250.0$ \\
\hline & Mezcladora & $\begin{array}{c}\text { Industria } \\
\text { nacional }\end{array}$ & $10 \mathrm{Tm} / \mathrm{H}$ & 1 & $11,550.0$ & $11,550.0$ \\
\hline & Tornillos helicoidales & $\begin{array}{c}\text { Industria } \\
\text { nacional }\end{array}$ & $15 \mathrm{Tm} / \mathrm{H}$ & 2 & $6,600.0$ & $13,200.0$ \\
\hline & Cinta Transportadora & $\begin{array}{l}\text { Industria } \\
\text { nacional }\end{array}$ & $10 \mathrm{Tm} / \mathrm{H}$ & 1 & $8,250.0$ & $8,250.0$ \\
\hline & $\begin{array}{l}\text { Moldes para } \\
\text { bloquetas }\end{array}$ & $\begin{array}{l}\text { Industria } \\
\text { nacional }\end{array}$ & $24 \mathrm{U}$ & 350 & 48.0 & $16,800.0$ \\
\hline & Montacarga & Toyota & $3.0 \mathrm{Tm}$ & 1 & $8,000.0$ & $8,000.0$ \\
\hline & Camión & $\mathrm{Jac}$ & $5.0 \mathrm{Tm}$ & 1 & $38,000.0$ & $38,000.0$ \\
\hline & Computadora & $\begin{array}{c}\text { HP - Corel } \\
\text { i3 }\end{array}$ & $1 \mathrm{~TB}$ & 1 & $2,000.0$ & $2,000.0$ \\
\hline & Herramientas & Marca & Capacidad & Cantidad & $\begin{array}{l}\text { P.U. } \\
\text { (S/.) }\end{array}$ & $\begin{array}{l}\text { Total } \\
(\mathrm{S} / .)\end{array}$ \\
\hline \multirow{11}{*}{ Herramienta } & Tinas plásticas & REY & $50 \mathrm{Lt}$. & 6 & 13.0 & 78.0 \\
\hline & Jarras plásticas & REY & $1 \mathrm{Lt}$. & 12 & 2.0 & 24.0 \\
\hline & Coladores & REY & Mediana & 12 & 1.5 & 18.0 \\
\hline & Tablas de Muestreo & REY & Mediana & 6 & 5.0 & 30.0 \\
\hline & Lampas & INCORESA & T. cuchara & 6 & 40.0 & 240.0 \\
\hline & $\begin{array}{l}\text { Dinos - Envases } \\
\text { Plásticos }\end{array}$ & REY & $200 \mathrm{Lt}$. & 3 & 90.0 & 270.0 \\
\hline & Recogedor & REY & Mediana & 12 & 4.0 & 48.0 \\
\hline & Paletas & REY & Mediana & 12 & 8.0 & 96.0 \\
\hline & Mat. laboratorio & Varios & & 1 & $1,000.0$ & $1,000.0$ \\
\hline & H. Mantenimiento & Varios & & 1 & $1,000.0$ & $1,000.0$ \\
\hline & Mesa de trabajo & Nacional & $3 \times 3 \mathrm{~m}$. & 3 & 50.0 & 150.0 \\
\hline
\end{tabular}




\section{ANEXO XVI: INVERSION EN CAPITAL DE TRABAJO}

\section{Ingresos por ventas}

\begin{tabular}{|l|rr|r|}
\cline { 2 - 4 } \multicolumn{1}{c|}{} & \multicolumn{2}{c|}{ Soles } & \multicolumn{2}{c|}{ Dólares } \\
\hline Precio x Millar & S/. & 432.90 & 130 \\
\hline
\end{tabular}

\begin{tabular}{|c|c|c|c|c|c|c|c|c|c|c|c|c|}
\hline & Enero & Febr & Marzo & Abril & Mayo & Junio & Julio & Agosto & Sept & Oct & Nov & Dic \\
\hline Und) & 250 & 250 & 250 & 250 & 250 & 250 & 250 & 250 & 250 & 250 & 250 & 250 \\
\hline$(\mathrm{S} /)$. & & 108 &, $225 \mathrm{cac}$ & da mes & & & & & & & & \\
\hline
\end{tabular}

2. Egreso por mano de obra

\begin{tabular}{|l|r|r|}
\hline \multicolumn{1}{|c|}{ LEYES SOCIALES } & \multicolumn{1}{c|}{ Tasa } & \multicolumn{1}{c|}{ Total } \\
\hline $\begin{array}{l}\text { Aportes del empleador al } \\
\text { empleado }\end{array}$ & & $\mathbf{4 2 . 3 3 \%}$ \\
\hline CTS & $8.33 \%$ & \\
\hline Gratificaciones & $16.67 \%$ & \\
\hline ESSALUD & $9.00 \%$ & \\
\hline Vacaciones & $8.33 \%$ & \\
\hline
\end{tabular}

\begin{tabular}{|c|c|c|c|c|c|c|}
\hline \multirow[b]{2}{*}{ Año } & \multicolumn{4}{|c|}{ PRODUCCIÓN } & \multirow{2}{*}{$\begin{array}{l}\text { ADMINIST. } \\
\text { Administrad. }\end{array}$} & \multirow{2}{*}{\begin{tabular}{|c|} 
VENTAS \\
Vendedores
\end{tabular}} \\
\hline & Operarios & Técnicos & $\begin{array}{l}\text { Asist. } \\
\text { Campo }\end{array}$ & $\begin{array}{c}\text { Gerente } \\
\text { Operaciones }\end{array}$ & & \\
\hline Año 1 & 4 & 1 & 1 & 1 & 1 & 4 \\
\hline $\begin{array}{l}\text { Sueldo / Salario } \\
(\mathrm{S} / .)\end{array}$ & 1000 & 1000 & 1000 & 3000 & 3000 & 850 \\
\hline Total mes (S/.) & 5,693 & 1,423 & 1,423 & 4,270 & 4,270 & 4,839 \\
\hline & & & 7,117 & & & \\
\hline
\end{tabular}

\section{Egreso por Insumos Directos}

\begin{tabular}{cllll}
\hline Año & $\begin{array}{c}\text { Producción } \\
(\text { MILLAR) }\end{array}$ & \multicolumn{3}{c}{ Requerimiento de Materia Prima } \\
Agua (M3) & $\begin{array}{c}\text { Plástico } \\
(\mathrm{Kg})\end{array}$ & Cemento $(\mathrm{Kg})$ \\
\hline Año 1 & 3,000 & 783 & 661,500 & $1,984,500$ \\
\hline
\end{tabular}




\begin{tabular}{ccc}
\hline \multicolumn{3}{c}{ Precios (S/.) } \\
\hline Agua (M3) & $\begin{array}{c}\text { Plástico } \\
(\mathrm{Kg})\end{array}$ & $\begin{array}{c}\text { Cemento } \\
(\mathrm{Kg})\end{array}$ \\
\hline & & \\
4.27 & 0.35 & 0.33 \\
\hline
\end{tabular}

Costo de Insumos Directos

\begin{tabular}{cccccc}
\hline \multirow{2}{*}{ Año } & $\begin{array}{c}\text { AGUA } \\
(\mathrm{S} / .)\end{array}$ & $\begin{array}{c}\text { PLASTICO } \\
(\mathrm{S} / .)\end{array}$ & $\begin{array}{c}\text { CEMENTO } \\
(\mathrm{S} / .)\end{array}$ & $\begin{array}{c}\text { TOTAL } \\
\text { ANUAL }(\mathrm{S} / .)\end{array}$ & $\begin{array}{c}\text { TOTAL } \\
\text { MES (S/.) }\end{array}$ \\
\hline Año 1 & 3,344 & 231,525 & 661,500 & 896,369 & 74,697 \\
\hline
\end{tabular}

\section{Egresos por insumos indirectos}

\begin{tabular}{cccccc}
\hline & \multicolumn{5}{c}{ Costo de insumos indirectos } \\
\cline { 2 - 6 } Año & $\begin{array}{c}\text { Hig. y Seg. } \\
(\text { S/.) }\end{array}$ & $\begin{array}{c}\text { Mantto } \\
(\text { S/.) }\end{array}$ & $\begin{array}{c}\text { Total } \\
(\text { S/.) }\end{array}$ & $\begin{array}{c}\text { Total Anual } \\
(\text { US\$) }\end{array}$ & $\begin{array}{c}\text { Total Mes } \\
(\text { US\$) }\end{array}$ \\
\hline Año 1 & 2,343 & 41,250 & 43,593 & 13,091 & 3,633 \\
Año 2 & 2,343 & 43,395 & 45,738 & 13,735 & 3,812 \\
Año 3 & 3,243 & 45,540 & 48,783 & 14,650 & 4,065 \\
Año 4 & 3,243 & 47,850 & 51,093 & 15,343 & 4,258 \\
Año 5 & 3,408 & 50,325 & 53,733 & 16,136 & 4,478 \\
\hline
\end{tabular}

\section{Higiene y seguridad industrial}

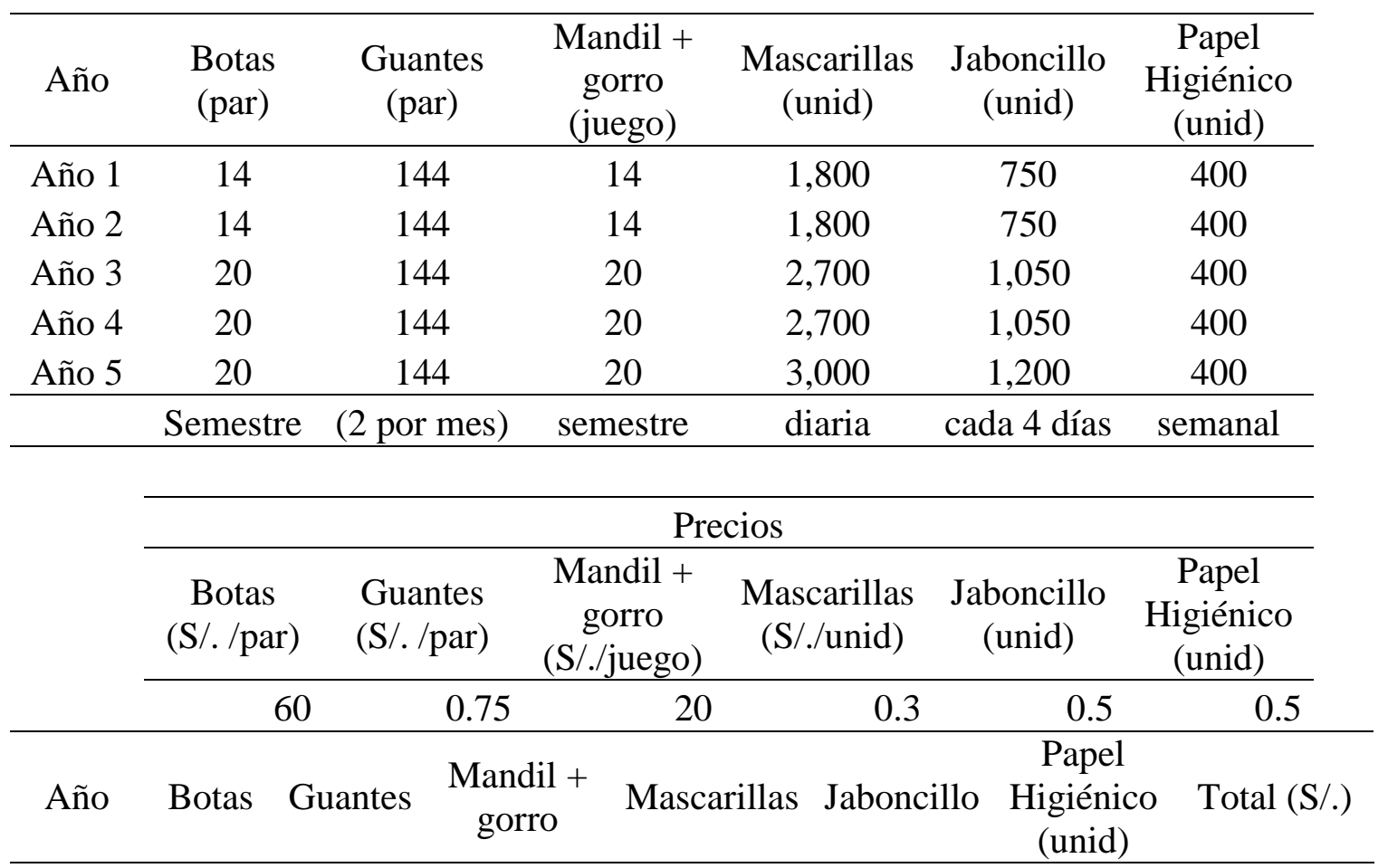




\begin{tabular}{cccccccc} 
Año 1 & 840 & 108 & 280 & 540 & 375 & 200 & 2,343 \\
Año 2 & 840 & 108 & 280 & 540 & 375 & 200 & 2,343 \\
Año 3 & 1,200 & 108 & 400 & 810 & 525 & 200 & 3,243 \\
Año 4 & 1,200 & 108 & 400 & 810 & 525 & 200 & 3,243 \\
Año 5 & 1,200 & 108 & 400 & 900 & 600 & 200 & 3,408 \\
\hline
\end{tabular}

\section{Limpieza}

\begin{tabular}{ccccc}
\hline Año & $\begin{array}{c}\text { Detergente } \\
(\mathrm{kg})\end{array}$ & $\begin{array}{c}\text { Escobillón } \\
(\text { unid })\end{array}$ & $\begin{array}{c}\text { Trapo } \\
(\mathrm{Kg})\end{array}$ & $\begin{array}{c}\text { Alcohol Ind. } \\
(\mathrm{Lt})\end{array}$ \\
\hline Año 1 & 1,500 & 300 & 3,000 & 1,500 \\
Año 2 & 1,578 & 316 & 3,156 & 1,578 \\
Año 3 & 1,656 & 331 & 3,312 & 1,656 \\
Año 4 & 1,740 & 348 & 3,480 & 1,740 \\
Año 5 & 1,830 & 366 & 3,660 & 1,830 \\
\hline
\end{tabular}

Cada Millar = 0.5 Kg. Deterg (Cada 10 Millares - 1 Escobillón) (Cada 2 Millares - 1 Lt Alcohol)

\begin{tabular}{cccc}
\hline \multicolumn{4}{c}{ Precios } \\
\hline $\begin{array}{c}\text { Detergente } \\
(\mathrm{S} / . / \mathrm{kg})\end{array}$ & $\begin{array}{c}\text { Escobillón } \\
(\mathrm{S} / . / \text { unid })\end{array}$ & $\begin{array}{c}\text { Trapo } \\
(\mathrm{S} / . / \mathrm{Kg})\end{array}$ & $\begin{array}{c}\text { Alcohol Ind. } \\
(\mathrm{S} / . / \mathrm{Lt})\end{array}$ \\
\hline 5.00 & 20.00 & 5.00 & 8.50 \\
\hline
\end{tabular}

\begin{tabular}{ccccccc}
\hline Año & $\begin{array}{c}\text { Detergente } \\
(\mathrm{S} / .)\end{array}$ & $\begin{array}{c}\text { Escobillón } \\
(\mathrm{S} / .)\end{array}$ & $\begin{array}{c}\text { Trapo } \\
(\mathrm{S} / .)\end{array}$ & $\begin{array}{c}\text { Alcohol Ind. } \\
(\mathrm{S} / .)\end{array}$ & Total (S/.) & $\begin{array}{c}\text { Total } \\
(\mathrm{US} \$)\end{array}$ \\
\hline Año 1 & 7,500 & 6,000 & 15,000 & 12,750 & 41,250 & 12,387 \\
Año 2 & 7,890 & 6,312 & 15,780 & 13,413 & 43,395 & 13,032 \\
Año 3 & 8,280 & 6,624 & 16,560 & 14,076 & 45,540 & 13,676 \\
Año 4 & 8,700 & 6,960 & 17,400 & 14,790 & 47,850 & 14,369 \\
Año 5 & 9,150 & 7,320 & 18,300 & 15,555 & 50,325 & 15,113 \\
\hline
\end{tabular}

\section{Mantenimiento}

\begin{tabular}{lccc}
\hline \multicolumn{1}{c}{ Rubro } & Valor Inicial & Tasa Anual & Monto Anual \\
& $(\mathrm{S} /)$. & $(\%)$ & $(\mathrm{S} /)$. \\
\hline Equipos y herramientas & $109,504.0$ & 0.1 & $13,140.5$ \\
Imprevistos (5\%) & $8,360.5$ & 0.1 & 418.0 \\
\hline \multicolumn{3}{c}{ Total } & $13,558.5$ \\
\hline
\end{tabular}




\section{Egresos por gastos administrativos}

\begin{tabular}{cccccccccc}
\hline & $\begin{array}{c}\text { Remun. } \\
\text { Año }\end{array}$ & Admin. & \multicolumn{2}{c}{ Serv. Básicos } & $\begin{array}{c}\text { Servic. } \\
\text { Agua }\end{array}$ & Luz & $\begin{array}{c}\text { Útiles } \\
\text { Internet }\end{array}$ & \multicolumn{2}{c}{ escritor. } \\
papeler. & $.5 \%$ & Año(S/.) & Mes(S/.) \\
\hline Año 1 & 51,239 & $2,856.1$ & 2,835 & 3,600 & 1,914 & 275.7 & $62,719.6$ & 5,227 \\
Año 2 & 68,318 & $3,004.6$ & 3,014 & 3,600 & 1,914 & 275.7 & $80,126.2$ & 6,677 \\
Año 3 & 68,318 & $3,153.1$ & 3,210 & 3,600 & 1,914 & 275.7 & $80,471.0$ & 6,706 \\
Año 4 & 68,318 & $3,313.0$ & 3,426 & 3,600 & 1,914 & 275.7 & $80,847.0$ & 6,737 \\
Año 5 & 68,318 & $3,484.4$ & 3,663 & 3,600 & 1,914 & 275.7 & $81,255.9$ & 6,771 \\
\hline
\end{tabular}

\section{Egresos por gastos de ventas}

\begin{tabular}{|c|c|c|c|c|c|c|c|c|}
\hline \multirow{2}{*}{ Año } & \multirow[t]{2}{*}{ Remuner. } & \multirow{2}{*}{$\begin{array}{c}\text { Bonos por } \\
\text { ventas } \\
\text { S/. } 10 \mathrm{x} \\
\text { Millar }\end{array}$} & \multirow[t]{2}{*}{$\begin{array}{l}\text { Alquiler } \\
\text { Locales } \\
\text { ventas }\end{array}$} & \multirow{2}{*}{$\begin{array}{c}\text { Servic. } \\
\text { Telef. e } \\
\text { Internet } \\
\text { (S/.) }\end{array}$} & \multirow{2}{*}{$\begin{array}{c}\text { Útiles } \\
\text { escritor. } \\
\text { Papeler. } \\
\text { (S/.) }\end{array}$} & \multirow{2}{*}{$\begin{array}{c}\text { Imprev } \\
5 \% \\
\text { (S/.) }\end{array}$} & \multicolumn{2}{|c|}{$\begin{array}{c}\text { Total de gastos de } \\
\text { venta }\end{array}$} \\
\hline & & & & & & & $\mathrm{S} /)$. & S/.) \\
\hline Año 1 & 58,071 & $30,000.0$ & 2,700 & 2400 & 472.5 & 143.6 & $93,786.8$ & 7,816 \\
\hline Año 2 & 58,071 & $31,560.0$ & 2,700 & 2400 & 1914 & 215.7 & $96,860.3$ & 8,072 \\
\hline Año 3 & 72,588 & $33,120.0$ & 2,700 & 2400 & 1914 & 215.7 & $112,938.0$ & 9,412 \\
\hline Año 4 & 72,588 & $34,800.0$ & 2,700 & 2400 & 1914 & 215.7 & $114,618.0$ & 9,552 \\
\hline Año 5 & 87,106 & $36,600.0$ & 2,700 & 2400 & 1914 & 215.7 & $130,935.7$ & 10,911 \\
\hline
\end{tabular}

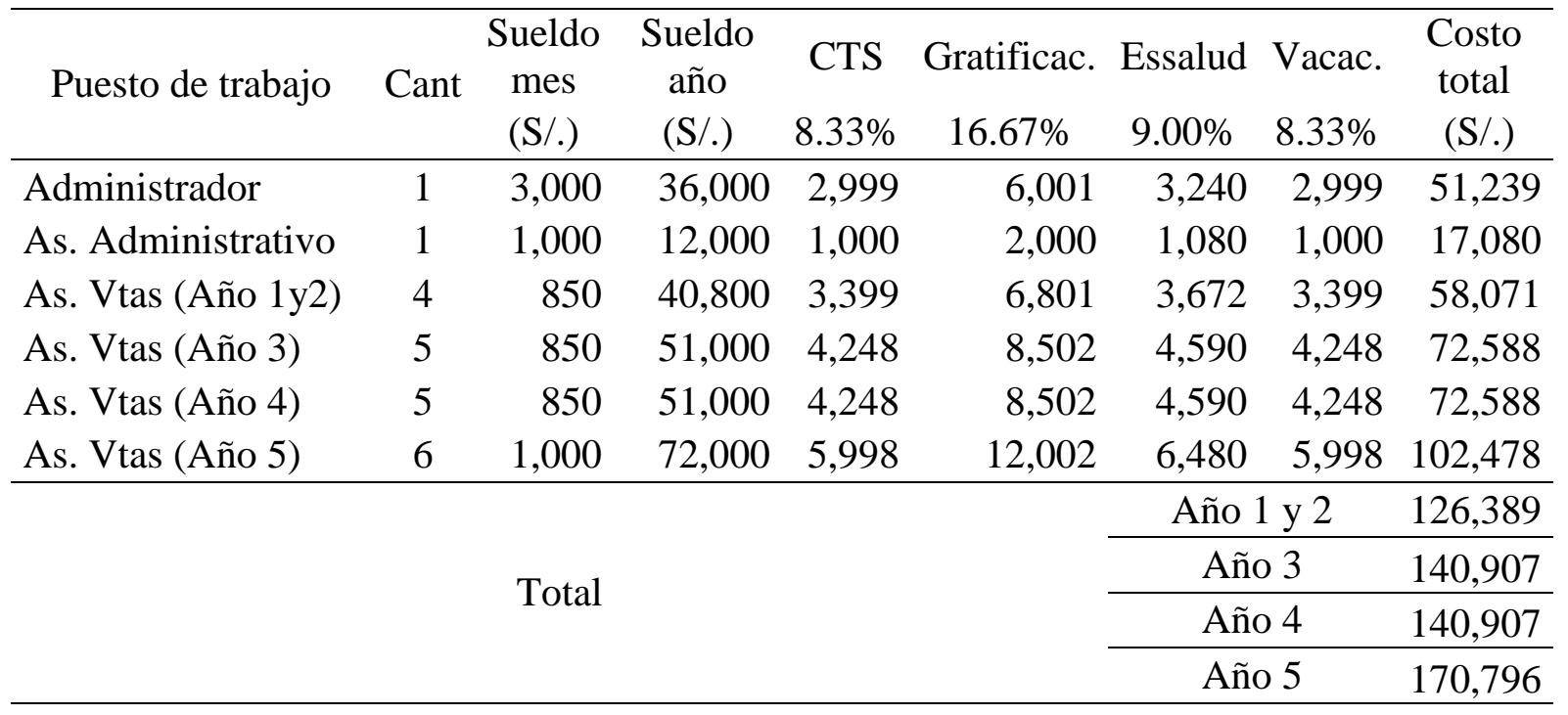


ANEXO XV : INVERSION INTANGIBLE

\begin{tabular}{lcccc}
\hline \multirow{2}{*}{\multicolumn{1}{c}{ Rubros }} & \multicolumn{3}{c}{ Inversión intangible } \\
\cline { 2 - 5 } & Monto (S/.) & $\%$ & $\begin{array}{c}\text { Monto } \\
\text { (USD) }\end{array}$ & $\%$ \\
\hline Estudios de Pre inversión & 2500 & $13 \%$ & 751 & $16 \%$ \\
Estudios Definitivos & 4623 & $24 \%$ & 1,388 & $32 \%$ \\
Organización & 1400 & $7 \%$ & 420 & $9 \%$ \\
Pruebas y Puesta en Marcha & 3500 & $19 \%$ & 1,051 & $3 \%$ \\
Intereses Pre operativos & 5977 & $32 \%$ & 1,795 & $38 \%$ \\
Imprevistos (5\%) & 918 & $5 \%$ & 276 & $2 \%$ \\
\hline \multicolumn{1}{c}{ Total Inversión intangible } & 18,918 & $100 \%$ & 5,681 & $100 \%$ \\
\hline
\end{tabular}




\section{ANEXO XVI: COSTO DE MANO DE OBRA}

MANO DE OBRA DIRECTA (Operarios)

\begin{tabular}{cccccccc}
\hline Año & Cant. $\begin{array}{c}\text { Costo } \\
\text { Año }\end{array}$ & CTS & Gratif. & ESSALUD & Vacaciones & $\begin{array}{c}\text { Costo } \\
\text { total }\end{array}$ \\
\hline Año 1 & 4 & 48,000 & 3,998 & 8,002 & 4,320 & 3,998 & 68,318 \\
Año 2 & 4 & 48,000 & 3,998 & 8,002 & 4,320 & 3,998 & 68,318 \\
Año 3 & 5 & 60,000 & 4,998 & 10,002 & 5,400 & 4,998 & 85,398 \\
Año 4 & 5 & 60,000 & 4,998 & 10,002 & 5,400 & 4,998 & 85,398 \\
Año 5 & 6 & 72,000 & 5,998 & 12,002 & 6,480 & 5,998 & 102,478 \\
\hline
\end{tabular}

\section{MANO DE OBRA INDIRECTA}

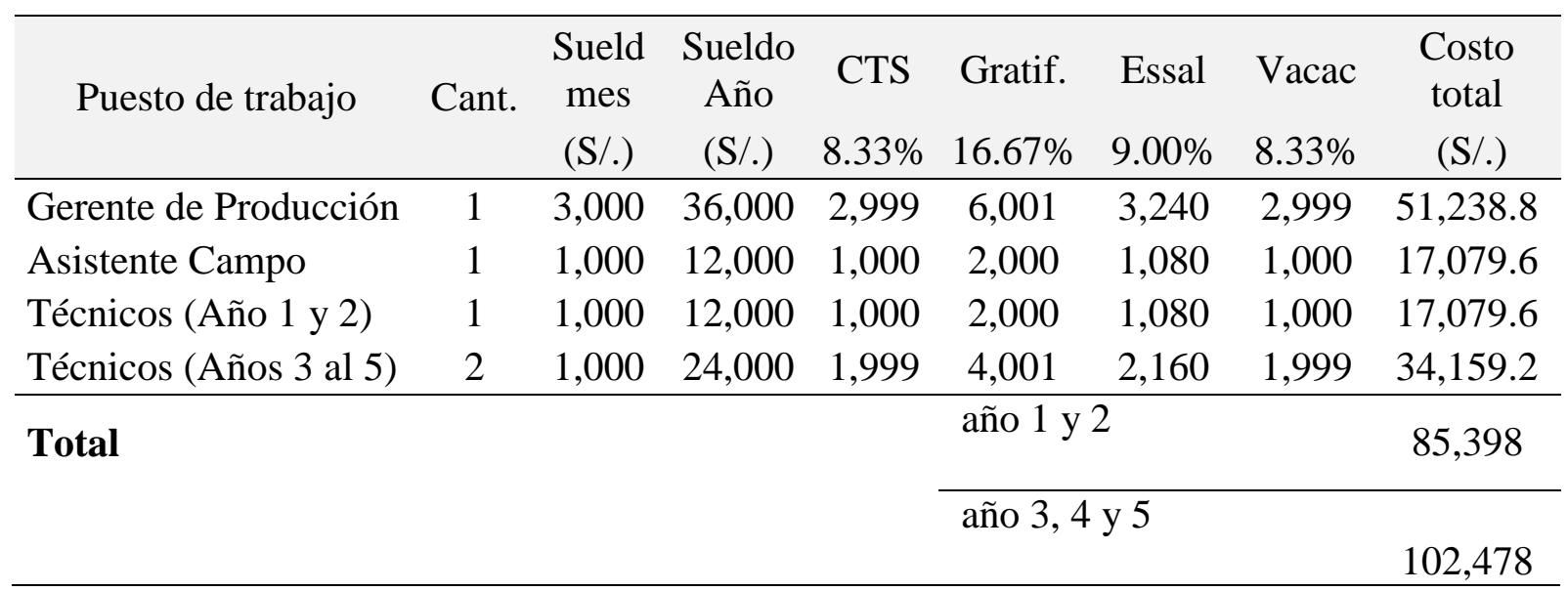




\section{ANEXO XVII: COSTO DIRECTOS}

Los valores de los costos directos son tomados del anexo XVI y el anexo XVIII

\begin{tabular}{cccc}
\hline Año & $\begin{array}{c}\text { Mano de Obra } \\
\text { Directa } \\
(\mathrm{S} / .)\end{array}$ & $\begin{array}{c}\text { Materia Prima } \\
(\mathrm{S} / .)\end{array}$ & $\begin{array}{c}\text { Costos Directos } \\
(\mathrm{S} / .)\end{array}$ \\
\hline Año 1 & $68,318.4$ & $896,369.3$ & $964,687.7$ \\
Año 2 & $68,318.4$ & $942,980.5$ & $1,011,298.9$ \\
Año 3 & $85,398.0$ & $989,591.7$ & $1,074,989.7$ \\
Año 4 & $85,398.0$ & $1,039,788.4$ & $1,125,186.4$ \\
Año 5 & $102,477.6$ & $1,093,570.6$ & $1,196,048.2$ \\
\hline
\end{tabular}


ANEXO XVIII: COMPRA DE MATERIAS PRIMAS

\begin{tabular}{rrrrr}
\hline \multirow{2}{*}{ Año } & $\begin{array}{c}\text { Producción } \\
\text { (MILLAR) }\end{array}$ & \multicolumn{3}{c}{ Requerimiento de Materia Prima } \\
& 3,000 & 783 & 661,500 & $1,984,500$ \\
Año 1 & 3,156 & 824 & 695,898 & $2,087,694$ \\
Año 2 & 3,312 & 865 & 730,296 & $2,190,888$ \\
Año 3 & 3,480 & 909 & 767,340 & $2,302,020$ \\
Año 4 & 3,660 & 956 & 807,030 & $2,421,090$ \\
Año 5 & & & & Cemento (Kg) \\
\hline
\end{tabular}

\begin{tabular}{rrr}
\hline \multicolumn{3}{c}{ Precios (S/.) } \\
\hline Agua (M3) & \multicolumn{1}{c}{ Plástico (Kg) } & Cemento (Kg) \\
\hline 4.27 & 0.35 & 0.33 \\
\hline
\end{tabular}

Requerimiento de Materia Prima

\begin{tabular}{crrrr}
\hline Año & AGUA (S/.) & PLASTICO (S/.) & $\begin{array}{c}\text { CEMENTO } \\
(\text { S/.) }\end{array}$ & TOTAL (S/.) \\
\hline Año 1 & 3,344 & 231,525 & 661,500 & 896,369 \\
Año 2 & 3,518 & 243,564 & 695,898 & 942,981 \\
Año 3 & 3,692 & 255,604 & 730,296 & 989,592 \\
Año 4 & 3,879 & 268,569 & 767,340 & $1,039,788$ \\
Año 5 & 4,080 & 282,461 & 807,030 & $1,093,571$ \\
\hline
\end{tabular}


ANEXO XIX COMPRA DE INSUMOS INDIRECTOS - HIGIENE Y SEGURIDAD

\begin{tabular}{cccccccc}
\hline Año & Botas & Guantes & $\begin{array}{c}\text { Mandil }+ \\
\text { gorro }\end{array}$ & Mascarillas & Jaboncillo & $\begin{array}{c}\text { Papel } \\
\text { Higiénico }\end{array}$ & $\begin{array}{c}\text { Total } \\
(\mathrm{S} / .)\end{array}$ \\
\hline Año 1 & 720 & 90 & 240 & 450 & 300 & 175 & 1,975 \\
Año 2 & 720 & 90 & 20 & 450 & 300 & 175 & 1,975 \\
Año 3 & 1 & 90 & 360 & 720 & 450 & 175 & 2,875 \\
Año 4 & 1,200 & 90 & 400 & 810 & 563 & 175 & 3,238 \\
Año 5 & 1,200 & 90 & 400 & 810 & 563 & 175 & 3,238 \\
\hline
\end{tabular}

Nota. Elaboración propia. 
ANEXO XX: COMPRA DE INSUMOS INDIRECTOS - MANTENIMIENTO

\begin{tabular}{cccccc}
\hline Año & $\begin{array}{c}\text { Detergente } \\
(\mathrm{S} / .)\end{array}$ & $\begin{array}{c}\text { Escobillon } \\
(\mathrm{S} / .)\end{array}$ & $\begin{array}{c}\text { Trapo } \\
(\mathrm{S} / .)\end{array}$ & $\begin{array}{c}\text { Alcohol Ind. } \\
(\mathrm{S} / .)\end{array}$ & Total (S/.) \\
\hline Año 1 & 6,000 & 4,800 & 12,000 & 10,200 & 33,000 \\
Año 2 & 6,900 & 5,520 & 13,800 & 11,730 & 37,950 \\
Año 3 & 7,950 & 6,360 & 15,900 & 13,515 & 43,725 \\
Año 4 & 9,150 & 7,320 & 18,300 & 15,555 & 50,325 \\
Año 5 & 10,530 & 8,424 & 21,060 & 17,901 & 57,915 \\
\hline
\end{tabular}

Nota. Adaptado del estudio de ingeniería del proyecto. 
ANEXO XXI: TABLA VALORES BETA POR TIPO DE NEGOCIO

\begin{tabular}{|c|c|c|c|}
\hline Industry Name & Number of firms & Beta & Tax rate \\
\hline Air Transport & 20 & 1.27 & $18.34 \%$ \\
\hline Auto \& Truck & 19 & 0.96 & $8.01 \%$ \\
\hline Auto Parts & 65 & 1.29 & $9.64 \%$ \\
\hline Bank (Money Center) & 9 & 1.11 & $25.82 \%$ \\
\hline Banks (Regional) & 644 & 0.51 & $24.11 \%$ \\
\hline Broadcasting & 29 & 1.29 & $21.20 \%$ \\
\hline Business \& Consumer Services & 159 & 1.19 & $13.76 \%$ \\
\hline Cable TV & 19 & 1.23 & $17.19 \%$ \\
\hline Chemical (Basic) & 42 & 1.17 & $8.24 \%$ \\
\hline Computer Services & 118 & 1.17 & $12.84 \%$ \\
\hline Construction Supplies & 52 & 1.65 & $17.00 \%$ \\
\hline Diversified & 26 & 1.01 & $15.20 \%$ \\
\hline Education & 40 & 1.05 & $12.05 \%$ \\
\hline Electrical Equipment & 120 & 1.15 & $6.58 \%$ \\
\hline Electronics (Consumer \& Office) & 25 & 1.23 & $9.71 \%$ \\
\hline Electronics (General) & 167 & 1.03 & $9.47 \%$ \\
\hline Engineering/Construction & 51 & 1.32 & $11.63 \%$ \\
\hline Entertainment & 84 & 1.21 & $3.25 \%$ \\
\hline Food Processing & 89 & 0.89 & $14.09 \%$ \\
\hline Food Wholesalers & 14 & 0.73 & $15.85 \%$ \\
\hline Furn/Home Furnishings & 30 & 1.23 & $15.53 \%$ \\
\hline Green \& Renewable Energy & 28 & 1.62 & $0.77 \%$ \\
\hline Utility (Water) & 18 & 0.47 & $14.60 \%$ \\
\hline Total Market & 7480 & 1.13 & $10.95 \%$ \\
\hline
\end{tabular}

Fuente: http://pages.stern.nyu.edu/ adamodar/New_Home_Page/datafile/Betas.html 


\section{ANEXO XXII :RIESGO PAÍS PERÚ 2016}

\section{Riesgo país de Perú sube dos puntos básicos a 1.54 puntos porcentuales}
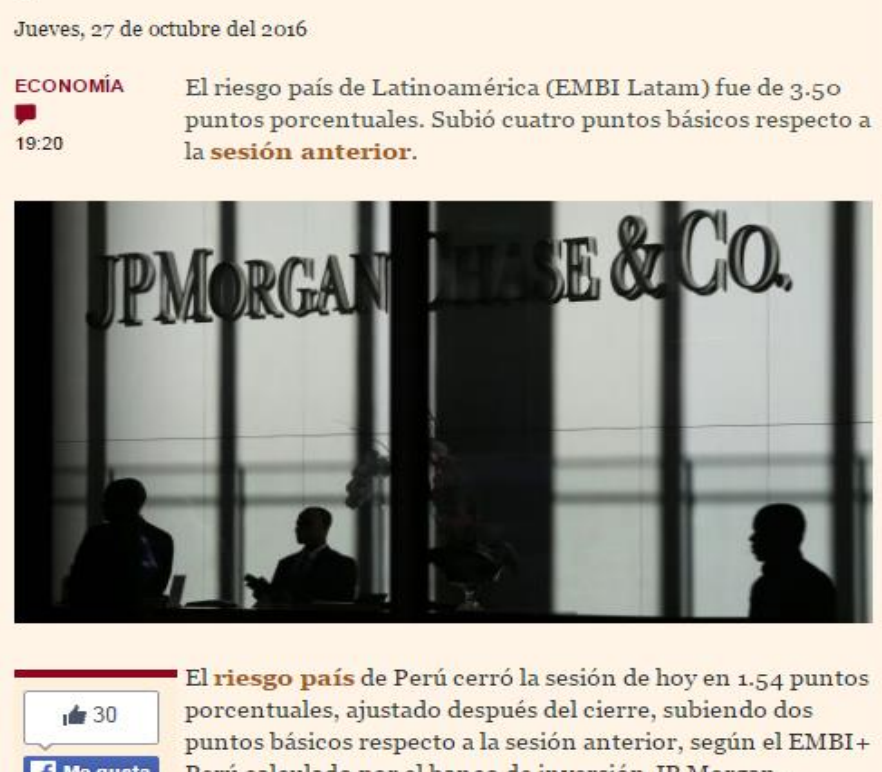

El riesgo país de Perú cerró la sesión de hoy en 1.54 punto porcentuales, ajustado después del cierre, subiendo dos puntos básicos respecto a la sesión anterior, según el EMBI+ Perú calculado nor el banco de inversión. JP Morgan.

\section{GESTIÓNTV}

\section{ÚLTIMA HORA} VER TODAS

29/10/16 | Clinton critica anuncio del FBI sobre nueva pesquisa a sus correos y Trump lo explota 00:05|¿Qué pasó en GESTIÓN hoy, hace...?

05:29 | Estas son las siete motocicletas más exóticas motociclas

06:00| Avocados from Peru cierra exitosa temporada de exportación de paltas este año

06:00 | La granja de peces de US\$ 100 millones que nadie quiere

06:00| Gurú zen prescribe viajar como cura de dolencias crónicas

06:00| Conozca qué puede hacer su empresa en caso de ciberataques

06:15 | Apoyando al

talento peruano - Vruja

Nota :Tomado de : http://gestion.pe/economia/riesgo-pais-peru-sube-dos-puntosbasicos-154-puntos-porcentuales-2173433. 


\section{ANEXO XXIII: CÁLCULO DE LA PRIMA DE RIESGO}

\begin{tabular}{lccc} 
Arithmetic Average & & \\
\hline \multicolumn{5}{c}{ S\&P500 } & $\begin{array}{c}\text { Stocks - } \\
\text { T.Bills }\end{array}$ & $\begin{array}{c}\text { Stocks - } \\
\text { T.Bonds }\end{array}$ \\
\hline $1928-2015$ & $11.41 \%$ & $3.49 \%$ & $5.23 \%$ \\
$1966-2015$ & $11.01 \%$ & $4.97 \%$ & $7.12 \%$ \\
$2006-2015$ & $9.03 \%$ & $1.16 \%$ & $5.16 \%$ \\
\hline
\end{tabular}

\begin{tabular}{|c|c|c|c|}
\hline \multicolumn{2}{|c|}{ Risk Premium } & \multicolumn{2}{|c|}{ Standard Error } \\
\hline $\begin{array}{l}\text { Stocks - } \\
\text { T.Bills }\end{array}$ & $\begin{array}{l}\text { Stocks - } \\
\text { T.Bonds }\end{array}$ & $\begin{array}{l}\text { Stocks - } \\
\text { T.Bills }\end{array}$ & $\begin{array}{l}\text { Stocks - } \\
\text { T.Bonds } \\
\end{array}$ \\
\hline $7.92 \%$ & $6.18 \%$ & $2.15 \%$ & $2.29 \%$ \\
\hline $6.05 \%$ & $3.89 \%$ & $2.42 \%$ & $2.74 \%$ \\
\hline $7.87 \%$ & $3.88 \%$ & $6.06 \%$ & $8.66 \%$ \\
\hline
\end{tabular}

\section{Risk}

Premium

\section{Geometric Average}

\begin{tabular}{|c|c|c|c|}
\hline $1928-2015$ & $9.50 \%$ & $3.45 \%$ & $4.96 \%$ \\
\hline $1966-2015$ & $9.61 \%$ & $4.92 \%$ & $6.71 \%$ \\
\hline $2006-2015$ & $7.25 \%$ & $1.14 \%$ & $4.71 \%$ \\
\hline
\end{tabular}

\begin{tabular}{|r|r|}
\hline $\begin{array}{l}\text { Stocks - } \\
\text { T.Bills }\end{array}$ & $\begin{array}{l}\text { Stocks - } \\
\text { T.Bonds }\end{array}$ \\
\hline $6.05 \%$ & $4.54 \%$ \\
\hline $4.69 \%$ & $2.90 \%$ \\
\hline $6.11 \%$ & $2.53 \%$ \\
\hline
\end{tabular}

Nota Tomado de http://www.stern.nyu.edu/ adamodar/pc/datasets/indname.xls 


\section{ANEXO XXIV: CÁLCULO DEL COSTO DE OPORTUNIDAD Y EL COSTO}

\section{DE CAPITAL PROMEDIO PONDERADO}

\section{Solución}

\begin{tabular}{|l|l|}
\hline \multicolumn{2}{|c|}{ Beta Económico } \\
\hline BOA & 1.65 \\
\hline
\end{tabular}

65

Beta Económico (Representativo del Negocio)

\begin{tabular}{|c|r|}
\hline \multicolumn{2}{|c|}{ KOA Económico } \\
\hline rf & $9.03 \%$ \\
\hline RM & $10.00 \%$ \\
\hline KOA $=$ rf + $\beta$ BA $^{\star}($ RM - rf) \\
\hline KOA & $10.63 \%$ \\
\hline
\end{tabular}

Costo de Capital Económico

\begin{tabular}{|l|r|}
\hline \multicolumn{2}{|c|}{ Financiamiento } \\
\hline$\%$ Deuda & $70.00 \%$ \\
\hline$\%$ Capital & $30.00 \%$ \\
\hline Ki & $7.10 \%$ \\
\hline
\end{tabular}

Supuesto

Costo de Deuda

\begin{tabular}{|c|r|}
\hline \multicolumn{2}{|c|}{ Beta Patrimonial } \\
\hline Tasa Imp PER & $\mathbf{3 1 . 0 0 \%}$ \\
\hline D/C PER & $\mathbf{2 . 3 3}$ \\
\hline $\boldsymbol{\beta E}=\boldsymbol{\beta O A}{ }^{\star}\left[1+(1-\mathrm{t})^{\star} \mathrm{D} / \mathrm{C}\right]$ & 4.31 \\
\hline $\boldsymbol{\beta E}$ PER & \\
\hline
\end{tabular}

beta apalancado

Beta Patrimonial (Apalancado)

\begin{tabular}{|c|r|}
\hline \multicolumn{2}{|c|}{ KE Patrimonial } \\
\hline rf & $9.03 \%$ \\
\hline RM & $10.00 \%$ \\
\hline KE $=$ rf $+\boldsymbol{\beta} E^{\star}(\mathbf{R M}-$ rf $)$ \\
\hline KE PER & $13.21 \%$ \\
\hline
\end{tabular}

Tasa Libre de Riesgo

Retorno de Mercado

Costo de Capital Patrimonial

\begin{tabular}{llrr}
\hline \multicolumn{2}{c|}{ Ko (CPPC) } & & \\
\hline Concepto & $\%$ & $\mathrm{~K}$ & \multicolumn{1}{c}{$\mathrm{K}^{*}(1-\mathrm{t})$} \\
\hline$\%$ Deuda & $70.00 \%$ & $7.10 \%$ & $4.90 \%$ \\
$\%$ Capital & $30.00 \%$ & $13.21 \%$ & $13.21 \%$ \\
\hline \multicolumn{2}{c}{$\mathrm{KO}=\% \mathrm{C}^{*} \mathrm{KE}+\% \mathrm{D}^{*} \mathrm{Ki}^{*}(1-\mathrm{t})$} & $\mathrm{KO}(\mathrm{CPPC})$ & $7.39 \%$ \\
\hline
\end{tabular}




\section{ANEXO XXV: CALCULO DEL VAN Y TIR ECONÓMICO Y FINANCIERO}

\section{VAN Y TIR ECONOMICO}

(Tasa Libre de Riesgo)

(Riesgo Sistemático de la EE) (Estimación de la

Rentabilidad de la EE)

(Riesgo País)

(Prima de Riesgo)

\begin{tabular}{|c|c|c|c|}
\hline \multicolumn{4}{|c|}{$\mathrm{Ke}=\mathrm{Rf}+\beta(\mathrm{Rm}-\mathrm{Rf})+\mathrm{RP}+\mathrm{PR}$} \\
\hline Rf: & 9.03 & \multirow{5}{*}{$\mathrm{Ke}=$} & \multirow{5}{*}{14.70} \\
\hline$\beta:$ & 1.65 & & \\
\hline $\mathrm{Rm}:$ & 10.00 & & \\
\hline RP: & 1.54 & & \\
\hline PR: & 2.53 & & \\
\hline
\end{tabular}

\begin{tabular}{|c|c|c|c|c|c|c|c|}
\cline { 2 - 8 } \multicolumn{2}{c|}{} & 0 & 1 & \multicolumn{1}{c|}{2} & \multicolumn{1}{c|}{3} & \multicolumn{1}{c|}{4} & \multicolumn{1}{c|}{5} \\
\hline fsa & $(1+\mathrm{Ke})^{\wedge}-\mathrm{n}$ & 1.000 & 0.872 & 0.760 & 0.663 & 0.578 & 0.504 \\
\hline fsc & $(1+\mathrm{Ke})^{\wedge} \mathrm{n}$ & 1.000 & 1.147 & 1.316 & 1.509 & 1.731 & 1.986 \\
\hline
\end{tabular}

\begin{tabular}{|c|c|c|c|c|c|c|c|}
\hline Año & $\begin{array}{c}\text { Flujo caja } \\
\text { económico } \\
\text { (S/.) }\end{array}$ & f.s.a. & Costos & Benefic. & $\begin{array}{l}\text { VAN } \\
\text { (S/.) }\end{array}$ & $\begin{array}{c}\text { Actualizac. } \\
\text { de } \\
\text { beneficios }\end{array}$ & $\begin{array}{c}\text { VAN } \\
\text { acumulado } \\
(\mathrm{S} / .)\end{array}$ \\
\hline Año 0 & $-300,334$ & 1.000 & \multirow[t]{6}{*}{$-300,334$} & \multirow[b]{2}{*}{$-5,807$} & $-300,334$ & & $-300,334$ \\
\hline Año 1 & $-6,661$ & 0.872 & & & $-5,807$ & $-5,063$ & $-306,142$ \\
\hline Año 2 & 105,039 & 0.760 & & 79,836 & 79,836 & 60,680 & $-226,306$ \\
\hline Año 3 & 211,688 & 0.663 & & 140,271 & 140,271 & 92,948 & $-86,035$ \\
\hline Año 4 & 367,053 & 0.578 & & 212,044 & 212,044 & 122,496 & 126,009 \\
\hline Año 5 & 538,742 & 0.504 & & 271,332 & 271,332 & 136,654 & 397,341 \\
\hline TIR & $42.57 \%$ & & & & & & \\
\hline \multicolumn{3}{|c|}{ VAN económico $=$} & & \multicolumn{2}{|c|}{$397,340.9$} & & \\
\hline \multicolumn{3}{|c|}{ TIR económico $=$} & & \multicolumn{2}{|c|}{$42.573 \%$} & & \\
\hline
\end{tabular}

\section{VAN Y TIR FINANCIERO}

(Tasa Libre de Riesgo)

(Riesgo Sistemático de la EE) (Estimación de la

Rentabilidad de la EE)

(Riesgo País)

\begin{tabular}{|c|c|c|}
\hline \multicolumn{3}{|c|}{$\mathrm{Ke}=\mathrm{Rf}+\beta(\mathrm{Rm}-\mathrm{Rf})+\mathrm{RP}+\mathrm{PR}$} \\
\hline $\mathrm{Rf}:$ & 9.03 & \\
\cline { 1 - 2 }$\beta:$ & 1.65 & \multirow{2}{*}{$\mathrm{Ke}=\quad 14.70$} \\
\cline { 1 - 2 } $\mathrm{Rm}:$ & 10.00 & \\
\hline $\mathrm{RP}:$ & 1.54 & \\
\hline
\end{tabular}




\begin{tabular}{|c|c|c|c|c|c|}
\hline \multicolumn{2}{|c|}{ (Prima de Riesgo) } & PR: & 2.53 & & \multirow[b]{2}{*}{ Tasa } \\
\hline Fuente & $\begin{array}{l}\text { Participación } \\
\text { total }(\%)\end{array}$ & \multicolumn{2}{|c|}{ Rubro de inversión } & $\begin{array}{l}\text { Tasa de } \\
\text { interés }\end{array}$ & \\
\hline Aporte Propio & $50.00 \%$ & & & $14.70 \%$ & $7.35 \%$ \\
\hline \multirow{2}{*}{$\begin{array}{l}\text { Banco } \\
\text { Continental }\end{array}$} & $36.36 \%$ & Capita & abajo & $13.40 \%$ & $4.87 \%$ \\
\hline & $13.64 \%$ & Inv. Fi & & $9.58 \%$ & $1.31 \%$ \\
\hline \multicolumn{5}{|c|}{ FSA FINANCIERO = } & $13.53 \%$ \\
\hline
\end{tabular}

\begin{tabular}{|l|l|r|r|r|r|r|r|}
\cline { 2 - 8 } \multicolumn{2}{c|}{} & 0 & 1 & 2 & 3 & 4 & 5 \\
\hline fsa & $(1+\mathrm{Ke})^{\wedge}-\mathrm{n}$ & 1.000 & 0.881 & 0.776 & 0.683 & 0.602 & 0.530 \\
\hline fsc & $(1+\mathrm{Ke})^{\wedge} \mathrm{n}$ & 1.000 & 1.135 & 1.289 & 1.463 & 1.661 & 1.886 \\
\hline
\end{tabular}

\begin{tabular}{|c|c|c|c|c|c|c|c|}
\hline Año & $\begin{array}{c}\text { Flujo de } \\
\text { caja } \\
\text { financiero } \\
(\mathrm{S} / .)\end{array}$ & $\begin{array}{c}\text { f.s.a. } \\
(29.06)\end{array}$ & Costos & $\begin{array}{l}\text { Benefici } \\
\text { os }\end{array}$ & $\begin{array}{l}\text { VAN } \\
\text { (S/.) }\end{array}$ & $\begin{array}{l}\text { Actualiza } \\
\text { ción de } \\
\text { beneficios }\end{array}$ & $\begin{array}{c}\text { VAN } \\
\text { acumulad } \\
\text { o (S/.) }\end{array}$ \\
\hline Año 0 & $-150,167$ & 1.000 & \multirow[t]{6}{*}{$-150,167$} & & $\begin{array}{c}- \\
150,167\end{array}$ & & $-150,167$ \\
\hline Año 1 & $-54,309$ & 0.881 & & $-47,836$ & $-47,836$ & $-42,135$ & $-198,003$ \\
\hline Año 2 & 53,732 & 0.776 & & 41,688 & 41,688 & 32,343 & $-156,316$ \\
\hline Año 3 & 200,630 & 0.683 & & 137,107 & 137,107 & 93,696 & $-19,209$ \\
\hline Año 4 & 359,655 & 0.602 & & 216,489 & 216,489 & 130,313 & 197,281 \\
\hline Año 5 & 531,343 & 0.530 & & 281,717 & 281,717 & 149,366 & 478,998 \\
\hline TIR & \multicolumn{2}{|l|}{$57.89 \%$} & & & & & \\
\hline \multicolumn{3}{|c|}{ VAN financiero = } & \multicolumn{2}{|c|}{$478,998.07$} & & & \\
\hline \multicolumn{3}{|c|}{ TIR financiero $=$} & \multicolumn{2}{|r|}{$57.9 \%$} & & & \\
\hline
\end{tabular}


VARIACION DEL VAN Y EL TIR EN FUNCION DE LA DEMANDA DEL PRODUTO

\begin{tabular}{ccccccccc}
\hline $\begin{array}{c}\% \text { de } \\
\text { Cambio }\end{array}$ & Año 0 & Año 1 & Año 2 & Año 3 & Año 4 & Año 5 & VAN & TIR \\
\hline$-20 \%$ & $-150,167$ & $-43,447$ & 42,986 & 160,504 & 287,724 & 425,075 & 353,165 & $50.1 \%$ \\
$-15 \%$ & $-150,167$ & $-46,162$ & 45,672 & 170,536 & 305,706 & 451,642 & 384,623 & $52.2 \%$ \\
$-10 \%$ & $-150,167$ & $-48,878$ & 48,359 & 180,567 & 323,689 & 478,209 & 416,082 & $54.2 \%$ \\
$-5 \%$ & $-150,167$ & $-51,593$ & 51,045 & 190,599 & 341,672 & 504,776 & 447,540 & $56.1 \%$ \\
$0 \%$ & $-150,167$ & $-54,309$ & 53,732 & 200,630 & 359,655 & 531,343 & 478,998 & $57.9 \%$ \\
$5 \%$ & $-150,167$ & $-57,024$ & 56,419 & 210,662 & 377,637 & 557,910 & 510,456 & $59.6 \%$ \\
$10 \%$ & $-150,167$ & $-59,740$ & 59,105 & 220,693 & 395,620 & 584,478 & 541,915 & $61.3 \%$ \\
$15 \%$ & $-150,167$ & $-62,455$ & 61,792 & 230,725 & 413,603 & 611,045 & 573,373 & $62.9 \%$ \\
$20 \%$ & $-150,167$ & $-65,170$ & 64,478 & 240,756 & 431,585 & 637,612 & 604,831 & $64.5 \%$ \\
\hline
\end{tabular}

\section{VARIACION DEL VAN Y EL TIR EN FUNCION DE LA VARIACION DEL COSTO DE MANO DE OBRA}

\begin{tabular}{ccccccccc}
\hline $\begin{array}{c}\% \text { de } \\
\text { Cambio }\end{array}$ & Año 0 & Año 1 & Año 2 & Año 3 & Año 4 & Año 5 & VAN & TIR \\
\hline$-20 \%$ & $-150,167$ & $-40,645$ & 42,986 & 160,504 & 287,724 & 425,075 & 355,633 & $50.5 \%$ \\
$-15 \%$ & $-150,167$ & $-44,061$ & 45,672 & 170,536 & 305,706 & 451,642 & 386,474 & $52.5 \%$ \\
$-10 \%$ & $-150,167$ & $-47,477$ & 48,359 & 180,567 & 323,689 & 478,209 & 417,316 & $54.4 \%$ \\
$-5 \%$ & $-150,167$ & $-50,893$ & 57,148 & 204,900 & 363,924 & 536,467 & 492,862 & $59.3 \%$ \\
$0 \%$ & $-150,167$ & $-54,309$ & 53,732 & 200,630 & 359,655 & 531,343 & 478,998 & $57.9 \%$ \\
$5 \%$ & $-150,167$ & $-57,725$ & 50,316 & 196,360 & 355,385 & 526,219 & 465,134 & $56.5 \%$ \\
$10 \%$ & $-150,167$ & $-61,140$ & 46,900 & 192,091 & 351,115 & 521,095 & 451,270 & $55.1 \%$ \\
$15 \%$ & $-150,167$ & $-64,556$ & 43,484 & 187,821 & 346,845 & 515,972 & 437,406 & $53.8 \%$ \\
$20 \%$ & $-150,167$ & $-67,972$ & 40,068 & 183,551 & 342,575 & 510,848 & 423,542 & $52.4 \%$ \\
\hline
\end{tabular}

VARIACION DEL VAN Y EL TIR EN FUNCION DE LA VARIACION EN EL COSTO DE MATERIA PRIMA

\begin{tabular}{ccrrrrrrr}
\hline $\begin{array}{c}\text { \% de } \\
\text { Cambio }\end{array}$ & Año 0 & \multicolumn{1}{c}{ Año 1 } & \multicolumn{1}{c}{ Año 2 } & Año 3 & Año 4 & Año 5 & VAN & TIR \\
\hline$-20 \%$ & $-150,167$ & 124,965 & 242,328 & 398,549 & 567,612 & 750,057 & $1,159,621$ & $139.5 \%$ \\
$-15 \%$ & $-150,167$ & 80,147 & 195,179 & 349,069 & 515,623 & 695,379 & 989,465 & $117.0 \%$ \\
$-10 \%$ & $-150,167$ & 35,328 & 148,030 & 299,589 & 463,633 & 640,700 & 819,309 & $95.9 \%$ \\
$-5 \%$ & $-150,167$ & $-9,490$ & 100,881 & 250,110 & 411,644 & 586,022 & 649,154 & $76.2 \%$ \\
$0 \%$ & $-150,167$ & $-54,309$ & 53,732 & 200,630 & 359,655 & 531,343 & 478,998 & $57.9 \%$ \\
$5 \%$ & $-150,167$ & $-99,127$ & 6,583 & 151,151 & 307,665 & 476,665 & 308,842 & $41.0 \%$ \\
$10 \%$ & $-150,167$ & $-143,946$ & $-40,566$ & 101,671 & 255,676 & 421,986 & 138,687 & $25.4 \%$ \\
$15 \%$ & $-150,167$ & $-188,764$ & $-87,715$ & 52,192 & 203,686 & 367,308 & $-31,469$ & $10.9 \%$ \\
$20 \%$ & $-150,167$ & $-233,583$ & $-134,864$ & 2,712 & 151,697 & 312,629 & $-201,625$ & $-2.8 \%$ \\
\hline
\end{tabular}




\section{Referencias}

América Económica (2015). Estabilidad política y económica en Perú. Alfredo Ferrero.

http://www.americaeconomia.com/economia-mercados/comercio/estabilidad-politica-yeconomica-en-peru.

Banco Central de Reserva del Perú (2016). Informe Económico y Social Región Arequipa, $155-157$.

Ministerio de Ambiente (2009), Detrás de los Ladrillos: una experiencia para la gestión integral del sector informal. Programa Regional Aire Limpio.

Ministerio de la Producción (2015). Ley de Promoción de la Investigación Científica, Desarrollo tecnológico e innovación tecnológica. http://www.innovateperu.gob.pe/incentivo-tributario/

Berretta, H.,Gatani, M. , Gaggino, R. \& Arguello, R.(2006). Manual de producción y aplicación del ladrillo de PET, Argentina: Buenos Aires: Nobuko.

Castells X. (2000), Reciclaje de residuos industriales. Ediciones Díaz de Santos.

Diario Gestión (2017). OEFA dará incentivos económicos a empresas con buenas prácticas ambientales.http://gestion.peleconomia/oefa-dara-incentivos-economicos-empresasque-buenas-practicas-ambientales-2100615

Diario el Pueblo (2016), El 80\% de construcción en Arequipa es informal. http://elpueblo.com.pe/noticia/locales/el-80-de-construcciones-en-arequipa-esinformal

Enrique Louffat (2010). Administración del Potencial Humano. Argentina: Edición Cengage Learning.

Fraternali, F., Spadea, S., \& Berardi, V. (2014), Effects of recycled PET fibres on the mechanical properties and seawater curing of Portland cement-based concretes, Constr. Build. Mater., vol. 61, pp. 293-302, 
Fred. R David (2013). Administración Estratégica. Mexico Editorial: Pearson Educación Gaggino, R. (2008).Ladrillos y placas prefabricadas con plásticos reciclados, Revista INVI Universidad de Chile, Volumen 23, Número 063.

Gitman, Lawrence J. Y Zutter, Chad J. (2012), Principios de administración financiera Decimosegunda edición, México, Pearson Educación.,

Gregory N. (2012), Principios de la Economía (6ta ed), DF, Mexico Editorial: Cengage Learning.

Hair , J.,Bush,R. \& Ortinau,D. (2010), Investigación de mercados. En un ambiente de información digital (4ta ed). DF., Mexico: Edición, Mcgraw Hill Educación.

Jaramillo, N.(2011) La Otra P:Principios de Publicidad (3ra ed.). Quito: Exel Impresores Gráficos 2011

Kinnear, T. \& Taylor,J. (1998 ) Investigación De Mercados (5ta ed), Santafe De Bogota ,Colombia Editorial :Mcgraw-Hill Interamerica S.A. ,

Kotler, P. \&, Keller (2012), Direccion de Marketing (14va ed), Mexico Editorial: Pearson Educación

Krajewski, L., Ritzman, L. \& Malhotra „K (2013), Administración de Operaciones (14va. Ed) , México: Mcgraw-Hill.

La Republica (2016). Edificios Verdes en el Perú. http://larepublica.pe/impresa/domingo/776165-edificios-verdesen-el-peru

Müller, A. (n.d.) Análisis de Mercado. Recuperado de http://webcache.googleusercontent.com/search?q=cache:hgcuKMI2LTMJ:www.lam olinavirtual.org/campus2/pluginfile.php/11697/mod_folder/content/0/IDEA\%2520D E\%2520NEGOCIO\%2520Y\%2520ESTUDIO\%2520DE\%2520MERCADO/estudio -de-mercado.pdf\%3Fforcedownload\%3D1+\&cd=3\&hl=es-419\&ct=clnk\&gl=pe 
Noguera, H., Torres, J.\& Zúñiga, L. (2015). Gestión integral y comercialización de residuos sólidos industriales peligrosos y no peligrosos.

http://repositorioacademico.upc.edu.pe/upc/handle/10757/592719

Padilla, C. (2011). Formulación y Evaluación de Proyectos (2da ed). Colombia: Editorial Ecoe.

Philip, K. \& Amstrong, G. (2012). Marketing (14va. ed.). México. Editorial: Pearson Educación.

Tarcica, J. \& Gonzalez, M. (2010) 120 Descripciones de Puestos . Recuperado de http://materialesrh.com/materiales/ebooks/120DescripcionesDePuestos.pdf

Thompson, Peteraf, Gamble, Strickland (2012), Administración estratégica (18va. ed.). Mexico. Editorial McGraw Hill.

Boletín de Investigación de la Comisión de Desarrollo Finanzas y Sistema Financiero - Sur Núm. 16, Colegio de Contadores Publicos de Mexico (2014-2016) Análisis del Costo Promedio Ponderado de Capital (CPPC) 